DoD Corrosion Prevention and Control Program

\title{
Demonstration of Cathodic Protection Systems for Utilities in Severely Corrosive Environments at Fort Jackson
}

Final Report on Project FAR-20 for FY06

L.D. Stephenson, Ashok Kumar, James B. Bushman, August 2009 and Bopinder Phull 



\section{Demonstration of Cathodic Protection Systems for Utilities in Severely Corrosive Environments at Fort Jackson}

Final Report on Project FAR-20 for FY06

L.D. Stephenson and Ashok Kumar

Construction Engineering Research Laboratory

U.S. Army Engineer Research and Development Center

2902 Newmark Drive

Champaign, IL 61822

James B. Bushman and Bopinder Phull

Bushman \& Associates

P. O. Box 425

Medina $\mathrm{OH} 44256$

Final report

Approved for public release; distribution is unlimited.

Prepared for Office of the Secretary of Defense (OUSD(AT\&L))

3090 Defense Pentagon

Washington, DC 20301-3090

Under $\quad$ Military Interdepartmental Purchase Request MIPR6FCERB1020, 20 Mar 06;

MIPR6H6AG3CPC1, 15 May 06; and MIPR6HMBHDE097, 31 May 06 


\begin{abstract}
This project demonstrated and implemented emerging corrosion protection technologies for utilities at Fort J ackson, SC. These consisted of three deep anode impressed current cathodic protection (ICCP) systems, 100 drive-by-type remote monitoring units (RMU) for monitoring the cathodic protection on the buried gas lines, and a new cathodic protection system in the elevated water storage tank, providing complete and uniform protection in the tank interior below the water line. The CP system in the water storage tank is also equipped with remote monitoring capability. The remote monitoring units have reduced the amount of time that it takes a trained technician to collect the data from about a week to only about 3 hours. The CP data collected from the drive by RMUs are collected and stored on a laptop computer for use in different analysis, including transfer into an Excel spreadsheet where it is automatically analyzed on a pass/ fail basis.
\end{abstract}

DISCLAIMER: The contents of this report are not to be used for advertising, publication, or promotional purposes. Citation of trade names does not constitute an official endorsement or approval of the use of such commercial products. All product names and trademarks cited are the property of their respective owners. The findings of this report are not to be construed as an official Department of the Army position unless so designated by other authorized documents. 


\section{Contents}

List of Figures and Tables.........................................................................................................

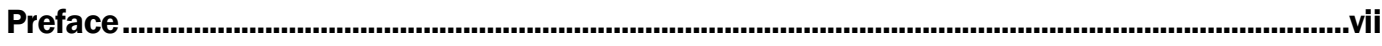

Executive Summary ......................................................................................................................................... viii

Unit Conversion Factors ....................................................................................................................... ix

1 Introduction

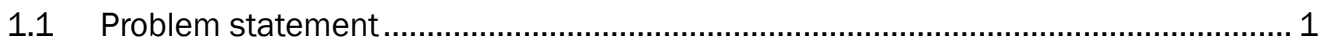

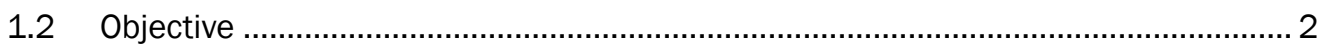

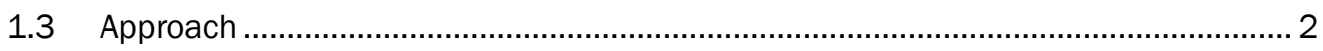

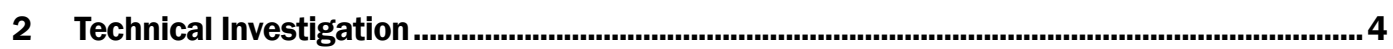

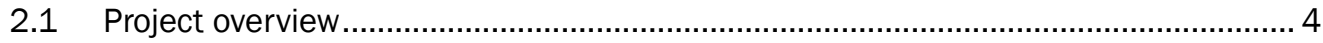

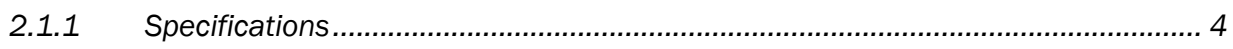

2.1.2 Application design details.................................................................................... 4

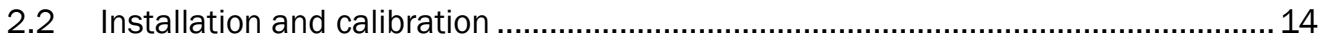

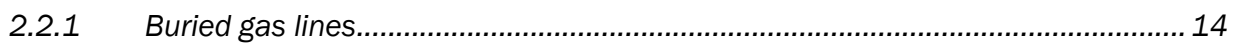

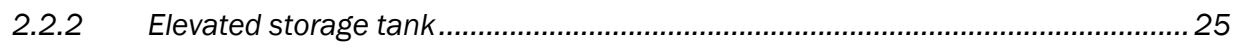

2.2.3 Rectifier power supply and controller ............................................................. 26

2.2.4 Reference electrode .......................................................................................... 28

2.2.5 DC positive, negative, and reference cell wiring and conduit................................ 28

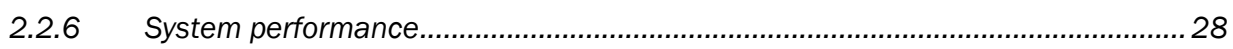

2.3 Technology operation and monitoring ............................................................. 28

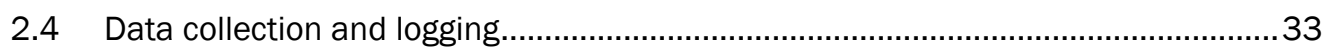

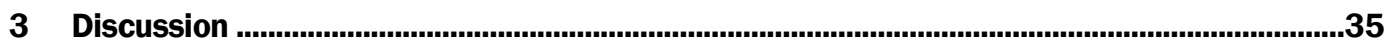

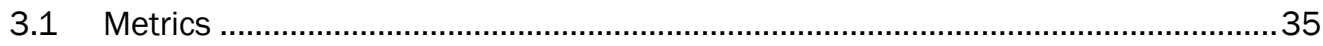

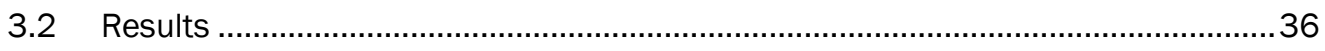

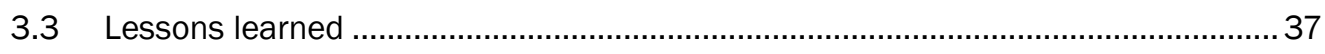

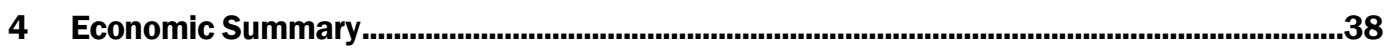

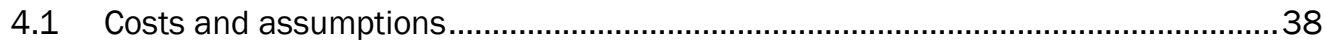

4.2 Return-on-investment computation ............................................................ 38

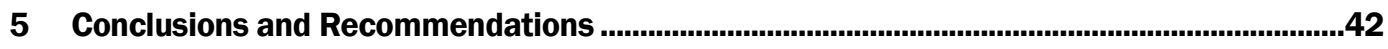

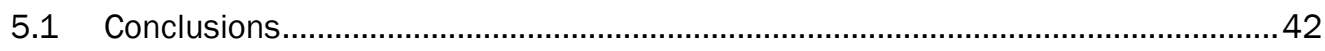

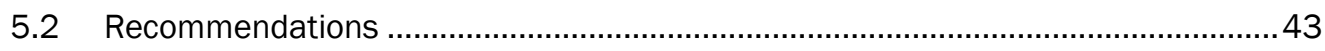

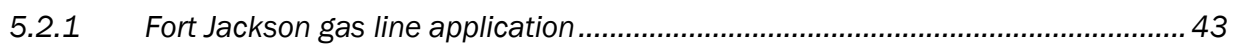

5.2.2 General technology applicability ...................................................................... 43

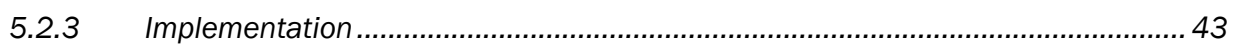


Appendix A: Comparison of Wireless Technologies for Remote Monitoring of Cathodic

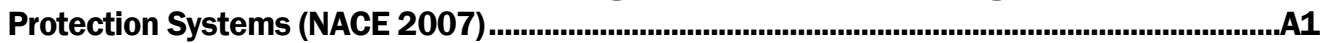

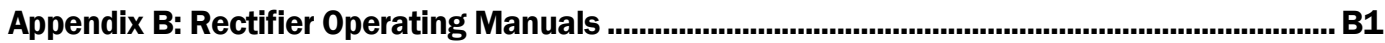

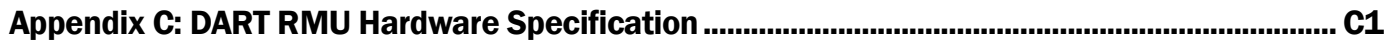

Appendix D: Baseline Native Potential Surveys................................................................ D1

Appendix E: Transformer/Rectifier Data

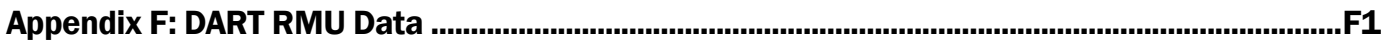

Report Documentation Page 


\section{List of Figures and Tables}

\section{Figures}

Figure 1. New tubular anode design to be used in deep anode wells at Fort Jackson........................ 6

Figure 2. Typical pressure reducing test station (PRTS). ......................................................................15

Figure 3. Typical gas line service entry into building. ........................................................................15

Figure 4. Drill truck setup .......................................................................................................................18

Figure 5. Overflow pan on right and coke breeze in front of drill rig. ...............................................18

Figure 6. Solid perforated pipe to be located at anode depth, solid pipe above anodes, and small vent pipe entire length of column. .......................................................................................19

Figure 7. Tubular ceramic anodes pre-attached to vent pipe before loading into column.................19

Figure 8. Loading anodes and vent pipe into column.......................................................................20

Figure 9. Alternate view of loading anodes and vent pipe.............................................................20

Figure 10. Mixing DW-3 coke and pumping into column.................................................................21

Figure 11. Fine sand encountered at all depths in southmost deep anode bed................................21

Figure 12. Top of deep anode column after anodes, vent pipe, and coke breeze installed .............22

Figure 13. Portion of hand-dug trench (24 in. minimum) ...................................................................22

Figure 14. Deep anode access box and hand-dug trench between pipe and rectifier,.....................23

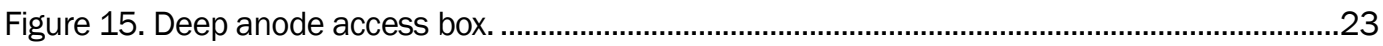

Figure 16. Rectifier power supply and anode junction box, Wall and Washington St). .....................24

Figure 17. Rectifier power supply and junction box, Hardee and Hill St. ...........................................24

Figure 18. Diagram of storage tank CP system configuration. .........................................................26

Figure 19. IRT rectifier faceplate.............................................................................................2

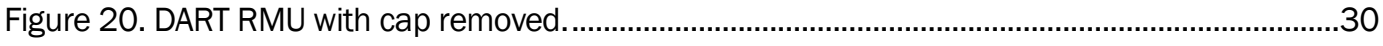

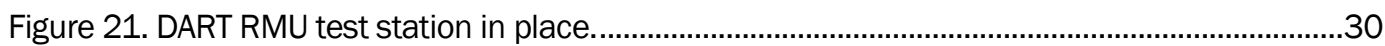

Figure 22. $\mathrm{Cu} / \mathrm{CuSO}_{4}$ reference electrode with integral main and spare coupons. ..........................31

Figure 23. Drive-by data collection system including GPS-enabled laptop computer. .......................31

Figure 24. Laptop screen showing GPS locations of RMUs (dots at lower right). ................................32

Figure 25. RMU rectifier reader unit inside rectifier cabinet, cover removed.....................................32

Figure 26. Close-up view of RMU rectifier reader unit. .......................................................................33

\section{Tables}

Table 1. Outer ring vertical anode calculations............................................................................

Table 2. Outer ring vertical anode calculations (continued)...........................................................10

Table 3.. Inner ring vertical anode calculations. …………............................................................11

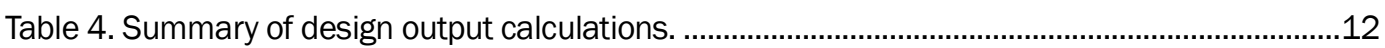

Table 5. Comparison of remote monitoring technologies...................................................................13 


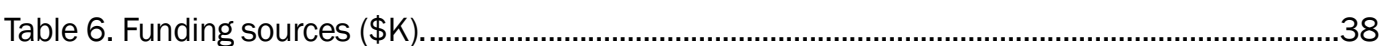

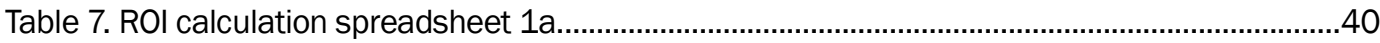

Table 8. ROI calculation spereadsheet 1b.................................................................................. 41 


\section{Preface}

This demonstration was performed for the Office of the Secretary of Defense (OSD) under Department of Defense (DoD) Corrosion Control and Prevention Project FAR-20, "Cathodic Protection Systems for Utilities in Severely Corrosive Environments". The proponent was the U.S. Army Office of the Assistant Chief of Staff for Installation Management (ACSIM), and the stakeholder was the U.S. Army Installation Management Command (IMCOM). The technical monitors were Daniel J . Dunmire (OUSD(AT\&L)Corrosion), Paul M. Volkman (IMPW-E), and David N. Purcell (DAIM-FDF).

The work was performed by the Engineering and Materials Branch (CEERD-CF-M), Facilities Division (CF), U. S. Army Engineer Research and Development Center- Construction Engineering Research Laboratory (ERDC-CERL), Champaign, IL. The ERDC-CERL project managers were Dr. Ashok Kumar and Dr. L.D. Stephenson. Significant portions of this work were performed by Mr. J ames Bushman and Dr. Bopinder Phull of Bushman \&Associates, Inc., Medina, OH. The contributions of subcontractors Loresco, Inc. of Hattiesburg, MS, Clearwater Drilling Company of Columbia, SC, and Freeman Industries of Dorset, $\mathrm{OH}$ are also acknowledged.

The Fort J ackson DPW personnel are gratefully acknowledged for their support and assistance in this project, especially Mr. Georges Dib, Electrical Engineer/ Energy Manager, with the DPW.

At the time this report was prepared, the Chief of the ERDC-CERL Materials and Structures Branch was Vicki L. Van Blaricum (CEERD-CF-M), the Chief of the Facilities Division was L. Michael Golish, (CEERD-CF), and the Technical Director for Installations was Martin J. Savoie (CEERDCV-ZT). The Deputy Director of ERDC-CERL was Dr. Kirankumar Topudurti and the Director was Dr. Ilker Adiguzel.

The Commander and Executive Director of the U.S. Army Engineer Research and Development Center was COL Richard B. J enkins and the Director was Dr. James R. Houston. 


\section{Executive Summary}

This OSD Corrosion Prevention and Control project demonstrated the use of new tubular ceramic anodes that can be placed $200 \mathrm{ft}$ deep in the ground. Their design makes them more water resistant than previous designs. These deep well impressed current ceramic anode beds help to more widely distribute the protection current from the ceramic anodes to protect pipelines. Three deep well anodes were placed at Fort J ackson which has a severely corrosive environment year round. 100 drive by type remote monitoring units were also installed facilitating cathodic protection data to be collected in three hours that previously took a week to collect. This data is automatically downloaded into a software program which allows the installation to quickly determine if the cathodic protection is working at each of those sites. All measurement parameters including time between data samples, length of time period during which instant off potential's are measured and time period over which polarization decay is assessed are all user selectable values. Thus the system can also be utilized on other pipe materials such as ductile iron, aluminum and copper which have different criteria for cathodic protection than that used on buried steel pipe.

A new ceramic mixed metal oxide anode system was installed in the 2 million gallon elevated water storage tank replacing a failing silicon - iron anode system. The new anode material connections are made above the high water line preventing the ingress of water into the connection and subsequent failure of the anode material. The anode life of the new ceramic wire anode material is conservatively calculated at greater than 40 years in this particular water storage tank. Data collected through the remote monitoring drive by system that was also installed, indicates that the tank is now receiving complete and uniform cathodic protection in the tank interior below the waterline.

Recommendations will be provided for revisions to Unified Facilities Guide Specifications (UFGS) -26 4215.0010 "Cathodic Protection System (Steel Water Tanks)" and UFGS -26 4217.0010 "Cathodic Protection System (Impressed Current)." These revisions include the specifications and instructions for installing the advanced impressed current cathodic protection systems in conjunction with the "drive-by" remote monitoring units for utilities as demonstrated under this project. 


\section{Unit Conversion Factors}

\begin{tabular}{|l|c|l|}
\hline Multiply & By & To Obtain \\
\hline degrees Fahrenheit & $(\mathrm{F}-32) / 1.8$ & degrees Celsius \\
\hline $\mathrm{ft}$ & 0.3048 & meters \\
\hline gallons (U.S. liquid) & $3.785412 \mathrm{E}-03$ & cubic meters \\
\hline inches & 0.0254 & meters \\
\hline mils & 0.0254 & millimeters \\
\hline square $\mathrm{ft}$ & 0.09290304 & square meters \\
\hline
\end{tabular}





\section{Introduction}

\subsection{Problem statement}

Fort J ackson, SC, is located in a severely corrosive environment, with highly corrosive soil and hot, humid weather. A recent corrosion protection survey there identified a lack of cathodic protection (CP) systems on underground natural gas distribution piping, which is required by law. Also, failed anodes were discovered in a 2 million gallon potable water storage tank. CP systems counteract the effects of corrosive soils on underground pipelines and the warm, humid corrosive environment inside water storage tanks.

Fort J ackson's natural gas piping system is made of coated welded steel pipe. A new CP system using tubular anodes was designed and implemented to protect the underground gas pipelines. A new CP system using mixed metal oxide (MMO) anode was designed and implemented to protect the inside of the water tank below the water line.

Providing CP systems for critical infrastructure is required to avoid utility service interruptions and safety hazards. Ensuring that CP systems provide continuous corrosion protection can be very time consuming for installation personnel, and higher-profile priorities may interfere with $\mathrm{CP}$ system inspections. The Office of the Secretary of Defense Corrosion Prevention and Control (CPC) Program demonstration project described here addressed both the need for purpose-designed CP systems at Fort J ackson and the need to facilitate frequent and comprehensive CP system monitoring and analysis. In that connection, the new CP systems implemented in this demonstration were outfitted with remote monitoring units (RMUs) to enable Fort J ackson personnel to monitor the performance of the new CP systems and log data from them in "drive-by" mode from a vehicle, using a standard laptop computer. The purpose of the drive by RMUs is to reduce the time and resources required to ensure that these critical CP systems are functioning properly over time. 


\subsection{Objective}

The objective of this project was to evaluate remote corrosion monitoring needs of pipes and other utility systems, and implement a remote corrosion monitoring system at Fort J ackson.

\subsection{Approach}

This projected entailed the following tasks:

- Install three new deep well anode CP systems with tubular anodes to protect the underground natural gas distribution pipes

- Install a new CP system to protect the elevated water storage tank.

- Install remote monitoring technology that uses a drive-by method in which CP system data can be automatically downloaded to a portable computer in a installation user friendly format that quickly identifies CP problem areas.

Similar deep anode impressed current cathodic protection systems with drive by remote monitoring units were installed at Fort Carson previously. The details and results of this work can be found in the technical report on CPC Project AR-F-321, ERDC-CERL TR-07-25 (Stephenson et al. 2007, in preparation). The Fort Carson work directly applied to how the Fort J ackson work was approached and accomplished.

Fort J ackson has a severely corrosive environment year round whereas Fort Carson's is more seasonal. The soil types vary over a depth of 1 to $5 \mathrm{ft}$, with sand at a depth of about $1 \mathrm{ft}$ deep, to loam at $2 \mathrm{ft}$, to clay from $3-5 \mathrm{ft}$ deep. This variation in types of soil and the constant high wetness throughout the year, due to an average annual rainfall of 50 inches creates corrosion cells at interfaces between the soil types. The deep well anode chosen for Fort J ackson was therefore chosen to withstand this harsher environment. The variation of the depth that bedrock was hit also impacted the placement of the deep well anodes.

Because of the warmer climate at Fort J ackson, the CP system designed for the water storage tank allowed the use of a new system that would be damaged if exposed to ice of more than 1-2 in. inside the tank, as happens at many installations. The new system is suspended from the roof of the tank making it easier to maintain and inspect, as it does not require draining of the tank. It is also less expensive to install. 
The remote monitoring system was also upgraded to allow the user more flexibility on what systems could be monitored, how often the systems were monitored and increased distance allowed to collect the data during drive by. The output of the system was designed to allow the field to easily determine if there was a problem with the CP.

Initial surveys of existing pipes were made to establish where the most beneficial placement for the deep well anodes and remote monitoring systems would be achieved. As there were not existing accurate historical records of piping, water main layouts, etc., great care had to be taken into account before and during placement of the deep well anodes.

The appendices to this report provide supplemental information on this demonstration, as follows:

- Appendix A: Comparison of Wireless Technologies for Remote Monitoring of Cathodic Protection Systems (NACE 2007)

- Appendix B: IRT Sentinel Rectifier Manuals

- Appendix C: DART RMU Hardware Specification

- Appendix D: Baseline Native Potential Surveys

- Appendix E: Test Rectifier Data

- Appendix F: DART RMU Data. 


\section{Technical Investigation}

\subsection{Project overview}

The solution to the problem of natural gas line protection was the installation of a cathodic protection (CP) system consisting of deep well ceramic anodes. Impressed CP systems protect the buried pipe by supplying electrons from the ceramic anodes that are made to assume a negative potential relative to the pipe. The mixed metal oxide (MMO) ceramic anodes were installed in 3 strategic locations 50-200 ft deep below the ground. Installation of deep well impressed current ceramic anode beds help to more widely distribute the protection current from ceramic anodes to protect pipelines. A new precious metal oxide coated continuous wire anode CP system was installed in the elevated water tank.

In addition, $\mathrm{CP}$ test stations were installed with drive by remote monitoring systems that include software that can alert base maintenance personnel of a problem with the $\mathrm{CP}$ current and potential readings.

\subsubsection{Specifications}

The cathodic protection system being placed to protect the underground gas lines had to withstand being exposed to water, had to be able to be buried 50-200 ft below ground and had to be replaceable. The CP system for the elevated water tank needed to have a longer life than the current high silicon cast-iron anode. The remote monitoring system had to be easy to use with drive by capabilities, parameter monitoring flexibility and useful to understand data output.

\subsubsection{Application design details}

\subsubsection{System design details for the deep well anodes}

In choosing the deep groundbed anodes several advantages and disadvantages of this type of placement were considered. Among these are the following, extracted from NACE Standard Recommended Practice RP05722001, Design, Installation, Operation, and Maintenance of Impressed Current Deep Ground Beds: 
4.2 The following advantages and disadvantages are characteristic of deep groundbeds and should be considered in the design of such a groundbed:

\subsubsection{Advantages}

4.2.1.1 Deep groundbeds may be located in congested areas where shallow groundbeds pose geographic, topographic, interference, or right-of-way problems.

4.2.1.2 Deep groundbeds may provide lower resistance than shallow groundbeds in areas of high-resistivity surface soils.

4.2.1.3 Deep groundbeds may result in lower anodic potential gradients to other structures than shallow groundbeds.

4.2.1.4 Deep groundbeds may provide better current distribution than shallow groundbeds.

4.2.1.5 Deep groundbeds eliminate some of the accidental damage that may occur to shallow groundbeds by excavation and land cultivation.

4.2.1.6 Deep groundbeds are less affected by seasonal moisture variations than shallow groundbeds and usually are not subject to freezing.

4.2.1.7 The use of open-hole deep groundbeds or closed-hole deep groundbeds specifically designed for anode replacement can facilitate inspection, repair, and replacement of groundbed components.

4.2.1.8 Deep groundbeds minimize surface disturbances in environmentally sensitive areas.

\subsubsection{Disadvantages}

4.2.2.1 Current requirement tests that accurately simulate actual deep groundbed installations are difficult to conduct.

4.2.2.2 Deep groundbeds are often more expensive to install than shallow groundbeds of similar current.

4.2.2.3 Inspection, replacement, or repair of closed hole deep groundbed installations may be difficult.

4.2.2.4 Closed-hole deep groundbeds require special design considerations because of their susceptibility to gas blockage. This disadvantage may not apply to continuous steel pipe or rail groundbeds.

4.2.2.5 Supplemental shallow groundbeds may be required to provide adequate protective current distribution to certain structures, or to provide adequate potential shifts for structures located in the immediate vicinity of the deep groundbed.

4.2.2.6 Compaction of backfill material around the anode in a deep groundbed may be difficult to achieve. The use of high-density backfill material can improve compaction. Poor compaction or absence of backfill can cause accelerated deterioration of the anode. 
4.2.2.7 Open-hole deep groundbeds require an aqueous electrolyte.

4.2.2.8 Open-hole deep groundbeds may require nonconductive casing to prevent cave-in.

4.2.2.9 Open-hole deep groundbeds usually require additional depth below the bottom anode to form a sump for the collection of sediment.

4.2.2.10 Prediction of deep groundbed performance is more difficult and less exact than for shallow groundbeds.

4.2.2.11 Problems may exist with the bridging of subsurface aquifers that may require special design considerations to prevent intermixing of waters.

The anode chosen for this project is a new type of ceramic anode used to protect underground pipes. They were installed in deep wells 50- $100 \mathrm{ft}$ deep. The deep-well ceramic anodes are in soil that has a 20- $70 \mathrm{ft}$ water head, and the connection between the anodes and the cable is the weakest link, which must be protected. This new ceramic anode configuration is called tubular as it consists of a titanium tube with an MMO ceramic coating, and a center connection, and sealed ends to protect it from water intrusion in the deep wells (Figure 1).

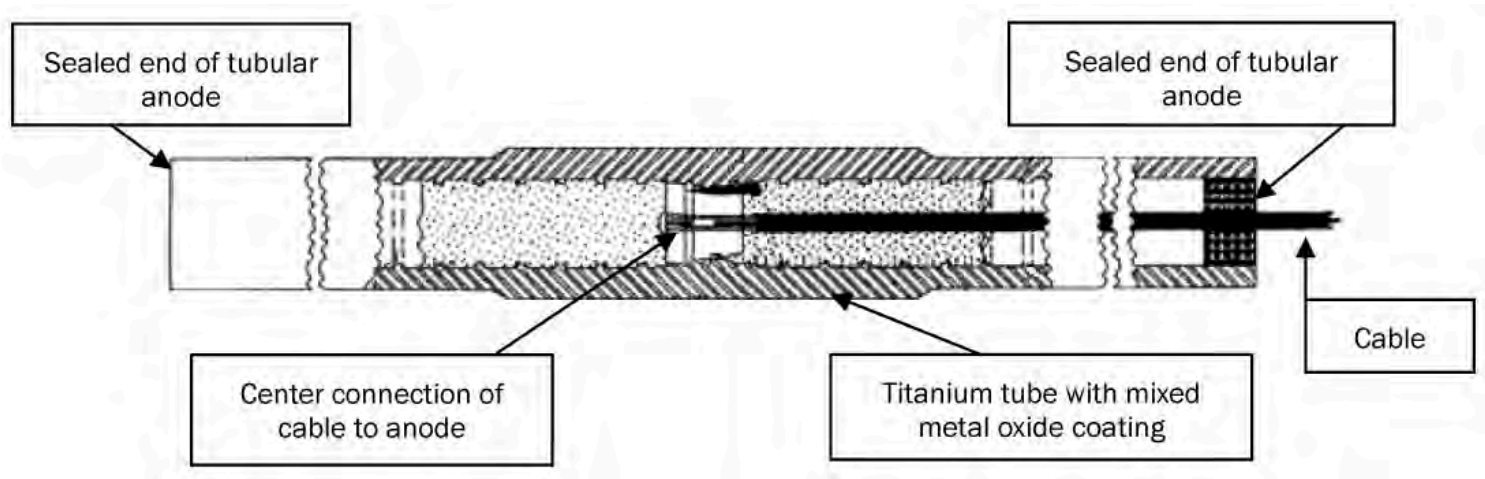

Figure 1. New tubular anode design to be used in deep anode wells at Fort Jackson.

The deep anode beds incorporate the use of double end lead wire feeding through ceramic (precious metal oxide) coated titanium anode tubes. The double end feed wire provides redundancy in case a flaw should develop in the anode wire. In addition, fluoro-polymer insulated lead wire with a high molecular weight polyethylene jacket is used. The fluoro-polymer insulation provides complete resistance to attack by any gases generated at the anode/ coke breeze interface. Connection of the lead wire to the anode tube is made internally at its central most point providing the longest sealing path and thus resistance to water penetration into the connection point. The more commonly used rod type anodes cannot be double end fed eco- 
nomically and cannot incorporate the long sealing path provided by the tubular shape. It was this older style anode that was used at Fort Carson.

The deep anode beds incorporate the latest design in replaceable systems which provide the same level of future ease of replacement of the anode material at significantly reduced costs by not including a steel lead and ball check valve at the bottom of the deep anode tube. Instead, the coke breeze is placed around the anode material in the conductive zone and the exterior of the perforated casing pipe simultaneously. The DW3 calcined fluid petroleum coke used on this project is both extremely conductive and has a very high density enabling it to displace any drilling materials that would otherwise remain within the deep anode bed column. These features were not incorporated into the Fort Carson project.

The area of the buried steel piping requiring protection at Fort J ackson is not known with any degree of accuracy because as-built drawings and historical records were unavailable. The area of other utility piping (e.g., water mains and distribution piping) believed to be electrically grounded to the gas piping is also unknown. Most of the gas piping system appears to be electrically shorted to these other piping systems subjecting the steel pipe of the natural gas distribution to significant dissimilar metal corrosion.

Without more information on where the gas piping is located, what other utilities are close and what material the piping is made of, it is not possible to design a meaningful CP system to protect the entire buried steel gas piping system. In view of this limitation, there was agreement between CERL and Bushman \&Associates (B\&A) that three (3) ceramic, deep anode groundbeds would be installed and operated to determine how much of the gas piping would be protected. Based on the results, recommendations would then be made for installation of additional deep anode groundbeds, as needed, to protect all of the gas piping. Thus, unlike a traditional design, current requirements could not be based on a specific design current density (e.g., $2 \mathrm{~mA} / \mathrm{ft}^{2}$ ) for steel and known surface area requiring protection.

\subsubsection{System design for the CP on the elevated water storage tank}

The previous cathodic protection system consisted of the more commonly used (less expensive and less durable) high silicon cast-iron anodes. A cathodic protection system consisting of precious metal oxide coated conti- 
nuous wire anodes suspended vertically in the water from the tank roof was chosen to replace the iron anodes. This vertical suspension was enabled by the lack of winter ice formations inside the tank in this southern climate. The new anode material connections are made above the high water line preventing the ingress of water into the connection and subsequent failure of the anode material.

This type of anode suspension from the roof of a water storage tank should only be considered for use on those tanks, which are virtually always free of significant ice formations during the winter months. Those tanks, which are subject to ice formations of more than one or 2 inches on the surface of the water inside the tank, should never incorporate this type design. Rather, they should only use the tethered hoop style system, which places the anodes significantly below the ice level in the tank, and thus prevents their damage.

The advantage of the vertically suspended anode system is that they can more easily be removed for inspection and maintenance replacement, should that be necessary in the future. The tethered hoop style anode system requires that the tank be drained before anode inspection and or replacement can be performed. The vertically suspended system is substantially less expensive to install when the environmental conditions preclude ice formations, which would damage the anode material, and clean water level fluctuations while the ice is present in the tank.

The initial system design was developed by B\&A, using a computer program they developed several years ago to automate the design process for impressed current cathodic protection design for water storage tanks. The program operates within Microsoft Excel and allows multiple iterations of the design to be developed and compared for capacity and power requirements. The following shows the final design parameters after multiple iterations: 
Table 1. Outer ring vertical anode calculations.

\section{Bare Impressed Current Ceramic Anode Resistance and Current Output Calculations Computation Program ${ }^{\odot}$ by Bushman \& Associates, Inc.}

\section{Case Name.: Fort Jackson 2MMG Elevated Water Storage Tank - Outer Ring Anodes -- Ver. 2.0 -- 31 Foot Long}

\begin{tabular}{|r|c|l|}
\hline Tank \& Content Variables & Value & \multicolumn{1}{|c|}{ Term } \\
\hline Tank Bowl Diameter & $\mathbf{1 , 2 0 0}$ & Inches \\
\hline Tank Range-in-Head & $\mathbf{4 8 0}$ & Inches \\
\hline Water Temp & $\mathbf{5 5}$ & degrees F \\
\hline Water Resistivity at Hot Water Temp & $\mathbf{8 8 0 0}$ & ohm-cm \\
\hline Current Density Req'd at Hot Water Temp & $\mathbf{2}$ & $\mathrm{mA} / \mathrm{Ft}^{2}$ \\
\hline Tank Sumberged Surface Area & $\mathbf{1 6 2 5 0}$ & $\mathrm{Ft}^{2}$ \\
\hline Coating Efficiency & $\mathbf{5 0 \%}$ & \\
\hline Total Current Required at Hot Water Temp & $\mathbf{1 6 2 5 0}$ & $\mathrm{mA}$ \\
\hline
\end{tabular}

\begin{tabular}{|c|c|c|c|}
\hline Anode Variables & Value & Term & \multirow{11}{*}{$\begin{array}{l}\text { Notes by Program Author J. B. Bushman } \\
\text { 1. Only Blue Variables can be changed } \\
\text { 2. All variables should be carefully considered } \\
\text { 3. This model works for all Impressed Current Anode }\end{array}$} \\
\hline Electrolyte Resistivity & 8800 & Ohm-Cm & \\
\hline sired Total CP Current (includes 20\% Safety Factor & 19.5 & Amperes & \\
\hline Anode Metal & $\begin{array}{l}\text { Platinum Coated } \\
\text { Niobium }\end{array}$ & & \\
\hline Anode Alloy & $\begin{array}{l}\text { Copper Cored - } 40 \% \\
\text { wall niobium with } 25 \\
\text { micro-in platinum }\end{array}$ & & \\
\hline Anode Model No. & $.025 / 40 / \mathrm{Cu} / \mathrm{Pt} / \mathrm{Nb}$ & & \\
\hline Desired Anode Life & 20 & Years & \\
\hline Anode Mfg. Rated Current for 20 Yr Life in Fresh Water & 0.020833333 & A/Lineal Inch & \\
\hline Anode Active Length (unsleeved) & 372 & Inches & \\
\hline $\begin{array}{r}\text { Selected Anode Maximum Rated Current for } \\
\text { Desired Life }\end{array}$ & 7.8 & Ampere & \\
\hline $\begin{array}{r}\text { Anode Efficiency (Percent used to provide CP } \\
\text { Current) }\end{array}$ & $100.0 \%$ & $\%$ Eff. & \\
\hline ercent of Total Used before Considered Depleted) & 1.00 & $\%$ Utilization & \\
\hline Rectifier Voltage & 60.00 & Volts & \\
\hline Desired Cathode Potential (mV vs. Cu-CuSO4) & 0.85 & Volts & \\
\hline Net Anode-to-Structure Driving Potential & 58.35 & Volts & \\
\hline Anode Diameter & 0.0625 & Inches & \\
\hline Anode Length & 372 & Inches & \\
\hline Anode Ring Diameter & 70 & Feet & \\
\hline No. of Anode in Ring & 10 & & \\
\hline Anode Center-to-Center Spacing (feet) & 24.43460953 & Feet & \\
\hline
\end{tabular}


Table 2. Outer ring vertical anode calculations (continued).

Calculated Current Output with Tests for Meeting Current Requirement and Anode Life

\begin{tabular}{|c|c|c|c|c|c|c|}
\hline \multicolumn{7}{|c|}{ Calculated Current Output with Tests for Meeting Current Requirement and Anode Life } \\
\hline No. of Anodes & $\begin{array}{c}\text { Anode to } \\
\text { Electrolyte } \\
\text { Resistance (in } \\
\text { Ohms) }\end{array}$ & $\begin{array}{l}\text { Total } \\
\text { Anode to } \\
\text { Electrolyte } \\
\text { Resistance } \\
\text { (Ohms) }\end{array}$ & $\begin{array}{c}\text { Total } \\
\text { Current } \\
\text { Output } \\
\text { (Amperes) }\end{array}$ & $\begin{array}{c}\text { Current } \\
\text { Output } \\
\text { per Anode } \\
\text { (Amperes) }\end{array}$ & $\begin{array}{c}\text { Is Desired } \\
\text { Current } \\
\text { Output Met? }\end{array}$ & $\begin{array}{l}\text { Is Anode } \\
\text { Desired } \\
\text { Life Met? }\end{array}$ \\
\hline 1 & 14.4509 & 14.4509 & 4.038 & 4.038 & No & Yes \\
\hline 2 & 7.7350 & 7.7350 & 7.544 & 3.772 & No & Yes \\
\hline 3 & 5.6638 & 5.6638 & 10.302 & 3.434 & Yes & Yes \\
\hline 4 & 4.5178 & 4.5178 & 12.916 & 3.229 & Yes & Yes \\
\hline 5 & 3.7817 & 3.7817 & 15.430 & 3.086 & Yes & Yes \\
\hline 6 & 3.2655 & 3.2655 & 17.869 & 2.978 & Yes & Yes \\
\hline 7 & 2.8816 & 2.8816 & 20.249 & 2.893 & Yes & Yes \\
\hline 8 & 2.5840 & 2.5840 & 22.581 & 2.823 & Yes & Yes \\
\hline 9 & 2.3460 & 2.3460 & 24.872 & 2.764 & Yes & Yes \\
\hline 10 & 2.1510 & 2.1510 & 27.127 & 2.713 & Yes & Yes \\
\hline 11 & 1.9879 & 1.9879 & 29.352 & 2.668 & Yes & Yes \\
\hline 12 & 1.8495 & 1.8495 & 31.549 & 2.629 & Yes & Yes \\
\hline 13 & 1.7303 & 1.7303 & 33.722 & 2.594 & Yes & Yes \\
\hline 14 & 1.6266 & 1.6266 & 35.872 & 2.562 & Yes & Yes \\
\hline 15 & 1.5354 & 1.5354 & 38.003 & 2.534 & Yes & Yes \\
\hline 16 & 1.4546 & 1.4546 & 40.114 & 2.507 & Yes & Yes \\
\hline 17 & 1.3824 & 1.3824 & 42.209 & 2.483 & Yes & Yes \\
\hline 18 & 1.3175 & 1.3175 & 44.288 & 2.460 & Yes & Yes \\
\hline 19 & 1.2589 & 1.2589 & 46.351 & 2.440 & Yes & Yes \\
\hline 20 & 1.2055 & 1.2055 & 48.401 & 2.420 & Yes & Yes \\
\hline 21 & 1.1569 & 1.1569 & 50.438 & 2.402 & Yes & Yes \\
\hline 22 & 1.1122 & 1.1122 & 52.463 & 2.385 & Yes & Yes \\
\hline 23 & 1.0711 & 1.0711 & 54.477 & 2.369 & Yes & Yes \\
\hline 24 & 1.0331 & 1.0331 & 56.479 & 2.353 & Yes & Yes \\
\hline 25 & 0.9979 & 0.9979 & 58.471 & 2.339 & Yes & Yes \\
\hline 26 & 0.9652 & 0.9652 & 60.453 & 2.325 & Yes & Yes \\
\hline 27 & 0.9347 & 0.9347 & 62.426 & 2.312 & Yes & Yes \\
\hline 28 & 0.9062 & 0.9062 & 64.390 & 2.300 & Yes & Yes \\
\hline 29 & 0.8795 & 0.8795 & 66.345 & 2.288 & Yes & Yes \\
\hline 30 & 0.8544 & 0.8544 & 68.292 & 2.276 & Yes & Yes \\
\hline 31 & 0.8308 & 0.8308 & 70.232 & 2.266 & Yes & Yes \\
\hline 32 & 0.8086 & 0.8086 & 72.163 & 2.255 & Yes & Yes \\
\hline
\end{tabular}


Table 3. Inner ring vertical anode calculations.

\section{Bare Impressed Current Ceramic Anode Resistance and Current Output Calculations Computation Program ${ }^{\odot}$ by Bushman \& Associates, Inc.}

\begin{tabular}{|l|l|}
\hline Case Name.: & $\begin{array}{l}\text { Fort Jackson 2MMG Elevated Water Storage Tank - } \\
\text { Inner Ring Anodes - Ver 2.0 - 20' Long Anodes }\end{array}$ \\
\hline
\end{tabular}

\begin{tabular}{|r|c|l|}
\hline Tank \& Content Variables & Value & \multicolumn{1}{|c|}{ Term } \\
\hline Tank Bowl Diameter & $\mathbf{1 , 2 0 0}$ & Inches \\
\hline Tank Range-in-Head & $\mathbf{4 8 0}$ & Inches \\
\hline Water Temp & $\mathbf{5 5}$ & degrees F \\
\hline Water Resistivity at Hot Water Temp & $\mathbf{8 8 0 0}$ & ohm-cm \\
\hline Current Density Req'd at Hot Water Temp & $\mathbf{2}$ & $\mathrm{mA} / \mathrm{Ft}^{2}$ \\
\hline Tank Sumberged Surface Area & $\mathbf{1 6 2 5 0}$ & $\mathrm{Ft}^{2}$ \\
\hline Coating Efficiency & $\mathbf{5 0 \%}$ & \\
\hline Total Current Required at Hot Water Temp & $\mathbf{1 6 2 5 0}$ & $\mathrm{mA}$ \\
\hline
\end{tabular}

\begin{tabular}{|c|c|c|c|}
\hline Anode Variables & Value & Term & \multirow{20}{*}{$\begin{array}{l}\text { Notes by Program Author J. B. Bushman } \\
\text { 1. Only Blue Variables can be changed } \\
\text { 2. All variables should be carefully considered } \\
\text { 3. This model works for all Impressed Current Anode }\end{array}$} \\
\hline Electrolyte Resistivity & 8800 & Ohm-Cm & \\
\hline sired Total CP Current (includes 20\% Safety Factor & 19.5 & Amperes & \\
\hline Anode Metal & $\begin{array}{c}\text { Platinum Coated } \\
\text { Niobium }\end{array}$ & & \\
\hline Anode Alloy & $\begin{array}{l}\text { Copper Cored - } 40 \% \\
\text { wall niobium with } 25 \\
\text { micro-in platinum }\end{array}$ & & \\
\hline Anode Model No. & $.025 / 40 / \mathrm{Cu} / \mathrm{Pt} / \mathrm{Nb}$ & & \\
\hline Desired Anode Life & 20 & Years & \\
\hline Anode Mfg. Rated Current for 20 Yr Life in Fresh Water & 0.020833333 & A/Lineal Inch & \\
\hline $\begin{array}{r}\text { Anode Active Length (unsleeved) } \\
\end{array}$ & 240 & Inches & \\
\hline $\begin{array}{r}\text { Selected Anode Maximum Rated Current for } \\
\text { Desired Life }\end{array}$ & 5.0 & Ampere & \\
\hline $\begin{array}{r}\text { Anode Efficiency (Percent used to provide CP } \\
\text { Current) }\end{array}$ & $100.0 \%$ & $\%$ Eff. & \\
\hline ercent of Total Used before Considered Depleted) & 1.00 & $\%$ Utilization & \\
\hline \begin{tabular}{rc|} 
Rectifier Voltage \\
\end{tabular} & 60.00 & Volts & \\
\hline Desired Cathode Potential (mV vs. Cu-CuSO4) & 0.85 & Volts & \\
\hline Net Anode-to-Structure Driving Potential & 58.35 & Volts & \\
\hline Anode Diameter & 0.0625 & Inches & \\
\hline Anode Length & 240 & Inches & \\
\hline Anode Ring Diameter & 20 & Feet & \\
\hline No. of Anode in Ring & 5 & & \\
\hline Anode Center-to-Center Spacing (feet) & 15.70796327 & Feet & \\
\hline
\end{tabular}

Calculated Current Output with Tests for Meeting Current Requirement and Anode Life

\begin{tabular}{|c|c|c|c|c|c|c|}
\hline \multicolumn{7}{|c|}{ Calculated Current Output with Tests for Meeting Current Requirement and Anode Life } \\
\hline No. of Anodes & $\begin{array}{c}\text { Anode to } \\
\text { Electrolyte } \\
\text { Resistance (in } \\
\text { Ohms) }\end{array}$ & $\begin{array}{c}\text { Total } \\
\text { Anode to } \\
\text { Electrolyte } \\
\text { Resistance } \\
\text { (Ohms) }\end{array}$ & $\begin{array}{c}\text { Total } \\
\text { Current } \\
\text { Output } \\
\text { (Amperes) }\end{array}$ & $\begin{array}{c}\text { Current } \\
\text { Output } \\
\text { per Anode } \\
\text { (Amperes) }\end{array}$ & $\begin{array}{c}\text { Is Desired } \\
\text { Current } \\
\text { Output Met? }\end{array}$ & $\begin{array}{l}\text { Is Anode } \\
\text { Desired } \\
\text { Life Met? }\end{array}$ \\
\hline 1 & 21.3942 & 21.3942 & 2.727 & 2.727 & Yes & Yes \\
\hline 2 & 11.4897 & 11.4897 & 5.078 & 2.539 & Yes & Yes \\
\hline 3 & 8.4488 & 8.4488 & 6.906 & 2.302 & Yes & Yes \\
\hline 4 & 6.7564 & 6.7564 & 8.636 & 2.159 & Yes & Yes \\
\hline 5 & 5.6657 & 5.6657 & 10.299 & 2.060 & Yes & Yes \\
\hline 6 & 4.8988 & 4.8988 & 11.911 & 1.985 & Yes & Yes \\
\hline 7 & 4.3275 & 4.3275 & 13.484 & 1.926 & Yes & Yes \\
\hline 8 & 3.8840 & 3.8840 & 15.023 & 1.878 & Yes & Yes \\
\hline 9 & 3.5288 & 3.5288 & 16.535 & 1.837 & Yes & Yes \\
\hline 10 & 3.2375 & 3.2375 & 18.023 & 1.802 & Yes & Yes \\
\hline
\end{tabular}


Table 4. Summary of design output calculations.

\begin{tabular}{|c|c|c|}
\hline \multicolumn{3}{|c|}{$\begin{array}{c}\text { Fort Jackson 2MMG Hydro-Pillar Style } \\
\text { Elevated Water Storage Tank - ICCP System } \\
\text { Output Calculations - Reference Worksheet } \\
\text { Tabs } 2 \text { and } 3\end{array}$} \\
\hline & Resistance & $\begin{array}{l}\text { Current } \\
\text { Output at } \\
\text { Rectifier } \\
\text { Rated Voltage }\end{array}$ \\
\hline Outer Ring Anode Strings & 2.1510 & 27.13 \\
\hline Inner Ring Anode Strings & 5.6657 & 10.30 \\
\hline $\begin{array}{r}\text { Total ICCP System Designed } \\
\text { Current Output Capacity }\end{array}$ & & 37.43 \\
\hline $\begin{array}{r}\text { Check - Anode Resistance of all } \\
\text { anodes in parallel - Ohms }\end{array}$ & 1.56 & \\
\hline Check - Calc. Current - Amperes & 37.52 & \\
\hline Total Submerged Bowl Area $\left(\mathrm{Ft}^{2}\right)$ & 16250.00 & \\
\hline $\begin{array}{r}\text { Total Current Required assuming } \\
75 \% \text { efficient coating and } 2 \mathrm{~mA} / \mathrm{ft}^{2} \\
\text { required for effective ICCP }\end{array}$ & 16.25 & \\
\hline
\end{tabular}

\subsubsection{Remote monitoring design}

A comparison of wireless technologies for remote monitoring of CP systems had been made prior to the start of this work (Table 5). Some of this research was presented as a paper at the NACE 2007 conference, and is included in Appendix A. 
Table 5. Comparison of remote monitoring technologies.

\begin{tabular}{|c|c|c|c|c|}
\hline & SCADA-Based System & Drive-by System & $\begin{array}{l}\text { Cell phone-Based } \\
\text { System }\end{array}$ & $\begin{array}{l}\text { Satellite Based } \\
\text { System }\end{array}$ \\
\hline Initial Cost & $\begin{array}{l}\$ 10,000 \text { per monitoring } \\
\text { station }\end{array}$ & $\begin{array}{l}\$ 2,000 \text { per } \\
\text { monitoring station }\end{array}$ & $\begin{array}{l}\$ 2,000 \text { per } \\
\text { monitoring station }\end{array}$ & $\begin{array}{l}\$ 500-700 \text { per } \\
\text { station }\end{array}$ \\
\hline $\begin{array}{l}\text { Maintenance } \\
\text { Requirements }\end{array}$ & Moderate & Low & Low & Very low \\
\hline Advantages & $\begin{array}{l}\text {-Takes advantage of } \\
\text { existing wireless system } \\
\text {-can take readings at } \\
\text { any time } \\
\text {-can control remotely } \\
\text { from a central location } \\
\text { at any time } \\
\text {-can interface with GIS } \\
\text { system }\end{array}$ & $\begin{array}{l}\text {-Low installation } \\
\text { cost } \\
\text { - can easily be } \\
\text { installed } \\
\text { - broadcast } \\
\text { frequencies are pre- } \\
\text { approved }\end{array}$ & $\begin{array}{l}\text {-Low installation cost } \\
\text { - can easily be } \\
\text { installed } \\
\text { - can take readings at } \\
\text { any time } \\
\text { - broadcast } \\
\text { frequencies are pre- } \\
\text { approved } \\
\text { - can control remotely } \\
\text { any location at any } \\
\text { time }\end{array}$ & $\begin{array}{l}\text {-Monitor CP system } \\
\text { virtually anytime, any } \\
\text { where in the world } \\
\text { through the internet }\end{array}$ \\
\hline Disadvantages & $\begin{array}{l}\text { High cost } \\
\text {-Signal path must be } \\
\text { properly planned for } \\
\text { adequate transmission } \\
\text { Signals must be line of } \\
\text { site (LOS) } \\
\text {-Signals are sometimes } \\
\text { lost if there are } \\
\text { impediments to LOS } \\
\text { - FCC approval is needed } \\
\text { for new SCADA } \\
\text { frequencies }\end{array}$ & $\begin{array}{l}\text {-Can not monitor } \\
\text { from central } \\
\text { location; must drive } \\
\text { by within } 0.1 \text { mile of } \\
\text { monitoring station }\end{array}$ & $\begin{array}{l}\text {-Cost of cell phone } \\
\text { services } \\
\text {-Cell phone signals } \\
\text { are sometimes lost in } \\
\text { certain locations }\end{array}$ & $\begin{array}{l}\text {-Charges } \\
\text { fee/reading/location } \\
\text {-Line of site } \\
\text { limitations }\end{array}$ \\
\hline Recommendation & $\begin{array}{l}\text {-Use where existing } \\
\text { SCADA system is } \\
\text { available, such as water } \\
\text { tanks } \\
\text {-Do not install additional } \\
\text { SCADA systems }\end{array}$ & $\begin{array}{l}\text {-Use where there are } \\
\text { no existing SCADA } \\
\text { systems } \\
\text {-Use when drive by } \\
\text { systems are viable }\end{array}$ & $\begin{array}{l}\text { Use where there are } \\
\text { no existing SCADA } \\
\text { systems } \\
\text {-Use where drive by } \\
\text { systems would not be } \\
\text { viable- very remote } \\
\text { areas }\end{array}$ & $\begin{array}{l}\text { Use where there are } \\
\text { no existing SCADA } \\
\text { systems } \\
\text {-Use where drive by } \\
\text { systems would not } \\
\text { be viable- very } \\
\text { remote areas }\end{array}$ \\
\hline
\end{tabular}

The use of drive by RMU systems versus those utilizing satellite based interrogation systems or SCADA systems is merely a matter of economics and the frequency that data acquisition is required. Since cathodic protection data acquisition is typically only required once each month, the cost of installing SCADA equipment at each cathodic protection test Station is simply not practical. Thus at US army facilities, the use of SCADA systems will only be practical at those locations where they already exist for other 
measurement and control purposes. Satellite systems may be cost competitive in the near future however they typically can only communicate in one direction. The drive-by system can communicate in both directions sending corrections and testing parameters to the monitor unit and receiving data based on the monitor parameters transmitted. The drive-by system is particularly economic for military facilities where the monitor points are relatively closely spaced geographically.

An upgraded remote monitoring unit (RMU) from what was used at Fort Carson was chosen for Fort J ackson. The system was designed to allow considerably more flexibility to the user in terms of increased distances for monitoring, types of systems that could be monitored by the system, variation of when data was taken and the big advantage of the data being presented in an excel data sheet clearly stating whether the $\mathrm{CP}$ is functioning or not.

\subsection{Installation and calibration}

\subsubsection{Buried gas lines}

An integral part of this project was to install 100 remote monitoring units to allow drive-by data collection for determining the level of $\mathrm{CP}$ being achieved on the buried gas lines. B\&A conducted a 2-week-long corrosion survey to locate and mark candidate locations for these units. The locations selected consisted of pressure-reducing test stations (PRTSs) or service entry points into buildings; examples of these are shown in Figure 2 and Figure 3, respectively. The native pipe-to-soil potentials measured at the 100 proposed remote monitoring test stations are described later. 


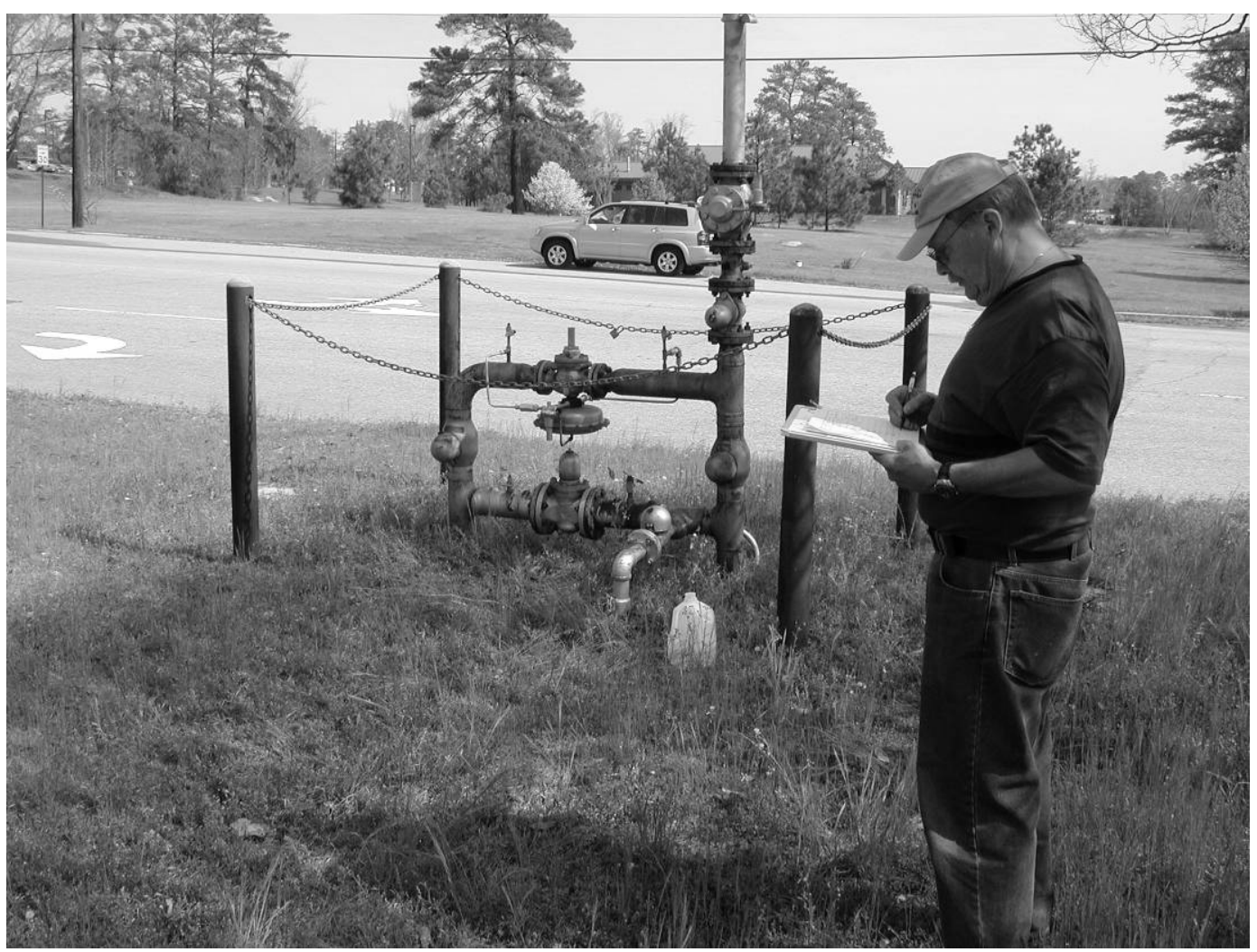

Figure 2. Typical pressure reducing test station (PRTS).

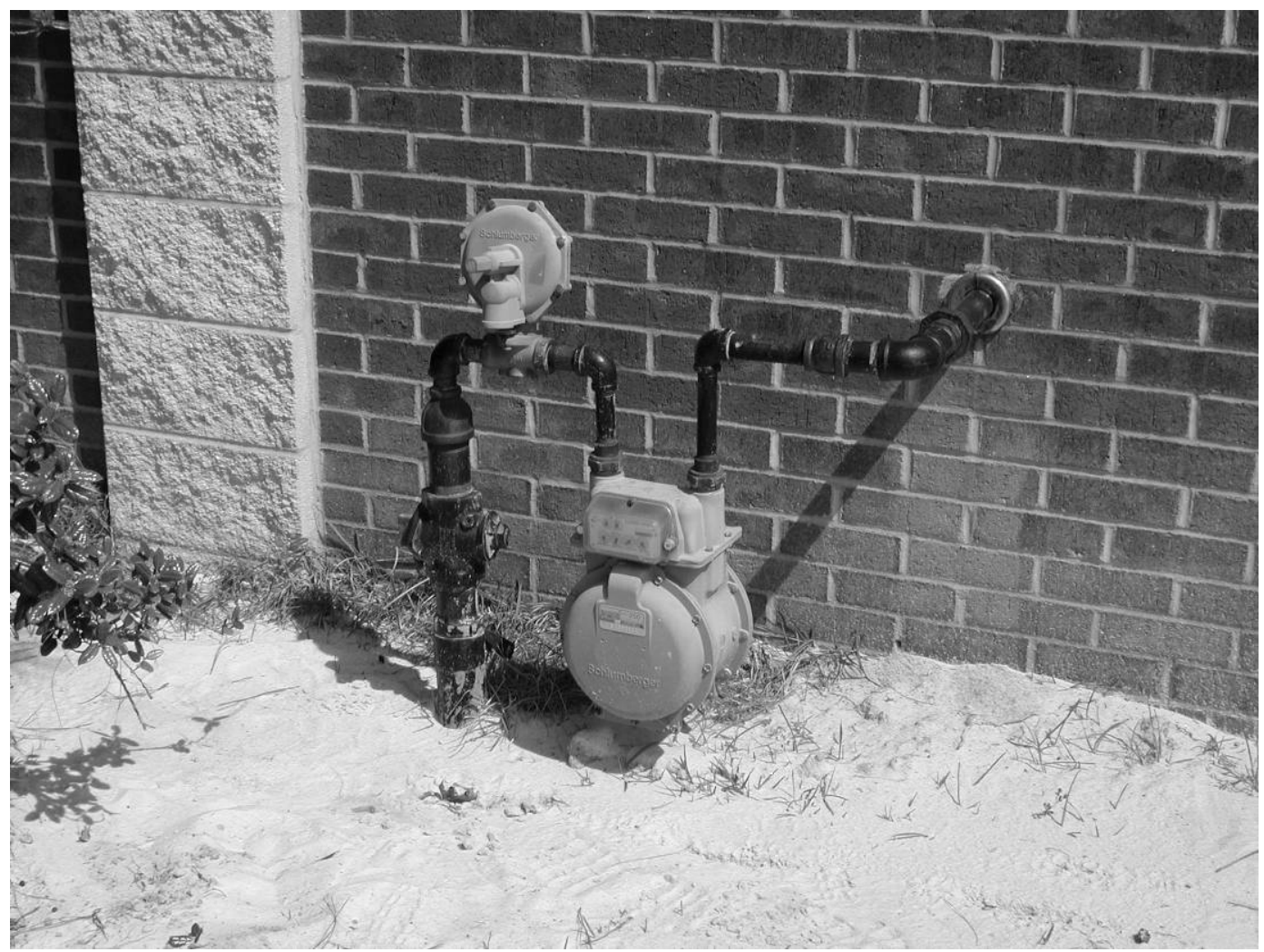

Figure 3. Typical gas line service entry into building. 
The original design called for installation of the deep groundbed anodes at a depth of $100 \mathrm{ft}$ in deep wells that would be drilled at three locations. B\&A made several visits to Fort J ackson and held detailed discussions with various DPW personnel. It was stated that the precise geology of the soil at the proposed anode deep wells would only be known when drilling was actually done. DPW facilitated in the application and approval process for environmental permits required by the State of South Carolina for wells deeper than $50 \mathrm{ft}$. The anode locations were selected after the aforementioned 100 remote monitoring locations were identified to provide a reasonably even distribution over the gas piping system.

B\&A subcontracted the installation of the deep anode beds to Loresco, Inc. of Hattiesburg, MS. Loresco was selected because it invented the replaceable deep anode system which B\&A elected to use on this project. This type system has the distinct advantage in that the anode material can usually be replaced easily in the future without redrilling the anode hole, which is a major portion of the cost of deep anode bed systems. Loresco, in turn, utilized the services of Clearwater Drilling Company of Columbia, South Carolina to perform the actual drilling of the $12 \mathrm{in}$. diameter holes to the specified depth (or to a depth where bedrock was encountered at $<100 \mathrm{ft}$ ).

Clearwater commenced drilling on 29 August 2007 in the open space at the intersection of Hill and Hardee Streets (across from the Central Energy Plant CEP\#2) building. As requested by Fort J ackson DPW, all holes were dug by hand for the first $5 \mathrm{ft}$ before using the mechanical drilling. As stated previously, there were no accurate maps of the underground infrastructure (including water, sewer, natural gas and buried communication cables) and DPW did not want to risk damaging any critical components. Further, DPW did not have any means for locating these facilities prior to installation of the anodes. The maximum depth reached at this site was $\sim 65 \mathrm{ft}$ before bedrock was encountered. With concurrence of Fort J ackson DPW personnel, B\&A made the decision to dig a second hole $\sim 50 \mathrm{ft}$ away (parallel to the street). This hole also reached a depth of $\sim 65 \mathrm{ft}$. Two ceramic MMO tubular anodes were installed in each well. All trenching for cables to a depth of $24 \mathrm{ft}$ minimum from the anode groundbeds to the transformer/ rectifier (T/R) was also dug by hand, as requested by DPW. This typically amounted to trench lengths from 50- $100 \mathrm{in.}$.

At the second location (intersection of Washington Rd and Hall St; 1000 $\mathrm{ft} \mathrm{from} \mathrm{CEP} \mathrm{\#} \mathrm{3),} \mathrm{the} \mathrm{first} \mathrm{hole} \mathrm{that} \mathrm{was} \mathrm{drilled} \mathrm{reached} \mathrm{bed} \mathrm{rock} \mathrm{at} \mathrm{a} \mathrm{depth}$ 
of $\sim 40 \mathrm{ft}$. B\&A elected to drill a second hole $\sim 50 \mathrm{ft}$ east of the first hole. It also encountered bedrock at $\sim 40 \mathrm{ft}$. Two ceramic MMO anodes were installed in each well.

At the third site (CEP\#1), utilities including piping and communication cable were encountered during the hand digging at the initially selected deep anode bed location. Another nearby location was selected, and in accordance with the directions of the DPW, this site was then hand dug to a depth of $5 \mathrm{ft}$ followed by rotary drilling. A final depth of almost $80 \mathrm{ft}$ was achieved at this site before hitting bed rock. Since no other locations were available at this site, four ceramic MMO anodes were installed in the single well. Extremely long trenches had to be hand dug both to the T/R and to the natural gas pipeline at this location.

At all 3 deep anode groundbed locations described above, perforated PVC casings and the ceramic MMO anodes were installed by Loresco; and the holes filled with fine granular, conductive carbon backfill (Loresco DW3 extra-high-grade, calcined fluid petroleum coke breeze). Loresco also mounted the T/ Rs and anode junction boxes on pre-existing power poles at each site. Each T/ $R$ was rated at $60 \mathrm{~V} / 34 \mathrm{~A}$ DC maximum output. A DPW subcontractor installed $120 \mathrm{VAC} 60 \mathrm{~Hz} 1 \mathrm{PH}$ power fused disconnects with switches on each power pole on the opposite side from each $T / R$.

Figure 4- Figure 17 depict various activities and hardware associated with the deep groundbed anodes installed at Fort J ackson. 


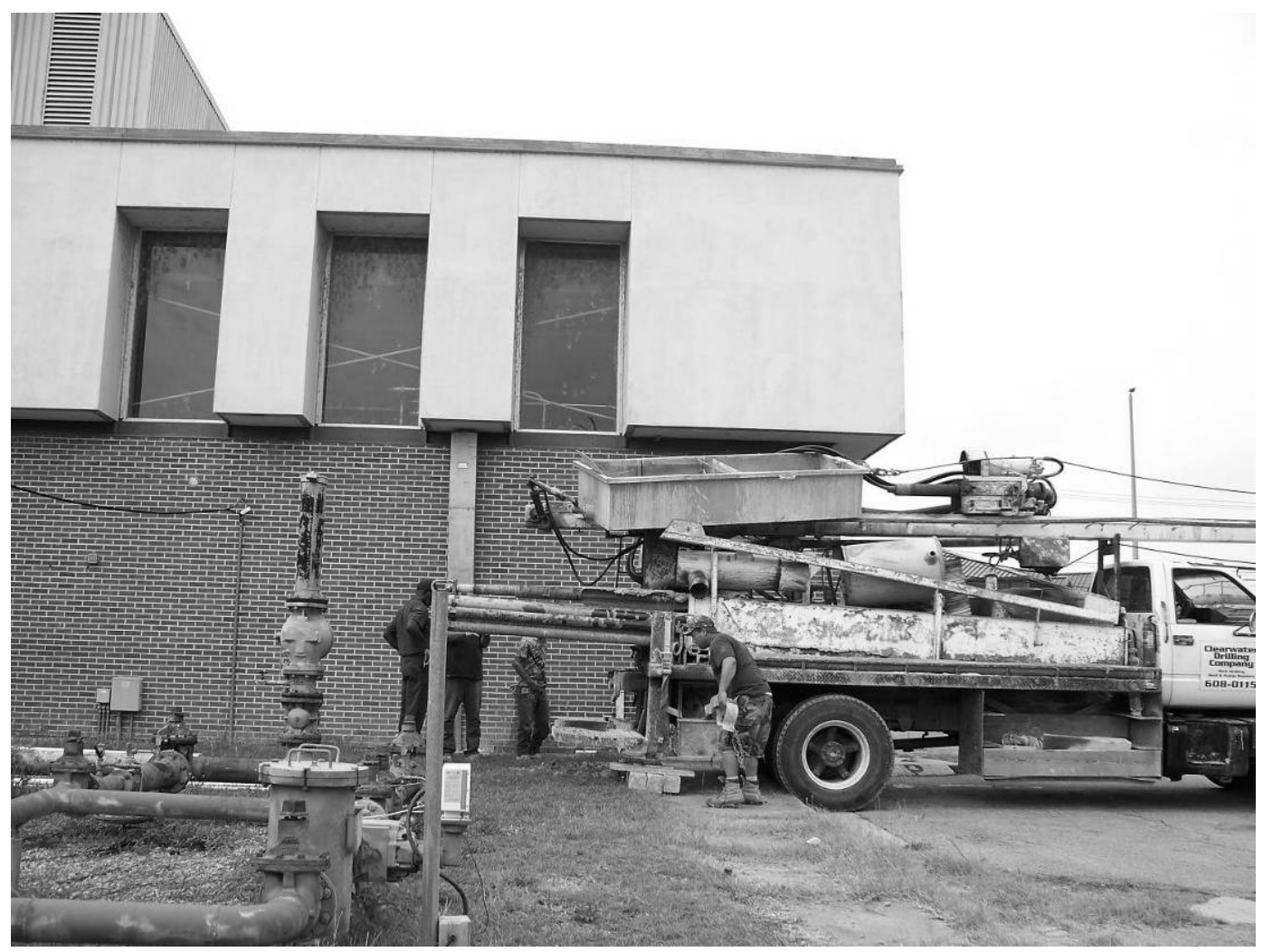

Figure 4. Drill truck setup.

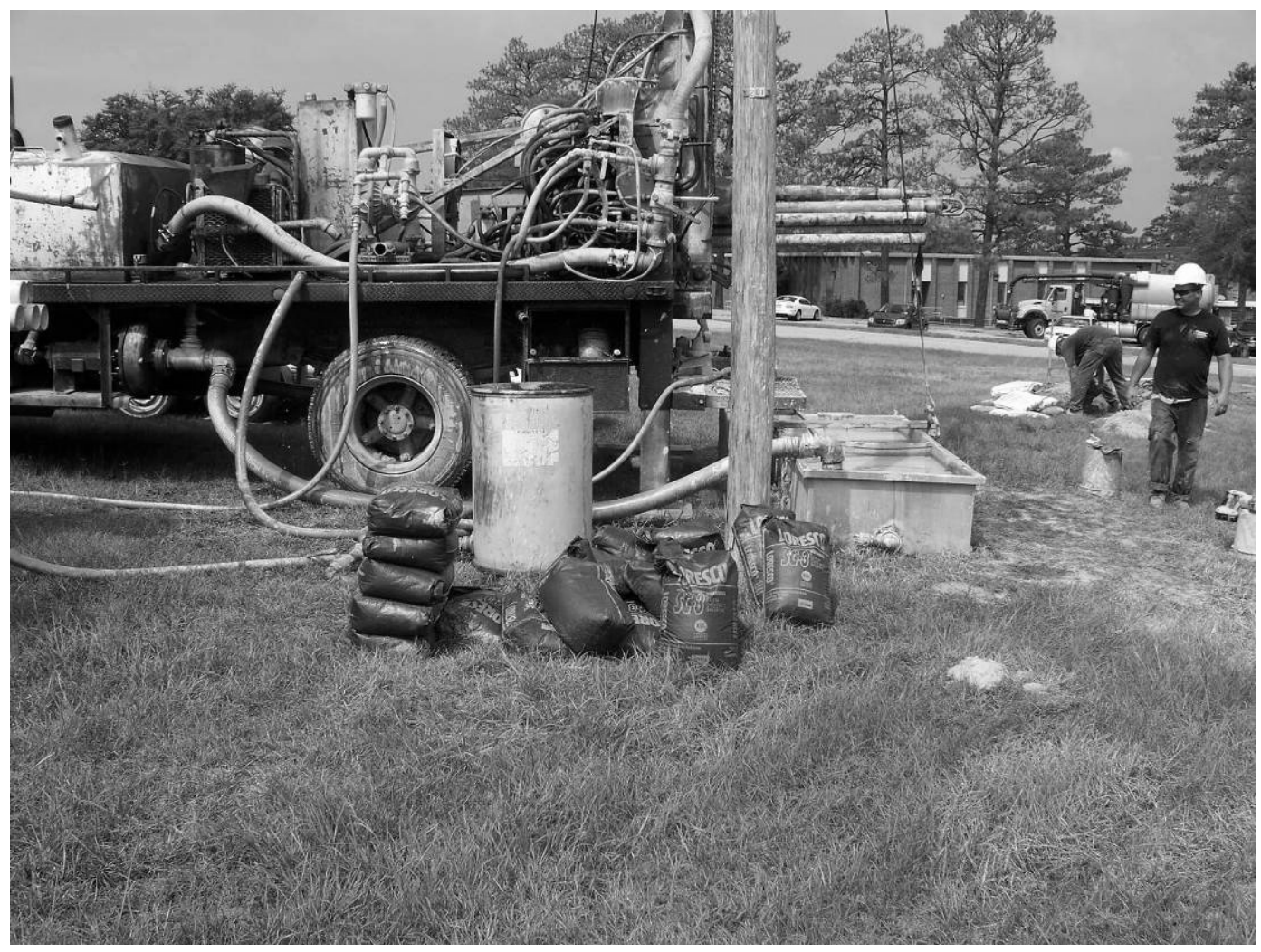

Figure 5. Overflow pan on right and coke breeze in front of drill rig. 


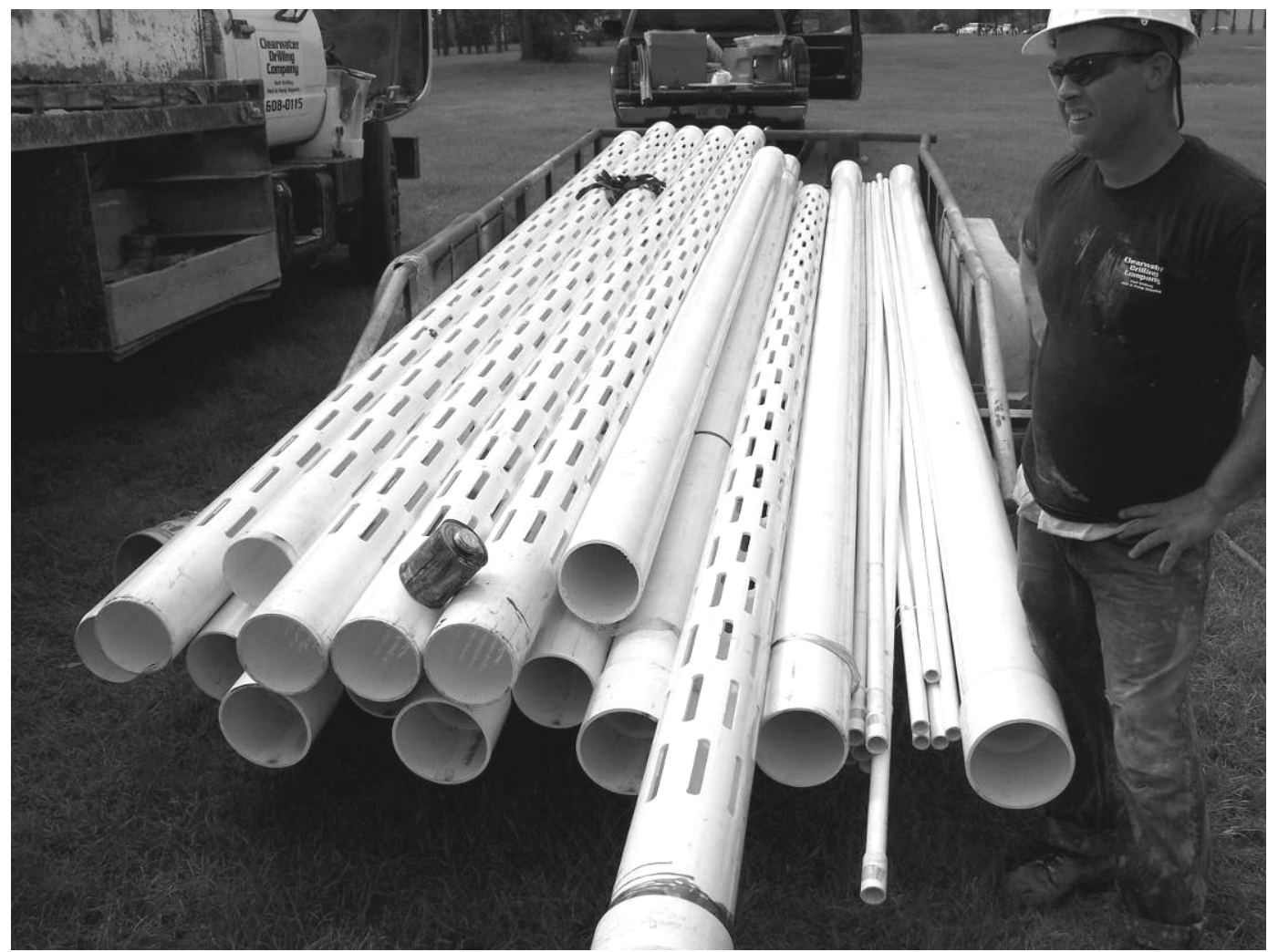

Figure 6. Solid perforated pipe to be located at anode depth, solid pipe above anodes, and small vent pipe entire length of column.

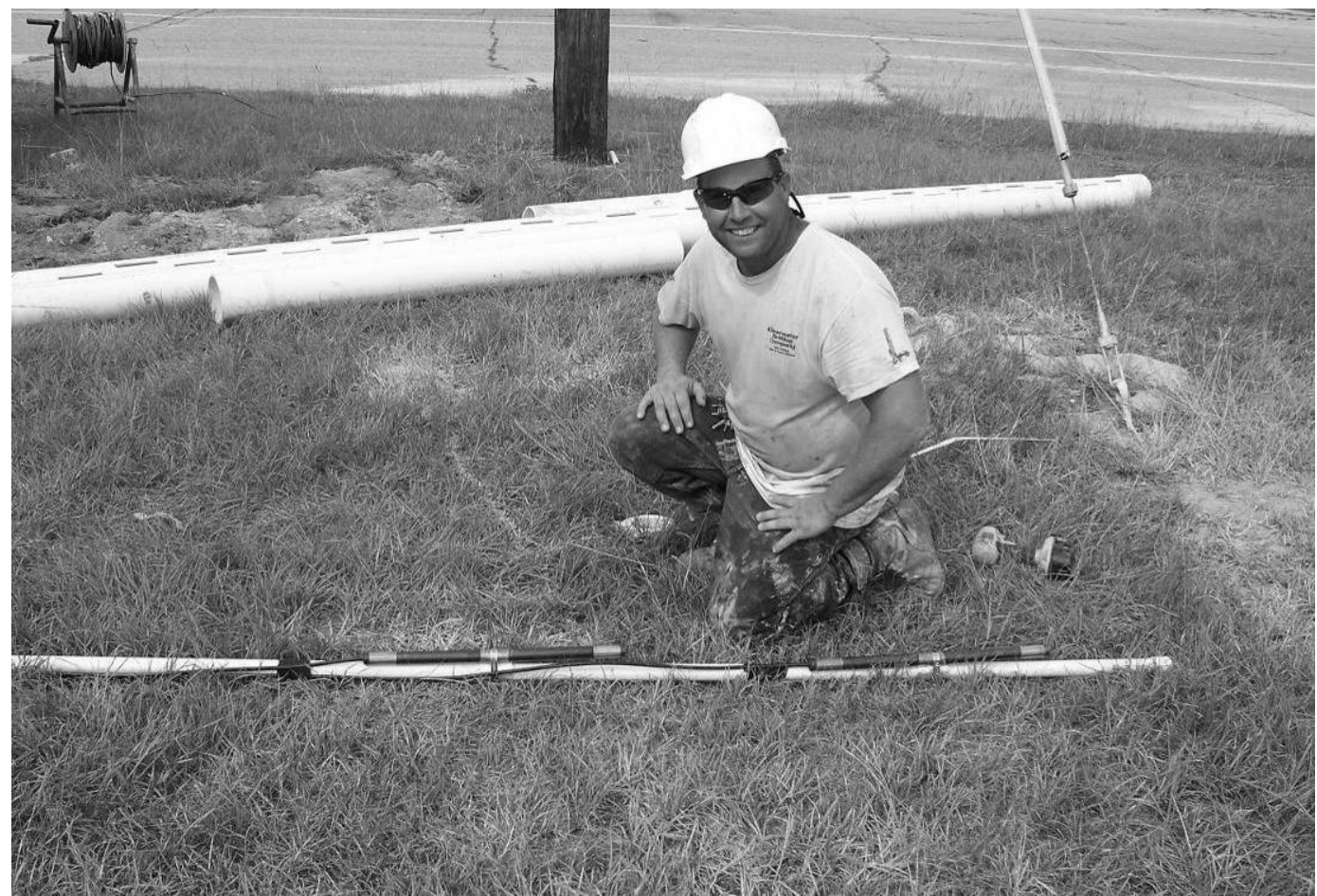

Figure 7. Tubular ceramic anodes pre-attached to vent pipe before loading into column. 


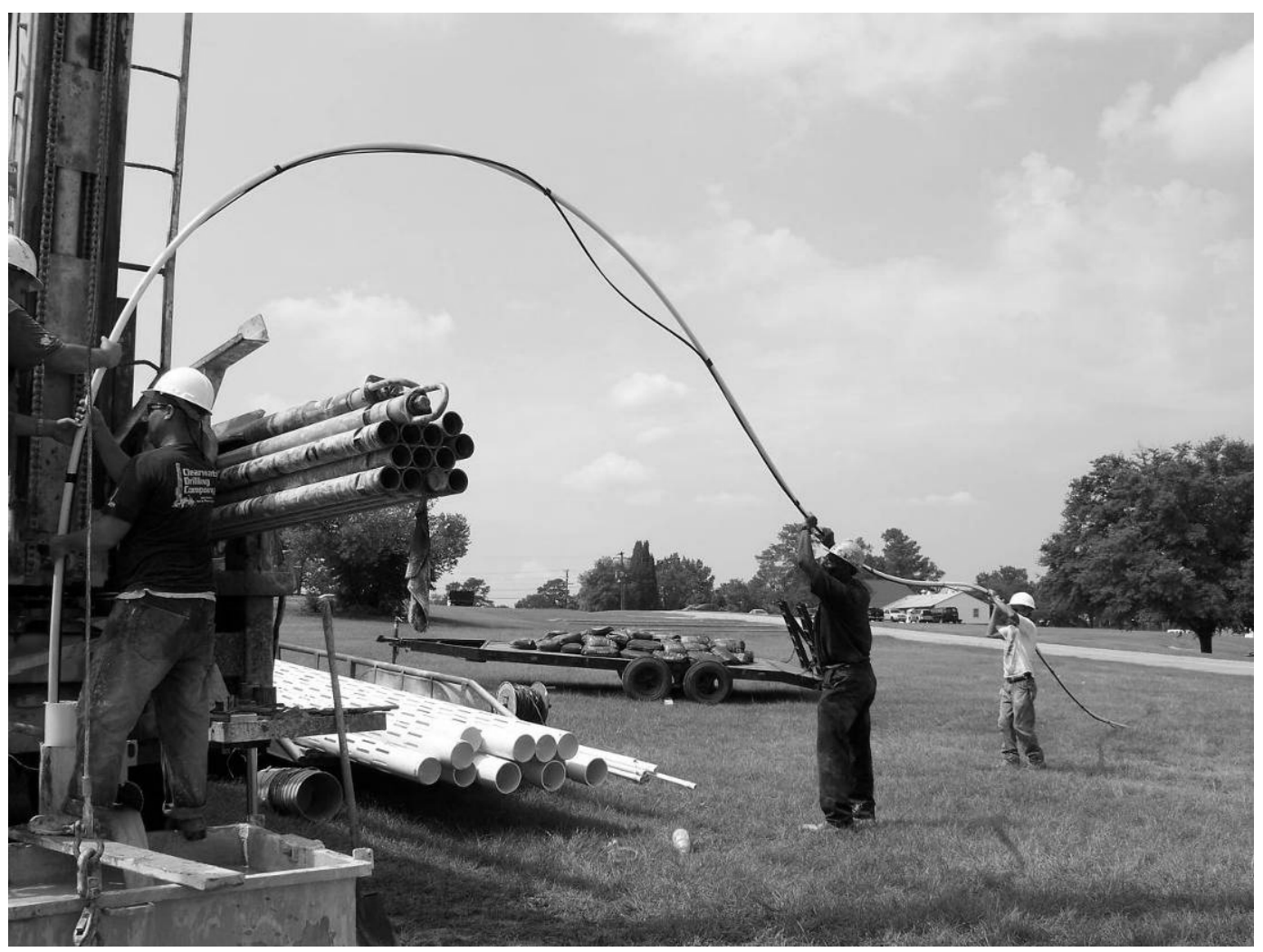

Figure 8. Loading anodes and vent pipe into column.

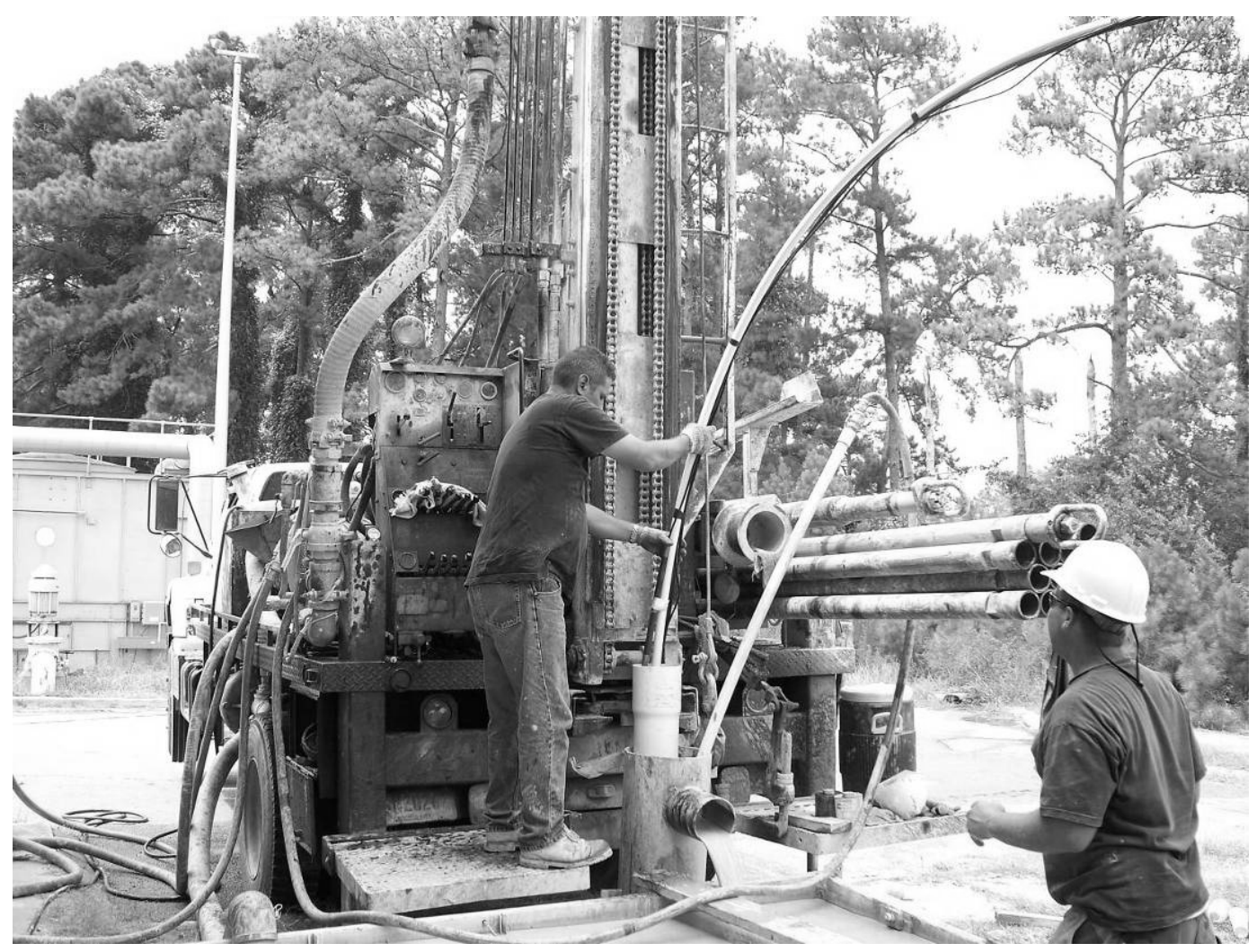

Figure 9. Alternate view of loading anodes and vent pipe. 


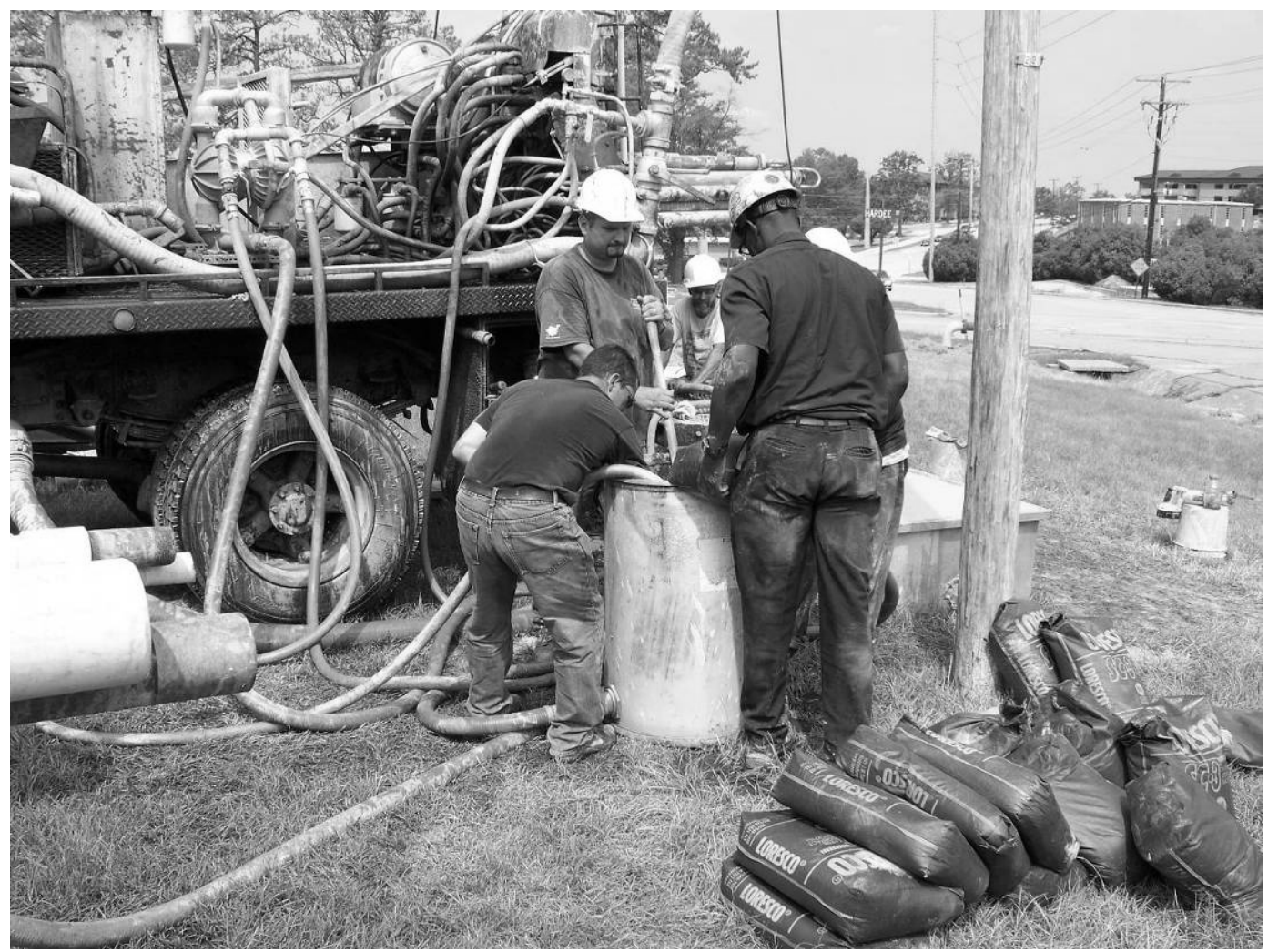

Figure 10. Mixing DW-3 coke and pumping into column.

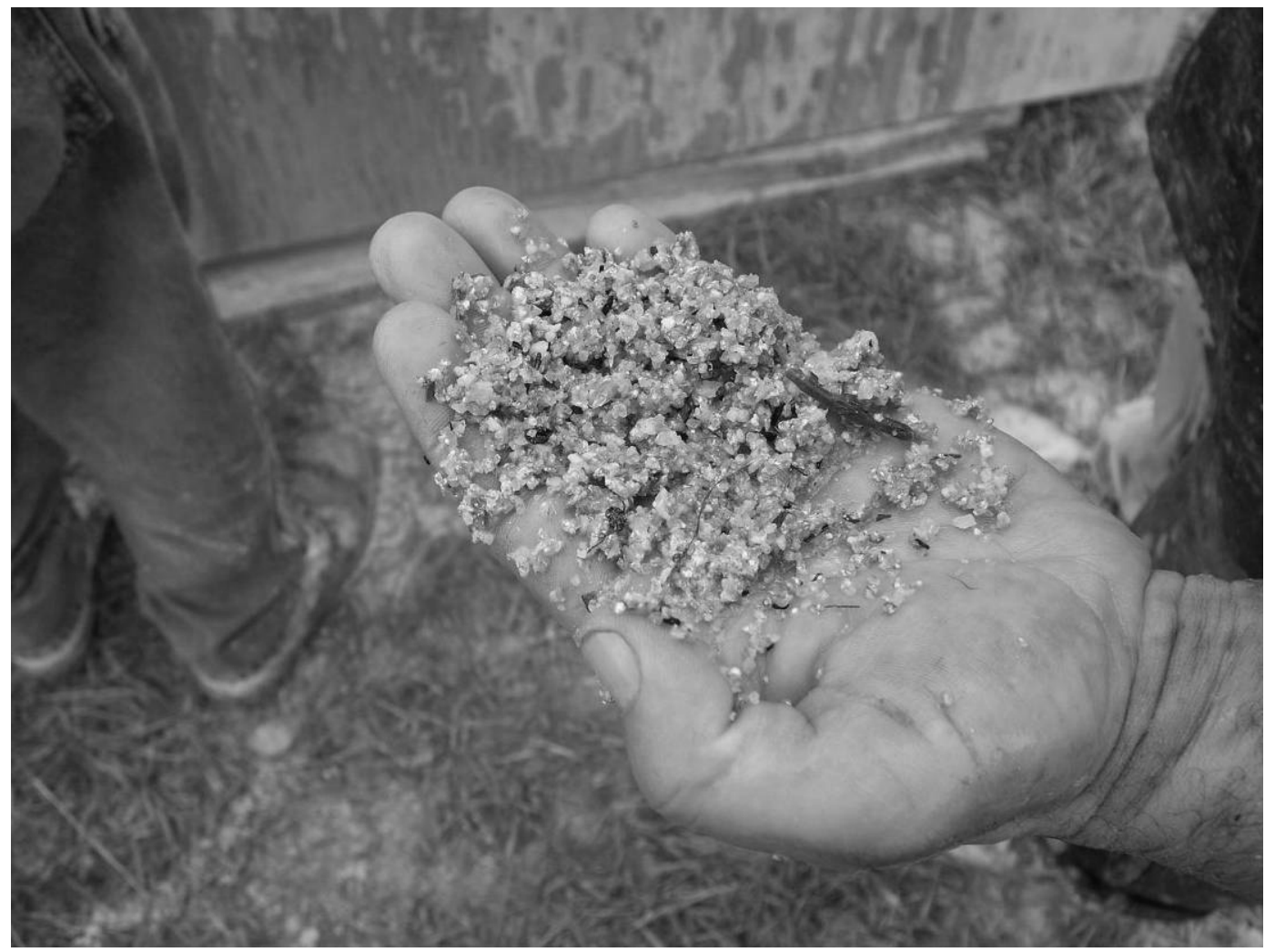

Figure 11. Fine sand encountered at all depths in southmost deep anode bed. 


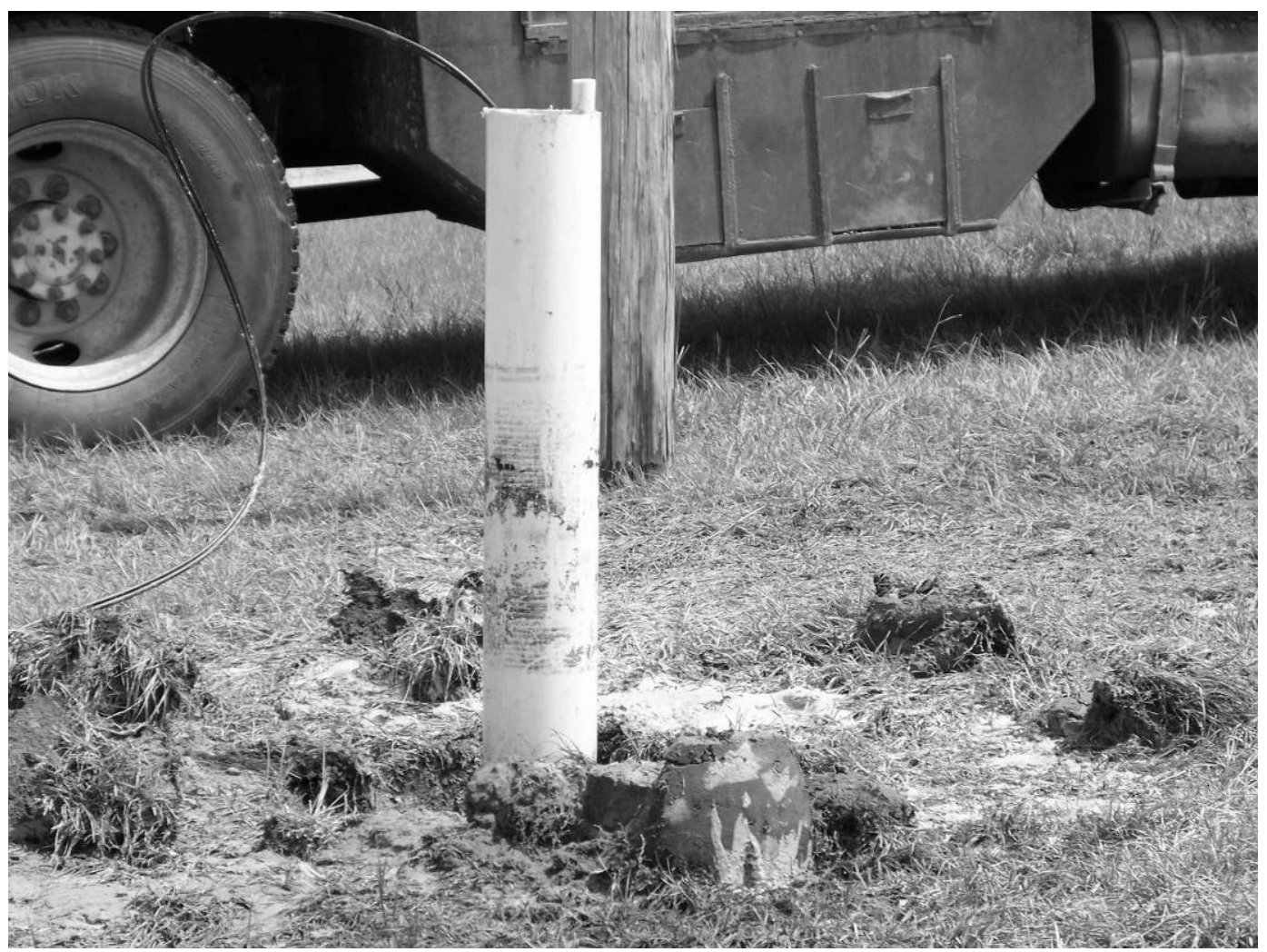

Figure 12. Top of deep anode column after anodes, vent pipe, and coke breeze installed

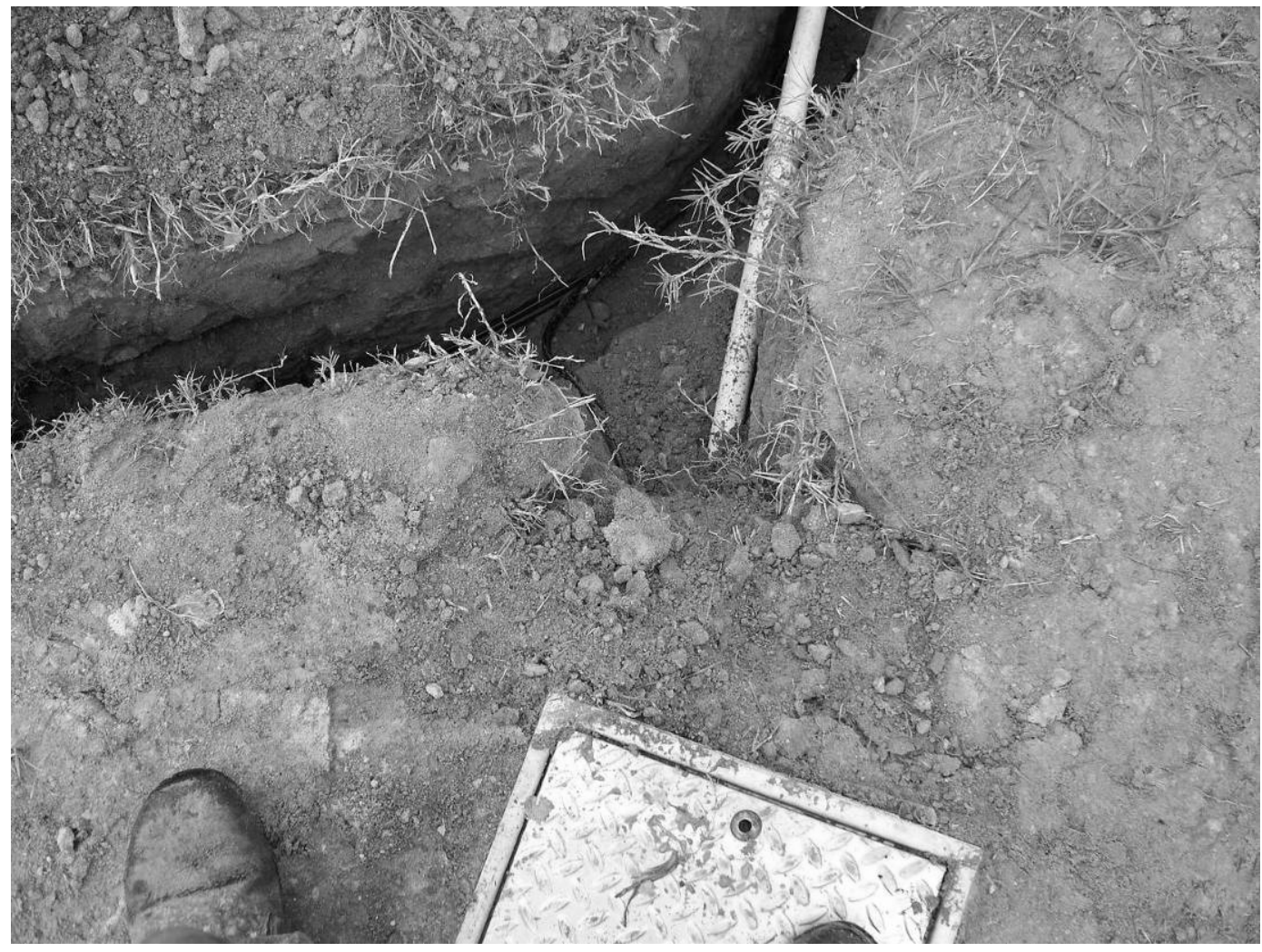

Figure 13. Portion of hand-dug trench (24 in. minimum) 


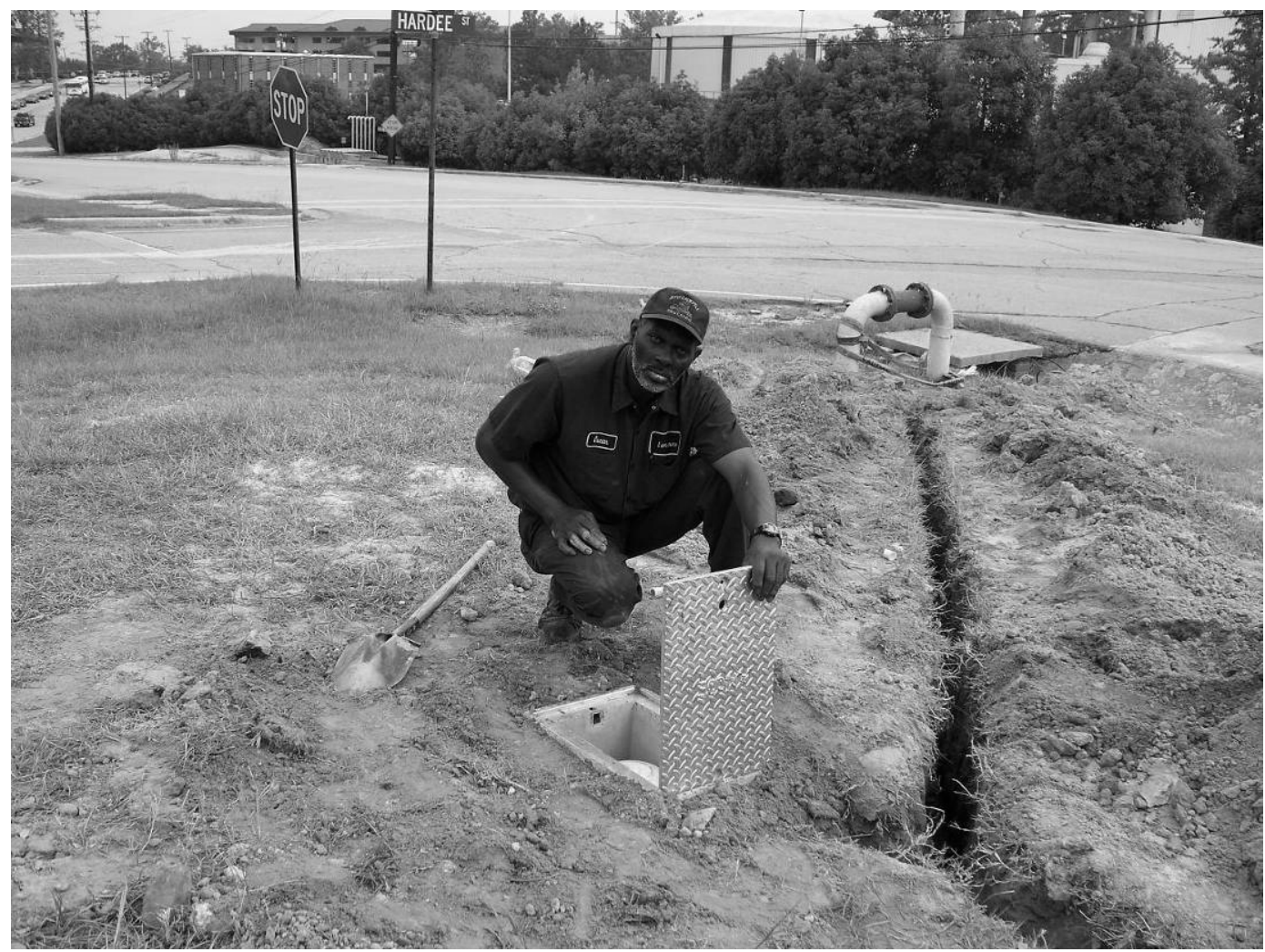

Figure 14. Deep anode access box and hand-dug trench between pipe and rectifier,

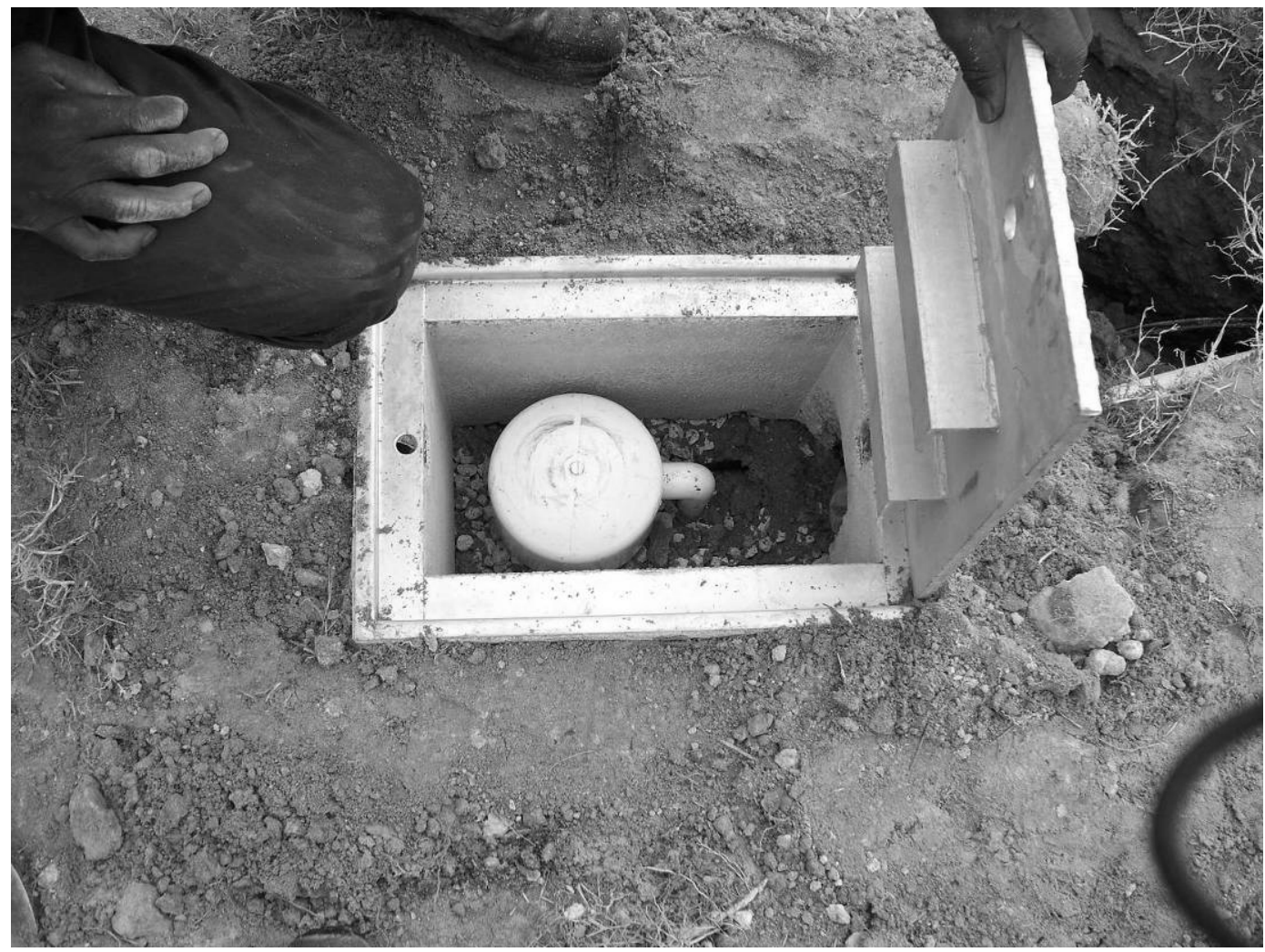

Figure 15. Deep anode access box. 


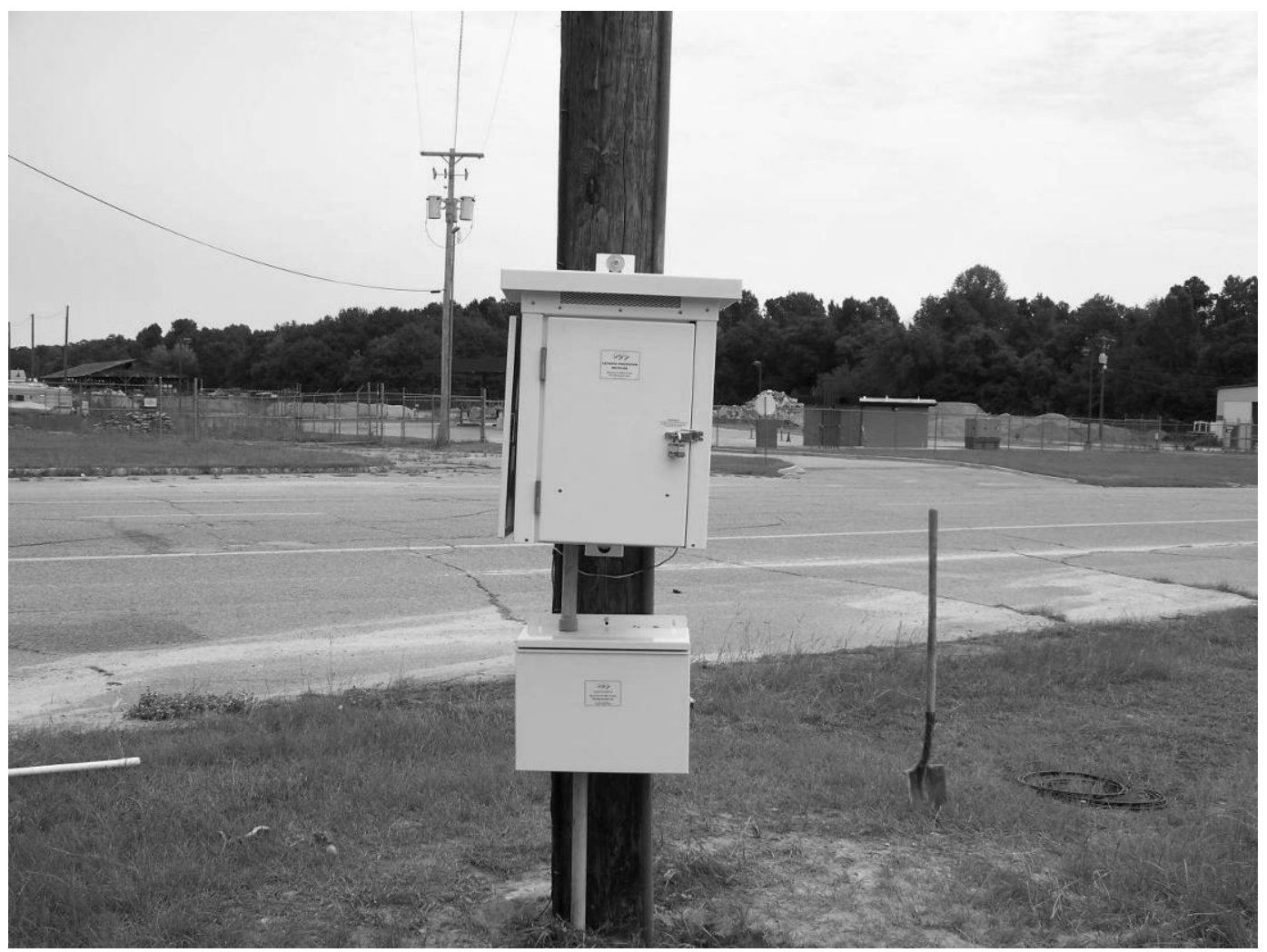

Figure 16. Rectifier power supply and anode junction box, Wall and Washington Streets.

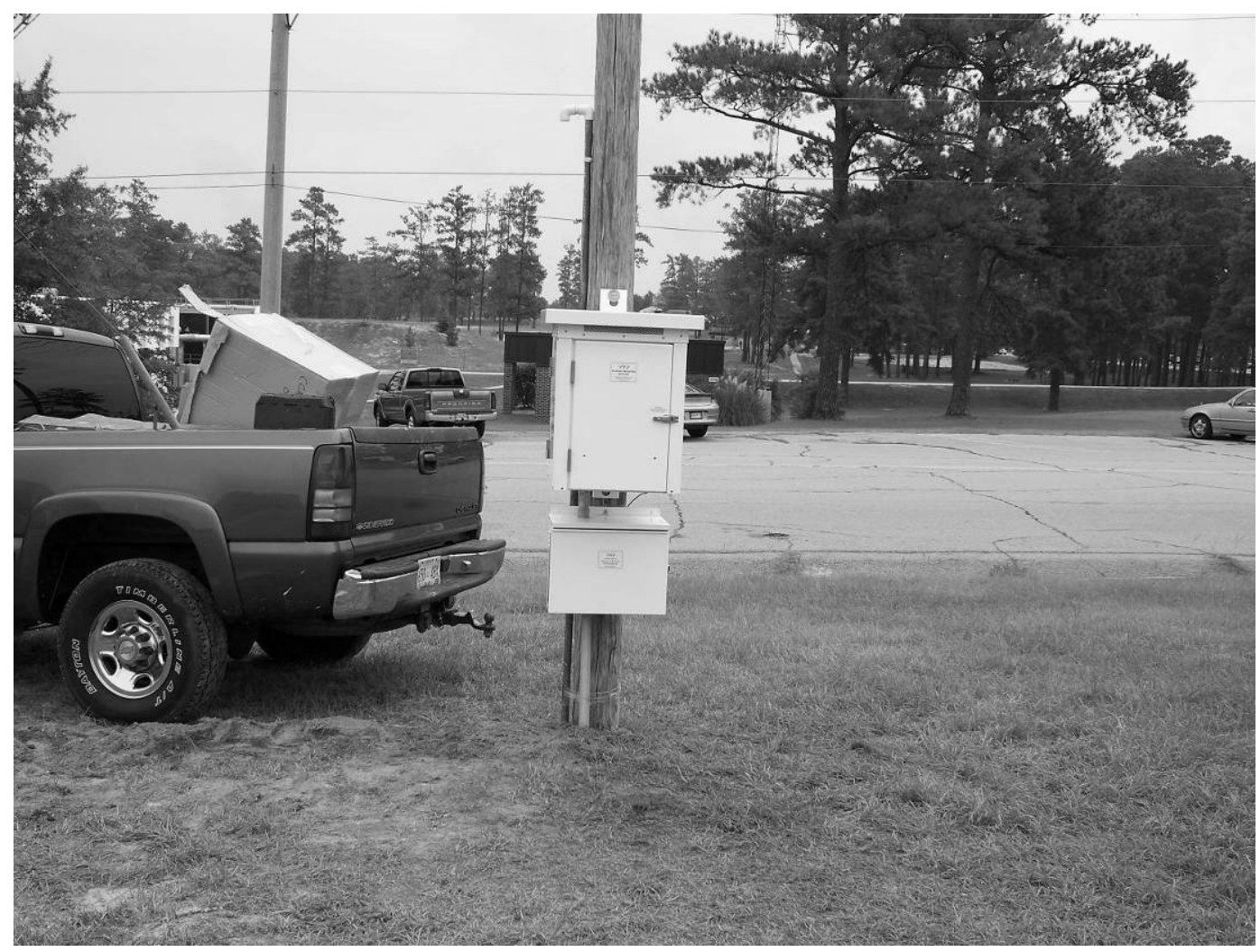

Figure 17. Rectifier power supply and junction box, Hardee and Hill Streets. 


\subsubsection{Elevated storage tank}

ERDC-CERL specified installation of ceramic MMO anodes for the interior $\mathrm{CP}$ of the 2 million gallon elevated water storage tank to replace the existing silicon-iron anodes that had failed. CP of the tank interior is only effective below the waterline. $\mathrm{CP}$ and a coating system on the tank interior are complementary; coating reduces CP current demand and CP prolongs coating life. Tank data are provided below:

- Manufacturer: Pitt-Des Moines, Inc.

- Year built: 1991

- Capacity: 2,000,000 gallons

- Diameter: $100 \mathrm{ft}$

- Height: $64 \mathrm{ft}$

For installation of the new CP system on the water tank, the subcontractor, Freeman Industries (Dorset, $\mathrm{OH}$ ) removed the existing rectifier, reference cell, anodes, under-roof wiring, insulators, and roof plates. New anodes, reference cell, insulators with stainless steel hardware, under-roof wiring, roof anode access hand-hole plates, and rectifier were installed. The existing mainline conduit between the interior base of the tank and the roof were left in place and used with the new system. New reference cell and structure grounds were installed using tapped holes and stainless steel bolts. New CP system information is provided below:

- Rectifier

o Manufacturer: Integrated Rectifier Technologies, Inc.

o Model: CIASFS 60-34 LMaOxQaVW, Type CP Sentinel Rectifier

o $60 \mathrm{v}, 34 \mathrm{amp}$ rated DC output with $120 / 240 \mathrm{v}, 60 \mathrm{~Hz}$, single phase AC input; IR-drop free potential controlled DC output circuit with optional manual control.

o Serial Number: 07R-0411.

- Anodes:

o The anodes consist of two concentric rings of vertically suspended .062" diameter ceramic wire anodes in the following configuration:

o Ring 1(outer)- 10 anodes suspended vertically from the roof of the tank uniformly spaced on a 35' radius circle, each with 33' of ceramic anode wire.

- Ring 2 (inner)- 5 anodes suspended vertically from the roof of the tank uniformly spaced on a $10^{\prime}$ radius, each with $20^{\prime}$ of ceramic anode wire. 
The anodes are suspended from \#10 RHW/ USE wires and are attached to the tank roof by using pin insulators with stainless steel hardware. New hand-hold/ access plate covers are located next to each anode for installation and servicing purposes. Each hand-hole is covered with an acrylic roof plate. The anodes are electrically connected to each other with \#10 RHW/ USE under roof wires which are run between the insulators and then to the mainline wire to the rectifier. A diagram of this tank cathodic protection system configuration is shown in Figure 18.
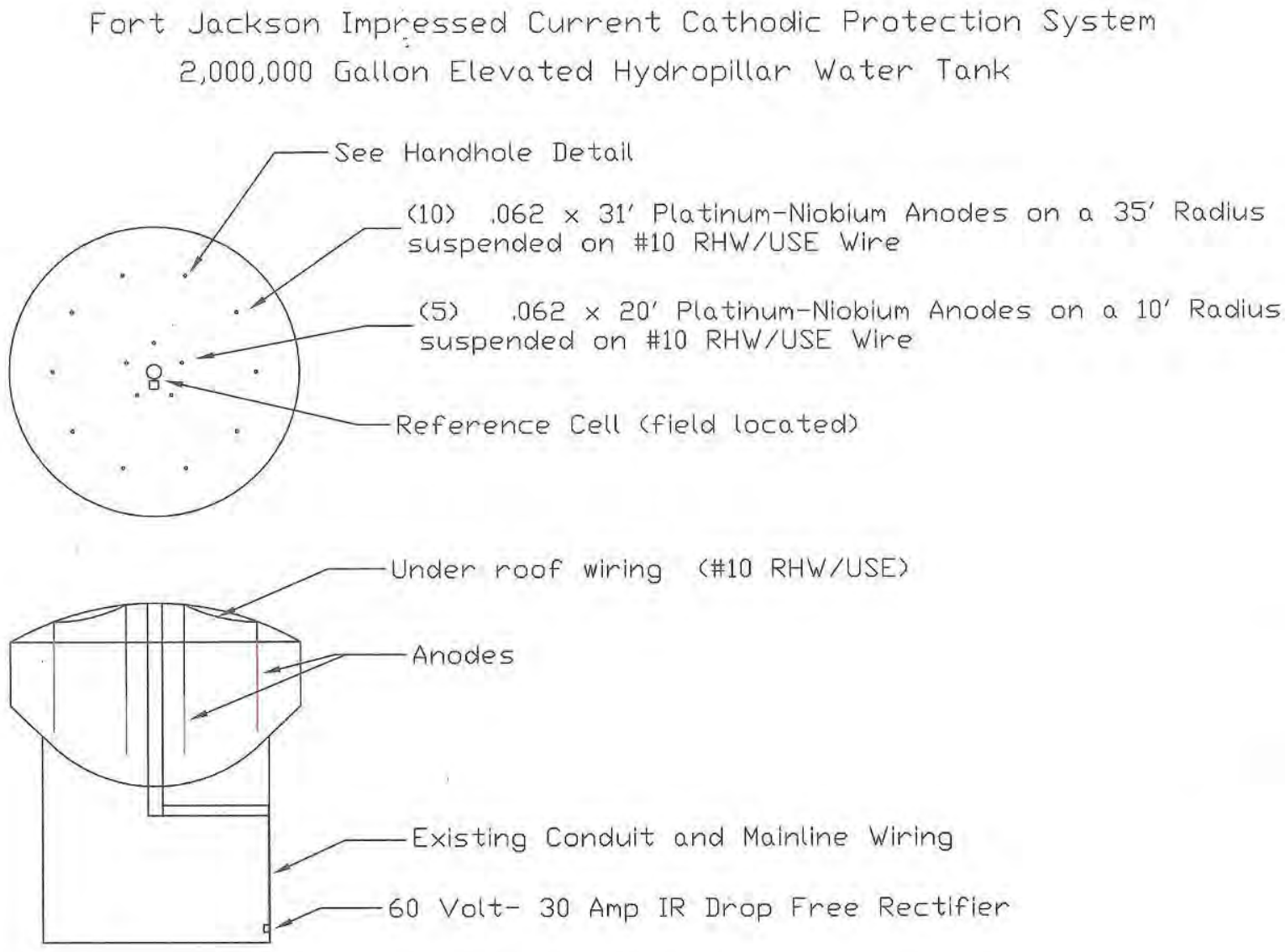

Figure 18. Diagram of storage tank CP system configuration.

\subsubsection{Rectifier power supply and controller}

The impressed current rectifier power supply selected for providing the energy to the ICCP system was of the automatic potential control type. Further, it was designated to utilize "IR drop free potential control" as the principal means for adjusting the system current output automatically. The supplier chosen for this rectifier unit was Integrated Rectifier Technology (IRT) with over 20 years of experience in manufacturing this rec- 
tifier. The faceplate of the rectifier is shown in Figure 19. A copy of the operating manual for this rectifier is included in Appendix B.

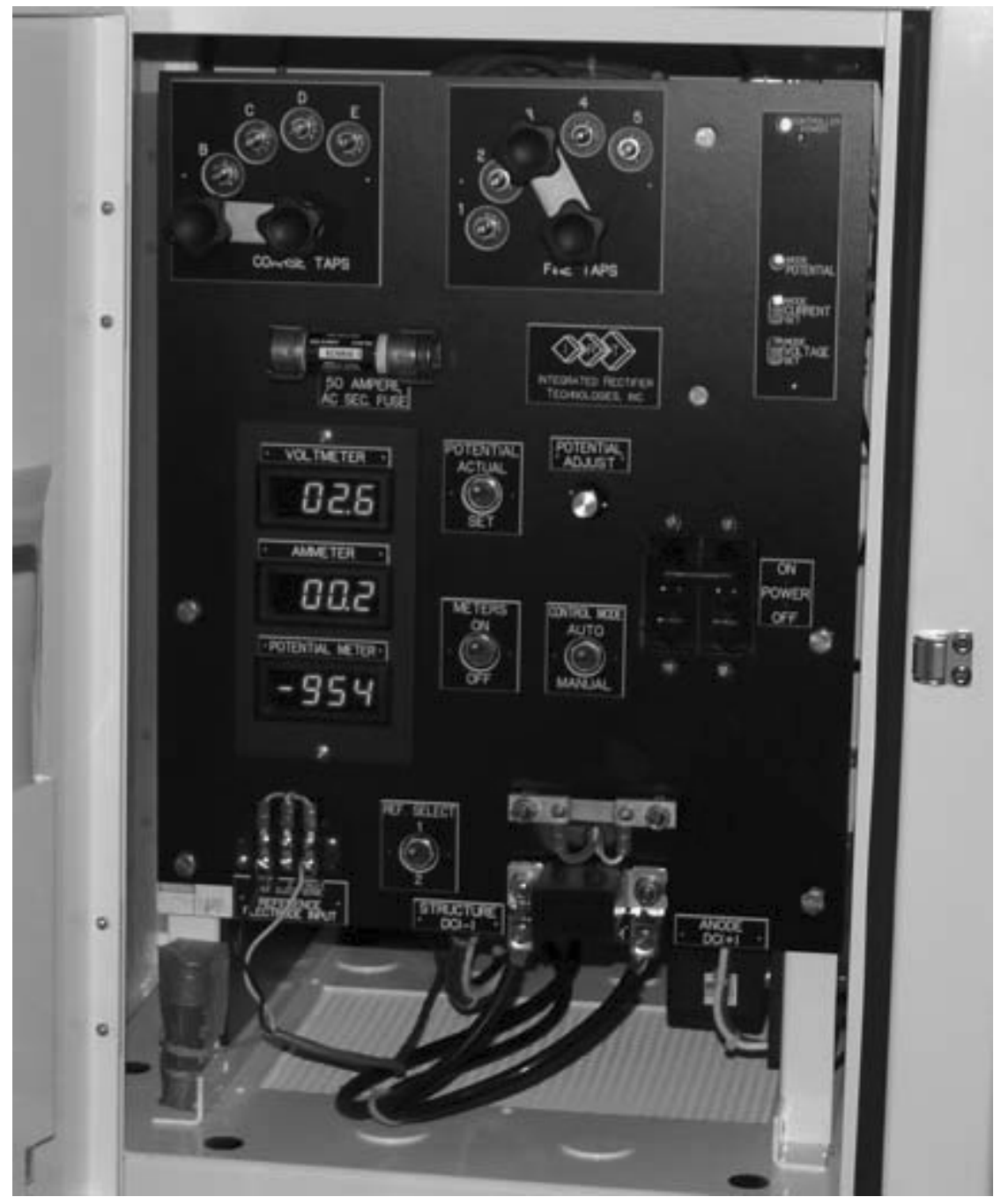

Figure 19. IRT rectifier faceplate.

The IRT rectifier can also be operated in manual mode or in constant current mode. The mode of operation is indicated by LED lights observable in the upper right-hand corner of the rectifier faceplate (Figure 19). The unit is a solid-state design with modular construction. The rectifier cabinet has side as well as front opening doors to facilitate replacement of any module should that become necessary in the future. 


\subsubsection{Reference electrode}

An Electrochemical Devices Inc. (EDI) Model IR Cu-CuSO 4 reference cell was suspended inside the tank bowl about $3 \mathrm{ft}$ from the access tube and 8 $\mathrm{ft}$ up from the bottom of the tank.

\subsubsection{DC positive, negative, and reference cell wiring and conduit}

The existing 0.75 in. galvanized conduit carries two AWG 4 wires and a 2 wire (AWB 18) twisted pair control cable from the rectifier to the top of the tank. The AWG 4 wires were used for the rectifier anode connection (+) and the rectifier structure (-) connection. The two-wire control cable transmits the reference cell potential and structure potential to the rectifier controller for automatic potential control.

\subsubsection{System performance}

The anode resistance was measured to be $1.9 \mathrm{ohms}$ with the water level 15 $\mathrm{ft}$ below overflow by using a Nilsson Model 400 Soil Resistance Meter. Given that the water level was down $15 \mathrm{ft}$, this is excellent correlation with the design calculations shown in the design section.

The reference cell resistance was measured to be $3000 \mathrm{ohms}$ with the water level $15 \mathrm{ft}$ below overflow by using a Nilsson Model 400 Soil Resistance Meter. Typically, permanent reference electrodes installed in water storage tanks have resistances less than 10,000 ohms.

Before the new CP system was energized on 5/29/07, the native potential with respect to the EDI Cu-CuSO 4 reference cell was measured to be 0.434 volts. After energizing, the potential measurements were in the 0.890 to $-0.930 \mathrm{~V}$ range from top to bottom, indicating that the submerged surfaces were completely protected from corrosion in accordance with NACE International Recommended Practices, while the uniformity of this corrosion control was also exceptional.

\subsection{Technology operation and monitoring}

Properly monitored CP systems help to verify if sufficient corrosion control is being achieved for the structure(s) intended to be protected. Monitoring serves as the basis of establishing proper CP system commissioning, routine operation and maintenance; and demonstrating efficacy of any corrective actions. The traditional monitoring method involves determina- 
tion of structure-to-soil potentials at conveniently-located test stations. The potential of the structure is measured with the aid of a highimpedance $\mathrm{DC}$ voltmeter and a reference electrode (e.g., $\mathrm{Cu} / \mathrm{CuSO}_{4}$ half cell) while the $\mathrm{CP}$ rectifier is turned off and on automatically. If there are a large number of test stations, manual measurements obviously are very time consuming. Monitoring can be automated in a number of ways. Presently, one very attractive approach is through the use of remote monitoring units (RMUs). In this project, DART RMUs (Borin Manufacturing, Culver City, CA) were used. Each unit consists of a data logger and radio transmitter incorporated into a very small battery-powered device that fits easily inside a 4 in. diameter PVC test post (Appendix C). The device is hard-wired through the test post interior to a permanent $\mathrm{Cu} / \mathrm{CuSO}_{4}$ half cell buried in the soil below. The RMU is powered by a long-life battery. The data stored in the DART can be downloaded during drive-by in a vehicle equipped with an antenna and laptop computer. A coupled GPS system aids the location of the test stations and software verifies that the data have been collected successfully.

Figure 20 and Figure 21 show a typical DART and test station, respectively. Bare carbon steel coupons incorporated into a $\mathrm{Cu} / \mathrm{CuSO}_{4}$ half cell are shown in Figure 22. Because of their very close proximity to the tip of the half-cell, the coupons are very useful in determining "ON" and "OFF" potentials of the structure being protected because IR drop errors are largely eliminated. Figure 23 shows the laptop computer used for the DART driveby data acquisition. Figure 24 is a closer view of the display showing the GPS system during the drive-by data collection from the DARTs; the normal dots (red) showing the DART test station locations change color (to white) as they are successfully read during the drive-by. Special DART units were also installed in the TRs to collect T/R data; Figure 25 and Figure 26 show a typical unit. 


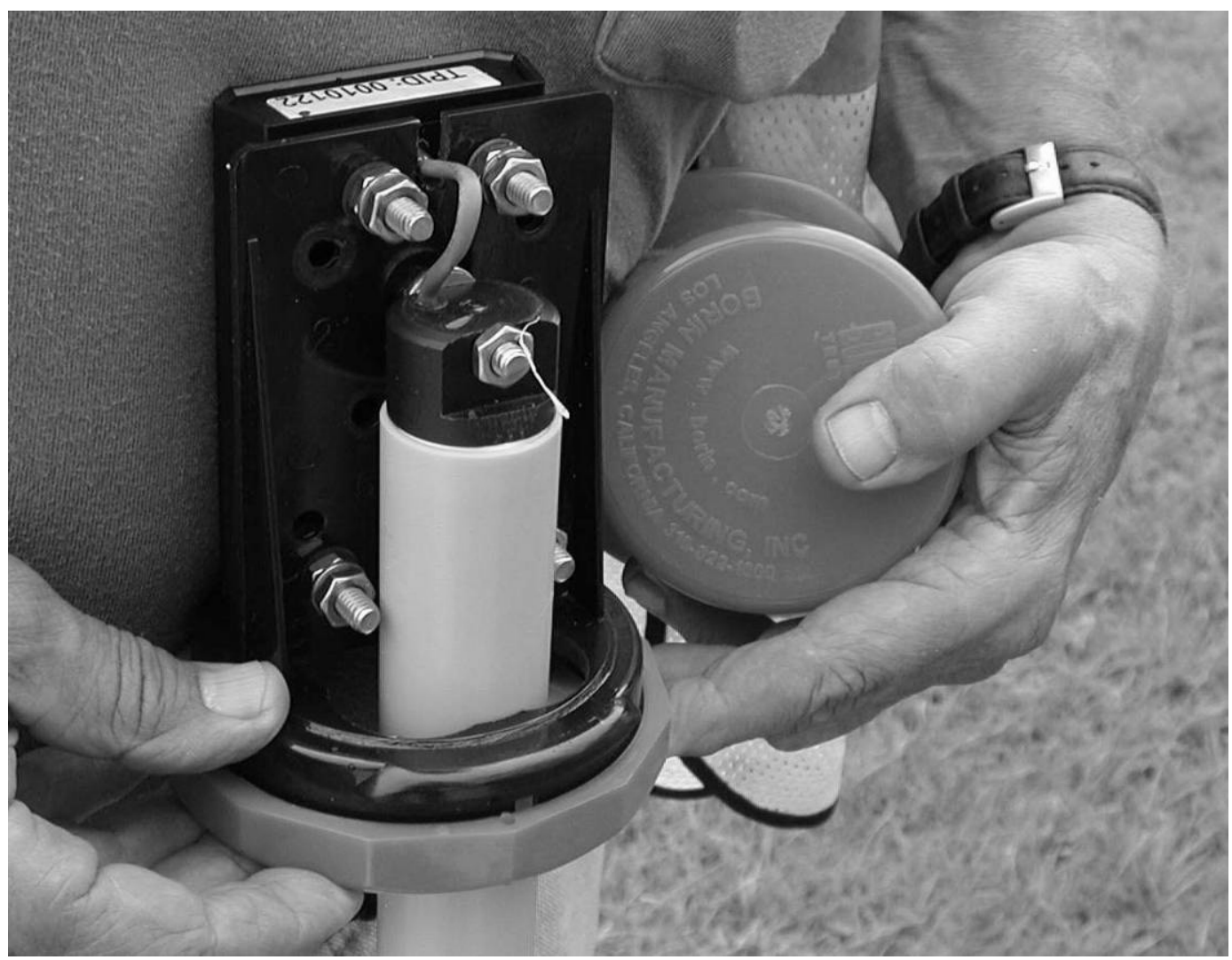

Figure 20. DART RMU with cap removed.

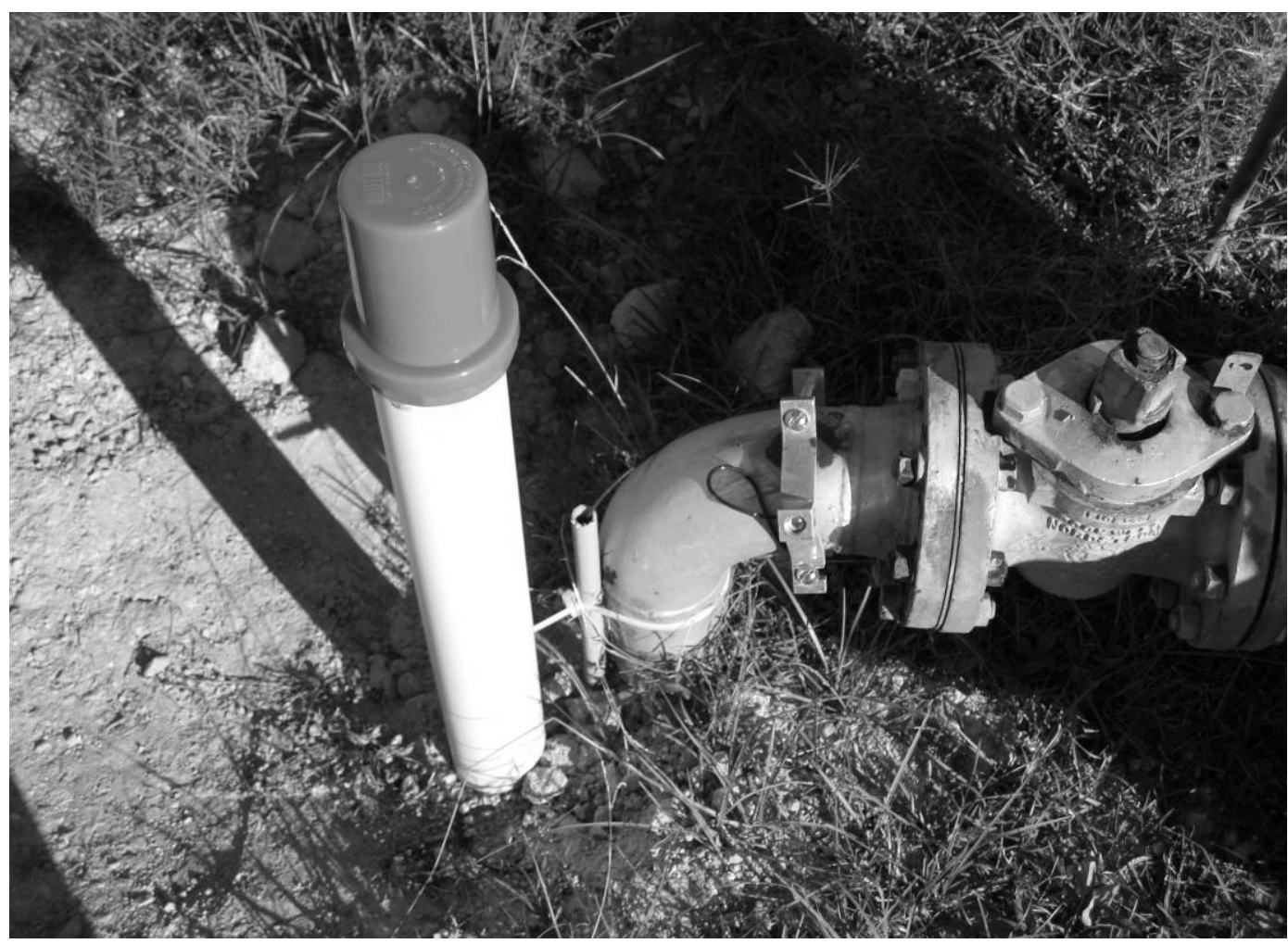

Figure 21. DART RMU test station in place. 


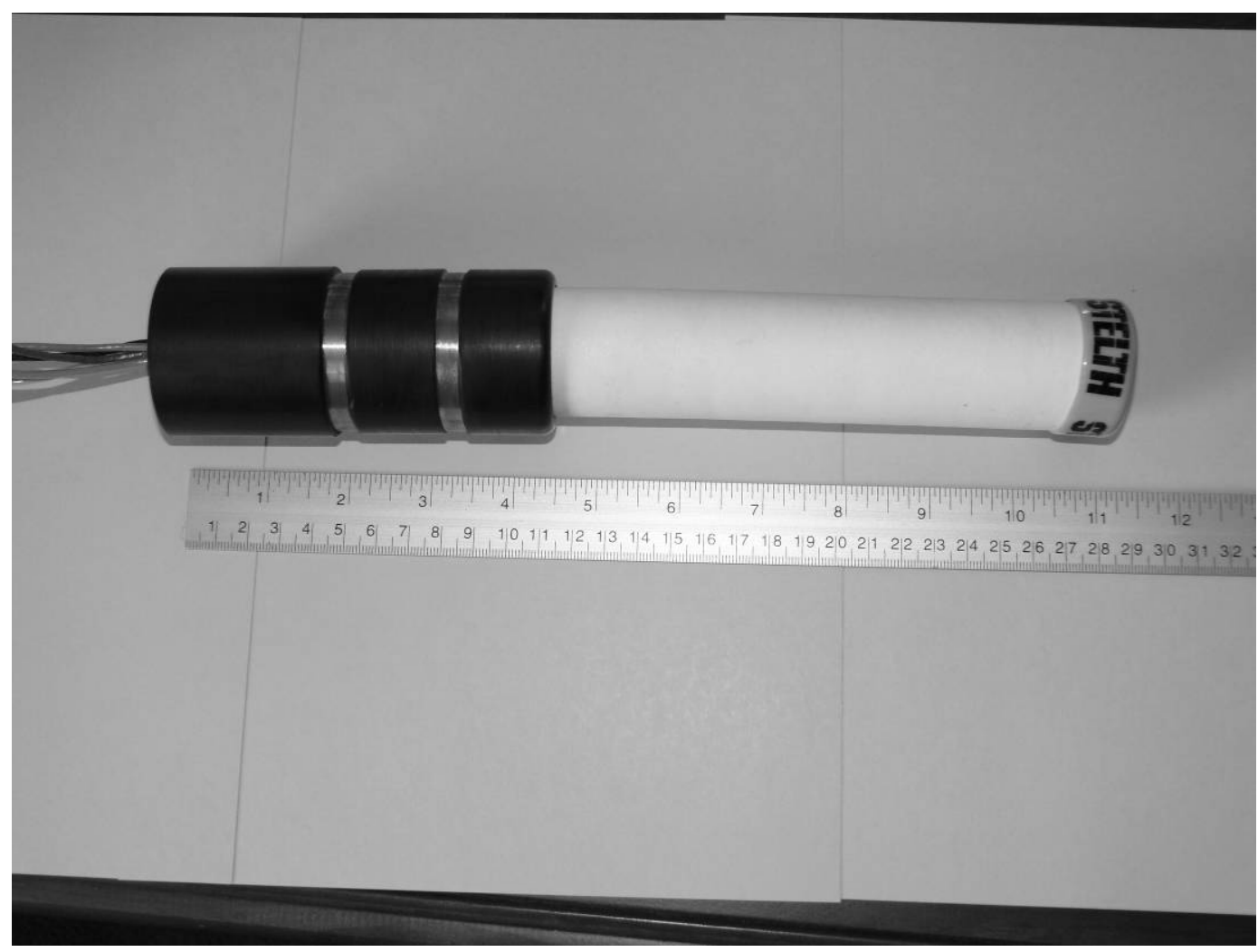

Figure 22. $\mathrm{Cu} / \mathrm{CuSO}_{4}$ reference electrode with integral main and spare coupons.

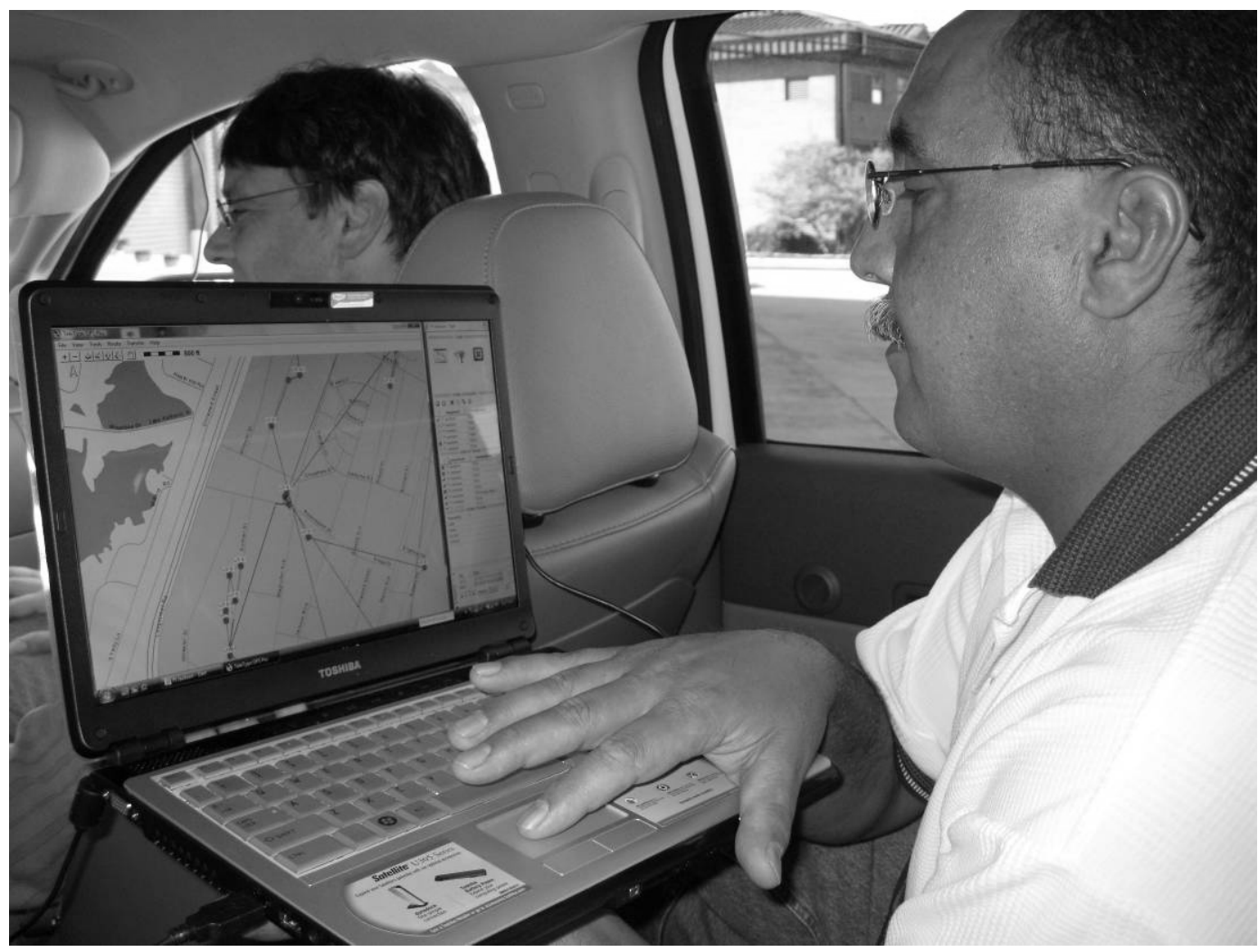

Figure 23. Drive-by data collection system including GPS-enabled laptop computer. 


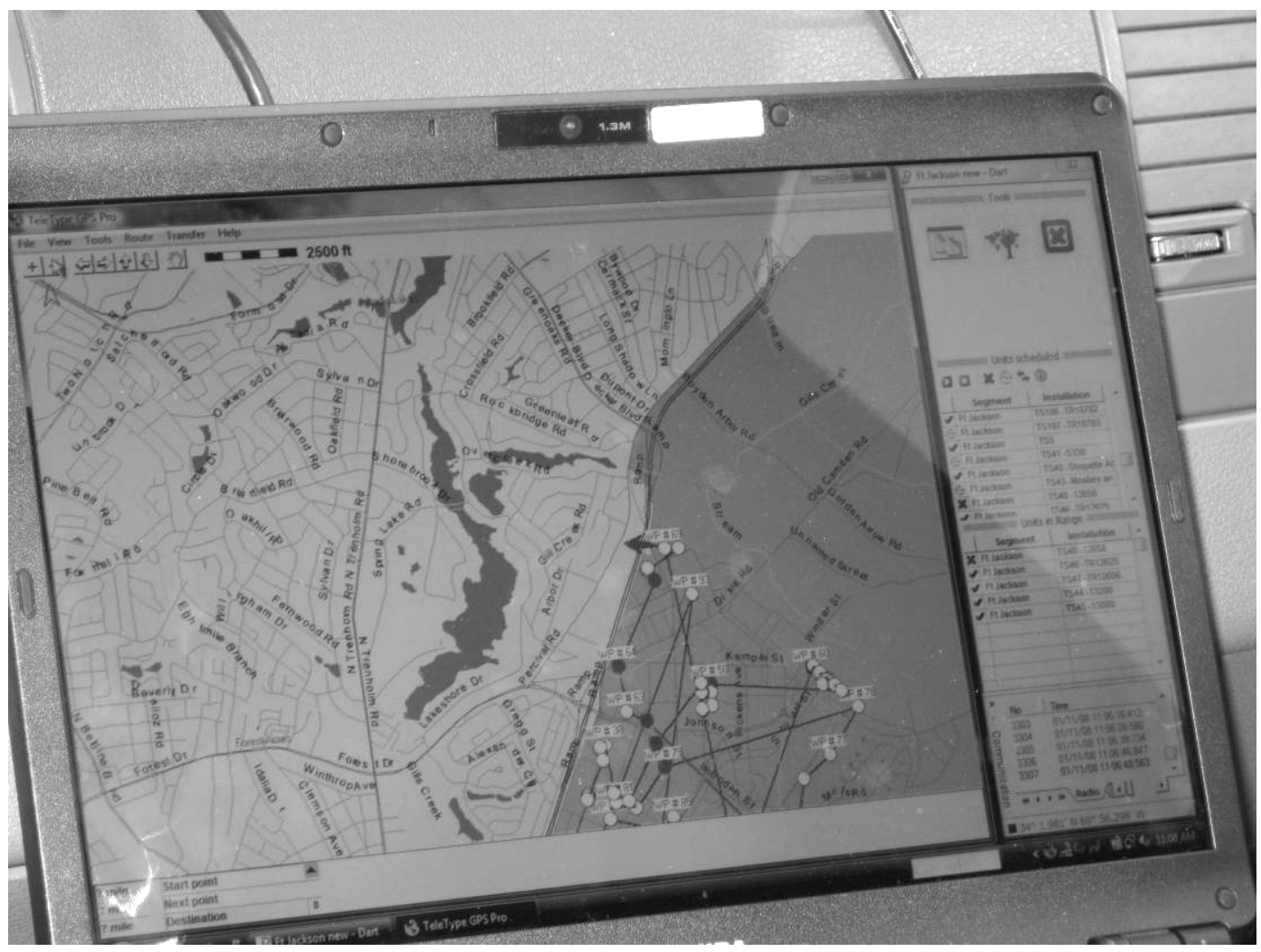

Figure 24. Laptop screen showing GPS locations of RMUs (dots at lower right).

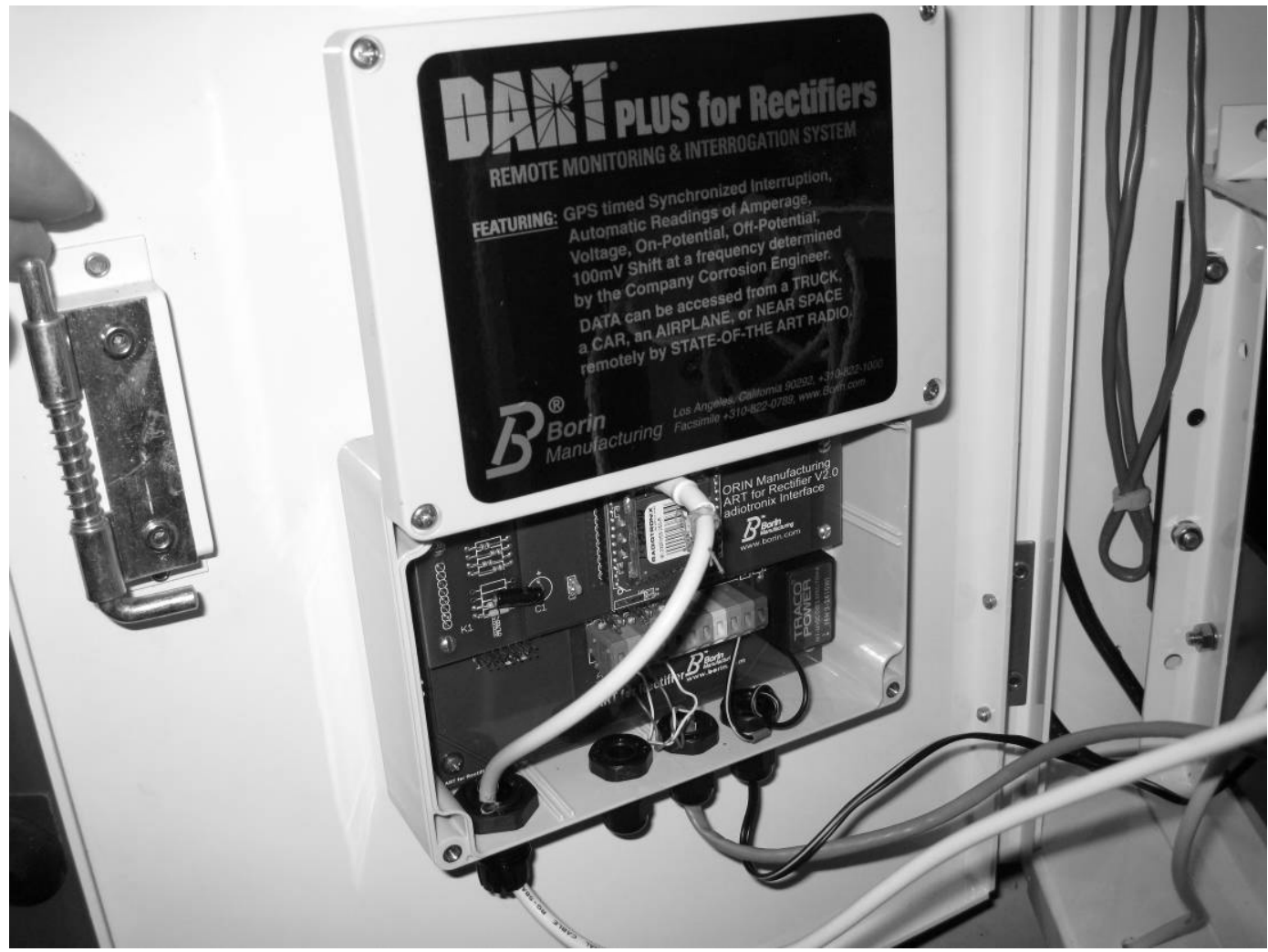

Figure 25. RMU rectifier reader unit inside rectifier cabinet, cover removed. 


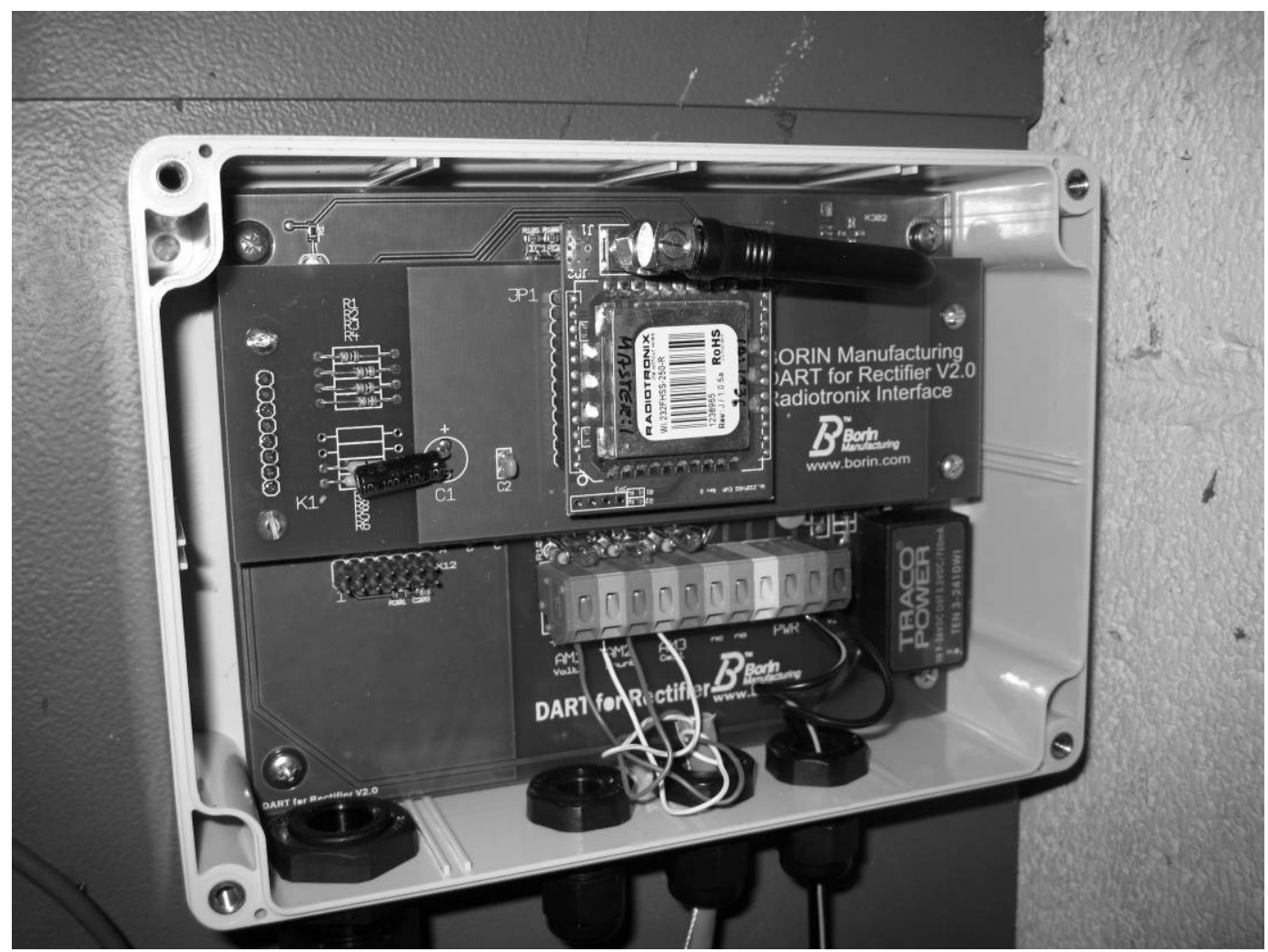

Figure 26. Close-up view of RMU rectifier reader unit.

\subsection{Data collection and logging}

The remote monitoring system installed at Fort J ackson utilizes an upgraded portable drive-by interrogation system from that at Ft. Carson, installed in a standard PC portable computer. The new system is capable of operating on computers running Windows Vista, XP, or 2000. It utilizes more powerful radios in both the test station monitoring units and the mobile data acquisition system increasing both the distance and the speed with which data can be acquired from the test stations. The new system reduces the time for data acquisition on a typical base wide system from less than eight hours to less than two hours. Increased capacity batteries have also been incorporated into the new design test station units increasing the frequency with which the units may be interrogated (from once a month to once a week) while still maintaining an operating life of more than 10 years before battery replacement is required.

The degree of flexibility provided by the new software furnished with the latest version of this drive-by RMU system has greatly increased the applicability of the RMU. All measurement parameters including time between data samples, length of time period during which instant off potentials are 
measured and time period over which polarization decay is assessed are all user selectable values. Thus the system can now be utilized on other pipe materials such as ductile iron, aluminum and copper which have different criteria for cathodic protection then that used on buried steel pipe. Software setup and use has been greatly simplified by the PC-based system with intuitive drop-down menus and screen presentations

The DART units installed at Fort J ackson are set to collect the data once weekly, on Monday. The data can then be read during the drive-bys either on Tuesday or Wednesday. For the remainder of the week the DART units are in a "sleep" mode to conserve battery power, which is guaranteed for 15 years. The data from the 100 remote monitoring units as well as from the water storage tank can be collected through the drive by method. These data are then automatically transferred into an Excel spreadsheet where it is automatically analyzed on a pass/ fail basis. The Fort J ackson personnel just have to look at the table to see if there are any trouble spots. 


\section{Discussion}

\subsection{Metrics}

The remote monitoring system is monitoring $100 \mathrm{CP}$ test stations and the DC voltage and current from ICCP system rectifiers. The test station systems measure the structure protection levels on a coupon that is normally connected to the structure and thus receiving the same level of $\mathrm{CP}$ as the structure. At a user selectable time interval, typically once each week, the test station reader automatically decouples the coupon for another user selectable time period (typically 0.5- 1 second) during which it automatically measures and records the instant off IR-drop free potential of the coupon. The potential is measured with respect to an integral permanent copper-copper sulfate reference electrode. If the coupon reading is -850 $\mathrm{mV}$ or more negative (this value can be set higher or lower by the user), the test is complete and the monitoring system becomes dormant for 1 week, at which time it repeats the measurement. A total of up to 12 readings are stored in the unit after which the oldest reading is cleared out and a new reading is stored in the memory, thus the 12 most recent readings are always available for interrogation by the portable drive-by data acquisition system.

If the weekly instant off reading is more positive than $-850 \mathrm{mV}$ (e.g., - 750 $\mathrm{mV}$ ), then the unit goes into a polarization decay mode, whereby it leaves the coupons decoupled from the structure for a user selectable time interval (NACE normally recommends a time interval (NACE RP-0169) of 4 hours). At the end of this time interval, the unit measures the value of the decayed potential and subtracts this value from the instant off value, in accordance with NACE criteria RP-0169. So long as the decay thus measured and calculated is greater than $100 \mathrm{mV}, \mathrm{CP}$ is confirmed on the coupon and the structure on which it is attached.

The rectifier reader unit measures the same values for a coupon installed near the rectifier and, in addition, measures the rectifier output DC voltage and current. The current is measured across the rectifier shunt resistor in $\mathrm{mV}$ and is converted to amperes using Ohm's Law. IR-Drop Free Potentials measured in this manner on the coupons were found to be within +/$5 \mathrm{mV}$ of the value similarly measured by a Fluke model 867 precision Voltohm meter (VOM), while the rectifier voltage and current values were 
tested similarly and were within a tolerance of $+/-2 \mathrm{mV}$ and $+/-200 \mathrm{~mA}$, thus verifying that the CP system and RMUs were operating as designed.

\subsection{Results}

On the water storage tank, before the new CP system was energized on 29

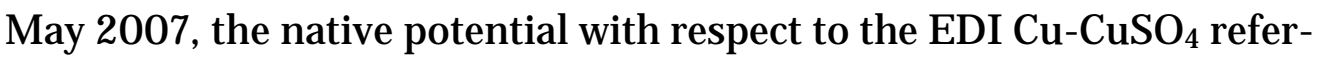
ence cell was measured to be -0.434 volts. After energizing, the potential measurements were in the -0.890 to $-0.930 \mathrm{~V}$ range from top to bottom, indicating that the submerged surfaces were completely protected from corrosion in accordance with NACE International Recommended Practices while the uniformity of this corrosion control was also exceptional.

The drive-by survey, typically performed by one person, reads all 100 DART stations and all the TRs (including the elevated water storage tank) in about 3 hours. In contrast, it is estimated that manual measurements of all these locations would probably take about 1 week.

In March 2007, a baseline native potential survey was performed at all the test locations where the DART units were intended to be installed. The data are summarized in Appendix D. It was noted that CP was being provided very locally at a few locations from the existing "old" CP system. The vast majority of the test locations indicated that the buried piping was unprotected; in many instances the potentials suggested that the steel was in contact with other structures such as copper grounding rods.

In October 2007, before the three deep anode groundbed systems were energized, another baseline potential survey performed (Appendix D). Data could not be collected from some test stations because of military activities under way on base at the time.

$\mathrm{T} / \mathrm{R}$ data collected during the course of the demonstration are summarized in Appendix E.

The data collected to date are shown in Appendix G. The data indicate that approximately 20 to $30 \%$ of the buried gas piping is receiving varying levels of cathodic protection which can change with time as polarization continues. A reading showing 25- 100\% cathodic protection at the test station is considered passing. The data were simplified into either a pass or fail condition on the excel printouts the system provided (Appendix F). 


\subsection{Lessons learned}

On many installations piping and other underground systems have been replaced or moved and documentation of these changes have not been consistently recorded in one easy to access place. Fort J ackson is one such installation where accurate historical and current as-built drawings for the underground systems were not readily available. When this is the case, the first part of digging for installation of deep well anodes, has to be performed by hand so that crucial communication, piping or other systems are not inadvertently disrupted. This also means that there has to be a contingency plan if the original planned site is where there are existing systems. Along with the initial digging for the well being done by hand, there also has to be trenches dug by hand to install the cabling connecting the anode groundbeds to the TRs. These trenches are typically $24 \mathrm{in.} \mathrm{mini-}$ mum in depth.

The many variances in the soil types and depths at Fort J ackson presented another need for having contingency plans as bedrock was encountered at varying depths. The first two sites for the deep bed anodes reached bedrock at around $65 \mathrm{ft}$ and $40 \mathrm{ft}$, respectively. These sites each got two holes and two anodes were installed in each well. But, the third site hit bedrock at $80 \mathrm{ft}$. Since there was no other site available to dig because of underground utilities encountered on the first digging, 4 ceramic anodes went into the one well. This third site also required considerable trenching to connect the anodes to the gas pipeline and the T/R.

The baseline native potential survey performed indicated that many of the test locations were not being cathodically protected. The potentials indicated that the steel was in contact with other structures such as copper grounding rods. It is also suspected that there are small segments of plastic pipe installed within the steel piping system making it difficult to determine if complete $\mathrm{CP}$ is being provided.

If the piping system is not properly isolated, cathodic protection of the system is much more difficult to achieve. 


\section{Economic Summary}

\subsection{Costs and assumptions}

The benefits of implementing CP systems on the subject infrastructure are bringing mission-critical natural gas piping infrastructure into compliance with legal requirements, reducing maintenance requirements and costs, and improving infrastructure safety, readiness, and reliability.

Table 6 lists the cost of implementing the subject technology at Fort J ackson.

Table 6. Funding sources (\$K).

\begin{tabular}{|l|l|l|}
\hline Funding Source & OSD & Service Matching \\
\hline Labor & 220 & 230 \\
\hline Materials & 200 & 200 \\
\hline Travel & 30 & 30 \\
\hline Report & 40 & 40 \\
\hline Air Force/Navy Participation & 10 & - \\
\hline TOTAL (\$K) & $\mathbf{5 0 0}$ & $\mathbf{5 0 0}$ \\
\hline
\end{tabular}

(1) Useful Life Savings (ULS) is equal to the "Net Present Value (NPV) of Benefits and Savings" calculated from the Spreadsheet shown in Table 7, which is based on Appendix B of OMB Circular A94.

(2) ULS=\$ 14,682 K, from OMB Spreadsheet in Table 7. Assumptions for this calculation are also given in Table 7.

(3) Project Cost (PC) is shown as "Investment required" in OMB Table $7 ; \mathbf{P C}=\mathbf{\$ 1 , 0 0 0 K}$.

(4) ULS $\$ 14,682 \mathrm{~K}$

$$
\text { ROI = ---------- = =------------- = } 14.7 \text { PC } \$ 1,000 \mathrm{~K}
$$

\subsection{Return-on-investment computation}

Assumptions for two alternate scenarios are summarized below. 
Scenario 1: Fort J ackson has the following systems that are in need of cathodic protection (CP) and remote monitoring systems in order to insure that the CP systems are properly maintained: (1) underground natural gas pipelines, and (2) a potable water storage tank. The natural gas lines will need to be replaced in years 5 and 25 at a cost of $\$ 14.3 \mathrm{M}$ each year. Average annualized maintenance costs are $\$ 50 \mathrm{~K}$, before replacement. After replacement, the annual maintenance costs again increase until rehab. in year 20 at a cost of $\$ 2 \mathrm{M}$, then decline (because of the rehab.) until the next major replacement. The cost for replacement of the water storage tank in year 10 is $\$ 2 \mathrm{M}$. All of these costs are shown under Baseline Cost in the ROI Spreadsheet.

Additional costs, shown in Spreadsheet $1 \mathrm{~b}$ (Table 8) will be for excavation to fix and repair leaks to the underground lines, emergency bottled water, and fire suppression water trucks standing by in case of fires and explosions from gas leaks. These costs are initially $\$ 120 \mathrm{~K}$ and they decrease in year 5, only to increase again in year 10 to $\$ 100,000$, when the most of the new systems are installed. Afterward, these additional costs track prior history, decreasing in years 20 and 25, when the there is a rehab or replacement and increase afterwards up to $\$ 20 \mathrm{~K}$, as shown in Table 8.

Scenario 2: Cathodic protection upgrades and remote monitoring of the $\mathrm{CP}$ system will be implemented in year 1, for the water storage tanks, and natural gas lines at an investment cost of $\$ 1,000 \mathrm{~K}$. Average annualized maintenance costs will be $\$ 25 \mathrm{~K}-\$ 30 \mathrm{~K}$ to maintain the CP system, as well as the tanks and pipes, as shown in the ROI Spreadsheet under New System Costs. Also, shown under New System cost is the cost of rehab of the $\mathrm{CP}$ systems in year 20 at $\$ 2 \mathrm{M}$. Comparing the two alternatives, the returnon-investment for Alternative 2 is 14.7. 
Table 7. ROI calculation spreadsheet 1 a.

\section{Return on Investment Calculation}

Investment Required

Return on Investment Ratio

Net Present Value of Costs and Benefits/Savings
14.68

837,118
$1,000,000$

Percent $1468 \%$

$15,519,595 \quad 14,682,477$

G

$G$

\begin{tabular}{|c|c|c|c|c|c|c|c|}
\hline $\begin{array}{c}\text { A } \\
\text { Future } \\
\text { Year }\end{array}$ & $\begin{array}{c}\text { B } \\
\text { Baseline Costs }\end{array}$ & $\begin{array}{c}\text { C } \\
\text { Baseline } \\
\text { Benefits/Savings }\end{array}$ & $\begin{array}{c}\text { D } \\
\text { New System } \\
\text { Costs }\end{array}$ & $\begin{array}{c}\text { E } \\
\text { New System } \\
\text { Benefits/Savings }\end{array}$ & $\begin{array}{c}F \\
\text { Present Value of } \\
\text { Costs }\end{array}$ & $\begin{array}{c}\mathbf{G} \\
\text { Present Value of } \\
\text { Savings }\end{array}$ & $\begin{array}{c}\mathbf{H} \\
\text { Total Present } \\
\text { Value }\end{array}$ \\
\hline & 170,000 & & 25,000 & & 23,365 & 158,882 & 135,517 \\
\hline 2 & 170,000 & & 25,000 & & 21,835 & 148,478 & 126,643 \\
\hline 3 & 170,000 & & 25,000 & & 20,408 & 138,771 & 118,364 \\
\hline 4 & 170,000 & & 25,000 & & 19,073 & 129,693 & 110,621 \\
\hline 5 & $14,350,000$ & & 25,000 & & 17,825 & $10,231,550$ & $10,213,725$ \\
\hline 6 & 70,000 & & 25,000 & & 16,658 & 46,641 & 29,984 \\
\hline 7 & 81,000 & & 25,000 & & 15,568 & 50,439 & 34,871 \\
\hline 8 & 92,000 & & 25,000 & & 14,550 & 53,544 & 38,994 \\
\hline 9 & 103,000 & & 25,000 & & 13,598 & 56,022 & 42,424 \\
\hline 10 & $2,114,000$ & & 25,000 & & $\mid 12,708$ & $1,074,546$ & $1,061,839$ \\
\hline 11 & 35,000 & & 30,000 & & 14,253 & 16,629 & 2,376 \\
\hline 12 & 43,000 & & 30,000 & & 13,320 & 19,092 & 5,772 \\
\hline 13 & 50,000 & & 30,000 & & 12,450 & 20,750 & 8,300 \\
\hline 14 & 62,000 & & 30,000 & & 11,634 & 24,044 & 12,410 \\
\hline 15 & 68,000 & & 30,000 & & 10,872 & 24,643 & 13,771 \\
\hline 16 & 75,000 & & 30,000 & & 10,161 & 25,403 & 15,242 \\
\hline 17 & 87,000 & & 30,000 & & 9,498 & 27,544 & 18,046 \\
\hline 18 & 95,000 & & 30,000 & & 8,877 & 28,111 & 19,234 \\
\hline 19 & 102,000 & & 30,000 & & 8,295 & 28,203 & 19,908 \\
\hline 20 & $2,001,000$ & & $2,000,000$ & & 516,800 & 517,058 & 258 \\
\hline 21 & 42,000 & & 25,000 & & 6,038 & 10,143 & 4,106 \\
\hline 22 & 50,000 & & 25,000 & & 5,643 & 11,285 & 5,643 \\
\hline 23 & 60,000 & & 25,000 & & 5,273 & 12,654 & 7,382 \\
\hline 24 & 65,000 & & 25,000 & & 4,928 & 12,812 & 7,884 \\
\hline 25 & $14,301,000$ & & 25,000 & & 4,605 & $2,634,244$ & $2,629,639$ \\
\hline 26 & 15,000 & & 25,000 & & 4,305 & 2,583 & $-1,722$ \\
\hline 27 & 20,000 & & 25,000 & & 4,023 & 3,218 & -805 \\
\hline 28 & 26,000 & & 25,000 & & 3,760 & 3,910 & 150 \\
\hline 29 & 32,000 & & 25,000 & & 3,515 & 4,499 & 984 \\
\hline 30 & 32,000 & & 25,000 & & 3,285 & 4,205 & 920 \\
\hline
\end{tabular}


Table 8. ROI calculation spereadsheet $1 \mathrm{~b}$.

\begin{tabular}{|c|c|c|c|c|c|c|c|c|}
\hline & \multicolumn{5}{|c|}{ Baseline Costs } & \multicolumn{3}{|c|}{ New System Costs } \\
\hline & \multicolumn{3}{|c|}{ Gas Line } & \multicolumn{2}{|l|}{ Tank } & & & \\
\hline Year & Maintain & Replace/Rehab. & Repair & Replace & Total & Maintain & Rehab & Total \\
\hline 1 & $\$ 50,000$ & & $\$ 120,000$ & & $\$ 170,000$ & $\$ 25,000$ & & $\$ 25,000$ \\
\hline 2 & $\$ 50,000$ & & $\$ 120,000$ & & $\$ 170,000$ & $\$ 25,000$ & & $\$ 25,000$ \\
\hline 3 & $\$ 50,000$ & & $\$ 120,000$ & & $\$ 170,000$ & $\$ 25,000$ & & $\$ 25,000$ \\
\hline 4 & $\$ 50,000$ & & $\$ 120,000$ & & $\$ 170,000$ & $\$ 25,000$ & & $\$ 25,000$ \\
\hline 5 & & $\$ 14,300,000$ & $\$ 50,000$ & & $\$ 14,350,000$ & $\$ 25,000$ & & $\$ 25,000$ \\
\hline 6 & $\$ 10,000$ & & $\$ 60,000$ & & $\$ 70,000$ & $\$ 25,000$ & & $\$ 25,000$ \\
\hline 7 & $\$ 11,000$ & & $\$ 70,000$ & & $\$ 81,000$ & $\$ 25,000$ & & $\$ 25,000$ \\
\hline 8 & $\$ 12,000$ & & $\$ 80,000$ & & $\$ 92,000$ & $\$ 25,000$ & & $\$ 25,000$ \\
\hline 9 & $\$ 13,000$ & & $\$ 90,000$ & & $\$ 103,000$ & $\$ 25,000$ & & $\$ 25,000$ \\
\hline 10 & $\$ 14,000$ & & $\$ 100,000$ & $\$ 2,000,000$ & $\$ 2,114,000$ & $\$ 25,000$ & & $\$ 25,000$ \\
\hline 11 & $\$ 15,000$ & & $\$ 20,000$ & & $\$ 35,000$ & $\$ 30,000$ & & $\$ 30,000$ \\
\hline 12 & $\$ 18,000$ & & $\$ 25,000$ & & $\$ 43,000$ & $\$ 30,000$ & & $\$ 30,000$ \\
\hline 13 & $\$ 20,000$ & & $\$ 30,000$ & & $\$ 50,000$ & $\$ 30,000$ & & $\$ 30,000$ \\
\hline 14 & $\$ 22,000$ & & $\$ 40,000$ & & $\$ 62,000$ & $\$ 30,000$ & & $\$ 30,000$ \\
\hline 15 & $\$ 23,000$ & & $\$ 45,000$ & & $\$ 68,000$ & $\$ 30,000$ & & $\$ 30,000$ \\
\hline 16 & $\$ 25,000$ & & $\$ 50,000$ & & $\$ 75,000$ & $\$ 30,000$ & & $\$ 30,000$ \\
\hline 17 & $\$ 27,000$ & & $\$ 60,000$ & & $\$ 87,000$ & $\$ 30,000$ & & $\$ 30,000$ \\
\hline 18 & $\$ 30,000$ & & $\$ 65,000$ & & $\$ 95,000$ & $\$ 30,000$ & & $\$ 30,000$ \\
\hline 19 & $\$ 32,000$ & & $\$ 70,000$ & & $\$ 102,000$ & $\$ 30,000$ & & $\$ 30,000$ \\
\hline 20 & & $\$ 2,000,000$ & $\$ 1,000$ & & $\$ 2,001,000$ & & $\$ 2,000,000$ & $\$ 2,000,000$ \\
\hline 21 & $\$ 37,000$ & & $\$ 5,000$ & & $\$ 42,000$ & $\$ 25,000$ & & $\$ 25,000$ \\
\hline 22 & $\$ 40,000$ & & $\$ 10,000$ & & $\$ 50,000$ & $\$ 25,000$ & & $\$ 25,000$ \\
\hline 23 & $\$ 45,000$ & & $\$ 15,000$ & & $\$ 60,000$ & $\$ 25,000$ & & $\$ 25,000$ \\
\hline 24 & $\$ 45,000$ & & $\$ 20,000$ & & $\$ 65,000$ & $\$ 25,000$ & & $\$ 25,000$ \\
\hline 25 & & $\$ 14,300,000$ & $\$ 1,000$ & & $\$ 14,301,000$ & $\$ 25,000$ & & $\$ 25,000$ \\
\hline 26 & $\$ 10,000$ & & $\$ 5,000$ & & $\$ 15,000$ & $\$ 25,000$ & & $\$ 25,000$ \\
\hline 27 & $\$ 10,000$ & & $\$ 10,000$ & & $\$ 20,000$ & $\$ 25,000$ & & $\$ 25,000$ \\
\hline 28 & $\$ 11,000$ & & $\$ 15,000$ & & $\$ 26,000$ & $\$ 25,000$ & & $\$ 25,000$ \\
\hline 29 & $\$ 12,000$ & & $\$ 20,000$ & & $\$ 32,000$ & $\$ 25,000$ & & $\$ 25,000$ \\
\hline 30 & $\$ 12,000$ & & $\$ 20,000$ & & $\$ 32,000$ & $\$ 25,000$ & & $\$ 25,000$ \\
\hline & & & & & & & & \\
\hline & & & & & & & & \\
\hline
\end{tabular}




\section{Conclusions and Recommendations}

\subsection{Conclusions}

Three deep anode impressed current groundbeds installed at Fort J ackson appear to be providing varying degrees of cathodic protection to the buried gas piping system. The level of protection can change with time as polarization continues. Data collected so far indicate that only $20-30 \%$ of the buried gas piping is receiving varying levels of cathodic protection (Appendix F). Some of the piping appears to be electrically isolated from the $\mathrm{CP}$ system due to the intermittent use of plastic pipes at various locations in the gas line.

The new cathodic protection system in the elevated water storage tank is providing complete and uniform protection in the tank interior bellow the waterline. The anode life of the new ceramic wire anode material is conservatively calculated at greater than 40 years in this particular water storage tank.

The remote DART monitoring system appears to be working well. Drive-by surveys can be typically performed in approximately 3 hours for all 100 test stations, including rectifiers. It is estimated that a manual survey of the same items would take up to a week.

At the present time not enough data have been collected to precisely determine the requirements for providing $\mathrm{CP}$ to protect all buried gas piping at Fort J ackson. Gas line CP data will continue to be collected monthly through September 2008. These data will be provided to the government for purposes of determining system-wide $\mathrm{CP}$ requirements.

Preliminary results indicate that cathodic protection could be extended to all the underground metallic natural gas piping with the addition of 10-30 shallower (smaller; depth approximately 40-50 ft each) semi-deep anode beds of 5- 10 amperes capacity each. 


\subsection{Recommendations}

\subsubsection{Fort Jackson gas line application}

It appears that there may be small segments of plastic pipe installed within the steel pipe line. If this is the case, some of the protective current distribution will be non-uniform, and may even create the conditions for straycurrent corrosion at these locations. It is essential that the DPW investigate whether such plastic pipe insertions exist between adjacent steel pipe sections within the gas distribution system. If such locations are found, continuity testing should be performed to determine if these separate steel sections are electrically continuous through other connections in the gas distribution system. If such continuity does not exist, it should be restored using standard bonding techniques.

One suggestion is that electrical isolation of the natural gas system from other underground utilities should be attempted, but this type of isolation could be expensive to perform and would be extremely difficult to maintain. An alternative would be that all utilities (with the exception of unbonded, electrically discontinuous ductile iron piping) be bonded together electrically and cathodically protected as one mass utility infrastructure using the aforementioned ICCP semi-deep anode beds.

\subsubsection{General technology applicability}

CP upgrades using deep anode beds should be used for all underground piping which have electrical continuity.

Remote monitoring units should be used to monitor CP system performance regularly for underground pipes and water storage tanks.

Where ice of 1- 2 in. thickness does not form in the water storage tank during the year, the vertically suspended CP system designed for this water storage tank is a good choice.

\subsubsection{Implementation}

This technology is recommended for use at Army and DoD Installations for corrosion protection of utilities. Recommended revisions to existing UFGS-26 4215.00 10, Cathodic Protection System (Steel Water Tanks), and UFGS - 2642 17.00 10, Cathodic Protection System (Impressed Current), are planned. Revisions will include the specifications and instruc- 
tions for installing the deep bed anode impressed current CP systems. In addition, specifications for the remote monitoring units for utilities will be included.

In UFGS-26 4217.00 10, a new paragraph describing "tubular anodes" needs to be added after 2.1.3 using the description presented in this report. Paragraph 3.5.9 should be modified to incorporate the capability to use drive by remote monitoring units using the information provided in this report as the criteria for installation and capabilities of the system.

InUFGS-26 42 15.00 10, add to paragraph 2.1.3.1 an example of a selection that can be made for an installation that does not experience 1-2" of ice in the water tank, is the precious metal anodes chosen for this project installed using a vertically suspended anode system. A paragraph also needs to be added after 3.5.1.3 that facilitates the use of the drive by remote monitoring systems, when there is not a SCADA system already in use, for testing and recording of data for the $\mathrm{CP}$ in the tanks. 


\title{
Appendix A: Comparison of Wireless Technologies for Remote Monitoring of Cathodic Protection Systems (NACE 2007)
}

\section{COMPARISON OF WIRELESS TECHNOLOGIES FOR REMOTE MONITORING OF CATHODIC PROTECTION SYSTEMS}

\author{
Ashok Kumar \\ and \\ Larry D. Stephenson \\ U.S. Army Corps of Engineers, Engineer Research and Development Center \\ Construction Engineering Research Laboratory, P. O. Box 9005, Champaign, IL \\ 61826-9005
}

\begin{abstract}
Impressed current cathodic protection (CP) systems for water storage tanks must be periodically tested in order to ensure proper performance. Wireless remote monitoring technologies provide the ability to monitor CP system performance data from remote locations using modem-equipped personal computers. Data can be provided to a central location through an existing supervisory control and data acquisition (SCADA) systems or through other wireless monitoring systems that can be installed economically. The technology provides capabilities to remotely monitor the cathodic protection system's current and "instant-on" and "instant off potentials," allowing allowed continuous monitoring of CP systems from a central location, and provide personnel with immediate warning of potential corrosion hazards. Case studies are presented for three Army Installations and one Air Force Installation, each with different approaches to remote monitoring of cathodic protection systems for potable water storage tanks and buried pipelines. The benefits of implementation of remote monitoring are the cost avoidance of traveling to remote sites to check each rectifier, and the added capability of instant notification of a malfunction in the cathodic protection system, thus increasing the life of the structures being protected.
\end{abstract}




\section{INTRODUCTION}

Many Military Installations are spread over large areas and have many water storage tanks that use corrosion protection systems known as "cathodic protection (CP)" systems, which protect the internal or "water-side" of the tank. The outer surfaces of underground pipes, such as water, or gas distribution systems, also must be protected from corrosion in the soil using similar CP systems. In either case, CP systems need to be monitored in order to make sure that they are providing enough voltage and current to maintain the cathodic protection.

Impressed current $\mathrm{CP}$ systems work by connecting an anode to the structure, and applying a negative potential to the structure and a positive potential to the anode through a current from an external source, controlled by a rectifier. In recent years, ceramic-coated anodes, usually made by depositing mixed metal oxides onto titanium substrates, have been used as an alternative to the silicon-iron and graphite anodes. The ceramic anode makes corrosion protection available at much less than the life cycle cost of previous technologies and in a size-reduction that permits installation in areas previously too small.

Current cathodic protection monitoring procedures require highly skilled engineer/technician personnel and are extremely burdensome for the maintenance staff. These procedures are often deficient, and do not identify all areas where corrosion protection is either inadequate or non-existent. Furthermore, these locations generally increase with time and remain undetected, until structure perforation and failure. (CP) systems for water storage tanks must be periodically tested in order to ensure proper performance.

\section{REMOTE MONITORING TECHNOLOGY}

Remote monitoring technology $1,2,3,4$ allows "on-demand" monitoring of CP systems: (1) from a central location, such as the Office of the Chief of Operations \& Maintenance (O\&M), or (2) from out in the field by simply driving within 1,000 feet of the $\mathrm{CP}$ monitoring station for a given cathodically protected structure, whereupon the CP system status information is instantly up-loaded into a portable computer or personal digital assistant (PDA), and will provide personnel with immediate warning of potential corrosion hazards.

Historically remote monitoring of cathodic protection levels has undergone several evolutions. In the 1980 's a system using ground transmitters and receivers placed in aircraft that routinely flew over the pipeline for inspections was promoted. The fly-by system proved uneconomical and ineffective due to communications frequency issues, low transmitter power, and the cost of the monitoring hardware. The remote monitoring systems in use today are: (1) cellular telephone based systems, (2) Supervisory Control and Data Acquisition (SCADA) based systems, and (3) "drive-by" remote monitoring units. These remote monitoring systems both greatly increase the accuracy, frequency, and number of monitoring locations to assure that complete protection is maintained on all the protected structures. Remote monitoring systems also automate the data storage and analysis to identify any areas needing remediation and repair before any significant corrosion occurs. 


\section{CASE STUDIES}

\section{Case Study 1: Cell Phone Based Remote Monitoring at Army Installation \#1}

Remote monitoring units (RMUs) installed on two elevated water storage tanks at a large Army Installation in the Southwest. They are identified as Structure \#1-1.5 MMG Elevated Water Tank, and Structure \#2-2.0 MMG Elevated Water Tank. It was anticipated that any Pentium based system with at least 64 Mbytes of RAM, 5 Gigabytes of unused hard drive capacity, $56 \mathrm{~K}$ modem directly accessing commercial telephone lines and using Microsoft's Windows 95,98, NT or 2000 would be sufficient (later to include Windows XP) for the projects needs. Each of the two water tank sites was visited and basic data gathered regarding the cathodic protection system operating parameters. These data are shown in Tables 1 and 2. It should be noted that although the cathodic protection system on the Tank \#2 was behaving somewhat erratically, it appeared to be providing effective corrosion protection to the tank.

Based on the photos and site inspection, it was determined that the RMU for the Tank \#1 could be installed directly on or adjacent to the CP Rectifier unit mounted on the tank support leg, while the other RMU for the tank \#2 would be mounted either inside on the exterior of the equipment building in which the CP rectifier was installed at the RMU contractors preference. (See Figures $1 \mathrm{a}$ and $1 \mathrm{~b}$ ). Two prospective manufacturers were identified as having relatively inexpensive RMUs (less than \$1000/RMU equipment cost) with the desired operating parameters. These parameters are shown in Table 3 .

TABLE 1. CATHODIC PROTECTION SYSTEM BASIC DATA FOR WATER TANK \#1

\begin{tabular}{|c|c|c|}
\hline Structure 1 & $\begin{array}{l}\text { 1.5 MMG Elevated } \\
\text { Water Storage Tank }\end{array}$ & \\
\hline AC Input & $\begin{array}{c}120 \mathrm{~V} / 60 \mathrm{~Hz} / 1 \text { phase - } \\
3.37 \mathrm{~A}\end{array}$ & \\
\hline DC Volts Max. & 30 & \\
\hline DC Amps Max. & 8 & \\
\hline $\begin{array}{r}\text { Current Output Shunt } \\
\text { Rating }\end{array}$ & $100 \mathrm{mV}=10$ Amperes & \\
\hline Operating Data & Rectifier Meter & Test Meter \\
\hline Volts: & 2.1 & 2.149 \\
\hline Amps: & 0.15 & $1.5 \mathrm{mV}$ where $10 \mathrm{mV}=1 \mathrm{Amp}$ \\
\hline IR Free Potential (mV): & -980 & -980 \\
\hline Potential Set Point (mV) & -980 & \\
\hline "On" Potential (mV): & & -1151 \\
\hline \multicolumn{2}{|c|}{$\begin{array}{l}\text { Note: This unit is a single circuit unit with no } \\
\text { separate riser protection circuit }\end{array}$} & \\
\hline
\end{tabular}


TABLE 2. CATHODIC PROTECTION SYSTEM BASIC DATA FOR WATER TANK \#2

\begin{tabular}{|c|c|c|}
\hline Structure 2: & $\begin{array}{l}\text { 2.0 MMG Elevated Water } \\
\text { Storage Tank }\end{array}$ & \\
\hline AC Input & $120 \mathrm{~V} / 60 \mathrm{~Hz} / 1$ phase $-3.37 \mathrm{~A}$ & \\
\hline DC Volts Max. & 30 & \\
\hline DC Amps Max. & 8 & \\
\hline Current Output Shunt Rating & $100 \mathrm{mV}=10$ Amperes & \\
\hline Operating Data & Rectifier Meter & Test Meter \\
\hline Volts: & $1.8-1.9$ & 2.149 \\
\hline Amps: & $0.02-0.03$ & $\begin{array}{c}0.0 \mathrm{mV} \text { where } 10 \\
\mathrm{mV}=1 \mathrm{Amp}\end{array}$ \\
\hline IR Free Potential $(\mathrm{mV})$ : & varied -969 to -987 & -980 \\
\hline Potential Set Point (mV) & -978 & \\
\hline "On" Potential (mV): & & -1028 \\
\hline \multicolumn{2}{|c|}{$\begin{array}{c}\text { Note: This unit has a rheostat controlled secondary output circuit to } \\
\text { protect the riser pipe }\end{array}$} & \\
\hline
\end{tabular}

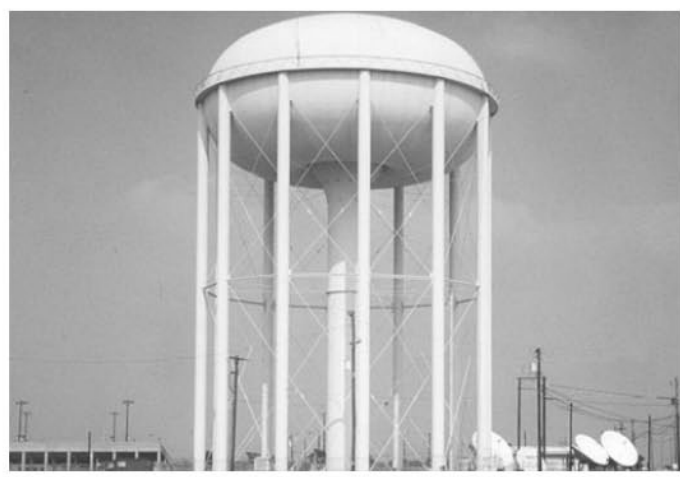

FIGURE. 1a- Elevated 2 MMG potable water storage tank at Army Installation \#1

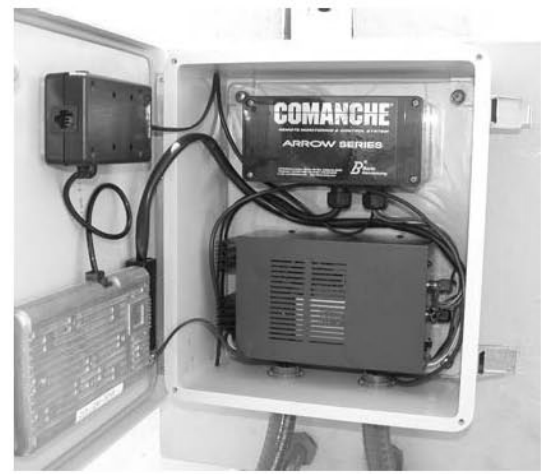

FIGURE 1b- Typical RMU installed on water storage tanks at Army Installation \#1 
TABLE 3. RMU OPERATING PARAMETERS

\begin{tabular}{|c|l|}
\hline \multicolumn{1}{|c|}{ Characteristic } & \multicolumn{1}{|c|}{ Description of Requirement } \\
\hline No. of Data Monitoring Channels & 2 \\
\hline Ampere Monitor & $\begin{array}{l}\text { mV drop across rectifier current shunt with } \\
\text { resolution of } 0.1 \text { millivolt and minimum } \\
\text { RMU channel input impedance of } 1 \text { megohm. }\end{array}$ \\
\hline Voltage Monitor & $\begin{array}{l}\text { Voltage at output terminals of Rectifier with } \\
\text { resolution of } 0.1 \text { volts and minimum RMU } \\
\text { channel input impedance of } 1 \text { megohm. }\end{array}$ \\
\hline Structure to Electrolyte Potential & $\begin{array}{l}\text { Ability to measure both "On" and "Instant } \\
\text { Off" potentials using existing permanently } \\
\text { installed reference electrode with resolution } \\
\text { of } 1 \text { millivolt and minimum RMU channel } \\
\text { input impedance of } 10 \text { megohm. }\end{array}$ \\
\hline Options & $\begin{array}{l}\text { With } 2 \text { monitoring channels, choice would } \\
\text { have to be made as to whether (1) system } \\
\text { voltage and amperage would be monitored or } \\
\text { (2) system amperage and structure to } \\
\text { electrolyte potential would be monitored }\end{array}$ \\
\hline Installation requirements & $\begin{array}{l}\text { System would have to be furnished and } \\
\text { installed complete by the same supplier. }\end{array}$ \\
\hline
\end{tabular}

The RMU chosen for installation communicated by cell phone modems with 2 channels of data acquisition plus the control channel. It was considered preferable to be able to measure all three parameters of CP system operating voltage, current and potential (both "On" and "Instant-Off"). The cell-phone based RMU hardware and its software were installed and commissioned at Tanks \#1 and Tank \#2. It took over 6 hours to complete the first installation (including gaining familiarity with local telephone communications requirements), but only 3 hours to complete the second installations and even less time for the software installation including setting parameters for site identification, data acquisition, values to be measured and alarm limits for each channel.

Data accuracy was determined by simultaneously acquiring data using the RMUs and personnel at each site using a precision voltmeter at each site to measure the same data. As can be seen from the data in Table 4, the accuracy of the system during the initial field tests was extremely good and well within the $2 \%$ accuracy limits set by the specifications. It should be noted that there were some communication problems with the Tank \#2. This occurred due to problems with the telephone company and were immediately resolved by re-setting the RMU at the site. The ability to "log" data on a continuing "real time" basis was also demonstrated

TABLE 4. RESULTS OF POST-INSTALLATION RMU TESTING

\begin{tabular}{|c|c|c|c|}
\hline Site & Parameter & $\begin{array}{c}\text { Voltmeter } \\
\text { Value }\end{array}$ & RMU Value \\
\hline Tank1 & Current (in & $0.28-.30$ & $0.28-0.29$ \\
\hline
\end{tabular}




\begin{tabular}{|c|c|c|c|}
\hline & amperes & $1.140-1.140$ \\
\hline Tank 1 & $\begin{array}{c}\text { Potential "On" } \\
\text { (in -mV) }\end{array}$ & $\begin{array}{c}1.140- \\
1.145\end{array}$ & $0.960-0.980$ \\
\hline Tank 1 & $\begin{array}{c}\text { Potential } \\
\text { "Instant Off" } \\
\text { (in -mV) }\end{array}$ & $\begin{array}{c}0.970- \\
0.980\end{array}$ & $0.04-0.04$ \\
\hline Tank 2 & $\begin{array}{c}\text { Current (in } \\
\text { amperes }\end{array}$ & $0.04-0.04$ & $1.050-1.145$ \\
\hline Tank 2 & $\begin{array}{c}\text { Potential "On" } \\
\text { (in -mV) }\end{array}$ & $\begin{array}{c}1.063- \\
1.097\end{array}$ & $0.960-0.980$ \\
\hline Tank 2 & $\begin{array}{c}\text { Potential } \\
\text { "Instant Off" } \\
\text { (in -mV) }\end{array}$ & $\begin{array}{c}0.970- \\
0.980\end{array}$ \\
\hline
\end{tabular}

\section{Case Study 2: SCADA Based Remote Monitoring Sy stem at Air Force Installation}

Many military Installations use Supervisory Control and Data Acquisition (SCADA) systems (5) to monitor water levels in potable water storage tanks and to monitor the performance parameters of sewage lift stations. ${ }^{5}$ The SCADA system is wireless; it transmits its data to a central control and monitoring station and receives control signals via radio frequency transmission. Control information for the water pumps and sewage lifts station can also be transmitted to the equipment from a central location through the SCADA.

One U. S. Air Force Base in the Southeast is already monitoring impressed current cathodic protection (ICCP) systems on 4 of 5 elevated water potable storage tanks using their existing Supervisory Control and Data Acquisition (SCADA) system. By installing 3 new deep well anode beds, the number of rectifiers in the $\mathrm{CP}$ system for underground pipes will be reduced from 40 to 20. The AFB existing SCADA system will be extended by installing 20 additional SCADA transmitting stations at a cost of $\$ 10,000$ each, at the locations where the 20 additional rectifiers will be installed and they will be interfaced to SCADA units. The SCADA system will transmit the $\mathrm{CP}$ data to a central location upon request. The SCADA also provides control of the rectifiers, from a central location at any given time.

The staff has utilized the services of their SCADA system sole source supplier to implement the first CP monitor system at their base on an elevated water storage tank. A schematic diagram of the SCADA based system is shown in Fig. 2a-d. This system can automatically read the rectifier voltage, amperage and the structure potential at the SCADA location. The SCADA Transmitter broadcasts line of site to an antenna on top of a water tower. The signal is re-broadcast to the main SCADA system and then can be stored in and displayed on computers in maintenance staff offices.

A typical SCADA system and cathodic protection system rectifier are shown in Figures $3 \mathrm{a}$ and $3 \mathrm{~b}$. The rectifier fine control taps are serviced by relays on the SCADA control board, which allow fine voltage control. The rectifier potentials are read directly from the rectifier into the SCADA electronic board. Also, a Hall Effect device (Figure 3b) provides rectifier current readings to the SCADA. From this "proof of concept" system, the Air Force Base has successfully replicated the first system at 3 other water tank locations 


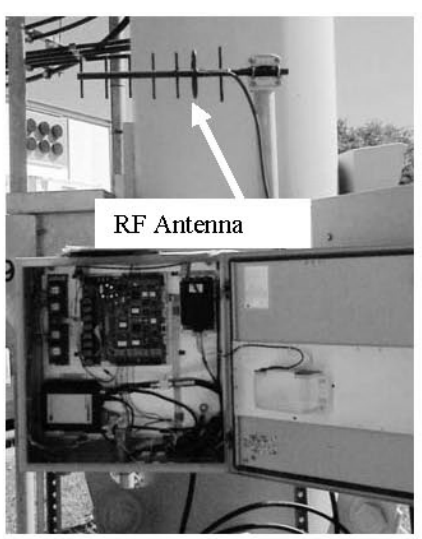

FIGURE. 3a- SCADA system to which CP data acquisition system is interfaced at a USAF Base. Note antenna for wireless transmission of data.

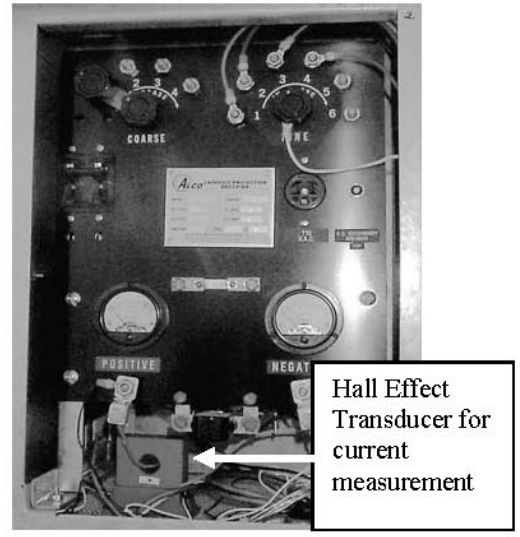

FIGURE 3b- Typical rectifier for CP system installed on elevated water storage tanks at USAF Base

CP data will be stored in the Air Force's Geographical Information System (GIS) database and be accessible through standard USAF GeoBase software. The SCADA system will allow condition based display of data at a central location to allow for graphical display of any CP problems within the GIS. For example, a point with questionable readings could be made to display the problem in yellow or red indications. Analysis software in the GIS will provide the capability to visualize any utility infrastructure endangered by a failure of the CP system. For example, a user could click on a "bad" point and see a display highlighting portions of the utility infrastructure at risk, along with an explanation of system maintenance needs.

The cost of implementation of the SCADA based CP monitoring/control system is very different for locations where existing SCADA already exists versus those locations where such is not the case. For example, at their water storage sites, this AF Base already has a SCADA to control the water level in each tank and to turn various pumps on and off. However, it will cost $\$ 10,000$ per location to install the SCADA at locations where it does not currently exist.

The only method the USAF Base has for monitoring test stations is by hard wiring the test station leads back to the nearest SCADA system. They have acknowledged that currently, this limits them to measuring only test points within a few hundred feet of the SCADA system. They have also expressed concerns that with the fact that these systems are limited to line of site radio frequency (RF) transmissions, and that in some cases the RF signals are attenuated by leaves on trees during the summer, in which case no CP data can be transmitted.

\section{Case Study 3: Drive by Remote Monitoring Units at Army Installation 2 and Army Installation 3}

Army Installation 2. At a second Army Installation, impressed current cathodic protection (ICCP) rectifiers and groundbeds were installed on one natural gas main, one steam main, one water storage 
reservoir, and three separate water supply mains. Selection of sites for ICCP installations included input by the Directorate of Public Works staff. This project demonstrated and implemented 6 deep anode impressed current cathodic protection systems (ICCP), 106 drive-by type remote monitoring units (TSDMU) for existing test stations, and 26 drive-by type remote monitoring units (RDMU) (See Figure 4) for existing and new rectifiers. Also, impressed current $\mathrm{CP}$ rectifiers and groundbeds were installed on one natural gas main, one steam main, one water storage reservoir, and three separate water supply mains. The six new rectifiers and deep anodes are capable of providing their full rated current output of 30 Amperes DC.

Based on the results of problems with cell phones and expense of installing the SCADA systems, the "drive-by" remote monitoring units (RMU) were installed at Army Installation 2. They were buried in the ground at about 200 impressed current $\mathrm{CP}$ monitoring stations. The units were programmed to "wake up" once a month, whereupon they transmit $\mathrm{CP}$ data using a low power RF signal. During the time window that the drive-by RMUs are transmitting, CP system maintenance personnel drive by within 0.1 mile of the remote monitoring points, guided by a global positioning system (GPS) map displayed on a laptop or PDA. Since each RMU is tied into the GPS, it broadcasts its location along with its data to the PDA. Once back in the office, the operator can down load the data into a computer where the CP files are stored and further trending analysis can be performed. ${ }^{6}$

The contractor who maintains the ICCP systems said that previously it would take him 2 months to obtain readings from the 106 ICCP test stations and 26 rectifiers that supply the cathodic protection current for necessary corrosion protection of those utilities. Now he can accomplish the same task in 2 days, with automated data saved in a format that allows him to establish trends for early signs that there may be a problem with the system that needs immediate attention.

Army Installation 3. At a third Army Installation, a similar drive-by remote monitoring system was implemented for a new state-of-the art ICCP system on natural gas piping, which included the use of a self-monitoring, self regulating constant output DC power supply energizing ceramic tubular shaped energy emitters (commonly referred to as cathodic protection anodes) buried deep into the earth (deep anode beds). In addition, the drive-by remote monitoring units were implemented for an ICCP system installed in a new 2 million gallon elevated water storage tank, which is this Installation's only source of potable water.

The battery operated remote monitoring system uses $10-15$ year life replaceable batteries. Installation maintenance personnel drive through the Installation once a month with a standard PC portable computer connected to a small radio transmitter/receiver with a magnetic antenna temporarily mounted on a pickup truck roof (See Figure 5). A GPS unit monitors both the vehicle location and shows all 106 monitoring points distributed around the base on map displayed on the PC screen. Six of these monitor locations measure the output of the six DC power supplies used to energize the ICCP systems, while the other 100 units monitor the corrosion control effectiveness at key locations throughout our buried gas piping system throughout the installation. It is anticipated that it will take as little as $2 \mathrm{hr}$. to accomplish the entire ICCP survey, compared to the 5-10 days that it would take for a trained technician's time to do the same work. As an additional benefit, the data is then automatically transferred in to an Excel spreadsheet where it is automatically analyzed on a "pass/fail" basis. 

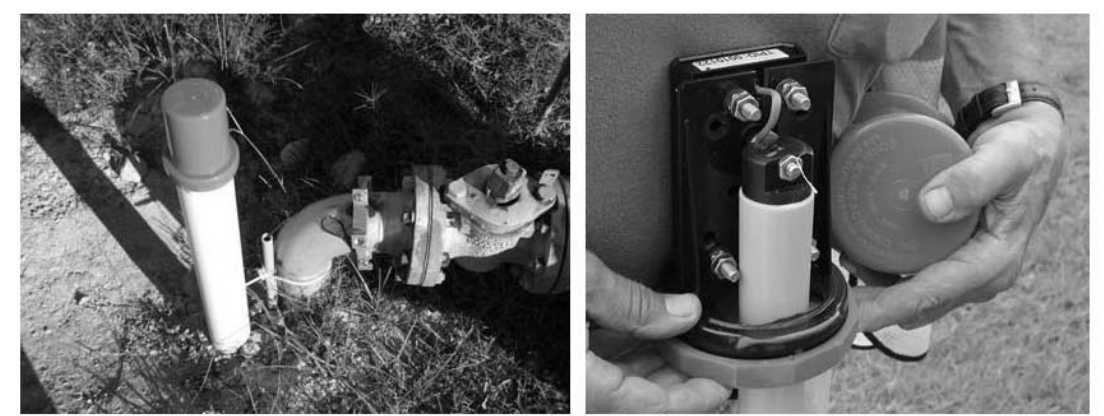

FIGURE 4- Left: Typical Pipe Protection Remote Monitoring Units Installed to Interrogate the Pipeline and Transmit Sy stem Corrosion Control Effectiveness Data.

Right: Remote Monitor Unit with Cap Removed Showing Terminal Connection Points

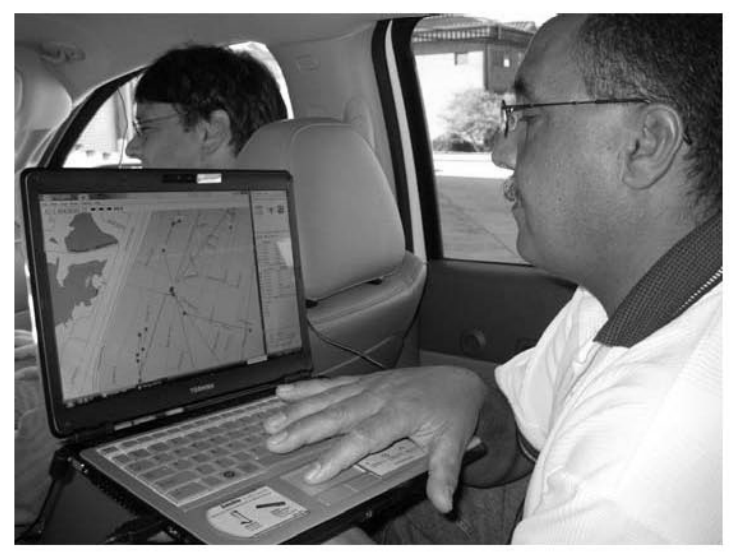

FIGURE 5- Army Installation personnel can use laptop $P C$ to automatically interrogate and record CP protection levels while being driven by each monitoring station

At both of these installations, for the rectifier sites where no existing SCADA exists (e.g. at rectifier units protecting piping, well casings, etc.), the SCADA would have to be installed first which had an estimated cost of $\$ 10,000$ per location. This makes the system uneconomic at this Army Installation. As the CP systems only require monitoring once a month at Army Installations \#2 and 3, it has been confirmed that personnel can obtain data for the same number of points at a cost of less than $\$ 12,000$ annually.

Given that these Army Installation have more than 100 monitoring points where no existing SCADA is located (and where none is anticipated to be required for other measurement purposes), the "drive by" system is currently the only economically justifiable system available for automating the data acquisition and recording process 
In some cases, direct burying of CP Test Station and monitor unit with 15 year nominal battery life at select locations is possible to prevent damage by normal grounds maintenance work particularly including lawn mowing work. These locations would be "marked" by easily locatable "magnetic" sensors. Implementation of "Drive by" Test Stations that can automatically acquire and transmit both "On" and "Instant-Off" potentials without interrupting impressed current CP system rectifier(s). A further development may allow the measuring of polarization decay where the $-850 \mathrm{mV}$ potential criteria is not being satisfied (this is under current development but may or may not be ready during the time of this project implementation, and would not require any new hardware (only software download into CP system test station units).

\section{COMPARISON OF WIRELESS CORROSION MONITORING TECHNOLOGIES}

Hardwired RMUs for CP systems require running miles of wiring between the central control system to each monitoring station, and are not practical for military installations. In cases where the SCADA system is not a viable option, cell phone based RMU systems are best used when it is not practical or cost effective to use drive by systems, or when the data must be taken more often than once a month. For example, a remote location many miles way from the central monitoring station would constitute a hardship for maintenance personnel to drive by the location to acquire data. Of course, in order to use the cell phones, it must be established that the cell phone signals for these systems are highly reliable in those locations.

Satellite based systems provide another alternative. They can usually provide CP data readings anywhere and at anytime through the internet. Their initial cost is only about $\$ 500-\$ 700$ per location, but the data cost per reading per location is generally $\$ 5-\$ 10$. For a large number of locations to be monitored, this fee could become rather expensive. Also, the satellite based systems are limited to line of site. If a small number of remote locations are to be monitored, the satellite-based monitoring systems may be suitable, however, if a very large number of locations need monitoring, the satellite monitoring system may not be cost effective. A comparison of the attributes of each system is presented in Table 5.

TABLE 5. COMPARISON OF REMOTE MONITORING TECHNOLOGIES

\begin{tabular}{|c|c|c|c|c|}
\hline & $\begin{array}{l}\text { SCADA-Based } \\
\text { System }\end{array}$ & Drive-by System & $\begin{array}{l}\text { Cell phone-Based } \\
\text { System }\end{array}$ & $\begin{array}{l}\text { Satellite Based } \\
\text { System }\end{array}$ \\
\hline Initial Cost & $\begin{array}{l}\$ 10,000 \text { per } \\
\text { monitoring station }\end{array}$ & $\begin{array}{l}\$ 2,000 \text { per } \\
\text { monitoring } \\
\text { station }\end{array}$ & $\begin{array}{l}\$ 2,000 \text { per } \\
\text { monitoring station }\end{array}$ & $\begin{array}{l}\$ 500-700 \text { per } \\
\text { station }\end{array}$ \\
\hline $\begin{array}{l}\text { Maintenance } \\
\text { Requirements }\end{array}$ & Moderate & Low & Low & Very low \\
\hline Complexity & High & Low & Low & High \\
\hline Advantages & $\begin{array}{l}\text {-Takes advantage of } \\
\text { existing wireless } \\
\text { system } \\
\text {-can take readings at } \\
\text { any time } \\
\text {-can control }\end{array}$ & $\begin{array}{l}\text {-Low installation } \\
\text { cost } \\
\text { - can easily be } \\
\text { installed } \\
\text { - broadcast } \\
\text { frequencies are }\end{array}$ & $\begin{array}{l}\text {-Low installation } \\
\text { cost } \\
\text { - can easily be } \\
\text { installed } \\
\text { - can take readings } \\
\text { at any time }\end{array}$ & $\begin{array}{l}\text {-Monitor CP } \\
\text { system virtually } \\
\text { anytime, any } \\
\text { where in the } \\
\text { world through the } \\
\text { internet }\end{array}$ \\
\hline
\end{tabular}




\begin{tabular}{|c|c|c|c|c|}
\hline & $\begin{array}{l}\text { remotely from a } \\
\text { central location at } \\
\text { any time } \\
\text {-can interface with } \\
\text { GIS system }\end{array}$ & pre-approved & $\begin{array}{l}\text { - broadcast } \\
\text { frequencies are } \\
\text { pre-approved } \\
\text { - can control } \\
\text { remotely any } \\
\text { location at any } \\
\text { time }\end{array}$ & \\
\hline Disadvantages & $\begin{array}{l}\text { High cost } \\
\text {-Signal path must be } \\
\text { properly planned for } \\
\text { adequate } \\
\text { transmission Signals } \\
\text { must be line of site } \\
\text { (LOS) } \\
\text {-Signals are } \\
\text { sometimes lost if } \\
\text { there are } \\
\text { impediments to LOS } \\
\text { - FCC approval is } \\
\text { needed for new } \\
\text { SCADA frequencies }\end{array}$ & $\begin{array}{l}\text {-Can not monitor } \\
\text { from central } \\
\text { location; must } \\
\text { drive by within } \\
0.1 \text { mile of } \\
\text { monitoring } \\
\text { station }\end{array}$ & $\begin{array}{l}\text {-Cost of cell } \\
\text { phone services } \\
\text {-Cell phone } \\
\text { signals are } \\
\text { sometimes lost in } \\
\text { certain locations }\end{array}$ & $\begin{array}{l}\text {-Charges } \\
\text { fee/reading/locati } \\
\text { on } \\
\text {-Line of site } \\
\text { limitations }\end{array}$ \\
\hline Recommendation & $\begin{array}{l}\text {-Use where existing } \\
\text { SCADA system is } \\
\text { available, such as } \\
\text { water tanks } \\
\text {-Do not install } \\
\text { additional SCADA } \\
\text { systems }\end{array}$ & $\begin{array}{l}\text {-Use where there } \\
\text { are no existing } \\
\text { SCADA systems } \\
\text {-Use when drive } \\
\text { by systems are } \\
\text { viable }\end{array}$ & $\begin{array}{l}\text { Use where there } \\
\text { are no existing } \\
\text { SCADA systems } \\
\text {-Use where drive } \\
\text { by systems would } \\
\text { not be viable- } \\
\text { very remote areas }\end{array}$ & $\begin{array}{l}\text { Use where there } \\
\text { are no existing } \\
\text { SCADA systems } \\
\text {-Use where drive } \\
\text { by systems would } \\
\text { not be viable- } \\
\text { very remote areas }\end{array}$ \\
\hline
\end{tabular}

\section{CONCLUSIONS}

The benefits of implementation of the RMUs along with upgrade of CP systems are the cost avoidance of traveling to remote sites to check each rectifier and test station, and the added capability of instant notification of a malfunction in the cathodic protection system. If SCADA systems are already available where the RMUs are to be installed, then the CP monitoring systems should be interfaced to the SCADA system. If the SCADA system is not readily available, either cell phone-based systems, satellite downlinked data systems, or drive-by systems should be implemented. The choice of whether to use cell phones based systems or drive-by systems depends on the reliability of the cell phone signals at those particular locations. By implementing remote monitoring for cathodic protection and ceramic anode-based impressed current cathodic protection systems, the life of the tank, water distribution, or gas system is expected to be extended by 30 years, while reducing the work load of Installation maintenance personnel.

Based on the results of these projects, recommendations are being provided for revisions to Unified Facilities Guide Specifications (UFGS) 13111A "Cathodic Protection System (Steel Water Tanks)" and 
UFGS 13112A "Cathodic Protection System (Impressed Current)." These revisions include the specifications and instructions for installing the advanced impressed current cathodic protection systems in conjunction with the "drive-by" remote monitoring units for cathodic protection systems.

\section{REFERENCES}

1. Vicki L Van Blaricum, William R. Norris, Michael J. Szeliga, James B Bushman, Demonstration of Remote Monitoring Technology for Cathodic Protection Systems, ERDC/CERL Report Number $97 / 76$ (1997).

2. Vicki L Van Blaricum, Jack T. Flood, Michael J. Szeliga, and James B. Bushman, Demonstration of Remote Monitoring Technology for Cathodic Protection Systems: Phase II, ERDC/CERL Report Number 98/82 (1998).

3. Vicki L Van Blaricum and William R. Norris, Remote Monitoring Equipment for Cathodic Protection Systems, ERDC/CERL Report Number 97/75 (1997).

4. Vicki L Van Blaricum. User Guide for Remote Monitoring Equipment for Cathodic Protection Systems: Phase II, ERDC/CERL Report Number 98/77 (1998).

5. "Harnessing SCADA Without Undermining Security," Journal of the American Water Works Association (AWWA), July 2004.

6. A. Kumar, L. D. Stephenson, and J. Bushman, "Remote Monitoring of Cathodic Protection and Cathodic Protection Upgrades for Tanks and Pipelines," ERDC/CERL TR-07-25, U. S. Army Corps of Engineers, Engineer Research and Development Center, Construction Engineering Research Laboratory, Champaign, IL (2007). 


\title{
Appendix B: Rectifier Operating Manuals
}

Deep anode bed application

\author{
C.P. SENTINEL AUTOMATIC TYPE \\ CATHODIC PROTECTION RECTIFIER
}

\author{
INSTALLATION, OPERATION, \& \\ MAINTENANCE MANUAL
}

\author{
SINGLE PHASE INPUT \\ MODEL: \\ CC - CURRENT CONTROL \\ CV - VOLTAGE CONTROL
}

INTEGRATEd RECTIFIER TECHNOLOGIES, INC.

15360 - 116 Avenue, Edmonton, Alberta, Canada T5M $3 Z 6$

Phone: (780) 447-1114

Fax: (780) 454-0004

Website: www.irtrectifier.com_Email: sales@irtrectifier.com 
C.P. SENTINEL AUTOMATIC CURRENT-VOLTAGE CATHODIC PROTECTION RECTIFIER MANUAL INTEGRATED RECTIFIER TECHNOLOGIES, INC.

Copyright ( ) IRT Integrated Rectifier Technologies Inc. All rights reserved. Unauthorized copying and distribution prohibited by law. The contents of this Manual are subject to change without notice

Doc \#: V-ICOO10 Rev, 2.0, April, 2005 Page 2 of 19 
C.P. SENTINEL AUTOMATIC CURRENT-VOLTAGE CATHODIC PROTECTION RECTIFIER MANUAL INTEGRATED RECTIFIER TECHNOLOGIES, INC.

INDEX

$\begin{array}{lc} & \text { PAGE } \\ \text { INTRODUCTION } & 3 \\ \text { DELIVERY INSPECTION } & 4 \\ \text { PRE-INSTALLATION STORAGE } & 4 \\ \text { SAFETY PRACTICES } & 5 \\ \text { GENERAL INSTALLATION RECOMMENDATIONS } & 6 \\ \text { RECTIFIER CONNECTIONS AT SITE } & 7 \\ \text { RECTIFIER OPERATION MODES } & 7 \\ \text { THE VI-SENTRY CONTROLLER } & 8 \\ \text { THE SILICON CONTROLLED RECTIFIER (SCR) } & 10 \\ \text { GENERAL COMPONENT DESCRIPTION } & 11 \\ \text { INITIAL ENERGIZATION } & 13 \\ \text { REGULAR MAINTENANCE AND ADJUSTMENT } & 15 \\ \text { TROUBLESHOOTING } & 17\end{array}$

APPENDIX:

INCLUDES ELECTRICAL SCHEMATIC, RECTIFIER DATA SHEET, AND ANY OTHER OPTIONAL INFORMATION 
C.P. SENTINEL AUTOMATIC CURRENT-VOLTAGE CATHODIC PROTECTION RECTIFIER MANUAL INTEGRATED RECTIFIER TECHNOLOGIES, INC.

\section{INTRODUCTION}

Corrosion of underground structures (pipelines, well casings, etc.) is a process that occurs every minute of every day. As such, continuous protection is required to effectively prevent damage that could cost a company significantly in lost revenues, manpower, and equipment. The proper selection, installation, and operation of a suitable corrosion prevention system can be crucial to ensure that this costly damage does not occur. For well-coated struclures, structures with small surface areas, or where minimal Cathodic Protection is required, a "sacrificial" type corrosion prevention system may be used. For poorly coated structures, structures with large surface areas, or where a larger amount of Cathodic Protection is required, an "impressed current" type corrosion prevention system is required. One key component of an impressed current corrosion protection system is a Cathodic Protection rectifier. A rectifier is a device that is used to convert "alternating current" ( $A C$ ), as provided by the power utility, to "direct current" (DC), as is required for Cathodic Protection. The rectifier should be selected based on the type of control required for the specific application, the amount of Cathodic Protection required to provide effective protection and the reliability of operation in the subject environment. IRT Integrated Rectlfier Technologies, Inc. manufactures Cathodic Protection rectifiers that exceed industry standards for superior corrosion prevention and, as such, an IRT rectifier unit is a smart investment for any company.

IRT Integrated Rectifier Technologies, Inc. Cathodic Protection rectifiers and associated products are designed by a knowledgeable engineering team with years of experience in the corrosion field and manufactured by skilled technicians with a dedication to quality. The IRT units are designed with superior components to provide a high quality, reliable rectifier with an economic cost for your application. IRT maintains a large volume of in-stock components and sub-assemblies to ensure that orders can be shipped to you in the shortest time frame possible.

IRT products are sold and serviced by leading corrosion prevention engineering companies throughout North America and Internationally. These companies have superior expertise in the corrosion industry and have the personnel to meet all of your corrosion prevention systern requirements including design, installation, and maintenance. IRT products are also available through leading material supply companies throughout North America.

Rectifiers manufactured by IRT Integrated Rectfier Technologles, Inc. are guaranteed against defects in design, workmanship, or material for a period of one year from the time of shipment from our facility. Please refer to our warranty statement for further details. 
C.P. SENTINEL AUTOMATIC CURRENT.VOLTAGE CATHOOIC PROTECTION RECTIFIER MANUAL. INTEGRATED RECTIFIER TECHNOLOGIES, INC.

\section{DELIVERY INSPECTION}

Although the rectifier unit may not be scheduled for immediate installation, we recommend that it be thoroughly inspected, both externally and internally, upon receipt to ensure that no damage has occurred during shipment. Please remember that although the outside of the rectifier packaging may not show any signs of damage, there may be internal damage that will not be apparent until the outer packaging is removed. Any damage, whether internal or external, must be reported to the freight carrier immediately. If any damage has occurred during shipment: an indication of this should made on the freight paperwork, the shipment should then be accepted, and a claim filed with the freight carrier. Please ensure to retain the original packaging that may indicate how the damage occurred.

If damage has occurred during shipment and repairs or a return to the factory is required, please contact us, or your local IRT distributor, with the Serial Number and the Model Number of the rectifier. This information is crucial for us to determine the rectifier unit in question and to be able to provide suitable assistance. A Return Materials Authorization (RMA) number must be obtained from the factory prior to return of any damaged rectifier units.

\section{PRE-INSTALLATION STORAGE}

If the rectifier unit is to be stored prior to installation, it is recommended that it be stored in a dry area, preferably indoors. If the unit is to be stored outdoors for an extended period of time, it is recommended that it be placed on a raised surface (pallet or platform) and covered with a protective sheet or tarp to ensure the packaging does not deteriorate due to rain or snow. Whether stored indoors or outdoors, the unit should be placed in an area where it is protected from accidental damage from moving vehicles or equipment. Ensure that the rectifier unit is transferred to and from the storage facility using proper handling techniques. 
C.P. SENTINEL AUTOMATIC CURRENT.VOLTAGE CATHODIC PROTECTION RECTIFIER MANUAL INTEGRATED RECTIFIER TECHNOLOGIES, INC.

\section{SAFETY PRACTICES}

This symbol denotes a possible shock or electrical hazard.

\section{DO NOT INSTALL, REMOVE, or REWIRE THIS EQUIPMENT WITH POWER APPLIED!!}

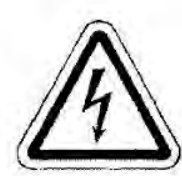

As Cathodic Protection rectifiers are connected to the AC utility power, electrical shock hazards are present within the rectifier units. It is recommended that only qualified electronic or electrical personnel operate and maintain these units and that those personnel familiarize themselves with the areas of possible hazard within the unit. Following these practices can enhance the safety of personnel.

1.) Prior to site maintenance or inspection, familiarize yourself with the rectifier and conditions at the site.

2.) Prior to doing any maintenance or troubleshooting on a rectifier unit, familiarize yourself with any possible hazard points within the unit by reviewing the electrical schematic and the physical layout of the rectifier.

3.) Whenever possible, set the AC disconnect from the power utility to the "OFF" position prior to starting any work on the rectifier unit. Even with the rectifier $A C$ input circuit breaker in the "OFF" position, hazardous voltages are still present at any terminals connected to the rectifier AC input terminals. Always tag and lock out the disconnect to ensure others do not energize it while you are completing the rectifier work.

4.) Prior to opening the rectifier enclosure door, lightly touch the back of your hand to the enclosure latch. If you feel an electrical tingle, set the fused $A C$ disconnect to the "OFF" position and contact an electrician for assistance.

5.) When taking readings across the rectifier terminals, it is recommended to use only one hand, if possible. 
C.P. SENTINEL AUTOMATIC CURRENT-VOLTAGE CATHOOIC PROTECTION RECTIFIER MANUAL INTEGRATED RECTIFIER TECHNOLOGIES, INC.

\section{GENERAL INSTALLATION RECOMMENDATIONS}

To ensure reliable, long-term operation of the Cathodic Protection rectifier, proper installation of the unit is required. Though most installation sites differ, there are several key guidelines that should be followed.

a) Prior to installation, check the connections (especially the electrical connections) on the rectifier unit to ensure that nothing has become loose during shipment. It is also recommended that if any scratches occur to the enclosure during installation. that these points be touched-up to prevent corrosion on the enclosure.

b) Selecting the site of installation is a very important factor. The rectifier should be installed in a location that is easily accessible by company personnel for regular adjustment, monitoring, and maintenance. However, it should not be located in areas where unauthorized personnel have easy access to the unit and may damage or vandalize it (i.e. residential areas, playgrounds, farm yards, etc.). The convenient access to $A C$ power and the cathodic protection DC connections must also be considered when choosing the rectifier location.

c) Proper ventilation and cooling of the rectifier unit is essential and must be considered when choosing a suitable location. Air-cooled rectifiers are cooled by the natural convection of cool air drawn into the bottom of the rectifier enclosure, passing over the internal components, and the resultant warm air expelled from the top or sides of the enclosure. Oil-cooled rectifiers are cooled by the natural circulation of oil from the bottom to the top of the rectifier tank, over the internal components, and the resultant heat is radiated from the upper walls of the rectifier tank. As such, when choosing the installation site for the rectifier, adequate spacing should be allowed for around the sides of the rectifier unit. The rectifier should not be located near sources of heat such as exhaust vents, power generators, etc. If possible, place the rectifier unit in an area where it will be shaded during the hottest part of the day. If the rectifier is to be installed in an area with a high ambient temperature and minimal natural shading, a protective sunshade is recommended.

d) The rectifier unit should be mounted on a secure surface. Ensure that the wall, pole, frame, or mounting pad is designed to hold the full weight of the rectifier unit.

e) If the rectifier is to be installed in an area subject to frequent lightning activity, upgraded, high-energy type surge arrestors are recommended. If possible, do not locate the rectifier on a hill top where there increased chances of lightning strikes. Use of a low resistance ground rod(s) is recommended. Locate the ground rods adjacent to, but away from the rectifier, the ground bed, and incoming CP cables. Remember, most damaging voltage surges are the result of induced pickup rather than a direct strike.

f) Do not install other equipment on or inside the rectifier enclosure without prior consent from the factory. Unauthorized equipment installation will invalidate the rectifier Warranty, as IRT has no control of the equipment added or the resultant detrimental affect to proper rectifier cooling / operation. 


C.P. SENTINEL AUTOMATIC CURRENT-VOLTAGE CATHODIC PROTECTION RECTIFIER MANUAL
INTEGRATED RECTIFIER TECHNOLOGIES, INC.
RECTIFIER CONNECTIONS AT SITE
DO NOT INSTALL, REMOVE, Or REWIRE
THIS EQUIPMENT WITH POWER APPLIED!!

After the rectifier has been installed in a suitable location, have a qualified electrician connect the rectifier unit to the $A C$ supply following local and national codes. Please note that most electrical codes require a disconnect device between the $A C$ power supply and the rectifier. Ensure that for dual AC input rectifiers ( $115 / 230$ or $230 / 460 \mathrm{VAC})$, that the $A C$ input terminal jumpers are properly configured for the actual $A C$ input voltage being supplied and that the $A C$ input wires are connected to the correct AC input terminals.

The grounding rod(s) should be connected to the ground lug terminal adjacent to the $A C$ input terminals within the rectifier.

Next, connect the cable(s) from the anode bed to the RECTIFIER POSITIVE output lug terminal(s) and the structure cable(s) to the RECTIFIER NEGATIVE output lug terminal(s). Ensure that these cables are suitably sized for the expected current and the length of the cable run. Also, it is absolutely imperative that the polarity of DC connections is correct. A reversal of the DC cables can actually cause accelerated corrosion and eventually, severe damage to the structure to be protected.

\section{RECTIFIER OPERATION MODES}

C.P. SENTINEL AUTOMATIC CURRENTNOLTAGE Rectifiers are capable of the following modes of operation.

CONSTANT VOLTAGE MODE: In this mode the rectifier control circuitry automatically adjusts the rectifier output to maintain the VOLTAGE at the preset level. In this mode, the Current Set potentiometer determines the current limit. When operating in this mode and maintaining the VOLTAGE set point, the RED LED is illuminated.

\section{CONSTANT CURRENT MODE:}

In this mode the Rectifier control circuitry automatically adjusts the rectifier output to maintain the CURRENT at the preset level. In this mode, the Voltage Set potentiometer determines the voltage limit. When operating in this mode and maintaining the CURRENT set point, the GREEN LED is iltuminated.

MANUAL MODE: (OPTIONAL)

Rectifiers equipped with this option are supplied with a conventional manual tap-adjusted transformer in addition to the automatic control circuitry. This mode permits the operator to control the rectifier output by gating 'on' the Silicon Controlled Rectifiers to conduct as conventional diodes. Manual rectifier output control is achieved by switching the AutomaticManual Switch to the Manual mode position and then adjusting the transformer secondary taps. 


C.P. SENTINEL AUTOMATIC CURRENT-VOLTAGE CATHODIC PROTECTION RECTIFIER MANUAL
INTEGRATED RECTIFIER TECHNOLOGIES, INC.
RECTIFIER CONNECTIONS AT SITE
DO NOT INSTALL, REMOVE, Or REWIRE
THIS EQUIPMENT WITH POWER APPLIED!!

After the rectifier has been installed in a suitable location, have a qualified electrician connect the rectifier unit to the $A C$ supply following local and national codes. Please note that most electrical codes require a disconnect device between the $A C$ power supply and the rectifier. Ensure that for dual AC input rectifiers ( $115 / 230$ or $230 / 460 \mathrm{VAC})$, that the $A C$ input terminal jumpers are properly configured for the actual $A C$ input voltage being supplied and that the $A C$ input wires are connected to the correct AC input terminals.

The grounding rod(s) should be connected to the ground lug terminal adjacent to the $A C$ input terminals within the rectifier.

Next, connect the cable(s) from the anode bed to the RECTIFIER POSITIVE output lug terminal(s) and the structure cable(s) to the RECTIFIER NEGATIVE output lug terminal(s). Ensure that these cables are suitably sized for the expected current and the length of the cable run. Also, it is absolutely imperative that the polarity of DC connections is correct. A reversal of the DC cables can actually cause accelerated corrosion and eventually, severe damage to the structure to be protected.

\section{RECTIFIER OPERATION MODES}

C.P. SENTINEL AUTOMATIC CURRENTNOLTAGE Rectifiers are capable of the following modes of operation.

CONSTANT VOLTAGE MODE: In this mode the rectifier control circuitry automatically adjusts the rectifier output to maintain the VOLTAGE at the preset level. In this mode, the Current Set potentiometer determines the current limit. When operating in this mode and maintaining the VOLTAGE set point, the RED LED is illuminated.

\section{CONSTANT CURRENT MODE:}

In this mode the Rectifier control circuitry automatically adjusts the rectifier output to maintain the CURRENT at the preset level. In this mode, the Voltage Set potentiometer determines the voltage limit. When operating in this mode and maintaining the CURRENT set point, the GREEN LED is iltuminated.

MANUAL MODE: (OPTIONAL)

Rectifiers equipped with this option are supplied with a conventional manual tap-adjusted transformer in addition to the automatic control circuitry. This mode permits the operator to control the rectifier output by gating 'on' the Silicon Controlled Rectifiers to conduct as conventional diodes. Manual rectifier output control is achieved by switching the AutomaticManual Switch to the Manual mode position and then adjusting the transformer secondary taps. 
C.P. SENTINEL AUTOMATIC CURRENT-VOLTAGE CATHODIC PROTECTION RECTIFIER MANUAL INTEGRATED RECTIFIER TECHNOLOGIES, INC.

\section{THE VI-SENTRY CONTROLLER}

C.P. SENTINEL AUTOMATIC CURRENT/VOLTAGE Rectifiers are controlled by the IRT VISENTRY Controller. Refer to the following layout of the VI-SENTRY Controller for location of controls and jumpers:

\section{NOTE:}

This section will describe the Controls, Jumpers, Test Points and Adjustments of interest for field setup and operation, as performed by QUALIFIED TECHNICAL PERSONNEL. All Remaining Factory Settings \& Calibrations SHOULD NOT be attempted or tampered with.

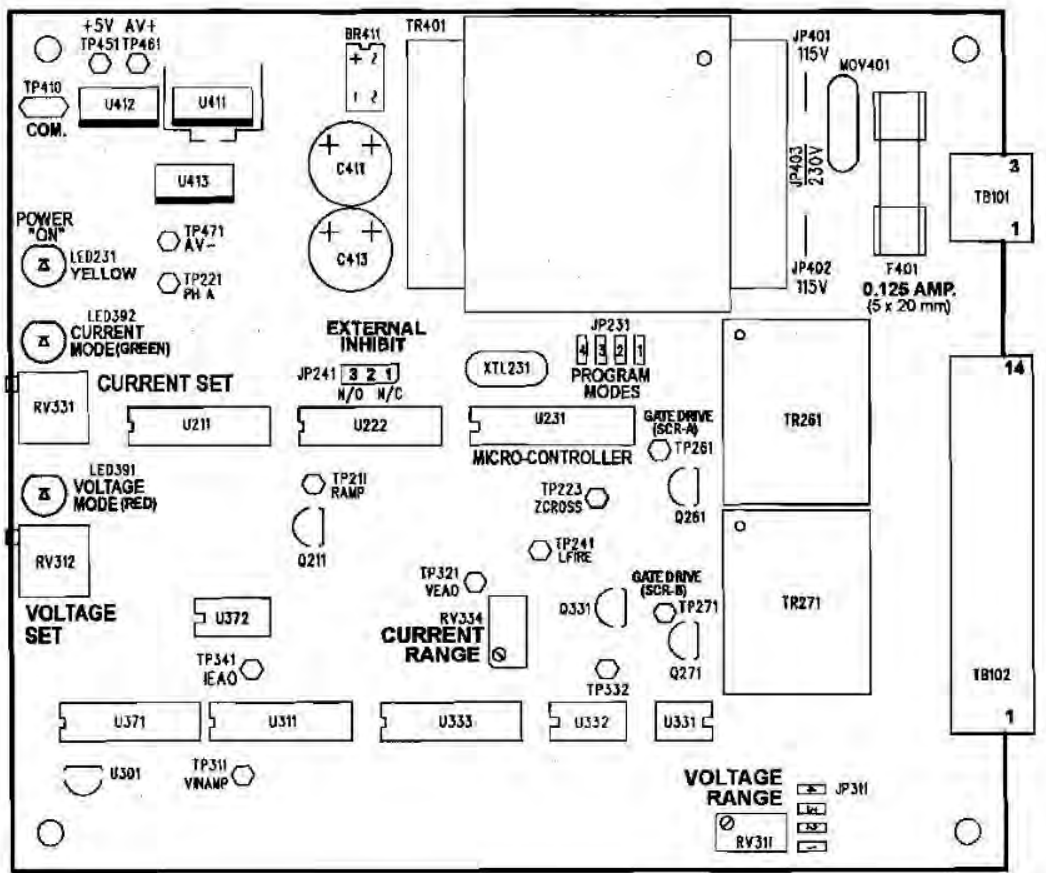

FIGURE 1.0 VI-SENTRY CONTROLLER

Doc \#: V-1C0010 Rev. 2.0. April, 2005 Page 8 of 19 
C.P. SENTINEL AUTOMATIC CURRENT-VOLTAGE CATHODIC PROTECTION RECTIFIER MANUAL INTEGRATED RECTIFIER TECHNOLOGIES, INC

CONTROLS:

Voltage and Current settings are adjusted via two potentiometers available on the VI-SENTRY Controller. These potentiometers are 20-Tum trim-pots located at the end of the controller board opposite the wiring connectors. (Refer to Figure 1.0, Page 8).

VOLTAGE: Rectifier output voltage (or Voltage Limit) is set by potentiometer "RV312". Rectifier operation in Voltage Mode or Voltage Limit will be indicated by the Red LED "LED391", adjacent the Voltage Set Potentiometer.

CURRENT: Rectifier output current (or Current Limit) is set by potentiometer "RV331" Rectifier operation in Current Mode or Current Limit will be indicated by the Green LED "LED392", adjacent the Current Set Potentiometer.

\section{NOTE}

Depending upon the model and/or configuration of the rectifier ordered, one or more of these potentiometers may be mounted external of the controller board on the rectifier instrument panel. Consult your Rectifier Specification Sheet.

\section{CAUTION!I}

Do NOT attempt to alter the settings of any other trim pots on the controller board. These are factory calibrations and tampering with these settings could jeopardize proper operation and scaling of the VI-SENTRY Controller.

\section{JUMPER SETTINGS:}

The VI-SENTRY Controller is designed to adapt and accommodate a wide variety of field installations and control situations. To make this accommodation easier, please review the following Jumper functions and settings:

A. INPUT VOLTAGE SELECTION (JP401,JP402, \& JP403)

\begin{tabular}{|c|c|c|c|c|}
\hline $\begin{array}{c}\text { INPUT } \\
\text { VOLTAGE }\end{array}$ & JP401 & JP402 & JP403 & COMMENT \\
\hline 115 VAC & INSTALLED & INSTALLED & OMITTED & DEFAULT POSITION \\
\hline $230 V A C$ & OMITTED & OMITTED & INSTALLED & OPTIONAL POSITION \\
\hline
\end{tabular}

B. SCR GATE DRIVE PROGRAM MODES (JP231)

\begin{tabular}{|c|c|c|}
\hline "JP231" SETTING & FUNCTION & COMMENT \\
\hline JP231 -1 & Increases number of gate pulses to 10 & INSTALLED \\
\hline JP231 - 2 & NOT USED & OMITTED \\
\hline JP231 - 3 & Doubles SCR Gating "ON" \& "OFF" times & INSTALLED \\
\hline JP231 -4 & Doubles SCR Gating "OFF" time & OPTIONAL \\
\hline
\end{tabular}


C.P. SENTINEL AUTOMATIC CURRENT-VOLTAGE CATHODIC PROTECTION RECTIFIER MANUAL INTEGRATED RECTIFIER TECHNOLOGIES, INC.

C: EXTERNAL INTERRUPT (JP241)

\begin{tabular}{|c|l|}
\hline "JP241" SETTING & \multicolumn{1}{|c|}{ FUNCTION } \\
\hline JP241 PINS 1 - 2 & Normally Closed contacts = Rectifier output current \\
\hline JP241 PINS 2 - 3 & Normally Open contacts = Rectifier output current (Default Setting) \\
\hline
\end{tabular}

D: VOLTAGE RANGE SETTINGS: "JPR311"

Header "JPR411" is factory set to determine the available output range of voltage control.

\section{OTHER CONTROLLER PARTS \& FUNCTIONS}

FUSE: "F401" is located on the circuit board near the control transformer. This a 0.125 ampere, slow-blow type of $5 \mathrm{~mm} \times 20 \mathrm{~mm}$ metric style fuse. Replace with same fuse type.

POWER ON LED: Controller "POWER ON" operation is indicated by "LED231", Yellow

WIRING CONNECTORS: "TB101" \& "TB102". These are 3-pin \& 14-pin plug on connectors, respectively. Ensure all wiring connections are secure by tightening the screw terminals on these connectors.

\section{THE SILICON CONTROLLED RECTIFIER (SCR)}

Automatically controlled rectifiers utilize phase control of the supplied 50 or $60 \mathrm{Hertz}$ AC voliage using a solid-state device called a Silicon Controlled Rectifier (SCR). This device is similar to a conventional diode, but is equipped with an extra terminal for control called the GATE. Although akin to a diode, this device has unique properties of being able to block conduction of current when the device is forward biased until an appropriate signal is applied to the Gate terminal. Once the appropriate gate signal is applied, the SCR remains in conduction while forward biased, or until the current trough the device goes to almost zero.

The control of the rectifier DC output is accomplished by "gating on" the SCR at the point in the AC waveform necessary to produce the desired output. This output can be the regulated DC Voltage, the DC Current, the Structure to Reference Electrode Potential or a combination of the three modes of control. A minimum of two SCR's are required to achieve full control over the AC waveform. The two SCR's are configured with two diodes into a full-wave bridge configuration.

Often SCR's and diodes are combined into full-wave controlled rectification modules. Typically the modules used are comprised of two SCR's and two diodes with the cathodes of the 2 SCR's connected to the module Positive $(+)$ terminal. SCR-Diode modules are then mounted to a suitably sized heatsink for cooling.
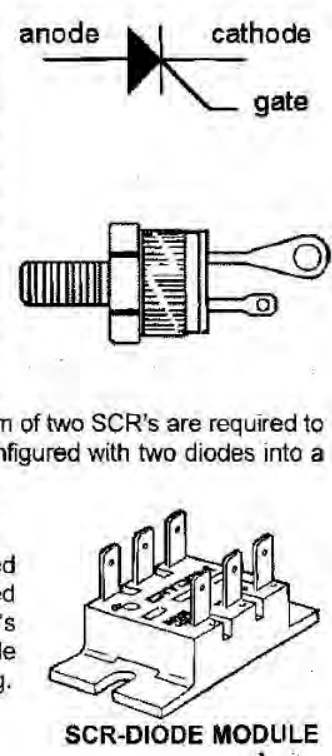

Doc \#: V-1C0010 Rev. 2.0, April, 2005 Page 10 of 19 


\section{C.P. SENTINEL AUTOMATIC CURRENT.VOLTAGE CATHODIC PROTECTION RECTIFIER MANUAL INTEGRATED RECTIFIER TECHNOLOGIES, INC. GENERAL COMPONENT DESCRIPTION}

When operating any equipment, it is a good practice to become familiar with the key components and the general operation of that piece of equipment. The following is a summary of the key components of a rectifier and their function:

The AC Input Surge Arrestor is a device that protects the rectifier components from voltage surges that may occur across the $A C$ inpul of the rectifier. It does this by providing a bypass circuit for the resultant current from these high voltage surges after a specific voltage threshoid has been reached. Most surge arrestors are designed to handle a certain number or energy value of surges prior to failing.

The rectifier AC Input Circuit Breaker (CB1) is a fully magnetic type that serves three key functions. It is used as an "OFF-ON" switch for the rectifier, it provides "short circuit" protection, and, to a lesser degree, provides input overload protection.

The rectifier Main Transformer ( $T 1$ ) provides full electrical isolation between the utility AC power and the Cathodic Protection DC circuit. It also steps the vollage up or down as required for the DC circuit and, for tap type units, provides a means of output adjustment.

The rectifier AC Secondary Fuse is a time lag or slow-blow type that provides protection from not only short-circuits or overloads in the DC output circuit but also in the diode bridge circuit.

The rectifier SCR-Diode Bridge Assembly is comprised of silicon controlled diodes (SCR's) and diodes configured into a full-wave bridge configuration. The SCR-diodes are supplied with suitably sized heatsinks to ensure that the SCR-diodes do not exceed $100^{\circ} \mathrm{C}$ at full rated output. The SCR-diode bridge controls and rectifies the AC secondary voltage of the transformer into DC voltage that can be used for Cathodic Protection. This DC voltage level is then automatically maintained by the VI-SENTRY Controller in Current or Voltage Mode, as set by the operator.

A Varistor is supplied across the AC input to the diode bridge to provide additional protection from any voltage surges that may pass the main $A C$ surge arrestor or be developed by the main transformer. A second varistor may also be supplied across the DC output of the diode bridge at special request.

The Current Monitoring Shunt is a block style calibrated resistor with an accuracy of $0.25 \%$. The DC current and voltage rating are stamped into the body of the shunt.

The rectifier Ammeter \& Voltmeter utilize an analog, taut-band type movement that provides $\pm 2 \%$ accuracy. The DC output amperage of the rectifier is monitored by a meter connection across the calibrated test screws of the above shunt. The DC output voitage of the rectifier is monitored by a meter connection across the DC output terminals of the rectifier.

External Interrupt Terminal Block: Two terminals are provided on the front panel of the rectifier for purposes of interrupting the rectifier output using the VI-SENTRY Controller. Jumper "JP241" on the controller board as required for Normally Open equals rectifier "ON" or Normally Closed contacts equals "rectifier "ON" as dictated by the interrupter being used. This is the preferred method to interrupt the rectifier by an external means. Special circuitry in the VI-SENTRY Controller retains all of the operating parameters for resumption of control parameters after conclusion of an interrupl procedure and will not reset the slow start circuitry.

Doc \#: V-IC0010 Rev. 2.0, April. 2005 Page 11 of 19 
C.P. SENTINEL AUTOMATIC CURRENT-VOLTAGE CATHODIC PROTECTION RECTIFIER MANUAL INTEGRATED RECTIFIER TECHNOLOGIES, INC.

The DC Output Surge Arrestor is a device that protects the rectifier components from voltage surges that may occur across the DC output of the rectifier. It's operation and characteristics are similar to the $A C$ input surge arrestor.

As many optional features / components are available for our customers, it is not practical for this manual to describe all of the possible options in detail. As such, it is recommended that the rectifier data sheet and the electrical schematic be reviewed in detail to become familiar with any features not detailed in this manual. 
C.P. SENTINEL AUTOMATIC CURRENT-VOLTAGE CATHODIC PROTECTION RECTIFIER MANUAL INTEGRATED RECTIFIER TECHNOLOGIES, INC.

\section{INITIAL ENERGIZATION}

After the rectifier has been properly connected to the $A C$ supply and the $D C$ output cables, the rectifier is ready to be energized. Before energizing, always double-check both the $A C$ and $D C$ connections to ensure they are properly connected. Ensure that for dual input rectifiers (115/ 230 or $230 / 460 \mathrm{VAC}$ ), the $A C$ input terminal jumpers are properly configured for the actual $A C$ input voltage being supplied and that the AC input wires are connected to the proper terminals. For Current Controlled rectifiers, ensure that the rectifier is at its lowest control setting, by adjusting the "Current Adjust" potentiometer to zero. Use a multi-meter to verify static Reference Electrode - Structure potentials (If installed) and record for later reference.

Place the $A C$ fused disconnect switch to the "ON" position and measure across the rectifier $A C$ input terminals to ensure the voltage present is as expected Next, place the rectifier AC input circuit breaker also to the "ON" position. The "POWER ON" Yellow LED on the VI-SENTRY Controller will illuminate. The VI-SENTRY Controller is designed with a "slow start" circuitry to minimize in-rush currents and to prevent the rectifier from starting at full output. This slow start time period will last from $3-10$ seconds. There will be some deflection on the panel meters, although this defiection may be quite minimal on the Ammeter and Voltmeter. For units with a metering switches, ensure to set this switches to the "ON" position.

For Constant Current operation, simply adjust the "Current Adjust" potentiometer to the required current. The GREEN LED will be illuminated; provided the VI-SENTRY Controller is not in Voltage Limiting mode (with RED LED illuminated). This current will be read on the rectifier Ammeter. The rectifier ammeter can be verified by measuring the voltage (in Millivolts) across the calibrated test screws of the rectifier shunt (not across the connection bolts). To determine the current through the shunt from the millivolt reading taken, the following formula can be used:

\section{Current ( ()$=$ Measured Shunt Voltage (Millivolts) $\times$ Rated Shunt Current} Rated Shunt Voltage (50 Millivolts typical)

Note: Rated shunt current and voltage values are stamped onto the body of the shunt and are also shown on the rectifier data page

The ammeter can also be verified with an external DC clamp-on type meter, if available.

For Constant Voltage operation, simply adjust the "Voltage Adjust" potentiometer to the required output voltage. The RED LED will be illuminated; provided the VI-SENTRY Controller is not in Current Limiting mode (with GREEN LED illuminated). This voitage will be read on the rectifier Voltmeter. The rectifier voltmeter can be verified by measuring the voltage at the rectifier output lugs.

It is recommended that all initial energization readings be recorded for future reference. Useful readings to record are structure potential levels prior to energization, AC input voltage \& current, DC output voltage and current, tap or adjustment dial setting, structure potential levels after energization, as well as any observed problems or possible future concerns with the installation, in general. 
C.P. SENTINEL AUTOMATIC CURRENT.VOLTAGE CATHODIC PROTECTION RECTIFIER MANUAL INTEGRATED RECTIFIER TECHNOLOGIES, INC.

Rectifiers equipped with MANUAL MODE Option: Adjustment of rectifiers equipped with this option requires the "Automatic-Manual" selector switch be switched to the "Manual" position. Start the rectifier with the Coarse \& Fine taps set to their lowest level (Coarse "A" - Fine " 1 "). Observe and record if necessary the rectifier output currents and voltage levels, and the polarization level of the Structure being protected. Incrementally, increase the transformer tap settings until either target current or polarization levels are altained. The VI-SENTRY Controller is NOT required for manual mode, and may be removed for repair if it is not functioning correctly.

After the structure polential readings have been taken and prior to leaving the site, it is recommended that the DC output connections to the rectifier be rechecked to ensure a secure connection. It is also beneficial to recheck the rectifier to ensure that all air iniet and outlet venting on the enclosure is not obstructed in any manner. The rectifier O\&M manual should be securely set in it's holder (for small rectifiers without a manual holder, it is recommended that the manual be kept with the main operator or in the control room of the closest station). Also verify that all holes within the enclosure (other than the venting screens) are suitably plugged (such as unused conduit knockouts). For rectifier units with "OFF-ON" meter switches, ensure that the switch is in the "OFF" position prior to leaving the site. 
C.P. SENTINEL AUTOMATIC CURRENT-VOLTAGE CATHODIC PROTECTION RECTIFIER MANUAL INTEGRATED RECTIFIER TECHNOLDGIES, INC.

\section{REGULAR MAINTENANCE \& ADJUSTMENT}

The basis for any effective CP system is routine documentation \& maintenance. Despite the rectifier maintaining the DC output "automatically", it is recommended that the rectifier be checked and adjusted if necessary at least twice per year. Some local regulatory bodies require a monthily or semi-monthly check to ensure proper protection levels are being maintained. These checks also allow you to ensure that the rectifier has not been damaged. When completing this maintenance and adjustment check, it is recommended that all readings and observations be recorded in the site file. With regular maintenance checks and by maintaining good records, future troubleshooting and repair costs can be reduced.

Prior to arriving at the site for the rectifier maintenance check. it is recommended that the technician review the existing rectifier site file to gain familiarization with the subject rectifier and site conditions. Upon arriving at the rectifier site, a visual check should be completed to determine if any changes have occurred. Things to look for are signs of new underground construction, buildings, pipeline tie-ins, bonds, etc. Prior to adjustment of the rectifier, it is recommended that structure potential readings be taken, to determine the adjustment level required. Even if the potential levels are within the required range, the rectifier should still be checked for proper operation.

When approaching the rectifier, ensure that no items have been placed near the rectifier enclosure in such a manner as to block the venting, either on the bottom or sides. As the vent openings on the rectifier enclosure are screened, there should be no refuse inside from birds or larger insects. However, after opening the door of the enclosure, ensure that there has been no significant accumulation of dirt, snow, or other small debris at the bottom of the enclosure, which may adversely affect proper venting.

\section{DO NOT INSTALL, REMOVE, or REWIRE THIS EQUIPMENT WITH POWER APPLIED!!}

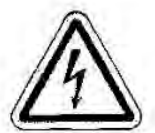

Prior to any adjustment of the rectifier, measure and record the "As Found" readings of the rectifier (DC voltage, DC amperage, etc.). Next, set the rectifier circuit breaker and the utility disconnect to the "OFF" position to allow for a detailed rectifier inspection.

At least once a year the rectifier should be inspected for loose electrical connections that could eventually cause damage to the electrical panel, wiring, or rectifier components. If an electrica: connection becomes loose, the resistance of the connection increases and causes it to heat up. This additional heat will cause the connection to oxidize and become even higher resistant until a failure occurs. The best way to check for a heated connection is with a temperature probe however, as these are not typically standard issue for Cathodic field maintenance, the visual inspection method will suffice. First, visually inspect all of the main electrical connections within the rectifier for signs of discoloration on the connection terminal, the electrical panel, or the wire attached to the terminal. Key points to check are the DC output lug terminal connections and the fuse holder connections. If you see a suspect connection, use a wrench or other suitable tools to see if the connection is indeed loose. (Note; Be careful when louching these types of connections with your hand as the temperature of loose high current connections can cause a significant burn.) If you do find a loose connection, it should be secured with suitable tools (make sure to secure both the front and rear of the double-nutted panel connections). If a loose connection has already caused damage to the electrical panel, the panel should be repaired or replaced, as re-tightening a connection on a degraded panel will most likely still lead to a future failure. 
C.P. SENTINEL AUTOMATIC CURRENT-VOLTAGE CATHODIC PROTECTION RECTIFIER MANUAL INTEGRATED RECTIFIER TECHNOLOGIES, INC.

Certain main components within the rectifier should also be inspected for signs of over-heating or other damage.

The main isolation transformer (T1) within the rectifier is designed to operate at a fairly high temperature and thus is usually somewhat discoloured. However, it should not be extremely dark or black. If it is, this could indicate insufficient / blocked venting or a problem within the transformer itself.

The AC primary, AC secondary, and the DC output surge arrestors should be checked to ensure that a significant voltage surge has not damaged them. Signs of damage to an arrestor device are usually visually noticeable by a blackened or cracked housing. Please note however that sometimes the operational status of an arrestor is not discernable visually and requires further checking (see Troubleshooting section).

The rectifier fusing should also be checked for overheating. If the fusing is a bolt-on type (for larger rectifier units), ensure that the fastening studs or bolts are secure on both the front and rear. Many smaller rectifier units utilize the "clip-type" fuse connectors that are very convenient for fuse replacement but are also infamous for becoming loose and oxidizing over time However, with regular checks and maintenance, problems can be avoided. For this type of connection, if oxidation is apparent, the fuse should be removed and both the fuse and the fuse contact surface of the clips cleaned up with some very fine sand paper or emery cloth (only the oxidation layer should be removed, not the protective coating on the copper). If the fuse clips have lost tension, they should be replaced. If replacements are not immediately available, the clips can be "squeezed" together and should then provide a suitable short-term connection to the fuse. A notation should be made however, in the site inspection form for replacement on the next maintenance check. The connection hardware on each fuse clip should also be checked and re-tightened if necessary.

If, after completing the inspection on the rectifier unit, a problem is found other than just a loose connection, refer to the "Troubleshooting" section of this manual. If no problems have been found, the rectifier can be adjusted to a new DC output setting (if deemed required based on the "as-found" structure potential levels). As per the adjustment procedure indicated in the "Initial Energization" section, adjust the DC output of the rectifier to the level required to provide suitable protection to the structure. If the rectifier is adjusted to or near it's maximum rated output, future replacement of the rectifier with a larger unit or the addition of anodes may need to be considered. If the required "target" DC output current from the rectifier varies significantly over the year due to load resistance changes, maintenance checks should be done frequently. 
C.P. SENTINEL AUTOMATIC CURRENT-VOLTAGE CATHODIC PROTECTION RECTIFIER MANUAL INTEGRATED RECTIFIER TECHNOLOGIES, INC.

\section{TROUBLESHOOTING}

If a problem is found with the rectifier during the maintenance inspection or reported by the local operator, the following troubleshooting procedure can be followed to determine the cause.

The only way to effectively determine the cause of a failure in any piece of equipment is to conduct a systematic analysis of the function and operation of the key components. For this troubieshooting procedure, we shall review the possible faults that may occur starting from the $D C$ output and working back to the $A C$ input.

\section{CAUTION!!}

Please be advised that hazardous voltages are present within the rectifier unit even with the rectifier $A C$ input circuit breaker in the "OFF" position. Extreme care should be observed when taking measurements on the front of the instrument panel or the side $A C$ input panel. Only qualified electronic or electrical technicians should attempt internal troubleshooting of the rectifier. The fused AC disconnect should be set to the "OFF" position prior to any internal rectifier maintenance or repair.

Please refer to the Rectifier Specifications Sheet, Electrical Schematic supplied with each rectifier and to the VI-SENTRY Controller layout on Page 8 of this manual for component descriptions and test points. Common rectifier fallures can be summarized and corrected as follows:

\section{A. NO RECTIFIER OUTPUT CURRENT: This fault may be caused by any one or more of the} following conditions:

- No AC Present: Check incoming utility supply for the presence of voltage and that it is correct for the rating of the rectifier. Consult your electrician or electrical utility to correct this problem.

- Rectifier AC Breaker Tripped: First: Do a visual inspection as described in the Maintenance \& Adjustment section of this manual. Secondly, attempt to reset the breaker and observe rectifier output. If the rectifier fails to function correctly, continue with this troubleshooting procedure.

- Blown Fuse: Check all rectifier fuses, including the control fuse located on the VI-SENTRY Controller circuit board. Replace as required with the identical type, size and rating as supplied. One spare for each fuse used in the unit is supplied with each rectifier.

- Check Interrupt Circuit: It is possible for field attached external interrupter to hold the output "Off". Refer to Page 10, Section "C" and Page 11 "External Interrupt Terminal Block" and correct any possible interrupter setting errors.

- Improper Settings: Review the settings on the VI-SENTRY Controller for Voltage, Current. Any one of these potentiometers set to "zero" will result in no rectifier output. Review "Controls" section of this manual on Page 9, and correct any setting errors.

- VI-SENTRY Controller Failure: Check for the board status LED's. "Power ON" LED is illuminated continually when the board is powered and the on-board microprocessor is functioning. One of the Mode LED's will function if any one of the rectifier output modes is being controlled. Due to board complexity, replace defective controller with a known working controller.

Doc \#: V-IC0010 Rev. 2.0, April, 2005 Page 17 of 19 
C.P. SENTINEL AUTOMATIC CURRENT-VOLTAGE CATHODIC PROTECTION RECTIFIER MANUAL INTEGRATED RECTIFIER TECHNOLOGIES, INC.

- Faulty Connections: Otten broken or high resistance connections will lead to no rectifier output or intermittent output. Disconnect power, check and re-tighten all connections. Be especially aware of any oxidized, burnt or discoloured connections. Repair or replace as required.

- DC voltage at output lugs, but no current: The principle reason for this failure is a broken $\mathrm{CP}$ system cables beyond the rectifier. Investigate and repair broken cables.

- DC voltage at output lugs, current flowing to load, but no current reading on ammeter: This could be the result of a defective ammeter, faulty leads, or failure of a metering switch. Repair or replace defective components.

B. LIMITED RECTIFIER OUTPUT CURRENT: This fault may be caused by any one or more of the following conditions:

- Improper Mode settings on the VI-SENTRY controller resulting in insufficient current to the CP system. Re-check seltings and limits for current \& voltage.

- Load resistivity too high for rating of the rectifier. This will usually be indicated by a "Voltage Limit" condition; where the Red LED is illuminated. Check anodes and ground bed resistance. Modify if necessary, or replace rectifier with a higher rated unit.

- Low supply voltage: Check incoming AC voltage to rectifier while rectifier is under load. Consult electrical maintenance personnel for adjustment if line voltage is low.

- Failure of SCR-Diode module: could result in "half-wave" output, which will yield only half of the rated output. Replace defective module with replacement.

- Failure of the VI-SENTRY Controller board. Remove defective board \& replace with known working control board.

\section{NOTE:}

The CURRENT MODE LED (Green) or the VOLTAGE MODE LED (Red) will only be illuminated if the current or voltage set points are maintained. If a set point cannot be maintained by the VI-SENTRY Controller due to a setting beyond the range of the rectifier or due to lack of $\mathrm{AC}$ input, or due to half-wave conduction from the Diode-SCR bridge: NO LED WILL ILLUMINATE!!

\section{RECTIFIER FUSE BLOWS: Fuse failure may be due to the following:}

- Fuses may blow due to either excessive current. In an automatic rectifier, this type of failure is mainly due to failure in the SCR-Diode module. Replace failed module and fuse, and re-energize rectifier.

- Fuses may blow due to excessive operating temperature. Excessive temperature on the fuse is typically caused by either corrosion or weakening of the gripping tension on the fuse clips or fuse holder. Replace defective fuse components when this occurs. 
C.P. SENTINEL AUTOMATIC CURRENT.VOLTAGE CATHODIC PROTECTION RECTIFIER MANUAL INTEGRATED RECTIFIER TECHNOLOGIES, INC

D. RECTIFIER AC BREAKER TRIPS: AC Breaker tripping may be resolved as follows:

- Visually inspect the rectifier AC input surge arrestor for damage (usually located adjacent to the $A C$ input terminals). If the housing of the arrestor is cracked or blackened, the arrestor has failed and should be replaced. Always replace the arrestor with one of the same type. If an immediate replacement cannot be obtained, the rectifier can operate without this arrestor for a limited period, however, please remember that the rectifier then has no protection against surges. In certain circumstances, the arrestor may also fail without any external signs of damage. As such, to ensure that the AC arrestor is not the problem and with the AC power "OFF", disconnect the wires of the arrestor from the circuit breaker terminals. If the rectifier circuit breaker now remains in the "ON" position when energized, the arrestor has failed and should be replaced.

- If the breaker stitl trips to the "OFF" position, disconnect the wires between output (bottom) terminals of the rectifier circuit breaker (CB1) and the AC primary of the main transformer (T1). If the rectifier circuit breaker now remains in the "ON" position when energized, the problem is further downstream in the rectifier.

- Reconnect the wires in the step above. Remove the wires from the transformer secondary to the SCR-Diode module. Note: This may be accomplished by opencircuiting the rectifier secondary fuse; if so equipped. If the breaker still trips to the "OFF" position, the main transformer has most likely failed and should be replaced (consult the factory for a replacement).

- Another possibility is that the AC configuration terminals of the main transformer (T1) (for dual input types only) are incorrectly set for the actual AC input voltage applied to the rectifier. Please confirm that these terminals are configured properly (refer to the electrical schematic) for the AC voltage being applied.

- The final possibility is most likely that the rectifier AC input circuit breaker itsel[ has failed and will require replacement.

\section{E. RECTIFIER OUTPUT IS INTERMITTENT: Possible causes for erratic are:}

- Broken or loose connections. Check all rectifier connections for loose or broken connections. Include the wiring connections to the VI-SENTRY Controller.

- Check if built-in or field attached interrupters are in operation.

\section{TROUBLESHOOTING SUMMARY:}

As rectifier problems in automatic units can be more easily solved by having a good working knowledge of the application and the workings of the rectifier, review this manual to ensure recommended installation practices have been followed. If a problem cannot be solved, please contact your rectifier dealer or the factory for technical assistance. 
Integrated Rectifier Technologies, inc.

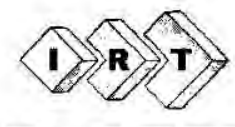

15360 - 116 Avenue, Edmonton, Alberta, Canada T5M 326

\section{RECTIFIER DATA SHEET}

MODEL No. : CCASFS 60-34 MaQa

CUSTOMER : LORESCO INC.

AC VOLTS : $\mathbf{1 1 5 / 2 3 0}$ INPUT V.A. : $\mathbf{3 , 8 0 0}$
SERIAL No. : 07R-0408 DATE : MAY 04, 2007

M.S.O. No. : 002717-3-2 P.O. \#: JT033007

DCVOLTS : 60 TYPE : AUTO-CURRENT

DC AMPS : 34 CCTS. : SINGLE

\begin{tabular}{|c|c|c|c|}
\hline QTY. & ITEM NUMBER & COMPONENT & COMPONENT DESCRIPTION \\
\hline 1 & $090-\bar{A}-0200$ & ENCLOSURE & A-2, 12 GAUGE MILL-GALV. STEEL, WHITE \\
\hline $1 / 1$ & $092-A-0200 / 0205$ & FRAME (LEFT \& RIGHT) & $\overline{A-2}, 12$ GAUGE MILL-GALV. STEEL, WHITE \\
\hline 2 & $092-A-0210$ & TX. MOUNTING BRACKET & A-2, 12 GAUGE MILL-GALV. STEEL, WHITE \\
\hline 1 & O95-M-A200 & INSTRUMENT PANEL & NEMA "XX", $1 / 4^{\prime \prime} \times 13.25^{41} \times 16.25^{\prime \prime}$ \\
\hline 1 & A-2 ADVANTAGE & AC INPUT CONN STRIP, "TS1" & $1 / 4^{\prime \prime}$ TERMINALS WITH BARRIER \\
\hline 1 & $031-\mathrm{B}-035 \mathrm{~A} / 600 \mathrm{~V}$ & AC CIRCUIT BREAKER, "CB1-A" & 350 AMPERE, 600 VAC, 1-POLE \\
\hline 1 & $031-\mathrm{B}-020 \mathrm{~A} / 600 \mathrm{~V}$ & ÁC CIRCUIT BREAKER, "CB1-B" & 20.0 AMPERE, 600 VAC, 1-POLE \\
\hline 1 & $008-\bar{A}-1124$ & AC SURGE ARRESTOR, "AA1" & $115 / 230$ VAC, 1-PHASE, 3-WIRE \\
\hline 1 & $008-P-279-1$ & AC ARRESTOR BRACKET & 16 GAUGE ALUMINUM, BARE \\
\hline 1 & T.060034-F16S04A & MAIN TRANSFORMER, "T1" & $115 / 230$ VAC, $60 \mathrm{~Hz}, 1$-PH, SCR-CONTROL, 4-SEC. TAPS \\
\hline 4 & $088-\mathrm{S}-00300$ & TRANSFORMER STRAP & EI-300, ZINC DICHROMATE PLATED \\
\hline 1 & $078-C-01000$ & AC SECONDARY TAP BAR & COPPER, NICKEL PLATED, $1 / 8^{\prime \prime} \times 0.75^{\prime \prime} \times 2.5^{\prime \prime}$ \\
\hline 2 & $054-\mathrm{K}-0014 \mathrm{P}$ & KNOB, TAP BAR ADJUST & PLASTIC BLACK C/W BRASS INSERT $1 / 4-20 \mathrm{NC}$ \\
\hline 2 & $037-R-0040$ & TX SECONDARY FUSE,"F1" & 40 AMPERE, 250 VOLT. TIME LAG \\
\hline 2 & $038-\mathrm{C}-0020$ & AC SECONDARY FUSE CLIP & COPPER, NICKEL PLATED, $13 / 16^{\prime \prime}$ DIA. $\times 2.00^{\prime \prime}$ \\
\hline 1 & $002-\mathrm{TB}-175 / 1200 \mathrm{~V}$ & SCR/DIODE MODULE, "BR1" & 70 AMPERE, $1200 \mathrm{~V}, \mathrm{c} / \mathrm{W}$ FREE-WHEELING DIODE \\
\hline 1 & $066-P-0486$ & HEATSINK, UNDRILLED & CLEAR CHROMATE \\
\hline 1 & $007-G-0 S 20 K 130$ & BRIDGE AC VARISTOR, "MOV1" & 130 VAC (RMS), 74 JOULES, $22.5 \mathrm{~mm}, 2$-WIRE \\
\hline 1 & $061-F-0100$ & VI-SENTRY CONTROLLER, REV 1.0 & CURRENT-VOLTAGE CONTROLLER, 115 VAC \\
\hline- & & VI-SENTRY MICRO FIRMWARE & FIRMWARE VERSION $16 \mathrm{C} 622$ AS- 0400 \\
\hline 1 & $062-P-0300$ & CONNECTOR, "TB101" & 3-PIN $3.5 \mathrm{~mm}$ SPACING \\
\hline 1 & $062-P-1400$ & CONNECTOR, "TB102" & 14-PIN, $3.5 \mathrm{~mm}$ SPACING \\
\hline 1 & $026-A-1010$ & POTENTIOMETER, "P1" & PANEL MOUNTED, SINGLE-TURN, $10 \mathrm{~K}$. \\
\hline 1 & $\longdiv { 0 4 7 - K - 0 1 0 0 0 }$ & POTENTIOMETER KNOB & $0.78^{\prime \prime}$ DIA., BLACK \\
\hline 2 & $055-\mathrm{S}-5000$ & INTERRUPT TERMINALS, "TS2" & 5-WAY BINDING POST, BLACK \\
\hline 1 & $041-C-0010 / 042-C-0075$ & VOLTMETER / SCALE, "V" & $3.5^{\circ}, 0.75$ VOLTS F.S.D 160 VOLT RED LINE \\
\hline 1 & $041-\mathrm{C}-0010 / 042-\mathrm{C}-0040$ & AMMETER / SCALE, "A" & 3.50 , 0-40 AMPERES F.S.D. /34 AMPERE RED LINE \\
\hline 1 & $043-B-S W 50040$ & BLOCK SHUNT, "SHT", & 40 AMPERE - 50mV. TYPE "SW" \\
\hline 1 & $008-0-1002$ & DC SURGE ARRESTOR, "DA1" & 100 Vpeak, 2-TERMINAL \\
\hline 2 & $051-C-0030$ & DC OUTPUT LUG TERMINALS & $\# 1 / 0-6$ AWG, 1-HOLE, COPPER, NICKEL PLATED \\
\hline 1 & $041-T-06000$ & ELAPSED HOUR COUNTER & 120VAC, $99,999.9$ HR. LCD-DISPLAY, (2-1/2' ROUND) \\
\hline & & & \\
\hline & & & \\
\hline & & & \\
\hline & & & \\
\hline 1 & $\frac{V 1-C 0010}{2010}$ & O\&M MANUAL & $8.5^{\prime \prime} \times 11^{n}$, INSIDE PROTECTIVE PACKET \\
\hline 1 & CCF1-H1B121-M̄aQa(C) & ELECTRICAL SCHEMATIC & $11^{\prime \prime} \times 17^{n}$, FOR INCLUSION WITH O\&M MANUAL \\
\hline
\end{tabular}

AC PRIMARY: \#10 TEW AC SECONDARY: \#8 EXANE DC OUTPUT: \#8TEW 


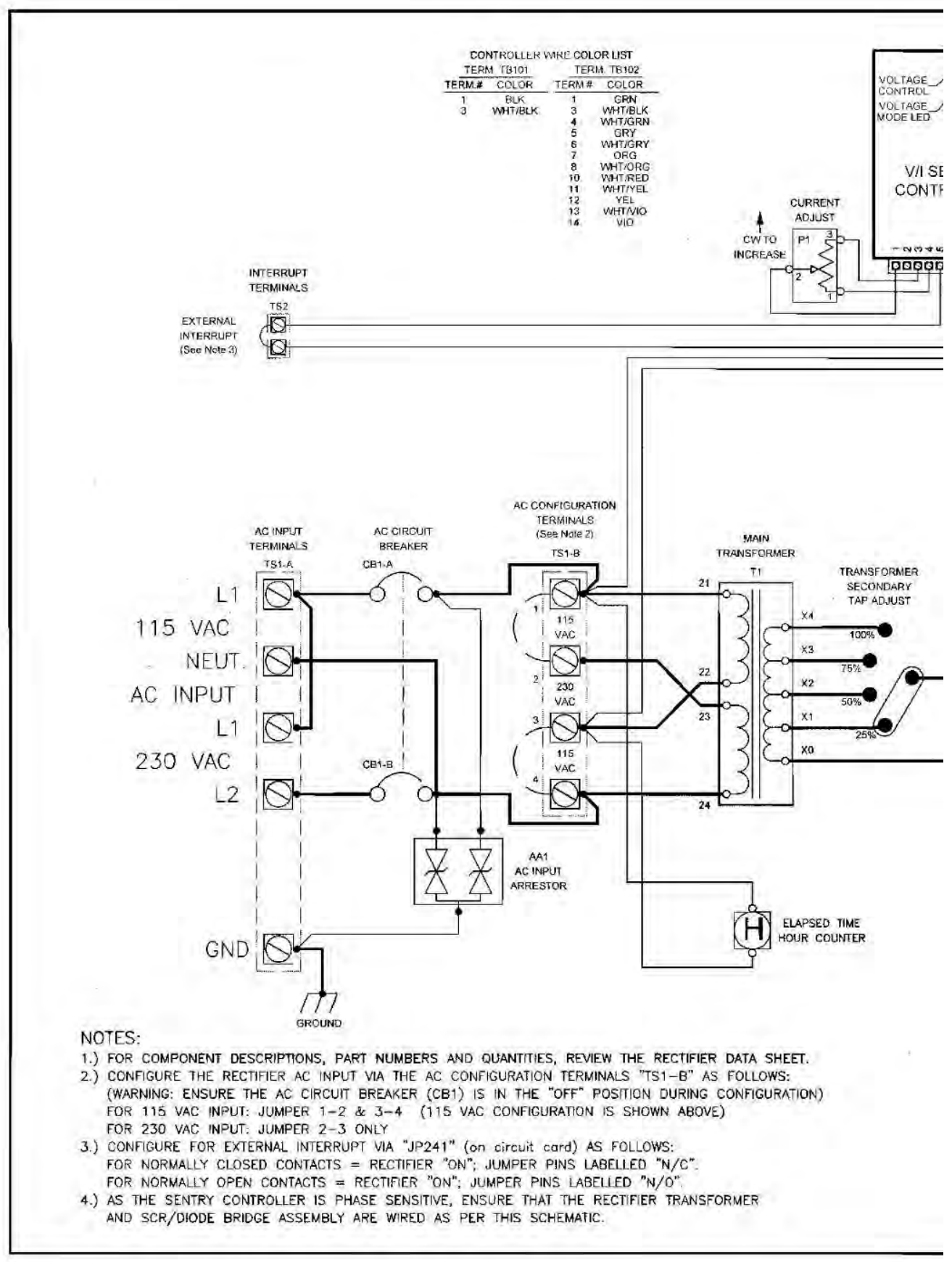




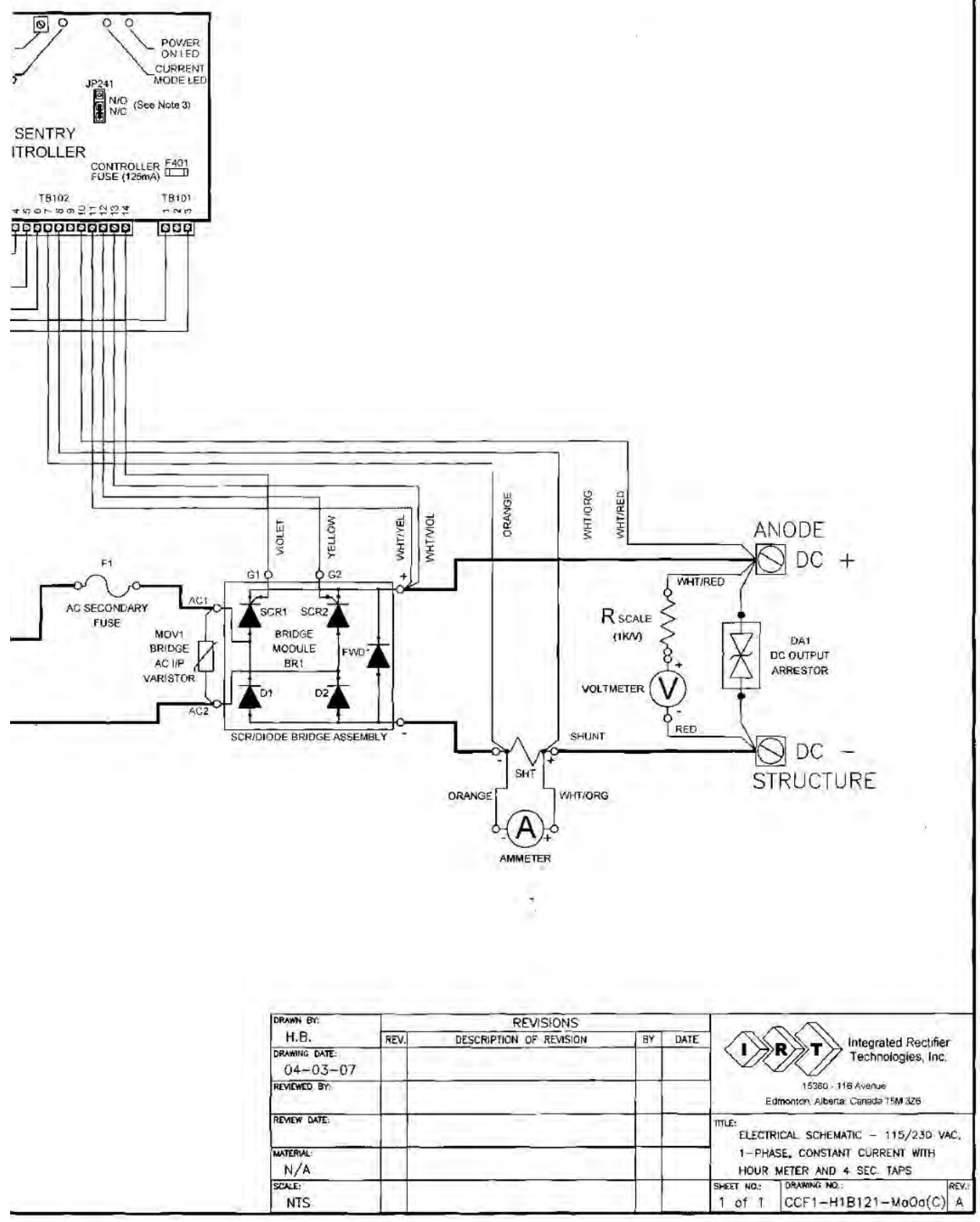


Elevated tank application

\title{
C.P. SENTINEL AUTOMATIC TYPE CATHODIC PROTECTION RECTIFIER
}

\section{INSTALLATION, OPERATION, \& MAINTENANCE MANUAL \\ REV. 3.0 NOVEMBER.2004}

\author{
SINGLE PHASE INPUT \\ MODEL: \\ CP - "ON" POTENTIAL CONTROL \\ $\mathrm{CI}$ - "IR FREE" POTENTIAL CONTROL.
}

INTEGRATEd RECTIFIER TECHNOLOGIES, INC.

$15360-116$ Avenue, Edmonton, Alberta, Canada T5M 326 Phone: (780) 447-1114

Fax: (780) 454-0004

Website: www.irtrectifier com_Email:sales@irtrectifier.com 
C,P. SENTINEL AUTOMATIC TYPE CATHODIC PROTECTION RECTIFIER MANUAL INTEGRATED RECTIFIER TECHNOLOGIES, INC,

INDEX

$\begin{array}{ll}\text { INTRODUCTION } & 3 \\ \text { DELIVERY INSPECTION } & 4 \\ \text { PRE-INSTALLATION STORAGE } & 4 \\ \text { SAFETY PRACTICES } & 5 \\ \text { GENERAL INSTALLATION RECOMMENDATIONS } & 6 \\ \text { RECTIFIER CONNECTIONS AT SITE } & 7 \\ \text { RECTIFIER OPERATION MODES } & 8 \\ \text { THE SENTRY CONTROLLER } & 9 \\ \text { THE SILICON CONTROLLED RECTIFIER (SCR) } & 12 \\ \text { POTENTIAL CONTROL AND EXTERNAL IR DROP } & 13 \\ \text { GENERAL COMPONENT DESCRIPTION } & 14 \\ \text { INITIAL ENERGIZATION } & 16 \\ \text { REGLILAR MAINTENANCE AND ADJUSTMENT } & 18 \\ \text { TROUBLESHOOTING } & 20 \\ \text { APPENIIX: } & \\ \text { INCLUDES ELECTRICAL SCHEMATIC, RECTIFIER DATA SHEET, AND ANY } \\ \text { OTHER OPTIONAL INFORMATION }\end{array}$


C.P. SENTINEL AUTOMATIC TYPE CATHODIC PROTECTION RECTIFIER MANUAL INTEGRATED RECTIFIER TECHNOLOGIES, INC.

Copyrigin $\Theta$ IRT Integrated Rectifier Technologies inc: All rights reserved. Unauthorized copying and distribution prohibited by faw. the contents of this Manual are subject to atiange without notice

DOC \# APCO010 Rev 3,0. November 2004 Page 2 of 2 ? 
C.P. SENTINEL AUTOMATIC TYPE CATHODIC PROTECTION RECTIFIER MANUAL INTEGRATED RECTIFIER TECHNOLOGIES, INC.

\section{INTRODUCTION}

Corrasion of underground structures (pipelines, well casings, etc.) is a process that occurs every minute of every day. As such, continuous protection is required to effectively prevent damage that could cost a company significantly in lost revenues. manpower, and equipment. The proper selection installation and operation of a suitable corrosion prevention system can be crucial to ensure that this costly damage does not occur. For well-coated structures, structures with small surface areas, or where minimal Cathodic Protection is required, a "sacrificial" type corrosion prevention system may be used. For poorly coated structures, structures with large surface areas or where a larger amount of Cathodic Protection is required, an "impressed current" type corrosion prevention system is required. One key component of an impressed current corrosion pratection system is a Cathodic Protection reclifier. A rectifier is a device that is used to convert "alternating current" (AC), as provided by the power utility, to "direct current" (DC). as is required for Cathodic Protection. The rectifier should be selected based on the type of control required for the specific application, the amount of Cathodic Protection required to provide effective protection, and the reliability of operation in the subject environment. IRT Integrated Rectifier Technologies, Inc. manufactures Cathodic Protection rectifiers that exceed industry standards for superior corrosion prevention and, as such, an IRT rectifier unit is a smart investment for any company.

IRT Integrated Rectifier Technologies, Inc Cathodic Protection rectifiers and associated products are designed by a knowledgeable engineering team with years of experience in the corrosion field and manufactured by skilled technicians with a dedication to quality. The IRT units are designed with superior components to provide a high quality, reliable rectifier with an economic cost for your application. IRT maintains a large volume of in-stock components and sub-assemblies to ensure that orders can be shipped to you in the shortest time frame possible

IRT products are sold and serviced by leading corrosion prevention engineering companies throughout North America and Internationally. These companies have superior expertise in the corrosion industry and have the personnet to meet all of your corrosion prevention system requirements including design, installation. and maintenance. IRT products are also available through leading material supply companies throughout Noth America

Rectifiers manufactured by IRT Integrated Rectifier Technologies, Inc. are guaranteed against defects in design, workmanship, or material for a period of one year from the time of shipment from our facility. Rlease refer to our warranty statement for further details.

Doc \# APC0010 


\section{C.P. SENTINEL AUTOMATIC TYPE CATHODIC PROTECTION RECTIFIER MANUAL INTEGRATED RECTIFIER TECHNOLOGIES, INC. \\ DELIVERY INSPECTION}

Although the rectifier unit may not be scheduled for immediate installation. we recommend that it be thoroughly inspected, both externally and internally, upon recejpt to ensure that no damage has occurred during shipment Please remember that although the outside of the rectifier packaging may not show any signs of damage, there may be internal damage that will not be apparent until the outer packaging is removed. Any damage, whether internal or external, must be reported to the freight carrier immediately. If any damage has occurred during shipment; an indication of this should made on the freight paperwork the shipment should then be accepted. and a claim filed with the freight carrier. Please ensure to retain the original packaging that may indicate how the damage occurred

If damage has occurred during shipment and repairs or a return to the factory is required please contact us, or your local IRT distributor, with the Serial Number and the Model Number of the rectifier. This information is crucial for us to determine the rectifier unit in question and to be able to provide suitable assistance. A Return Materials Authorization (RMA) number mus be obtained from the factory prior to return of any damaged rectifier units.

\section{PRE-INSTALLATION STORAGE}

If the rectifier unit is to be stored prior to installation, it is recommended that it be stored in a dry area, preferably indoors. If the unit is to be stored outdoors for an extended period of time, it is recommended that it be placed on a raised surface (pallet or platiorm) and covered with a protective sheet or tarp to ensure the packaging does not deteriorate due to rain or snow Whether stored indoors or outdoors, the unit should be placed in an area where it is protected from accidental damage from moving vehicles or equipment. Ensure that the rectifier unit is transferred to and from the storage facility using proper handling techniques. 
C.P. SENTINEL AUTOMATIC TYPE CATHODIC PROTECTION RECTIFIER MANUAL INTEGRATED RECTIFIER TECHNOLOGIES, INC.

\section{SAFETY PRACTICES}

This symbol denotes a possible shock or electrical hazard

\section{DO NOT INSTALL, REMOVE, or REWIRE THIS EQUIPMENT WITH POWER APPLIED!!

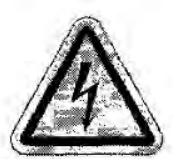

As Cathadic Protection rectifiers are connected to the AC utility power, electrical shock hazards are present within the rectifier units. It is recommended that only qualified electronic or electrical personnel operate and maintain these units and that those personnel familiarize themselves with the areas of possible hazard within the unit Following these practices can enhance the safety of personnel.

1.) Prior to site maintenance or inspection, familiarize yourself with the rectifier and conditions at the site.

2.) Prior to doing any mantenance or troubleshooting on a rectifier unit, familiarize yourself with any possible hazard points within the unit by reviewing the electrical schematic and the physical layout of the rectifier

3.) Whenever possible, set the AC disconnect from the power utility to the "OFF" position prior to starting any work on the rectifier unit. Even with the rectifier AC input circuit breaker in the "OFF" position, hazardous voltages are still present at any terminals connected to the rectifier $A C$ input terminals. Always tag and lock out the disconnect to ensure others do not energize it while you are completing the rectifier work

4) Prior to opening the rectifier enclosure door, lightly touch the back of your hand to the enclosure latch. If you feel an electrical tingle, set the fused $A C$ disconnect to the "OFF" position and contact an electrician for assistance.

5.) When taking readings across the rectifier terminals, it is recommended to use oniy one hand, if possible

Doc \# APCD010 Rev 30, November 2004 
C.P. SENTINEL AUTOMATIC TYPE CATHOOIC PROTECTION RECTIFIER MANUAL INTEGRATED RECTIFIER TECHNOLOGIES, INC.

\section{GENERAL INSTALLATION RECOMMENDATIONS}

To ensure reliable long-term operation of the Cathodic Protection rectifier, proper instaliation of the unit is required. Though most installation sites differ, there are several key guidelines that should be followed.

a) Prior to installation, check the connections (especially the electrical connections) on the rectifier unit to ensure that nothing has become loose during shipment. It is also recommended that if any scratches occur to the enclosure during installation, that these points be touched-up to prevent corrosion on the enclosure.

b) Selecting the site of installation is a very important factor. The rectifier should be installed in a location that is easily accessible by company personnel for regular adjustment, monitoring, and maintenance. However, it should not be located in areas where unauthorized personnel have easy access to the unit and may damage or vandalize it (ie residential areas playgrounds, farm yards, etc.). The convenient access to $\mathrm{AC}$ power and the cathodic protection $\mathrm{DC}$ connections must also be considered when choosing the rectifier location

c) Proper ventilation and cooling of the rectifier unit is essential and must be considered when choosing a suitable location. Air-cooled rectifiers are cooled by the natura convection of cool air drawn into the bottom of the rectifier enclosure, passing over the internal components, and the resultant warm air expelled from the top or sides of the enclosure. Oil-cooled rectifiers are cooled by the natural circulation of oil from the bottom to the top of the rectifier tank, over the internal components and the resultant heat is radiated from the upper walls of the rectifier tank. As such, when choosing the installation site for the rectifier, adequate spacing should be allowed for around the sides of the rectifier unit. The rectifier should not be located near sources of heat such as exhaust vents, power generators. etc. If possible. place the rectifier unit in an area where it will be shaded during the hottest part of the day. If the rectifier is to be installed in an area with a high ambient temperature and minimal natural shading, a protective sunshade is recommended.

d) The rectifier unit should be mounted on a secure surface. Ensure that the wall. pole frame. or mounting pad is designed to hold the full weight of the rectifier unit

e) If the rectifier is to be installed in an area subject to frequent lightning activity. upgraded high-energy type surge arrestors are recommended. If possible, do not locate the rectifier on a hill top where there increased chances of lightning strikes. Use of a low resistance ground rod(s) is recommended. Locate the ground rods adjacent to, but away from the rectifier, the ground bed. and incoming CP cables. Remember, most damaging voltage surges are the result of induced pickup rather than a direct strike

f) Do not install other equipment on or inside the rectifier enclosure without prior consent from the factory. Unauthorized equipment installation will invalidate the rectifier Warranty as IRT has no control of the equipment added or the resultant detrimental affect to proper rectifier cooling $/$ operation. 


\section{C.P. SENTINEL AUTOMATIC TYPE CATHODIC PROTECTION RECTIFIER MANUAL INTEGRATED RECTIFIER TECHNOLOGIES, INC. \\ RECTIFIER CONNECTIONS AT SITE DO NOT INSTALL, REMOVE, or REWIRE
THIS EQUIPMENT WITH POWER APPLIED!!

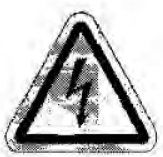

After the rectifier has been installed in a suitable location, have a qualified electrician connect the rectifier unit to the $A C$ supply following local and national codes Please note that most electrical codes require a disconnect device between the $A C$ power supply and the rectifier Ensure that for dual $A C$ input rectifiers $(115 / 230$ or $230 / 460 \mathrm{VAC})$, that the $A C$ input terminal jumpers are properly configured for the actual $A C$ input voltage being supplied and that the $A C$ input wires are connected to the correct $A C$ input terminals.

The grounding rod(s) should be connected to the ground lug terminal adjacent to the $A C$ input terminals within the rectifier.

Next, connect the cable(s) from the anode bed to the RECTIFIER POSITIVE output lug terminal(s) and the structure cable(s) to the RECTIFIER NEGATIVE output lug terminal(s). Ensure that these cables are suitably sized for the expected current and the length of the cable run. Also, it is absolutely imperative that the polarity of DC connections is correct A reversal of the DC cables can actually cause accelerated corrosion and eventually, severe damage to the structure to be protected.

C.P. SENTINEL Automatic Potenfial Controlled Rectifiers require two additional connections for proper operation, the Reference Electrode and the Structure Sensing leads. Connect the Reference Electrode to the rectifier terminal marked "REFEREINCE" (REF) and the Structure Sensing lead to the ferminal marked "STRUCTURE" (STR.). The Structure Sensing lead must be a separate non-current carrying lead connected to the protected Structure, usually adjacent the Reference Electrode.

\section{APPLICATION NOTES:}

1 Superior Potential Mode control is achieved by minimizing noise on the lead wires used for the REFERENCE Electrode \& STRUCTURE sensing. It is recommended that lead lengths in excess of 25 feet or leads in noisy electrical environments be shielded in a separate conduit, or consist of shielded, twisted-pair conductors installed using recommended shielding practices

2. C.P. SENTINEL Automatic Potential controlled rectifiers are equipped with "Loss-ofReference" shutdown feature. Upon degrading or failure of the Reference Electrode, internal cell resistivity increases and the voltage "reference" decreases. The natural condition for an automatic potential rectifier is to increase to full output to counter the reduced voltage sensed. This feature is designed to prevent structure coating failure due to excessive polarization if this cell failure condition occurs. If this type of rectifier is to be used in Current or Voltage Modes without a Reference Electrode attached, it will be necessary to jumper the REFERENCE- STRUCTURE hook-up terminals of the rectifier. The rectifier REFERENCE SELECT switch must be set to sense an active and functional Reference Cell input or no output will occur from the unit. A "Loss-ofReference" shutdown will be evident by the analog Potential Meter reading full scale or if equipped with a digital Potential Meter reading overload; first digit a " 1 " followed by remaining digits blank. 


\section{C.P. SENTINEL AUTOMATIC TYPE CATHODIC PROTECTION RECTIFIER MANUAL INTEGRATED RECTIFIER TECHNOLOGIES, INC. \\ RECTIFIER OPERATION MODES}

Depending upon the Model and the Options supplied with the rectifier, the C.P. SENTINEL Automatic Rectifiers are available with the following modes of operation:

CONSTANT VOLTAGE MODE: (SUPPLIED ON ALL MODELS)

In this mode the rectifier control circuitry automatically adjusts the rectifier output to maintain the VOLTAGE at the preset level In this mode, the Current Set potentiometer determines the current limit. When operating in this mode, the RED LED is illuminated

CONSTANT CURRENT MODE: (SUPPLIED ON ALL MODELS)

In this mode the Rectifier control circuitry automatically adjusts the rectifier output to maintain the CURRENT at the preset level. In this mode, the Voltage Set potentiometer determines the voltage limit. When operating in this mode, the GREEN LED is illuminated

IR-FREE POTENTIAL MODE: (OPTIONAL)

In this mode the Rectifier control circuitry automatically adjusts the rectifier output to maintain the Reference Electrode to Structure POTENTIAL at the preset level. The Reference Electrode to Structure POTENTIAL is maintained free of the error caused by current flow in the anode-cathode circuit. IR-Free Potential mode is available on non-filtered single phase rectifiers only, in this mode, the CURRENT Set potentiometer determines the current limit and the VOLTAGE Set potentiometer determines the voltage limit. When operating in this mode the YELLOW LED is illuminated

\section{NOTE:}

C.P. SENTINEL Automatic Rectifiers encompass full galvanic isolation of the Reference Electrode and Structure input signals. Therefore it will be necessary to connect separate lead wires for the REFERENCE Electrode and STRUCTURE sensing

"ON" POTENTIAL MODE: (OPTIONAL)

In this mode the Rectifier control circuitry automatically adjusts the rectifier output to maintain the Reference Cell to Structure POTENTIAL at the preset level. However, the Reference Electrode to Structure POTENTIAL is maintained while there is current flow in the anodecathode circuit. In this mode the Current Set potentiometer determines the current limit and the Voltage Set potentiometer determines the voltage limit. When operating in this mode, the YELLLW LED is illuminated

MANUAL MODE: (OPTIONAL)

Rectifiers equipped with this option are supplied with a conventional manual tap-adjusted transformer in addition to the automatic control circuitry. This mode permits the operator to control the rectifier output by gating 'on' the Silicon Controlled Rectifiers to conduct as conventional diodes. Manual rectifier output control is achieved by switching the AutomaticManual Switch to the Manual mode position and then adjusting the transformer secondary taps. 
C.P. SENTINEL AUTOMATIC TYPE CATHODIC PROTECTION RECTIFIER MANUAL INTEGRATED RECTIFIER TECHNOLOGIES, INC

\section{THE SENTRY CONTROLLER}

The C.P. SENTINEL Automatic Rectifiers are controlled by the IRT SENTRY Controller. Refer to the following layout of the SENTRY Controller for location of controls and jumpers:

Nots section will describe the Controis, Jumpers. Test Points and Adjustments of interest
for field setup and operation, as performed by QUALIFIED TECHNICAL PERSONNEL. All

Remaining Factory Settings \& Calibrations SHOULD NOT be attempted or tampered with.

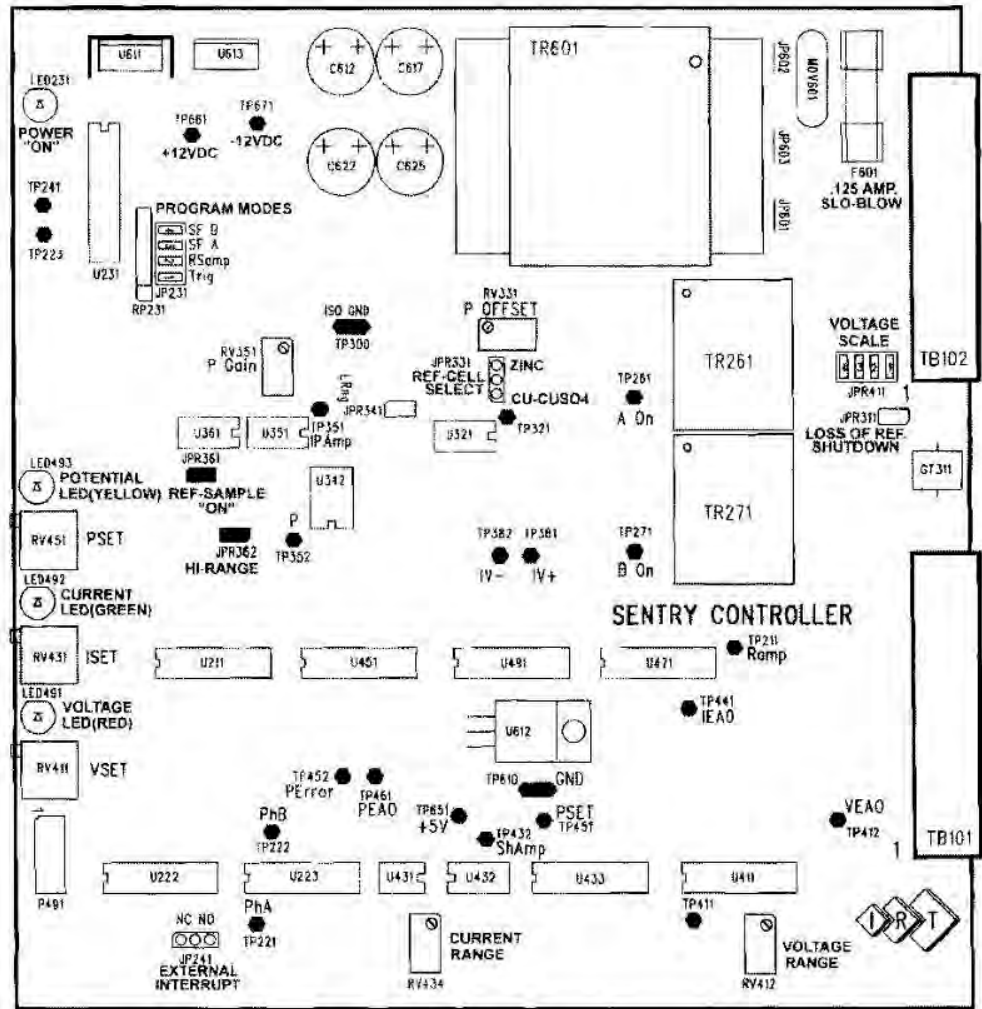

FIGURE 1.0 SENTRY CONTROLLER (FOR BOARD REV 2.0)

Doc \#: APCOO10
Rev. 3.0, November, 2004 Page 9 of 22 
C.P. SENTINEL AUTOMATIC TYPE CATHODIC PROTECTION RECTIFIER MANUAL INTEGRATED RECTIFIER TECHNOLOGIES, INC.

CONTROLS:

Voltage, Current and Potential settings are adjusted via three potentiometers available on the SENTRY Controller. These potentiometers are 20-Turn trim-pots located at the end of the controller board opposite the wiring connectors. (Refer to Figure 1.0, Page 9).

VOLTAGE: Rectifier output voltage (or Voltage Limit) is set by potentiometer "RV411" Rectifier operation in Voltage Mode or Voltage Limit will be indicated by the Red LED "LED491", adjacent the Voltage Set Potentiometer.

CURRENT Rectifier output current (or Current Limit) is set by potentiometer "RV431" Rectifier operation in Current Mode or Current Limit will be indicated by the Green LED "LED492", adjacent the Current Set Potentiometer

POTENTIAL: On rectifiers equipped with this option: Rectifier Structure to Reference Electrode Potential is set by potentiometer "RV451", in conjunction with the "Press-toSet/Actual" selector switch. Rectifier operation in the Potential Mode will be indicated by the Yellow LED "LED493", adjacent the Potential Set Potentiometer. Both Potential Set Point and Actual Structure-Reference Electrode potential may be read on the rectifier's potential meter via the "Press-to-Set/Actual" selector switch

[ - - - NOTE:

Depending upon the model and/or configuration of the rectifier ordered, one or more of these potentiometers may be mounted external of the controlier board on the rectifier instrument panel. Consult your Rectifier Specification Sheet.

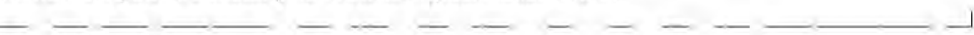

\section{CAUTION!!}

Do NOT attempt to alter the settings of any other trim pots on the controller board. These are factory calibrations and tampering with these settings could jeopardize proper operation and scaling of the SENTRY Controller.

JUMPER SETTINGS:

The SENTRY Controller is designed to adapt and accommodate a wide variety of fieid installations and control situations. To make this accommodation easier, please review the following Jumper functions and settings:

A. INPUT VOLTAGE SELECTION (JP601, JP602, \& JP603)

\begin{tabular}{|c|c|c|c|c|}
\hline $\begin{array}{c}\text { INPUT } \\
\text { VOLTAGE }\end{array}$ & JP601 & JP602 & JP603 & COMMENT \\
\hline 115 VAC & INSTALLED & INSTALLED & OMITTED & DEFAULT POSITION \\
\hline $230 V A C$ & OMITTED & OMITTED & INSTALLED & OPTIONAL POSITION \\
\hline
\end{tabular}

DoC \#: APCOO10 
C.P. SENTINEL AUTOMATIC TYPE CATHODIC PROTECTION RECTIFIER MANUAL INTEGRATED RECTIFIER TECHNOLOGIES, INC.

B. PROGRAM MODES (JP231) USE WITH FIRMWARE VERSION 16C622AS-1.00

\begin{tabular}{|l|l|l|}
\hline "JP231" SETTING & \multicolumn{1}{|c|}{ FUNCTION } & \multicolumn{1}{|c|}{ CONIVENT } \\
\hline JP231 - 1 (TRIG) & NOT SUPPORTED & NOT USED \\
\hline JP231 - 2 (Rsamp) & $\begin{array}{l}\text { INSTALLED Reference Electrode } \\
\text { Sampled ust prior to SCR Gate-on }\end{array}$ & $\begin{array}{l}\text { DEFAULT Use in IR-Free } \\
\text { mode \& Choke Filtering }\end{array}$ \\
\hline JP231 - 2 (Rsamp) & $\begin{array}{l}\text { REMOVED Reference Electrode Sampled } \\
\text { after Zero-Crossing AC waveform }\end{array}$ & Use with AC Interference \\
\hline JP231 - 3 (SF A) & Doubles SCR Galing "ON" \& "OFF" times & INSTALLED (DEFAULT) \\
\hline JP231 - 4 (SF B) & Doubles the "SF-A" SCR Gating "OFF" time & INSTALLED (DEFAULT) \\
\hline
\end{tabular}

C: EXTERNAL INTERRUPT (JP241)

\begin{tabular}{|c|c|}
\hline "JP241" SETTING & \multicolumn{1}{|c|}{ FUNCTION } \\
\hline JP241 PINS 1-2 & Normally Closed contacts = Rectifier output current (Optional Serting) \\
\hline JP241 PINS 2-3 & Normally Open contacts = Rectifier output current (Default Sefting) \\
\hline
\end{tabular}

D: POTENTIAL MODE SETTINGS

\begin{tabular}{|l|l|c|}
\hline \multicolumn{1}{|c|}{ JUMPER } & \multicolumn{1}{|c|}{ FUNCTION - DESCRIPTION } & COMMENT \\
\hline JPR311, PINS 1-2 & LLoss of Reference Shutdown" Enabled & INSTALLED \\
\hline JPR331, PINS 1-2 & Select Type of Reference Cell = CU-CUSO 4 or Ag-CL & DEFAULT \\
\hline JPR331, PINS 2-3 & Select Type of Reference CelI = ZINC & OPTIONAL \\
\hline $\begin{array}{l}\text { JPR341, (CLOSED) } \\
\text { JPR362, JOPEN) }\end{array}$ & Select Low Range (Max. Potentials less than \pm 3.0 Volts) & OPTIONAL \\
\hline $\begin{array}{l}\text { JPR341, (OPEN) } \\
\text { JPR362, CLOSED) }\end{array}$ & Select High Range (Maximum Potentials $>$ than \pm 3.0 Volts) & DEFAULT \\
\hline JPR361, PINS 1-2 & Select Continuous "ON-Potential" Control \& Sampling & DEFAULT \\
\hline
\end{tabular}

E: VOLTAGE RANGE SETTINGS: "JPR411"

Header "JPR411" is factory set to determine the avallable output range of voltage control.

\section{OTHER CONTROLLER PARTS \& FUNCTIONS}

FUSE: "F601" is located on the circuit board near the board-mounted control transformer This a 0.125 ampere, slow-blow type of $5 \mathrm{~mm} \times 20 \mathrm{~mm}$ metric style fuse. Replace with same fuse type and rating

POWER ON LED: Controller "POWER ON" operation is indicated by "LED231". Yellow

WIRING CONNECTORS: "TB101" \& "TB102". These are 14-pin plug on connectors, Ensure all wiring connections are secure by tightening the screw terminals on these connectors. 
C.P. SENTINEL AUTOMATIC TYPE CATHODIC PROTECTION RECTIFIER MANUAL INTEGRATED RECTIFIER TECHNOLOGIES, INC.

\section{THE SILICON CONTROLLED RECTIFIER (SCR)}

Automatically controlled rectifiers utilize phase control of the supplied 50 or $60 \mathrm{Hertz} A C$ voltage using a solid-state device called a Silicon Controlled Rectifier (SCR). This device is similar to a conventional diode, but is equipped with an extra terminal for control called the GATE. Although akin to a diode. this device has unique properties of being able to block conduction of current when the device is forward biased until an appropriate signal is applied to the Gate terminal. Once the appropriate gate signal is applied, the SCR remains in conduction while forward biased or until the current trough the device goes to almost zero

The control of the rectifier DC output is accomplished by "gating on" the SCR at the point in the AC waveform necessary to produce the desired output. This output can be the regulated DC Voltage, the DC Current, the Structure to Reference Electrode Potential or a combination of the three modes of control. A minimum of two SCR's are required to achieve full control over the AC waveform. The two SCR's are configured with two diodes into a full-wave bridge configuration.

Often SCR's and diodes are combined into full-wave controlled rectification modules. Typically the modules used are comprised of two SCR's and two diodes with the cathodes of the 2 SCR's connected to the module Positive $(+)$ terminal SCR-Diode modules are then mounted to a suitably sized heatsink for cooling
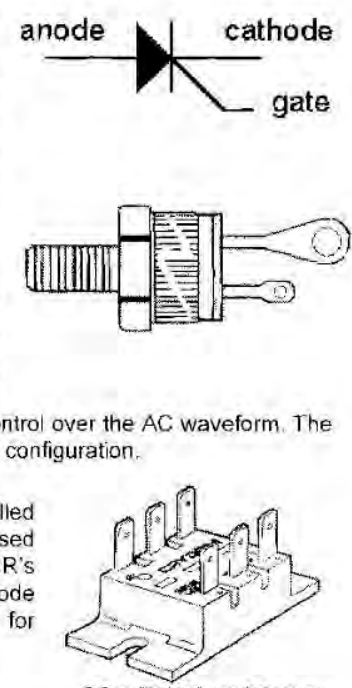

SCR-DIODE MODULE 
C.P. SENTINEL AUTOMATIC TYPE CATHODIC PROTECTION RECTIFIER MANUAL INTEGRATED RECTIFIER TECHNOLOGIES, INC.

POTENTIAL CONTROL AND EXTERNAL IR DROP

\section{NOTTE}

This section applies only to C.P. SENTINEL Automatic Rectifiers which have been ordered and manufactured to function as IR-Drop Free Reference Electrode controlled outputs. Consult your Rectifier Specification Sheet.

In applying and operating IR-Drop Free C.P. SENTINEL Automatic Rectifiers, it is important that Cathodic Protection personnel are familiar with the methods \& principles of using this type of rectifier to mitigate corrosion. Briefly described as follows:

Current flowing in the measurement circuit will cause a voltage drop freferred to the Ohm's Law equivalent of Current "I" multiplied by Resistance " $R$ " or "IR"), which becomes incorporated into measurements as an error. In addition, any external currents flowing through the electrolyte in the area between the reference electrode and the structure will cause their own voltage drop, which also becomes part of the measurement as an additional error. Cathodic protection systems and AC \& DC electrical power systems are some of the possible sources of these currents. The magnitude of errors from external IR drops can be substantial. To accurately maintain the required polarization potential on a given structure, these errors must be minimized during the design phase and then eliminated by electronic circuitry within the SENTRY Controller, which is used in the C.P. SENTINEL Automatic Rectifiers.

The SENTRY Controller removes the IR drop error from the potential measurement by interrupting the cathodic protection current supplied by the rectifier momentarily. This action produces an instantaneous voltage drop, which is considered to be the external IR Drop. The potential from Reference Electrode to Structure is measured immediately after this instantaneous drop, and is considered to be the "IR Drop Free" potential of the structure.

Clearly, this method only works with an impressed current cathodic protection system where all the rectifiers on that system can be interrupted simultaneously, and there are no other sources of current flowing through the electrolyte.

An issue that should be considered when using current interruption for instant-off measurements is: What is meant by instantaneous? The answer is not simple since it depends upon the structure, the electrolyte and the method of interrupting the current. Putting the answer in electrical terms, it depends upon the capacitance and the inductance of the circuit. IR drop free measurements can be made microseconds after current interruption on small. uncoated specimens in a low resistance electrolyte. Large coated structures, such as pipelines, or high resistance electrolytes, such as concrete, usually require several hundred milliseconds or more for IR-drop free measurements. Interrupting current on the AC side rather than on the DC side of the rectifier will increase the time delay because the circuit inductance is higher. An oscilloscope should be used if measurement precision is necessary; it should be either battery powered or connected through an isolation transformer to eliminate graund loops. 


\section{C.P. SENTINEL AUTOMATIC TYPE CATHODIC PROTECTION RECTIFIER MANUAL INTEGRATED RECTIFIER TECHNOLOGIES, INC. \\ GENERAL COMPONENT DESCRIPTION}

When operating any equipment, it is a good practice to become familiar with the key components and the general operation of that piece of equipment. The following is a summary of the key components of a rectifier and their function

The AC Input Surge Arrestor is a device that protects the rectifier components from voltage surges that may occur across the $A C$ input of the rectifier. It does this by providing a bypass circuit for the resultant current from these high voltage surges after a specific voltage threshold has been reached. Most surge arrestors are designed to handle a certain number or energy value of surges prior to failing.

The rectifier AC Input Circuit Breaker (CB1) is a fully magnetic type that serves three key functions. It is used as an "OFF-ON" switch for the rectifier, it provides "short circuit" protection, and. to a lesser degree, provides input overload protection.

The rectifier Main Transformer (T1) provides full electrical isolation between the utility AC power and the Cathodic Protection DC circuit if also steps the voltage up or down as required for the DC circuil and, for tap type units, provides a means of output adjustment.

The rectifier AC Secondary Fuse is a time lag or slow-blow type that provides protection from not only short-circuits or overloads in the DC output circuit but also in the diode bridge circuit

The rectifier SCR-Diode Bridge Assembly is comprised of silicon controlled diodes (SCR's) and diodes configured into a full-wave bridge configuration. The SCR-diodes are supplied with suitably sized heatsinks to ensure that the SCR-diodes do not exceed $100^{\circ} \mathrm{C}$ at full rated output. The SCR-diode bridge controls and rectifies the AC secondary voltage of the transformer into DC voltage that can be used for Cathodic Protection. This DC voltage level is then automatically maintained by the SENTRY Controller in Potential Current or Voltage Mode, as set by the operator

A Varistor is supplied across the AC input to the diode bridge to provide additional protection from any voltage surges that may pass the main $A C$ surge arrestor or be developed by the main transformer. A second varistor may also be supplied across the DC output of the diode bridge at special request.

The Current Monitoring Shunt is a block style calibrated resistor with an accuracy of $0.25 \%$ The DC current and voltage rating are stamped into the body of the shunt Shunts used in rectifiers equipped with digital meters will be either 1 Millivolt or 10 Millivolts per ampere depending upon the rectifier output current rating.

The rectifier Ammeter \& Voltmeter utilize an analog taut-band type movement that provides $\pm 2 \%$ accuracy. The DC output amperage of the rectifier is monitored by a meter connection across the calibrated test screws of the above shunt. The DC output voltage of the rectifier is monitored by a meter connection across the DC output terminals of the rectifier

On Potential Controlled rectifiers, an additional Potential Meter is supplied to monitor the Structure to Reference Cell Potential, and the desired "Set Potential". This meter receives the potential reading from the SENTRY Controller. 
C.P. SENTINEL AUTOMATIC TYPE CATHODIC PROTECTION RECTIFIER MANUAL INTEGRATED RECTIFIER TECHNOLOGIES, INC.

Potential Adjust Potentiometer is a front, panel-mounted multi-turn potentiometer used to set the required Structure to Reference Electrode potential required by the CP System. The setting can be read on the Potential Meter by activating the Potential Switch to the "Set" position.

The "Set-Actual" Switch permits the operator to monitor, via the rectifier Potential Meter. either the "Actual" potential or the "Set" potential of the rectifier. The "Actual" potential may be either free of IR-Drop error, as determined by the SENTRY Controller, or the "ON" potential, if the rectifier is equipped with filtering or if configured to operate in the "ON" potential Mode.

Metering Test Points (Optionally supplied) are located on the touch-safe instrument panel for purposes of verifying the digital meter readings. Metering Test Points are 0.093 diameter test jacks, with polarity and function as indicated by the silk screening on the panel. The "Potential" test points will indicate the potential voltage reading as determined by the "POTENTIAL. ACTUAL/SETPOINT" toggle switch

The Reference Electrode (Cell) - Structure Input Terminal Block is used to make field connections to the CP system Reference Cell and Structure sensing leads.

\section{NOTE:}

If no reference electrode is used, a jumper should be placed across these input terminals.

External Interrupt Terminal Block: (NOT Supplied on IR-Free rectifiers) Two terminals are provided on the front panel of the rectifier for purposes of interrupting the rectifier output using the SENTRY Controlier Jumper "JP241" on the controller board as required for Normally Open equals rectifier "ON" or Normally Closed contacts equals "rectifier "ON" as dictated by the interrupter being used. This is the preferred method to interrupt the rectifier by an external means. Special circuitry in the SENTRY Controller retains all of the operating parameters for resumption of control parameters after conclusion of an interrupt procedure and will not reset the slow start circuitry.

\section{APPLICATION ALERT!!}

IR-Free Automatic Potential controlled rectifiers typically do not utilize external interrupters when operating. For proper IR-Free potential control, the SENTRY Controller must not be impeded by external interrupter cycles as it controls the desired "Set Potential" of the CP system.

The DC Output Surge Arrestor is a device that protects the rectifier components from voltage surges that may occur across the $O C$ output of the rectifier. It's operation and characteristics are similar to the $A C$ input surge arrestor.

As many optional features / components are available for our customers, it is not practical for this manual to describe all of the possible options in detail. As such, it is recommended that the rectifier data sheet and the electrical schematic be reviewed in detail to become familiar with any features not detailed in this manual. 
C.P. SENTINEL AUTOMATIC TYPE CATHODIC PROTECTION RECTIFIER MANUAL INTEGRATED RECTIFIER TECHNOLOGIES, INC.

\section{INITIAL ENERGIZATION}

After the rectifier has been properly connected to the AC supply and the DC output cables (and Reference Electrode - Structure Sensing leads in the case of a potentially controlled type of rectifier) it is ready to be energized. Before energizing. always double-check both the $A C$ and DC connections to ensure they are properly connected. Ensure that for dual input rectifiers ( $115 / 230$ or $230 / 460 \mathrm{VAC})$, the $\mathrm{AC}$ input terminal jumpers are properly configured for the actual $A C$ input voltage being supplied and that the $A C$ input wires are connected to the proper terminals. For Current Controlled rectifiers, ensure that the rectifier is at its lowest control setting, by adjusting the "Current Adjust" potentiometer to zero. Use a multi-meter to verify static Reference Electrode - Structure potentials and record for later reference.

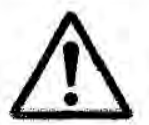

\section{ENERGIZATION ALERT!}

If the rectifier is to be used on a CP system protecting the inside of a vessel ensure the vessel contains fluid sufficient to cover the anode system and the Reference Electrode

Place the $A C$ fused disconnect switch to the "ON" position and measure across the rectifier $A C$ input terminals to ensure the voltage present is as expected. Next, place the rectifier AC input circuit breaker also to the "ON" position. The "POWER ON" Yellow LED on the SENTRY Controller will illuminate. The SENTRY Controller is designed with a "slow start" circuitry to minimize in-rush currents and to prevent the rectifier from starting at full output. This slow start time period will iast from 3-10 seconds. There will be some deflection on the panel meters, especially the Potential Meter (aithough this deflection may be quite minimal on the Ammeter and Voltmeter). For units with a metering switch, ensure to set this switch to the "ON" position.

For Automatic Current rectifiers, simply adjust the "Current Adjust" potentiometer to the required current. This current will be read on the rectifier Ammeter. The rectifier ammeter can be verified by measuring the voltage (in Millivolts) across the calibrated test screws of the rectifier shunt (not across the connection bolts). To determine the current through the shunt from the millivolt reading taken, the following formula can be used:

\section{Current (I) $=$ Measured Shunt Voltage (Millivolts) $\times$ Rated Shunt Current Rated Shunt Voltage (50 Millivolts typical)}

Note Rated shunt current and voltage values are stamped onto the body of the shunt and are also shown on the rectifier data page.

The ammeter can also be verified with an external DC clamp-on type meter, if available

It is recommended that all initial energization readings be recorded for future reference. Useful readings to record are structure potential levels prior to energization, $A C$ input voltage \& current, DC output voltage and current, tap or adjustment dial setting, structure potential levels after energization, as well as any observed problems or possible future concerns with the inslallation, in general

For Automatic Potential Rectifiers, activate the Potential Switch to the "SET" position and observe the "SET" level of potential control on the Potential Meter. Adjust the required potential control level with the Potential Adjust potentiometer to the desired level of control. Release the Potential Switch and observe the "Actual" potential on the Potential Meter. When operating in this mode, the Yellow LED will be illuminated it is important to note that if the 
C.P. SENTINEL AUTOMATIC TYPE CATHODIC PROTECIION RECTIFIER MANUAL INTEGRATED RECTIFIER TECHNOLOGIES, INC.

potential control "Set" level cannot be initially attained due to the polarization time of the Structure, the rectifier will ramp up the DC output to either the Voltage set point (Voltage Limit; Red LED illuminated) or the Current set point (Current Limit; Green LED illuminated). Once the potential control "Set" level is attained, the SENTRY Controller will automatically revert into Potential Mode and maintain the Structure to Reference Electrode potential at the preset level. The Yellow LED will then be illuminated.

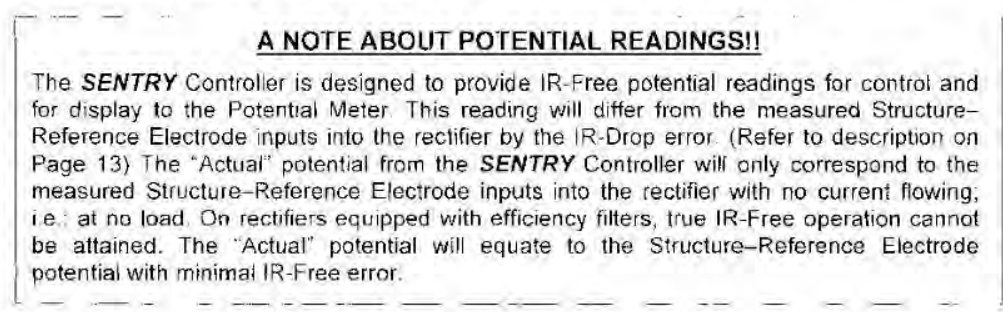

T APPLICATION NOTES:

1. Remember, the C.P. SENTINEL AQUA-LINE rectifiers are equipped with Loss-otReference" shutdown feature. The rectifier "REFERENCE SELECT" switch must be set to sense an active and functional Reference Cell input or no output will occur from the unit. Alternately, jumper the "REF, CELL" inputs on the front of the rectifier pane to obtain a current output. A "Loss-of-Reference" shutdown will be evident by the digital Potential Meter reading overload, first digit a " 1 " followed by remaining digits blank.

2. To function in current mode up to rated current, the output of the rectifier cannot be limited by either the "VOLTAGE SET" or the "POTENTIAL SET" potentiometers.

Rectifiers equipped with MANUAL MODE Option: Adjustment of rectifiers equipped with this option requires the "Automatic-Manual" selector switch be switched to the "Manual" position Start the rectifier with the Coarse \& Fine taps set to their lowest level (Coarse "A" - Fine "1") Observe and record if necessary the rectifier output currents and voltage levels, and the polarization level of the Structure being protected. Incrementally. increase the transformer tap seltings until either target current or polarization levels are attained. The SENTRY Controller is NOT required for manual mode, and may be removed for repair if it is not functioning correctly.

After the structure potential readings have been taken and prior to leaving the site, it is recommended that the DC output connections to the rectifier be rechecked to ensure a secure connection. It is also beneficial to recheck the rectifier to ensure that all air inlet and outlet venting on the enclosure is not obstructed in any manner. The rectifier O\&M manual should be securely set in it's holder (for small rectifiers without a manual holder. it is recommended that the manual be kept with the main operator or in the control room of the closest station). Also verify that all holes within the enclosure (other than the venting screens) are suitably plugged (such as unused conduit knockouts). For rectifier units with "OFF-ON" meter switches, ensure that the switch is in the "OFF" position prior to leaving the site. 
C.P. SENTINEL AUTOMATIC TYPE CATHODIC PROTECTION RECTIFIER MANUAL INTEGRATED RECTIFIER TECHNOLOGIES, INC

\section{REGULAR MAINTENANCE \& ADJUSTMENT}

The basis for any effective CP system is routine documentation \& maintenance Despite the rectifier maintaining the DC output "automatically", it is recommended that the rectifier be checked and adjusted if necessary at least twice per year. Some local regulatory bodies require a monthly or semi-monthly check to ensure proper protection levels are being maintained These checks also allow you to ensure that the rectifier has not been damaged When completing this maintenance and adjustment check. it is recommended that all readings and observations be recorded in the site file. With regular maintenance checks and by maintaining good records, future troubleshooting and repair costs can be reduced.

Prior to arriving at the site for the rectifier maintenance check it is recommended that the technician review the existing rectifier site file to gain familiarization with the subject rectifier and site conditions. Upon arriving at the rectifier site, a visual check should be completed to determine if any changes have occurred. Things to look for are signs of new underground construction buildings, pipeline tie-ins, bonds, etc. Prior to adjustment of the rectifier, it is recommended that structure potential readings be taken, to determine the adjustment level required. Even if the potential levels are within the required range, the rectifier should still be checked for proper operation

When approaching the rectifier, ensure that no items have been placed near the rectifier enclosure in such a manner as to block the venting, either on the bottom or sides. As the vent openings on the rectifier enclosure are screened, there should be no refuse inside from birds or larger insects. However. after opening the door of the enclosure, ensure that there has been no significant accumulation of dirt, snow, or other small debris at the bottom of the enclosure. which may adversely affect proper venting.

\section{DO NOT INSTALL, REMOVE, or REWIRE THIS EQUIPMENT WITH POWER APPLIED!!}

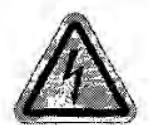

Prior to any adjustment of the rectifier. measure and record the "As Found" readings of the rectifier (DC voltage, DC amperage, etc.). Next, set the rectifier circuit breaker and the utility disconnect to the "OFF" position to allow for a detailed rectifier inspection.

At least once a year the rectifier should be inspected for loose electrical connections that could eventually cause damage to the electrical panel, wiring, or rectifier components. If an electrical connection becomes loose, the resistance of the connection increases and causes it to heat up. This additional heat will cause the connection to oxidize and become even higher resistant until a failure occurs. The best way to check for a heated connection is with a temperature probe, however, as these are not typically standard issue for Cathodic field maintenance, the visual inspection method will suffice First, visually inspect all of the main electrical connections within the rectifier for signs of discoloration on the connection terminal, the electrical panel, or the wire attached to the terminal Key points to check are the DC output lug terminal connections and the fuse hoider connections. If you see a suspect connection, use a wrench or other suitable tools to see if the connection is indeed loose (Note: Be careful when touching these types of connections with your hand as the temperature of loose high current connections can cause a significant burn.) If you do find a loose connection, it should be secured with suitable tools (make sure to secure both the front and rear of the double-nutted panel connections). If a loose connection has already caused damage to the electrical panel the panel should be repaired or replaced, as re-tightening a connection on a degraded pane will most likely still lead to a future failure. 
C.P. SENTINEL AUTOMATIC TYPE CATHODIC PROTECTION RECTIFIER MANUAL INTEGRATED RECTIFIER TECHNOLOGIES, INC.

Certain main components within the rectifier should also be inspected for signs of over-thealing or other damage.

The main isolation transformer (T1) within the rectifier is designed to operate at a fairly high temperature and thus is usually somewhal discoloured. However, it should not be extremely dark or black. If it is, this could indicate insufficient / blocked venting or a problem within the transformer itself.

The AC primary, AC secondary, and the DC output surge arrestors should be checked to ensure that a significant voltage surge has not damaged them. Signs of damage to an arrestor device are usualiy visually noticeable by a blackened or cracked housing. Please note however that sometimes the operational status of an arrestor is not discernable visually and requires further checking (see Troubleshooting section).

The rectifier fusing should also be checked for overheating. If the fusing is a bolt-on type (for larger rectifier units), ensure that the fastening studs or bolts are secure on both the front and rear. Many smaller rectifier units utilize the "clip-type" fuse connectors that are very convenient for fuse replacement but are also infamous for becoming loose and oxidizing over time. However, with regular checks and maintenance, problems can be avoided. For this type of connection, if oxidation is apparent, the fuse should be removed and both the fuse and the fuse contact surface of the clips cleaned up with some very fine sand paper or emery cloth (only the oxidation layer should be removed, not the protective coating on the copper). If the fuse clips have lost tension, they should be replaced. If replacements are not immediately available, the clips can be squeezed" together and should then provide a suitable short-term connection to the fuse. A notation should be made however, in the site inspection form for replacement on the next maintenance check. The connection hardware on each fuse clip should also be checked and re-tightened if necessary.

If, after completing the inspection on the rectifier unit, a problem is found other than just a loose connection, refer to the "Troubleshooting" section of this manual. If no problems have been found, the rectifier can be adjusted to a new DC output setting (if deemed required based on the "as-found" structure potential levels). As per the adjustment proceduse indicated in the "Initial Energization" section, adjust the DC output of the rectifier to the level required to provide suitable protection to the structure. If the rectifier is adjusted to or near it's maximum rated output, future replacement of the rectifier with a larger unit or the addition of anodes may need to be considered. If the required "target" DC output current from the rectifier varies significantly over the year due to load resistance changes, maintenance checks should be done frequently 
C.P. SENTINEL AUTOMATIC TYPE CATHODIC PROTECTION RECTIFIER MANUAL INTEGRATED RECTIFIER TECHNOLOGIES, INC.

\section{TROUBLESHOOTING}

If a problem is found with the rectifier during the maintenance inspection or reported by the local operator, the following troubleshooting procedure can be followed to determine the cause

The only way to effectively determine the cause of a failure in any piece of equipment is to conduct a systematic analysis of the function and operation of the key components. For this troubleshooting procedure, we shall review the possible faults that may occur starling from the $D C$ output and working back to the $A C$ input.

PAUTION!!
Please be advised that hazardous voltages are present within the rectrfier unit even with
observed when taking measurements on the front of the instrument panel or the side AC
input panel. Only qualified electronic or electrical technicians shouid attempt internal
troubleshooting of the rectifier. The fused AC disconnect should be set to the "OFF"
position prior to any internal rectifier maintenance or repair.
Please refer to the Rectifier Specifications Sheet. Electrical Schematic supplied with each
rectifier and to the SENTRY Controller layout on Page 9 of this manual for component
descriptions and test points. Common rectifier failures can be summarized and corrected as
follows:

A. NO RECTIFIER OUTPUT CURRENT: This fault may be caused by any one or more of the following conditions:

- No AC Present. Check incoming utility supply for the presence of voltage and that it is correct for the rating of the rectifier. Consult your electrician or electrical utility to correct this problem.

- Rectifier AC Breaker Tripped: First: Do a visual inspection as described in the Maintenance \& Adjustment section of this manual Secondly, attempt to reset the breaker and observe rectifier output. If the rectifier fails to function correctly. continue with this troubleshooting procedure.

- Blown Fuse: Check all rectifier fuses, including the control fuse located on the SENTRY Controller circuit board. Replace as required with the identical type, size and rating as supplied. One spare for each fuse used in the unit is supplied with each rectifier.

- Check Interrupt Circuit: It is possible for field attached external interrupter to hold the output "Off". Refer to Page 11, Section " $C$ " and Page 15 "External Interrupt Terminal Block' and correct any possible interrupter setting errors.

- Improper Settings: Review the settings on the SENTRY Controller for Voltage, Current and Potential (if applicable). Any one of these potentiometers set to "zero" will result in no rectifier output. Review "Controls" section of this manual on Page 10, and correct any setting errors

- SENTRY Controller Failure: Check for the board stalus LED's. "Power ON" LED is illuminated continually when the board is powered and the on-board microprocessor is functioning. One of the Mode LED's will function if any one of the rectifier output modes is being controlied. Due to board complexity, replace defective controller with a known working controller.

DOC \#. APCD010 
C.P. SENTINEL AUTOMATIC TYPE CATHODIC PROTECTION RECTIFIER MANUAL INTEGRATED RECTIFIER TECHNOLOGIES, INC.

- Faulty Connections: Often broken or high resistance connections will lead to no rectifier output or intermittent output. Disconnect power, check and re-tighten all connections. Be especially aware of any oxidized, burnt or discoloured connections Repair or replace as required.

- DC voltage at output lugs but no curient: The principle reason for this failure is a broken CP system cables beyond the rectifier. Investigate and repair broken cables.

- DC voltage at output lugs, current flowing to load, but no current reading on ammeter: This could be the result of a defective ammeter, faulty leads, or failure of a metering switch. Repair or replace defective components.

- Faliure of Reference Electrode The SENTRY Controller is equipped with "Loss of Reference Electrode" shut-down circuitry to prevent coating damage due to excessive polarization upon failure Reference Electrode. Replace defeclive Reference Electrode and re-energize rectifier. Refer to Page 7.

B. LIMITED RECTIFIER OUTPUT CURRENT: This fault may be caused by any one or more of the following conditions:

- improper Mode settings on the SENTRY controller resulting in insufficient current to the CP system. Re-check settings and limits for current, voltage and potential (If applicable).

- Load resistivity too high for rating of the rectifier. This will usually be indicated by a "Voltage Limit" condition, where the Red LED is illuminated. Check anodes and ground bed resistance. Modify if necessary, or replace rectifier with a higher rated unit.

- Low supply voltage Check incoming $A C$ voltage to rectifier while rectifier is under load. Consult electrical maintenance personnel for adjustment if line voltage is low

- Excessive AC interference on Reference Electrode to Structure inputs may reduce the rectifier DC output (on Potential controlled rectifiers) Although equipped with circuitry to minimize $A C$ interference on the potential measuring circuit, excessive amounts of interference can cause the SENTRY Controller to reduce output current or voltage in response to this outside interference. Review installation practices outlined on Page 7

- Failure of SCR-Diode module: could result in "half-wave" output, which will yield only half of the rated output. Replace defective module with replacement.

- Failure of the SENTRY Controller board. Remove defective board \& replace with known working control board.

C. POTENTIAL SET POINT NOT MAINTAINED: This fault may be due to one or more of the following conditions

- Rectifier output being limited by either the Voltage Limit or the Current Limit. Adjust these limits to the maximum rating of the rectifier.

- Rectifier output being limited by the Manual Tap adjustment (On rectifiers equipped with this option) Sufficient voltage must be supplied from the transformer taps to maintain the set point potential.

- Failure of the Reference Electrode results in limited or no output See Page 7.

- Excessive AC input on Reference Cell-Structure leads, See Item "B", above.

- Defective "Press-to-Set" selector switch Oxidized contacts could result in the "Set Potential" not being switched correctly into the SENTRY Controller

DOC\# APC0010 Kev. 3.0, Novernber, 2004 Page 21 of 22 
C.P. SENTINEL AUTOMATIC TYPE CATHODIC PROTECTION RECTIFIER MANUAL INTEGRATED RECTIFIER TECHNOLOGIES, INC.

D. RECTIFIER FUSE BLOWS: Fuse failure may be due to the following:

- Fuses may blow due to either excessive current. In an automatic rectifier, this type of failure is mainly due to failure in the SCR-Diode module. Replace failed moduie and fuse, and re-energize rectifier

- Fuses may blow due to excessive operating temperature. Excessive temperature on the fuse is typically caused by either corrosion or weakening of the gripping lension on the fuse clips or fuse holder Replace defective fuse components when this occurs,

E. RECTIFIER AC BREAKER TRIPS: AC Breaker tripping may be resolved as follows:

- Visually inspect the rectifier $A C$ input surge arrestor for damage (usually located adjacent to the $A C$ input terminals). If the housing of the arrestor is cracked or blackened, the arrestor has failed and should be replaced. Always replace the arrestor with one of the same type. If an immediate replacement cannot be obtained, the rectifier can operate without this arrestor for a limited period. however, please remember that the rectifier then has no protection against surges. In certain circumstances, the arrestor may also fail without any external signs of damage As such, to ensure that the $A C$ arrestor is not the problem and with the AC power "OFF", disconnect the wires of the arrestor from the circuit breaker terminals. If the rectifier circuit breaker now remains in the "ON" position when energized, the arrestor has failed and should be replaced.

- If the breaker still trips to the "OFF" position cisconnect the wires between output (bottom) terminals of the rectifier circuit breaker (CB1) and the AC primary of the main transformer (T1). If the rectifier circuit breaker now remains in the "ON" position when energized the problem is further downstream in the rectifier.

- Reconnect the wires in the step above. Remove the wires from the transformer secondary to the SCR-Diode module. Note: This may be accomplished by opencircuiting the rectifier secondary fuse, if so equipped. If the breaker still trips to the "OFF" position, the main transformer has most likely failed and should be replaced (consult the factory for a replacement).

- Another possibility is that the AC configuration terminals of the main transformer (T1) (for dual input types only) are incorrectly set for the actual $A C$ input voltage applied to the rectifier. Please confirm that these terminals are configured properly (refer to the electrical schematic) for the $A C$ voltage being applied.

- The final possibility is most likely that the rectifier AC input circuit breaker itself has failed and will require replacement.

\section{F. RECTIFIER OUTPUT IS INTERMITTENT. Possible causes for erratic are}

- Broken or loose connections. Check all rectifier connections for loose or broken connections. Include the wiring connections to the SENTRY Controller.

- Check if built-in or field attached interrupters are in operation

TROUBLESHOOTING SUMMARY

As rectifier problems in automatic units can be more easily solved by having a good working knowledge of the application and the workings of the rectifier, review this manual to ensure recommended installation practices have been followed. If a problem cannot be solved please contact you rectifier dealer or the factory for technical assistance. 
INTEGRATEd ReCtifier TECHNOLOGIES, INC.

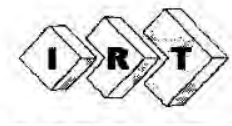

15360 - 116 Avenue, Edmonton, Alberta, Canada T5M 3Z6

\section{RECTIFIER DATA SHEET}

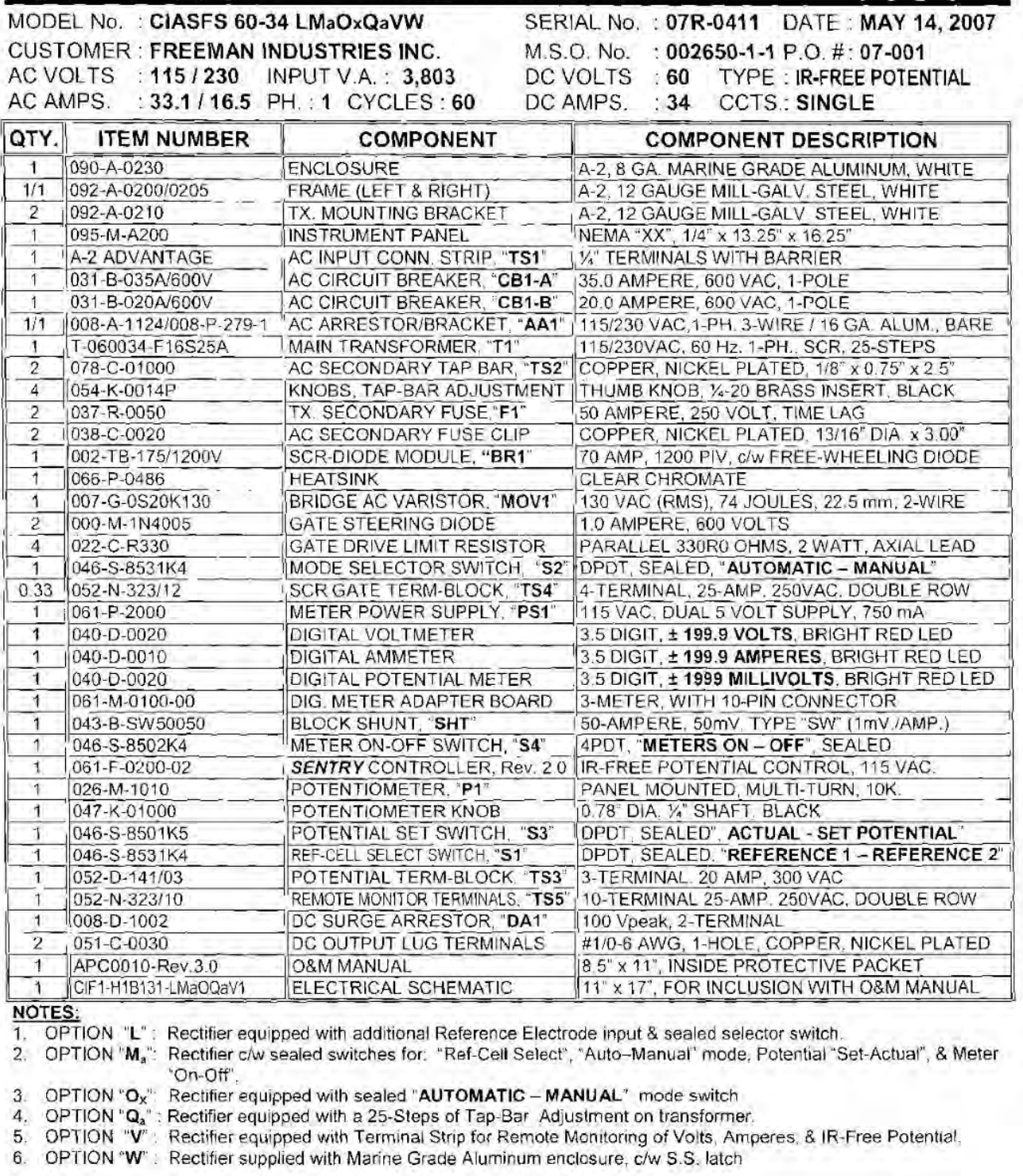

AC PRIMARY: \#10 TEW AC SECONDARY: \#8 TEW $\quad$ DC OUTPUT: \#10 TEW 
IMPORTANT NOTICE

This ducument, any facsilmie thereof, and all nformation presented are the

exclusive property of IRT Integrated Rectitler Technologies, inc Any company

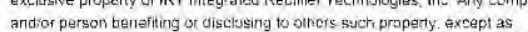

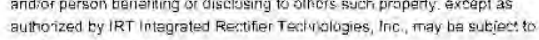

resultarit legal action

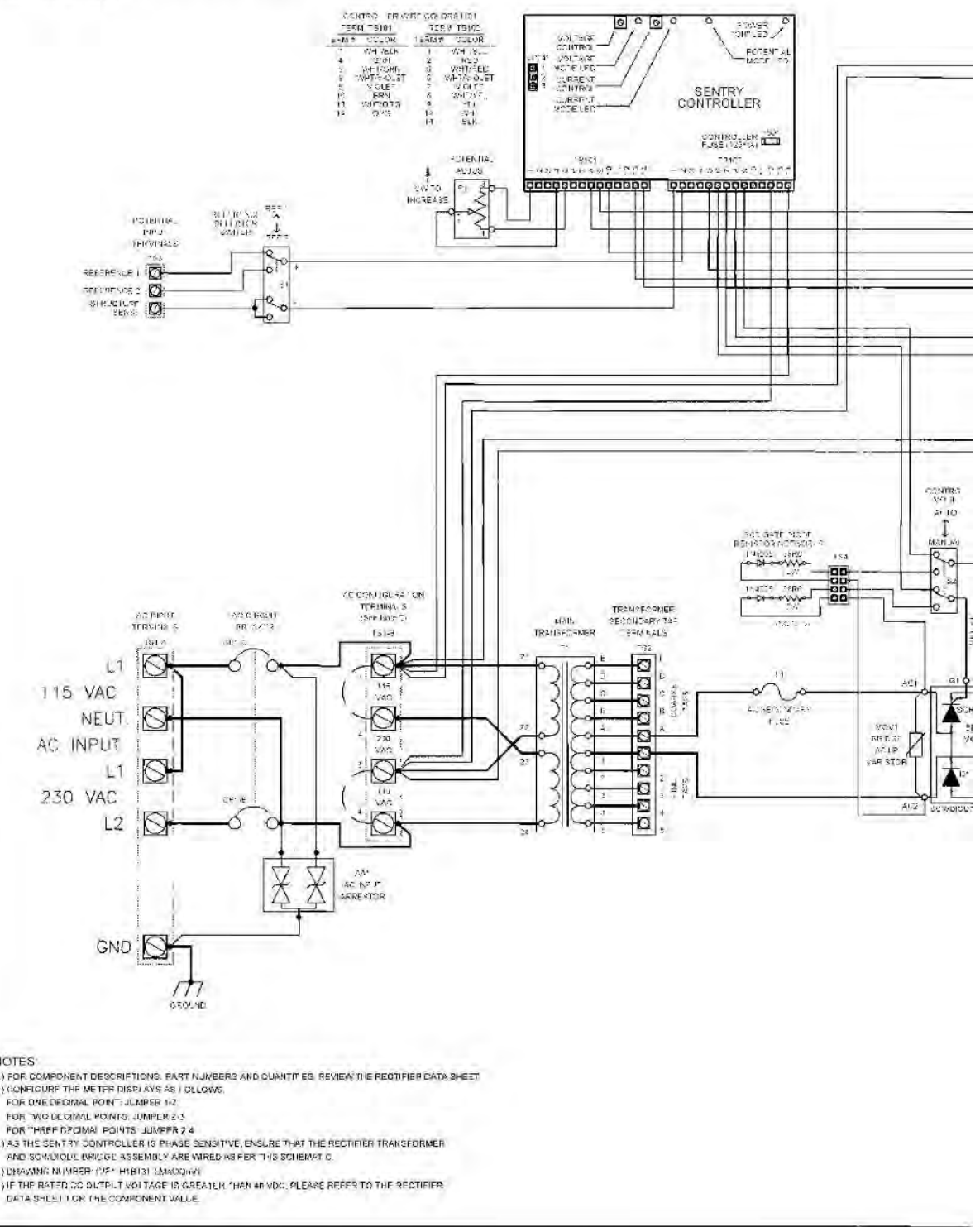




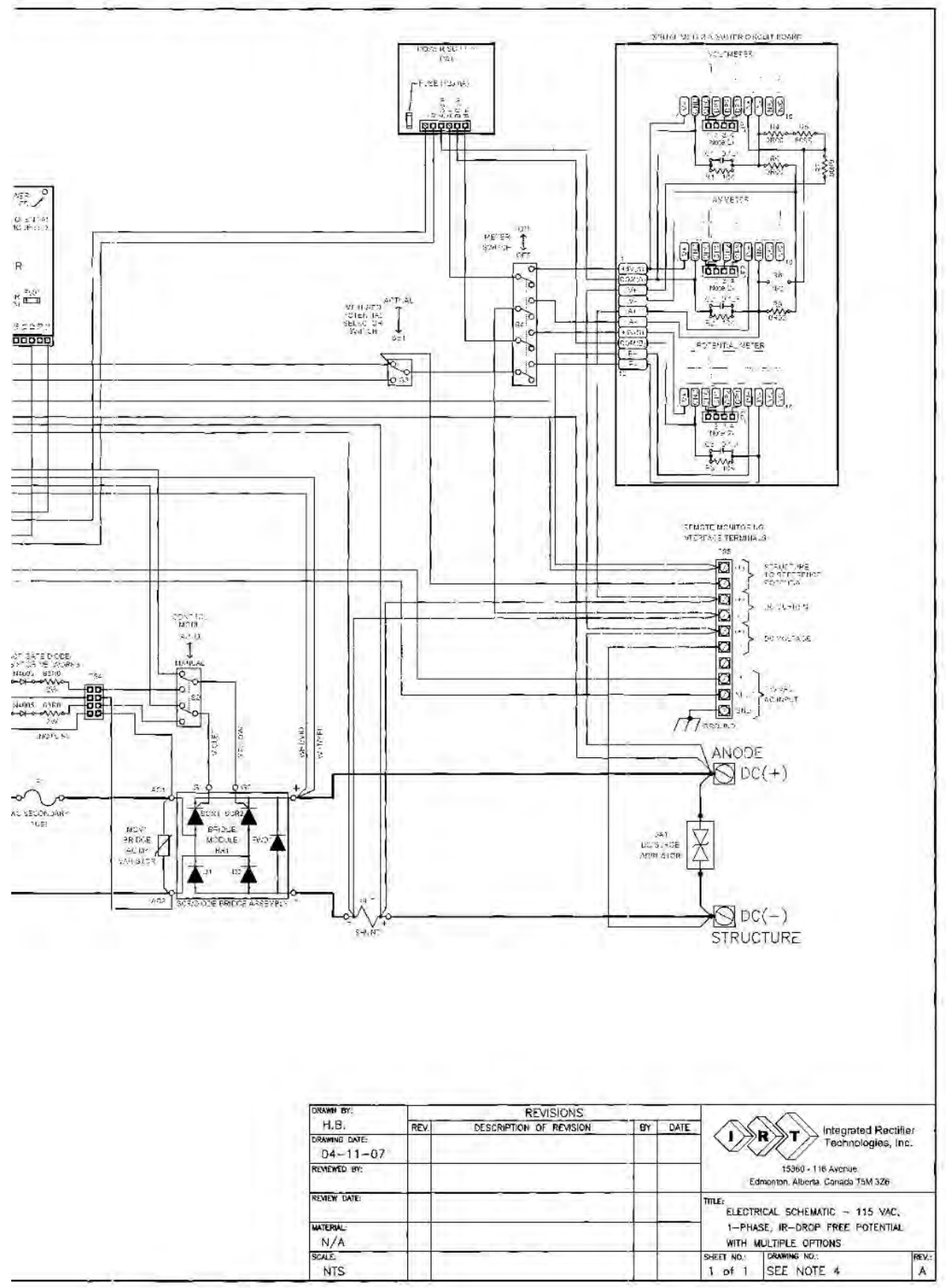




\title{
Appendix C: DART RMU Hardware Specification
}

Dart for Rectifier - Hardware Specification 2007-07-30 -

\section{DART for Rectifier - Hardware Specification -}

\author{
1. Power Supply \\ 1.01. Input Voltage: $\quad 9 \mathrm{~V}$ to $36 \mathrm{~V} D C$ \\ 1.02. Input Current : $\quad 100 \mathrm{~mA}$ at $12 \mathrm{~V}$
}

2. Radio Specification

2.01. Frequency:

2.02. Power:

2.03. Data Rate:

列

$130 \mathrm{~dB}$ link budget ( $250 \mathrm{~mW}$ )

$152.34 \mathrm{kbit} / \mathrm{sec}$ maximum RF data rate

2.04. Antenna connector

SMA

3. Dimensions (Approximately)

3.01. Length

3.02. Width

3.03. Hight:

3.04. Weight :

$2^{\prime \prime}($ ca. $5 \mathrm{~cm})$

$7^{\prime \prime}$ ( ca. $17,5 \mathrm{~cm}$ )

$6^{\prime \prime}$ ( ca. $15 \mathrm{~cm}$ )

$161 / 4 \mathrm{oz}$ (ca. $460 \mathrm{~g}$ )

4. Terminal block (From left to right)

$\begin{array}{ll}\text { 4.01. Orange: } & \begin{array}{l}\text { Rectifier voltage, positive } \\ \text { Rectifier voltage, negative }\end{array} \\ \text { 4.02. Grey: } & \text { Rectifier amperage ( shunt), positive } \\ \text { 4.03. Orange: } & \text { Rectifier amperage ( shunt), negative } \\ \text { 4.04. Grey: } & \text { Structure potential, positive (Structure) } \\ \text { 4.05. Orange: } & \text { Structure potential, negative (Reference Cell) } \\ \text { 4.06. Grey: } & \text { Relay1, normally closed contact } \\ \text { 4.07. Blue: } & \text { Relay, common contact } \\ \text { 4.08. White: } & \text { Relay2, normally open contact } \\ \text { 4.09. Blue: } & \text { Power supply, positive } \\ \text { 4.10. Orange } & \text { Power supply, negative } \\ \text { 4.11. Grey: } & \end{array}$

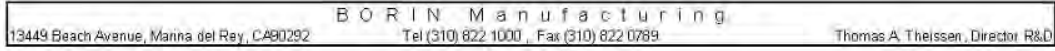
Page 1 of 5 


\section{Electrical characteristics}

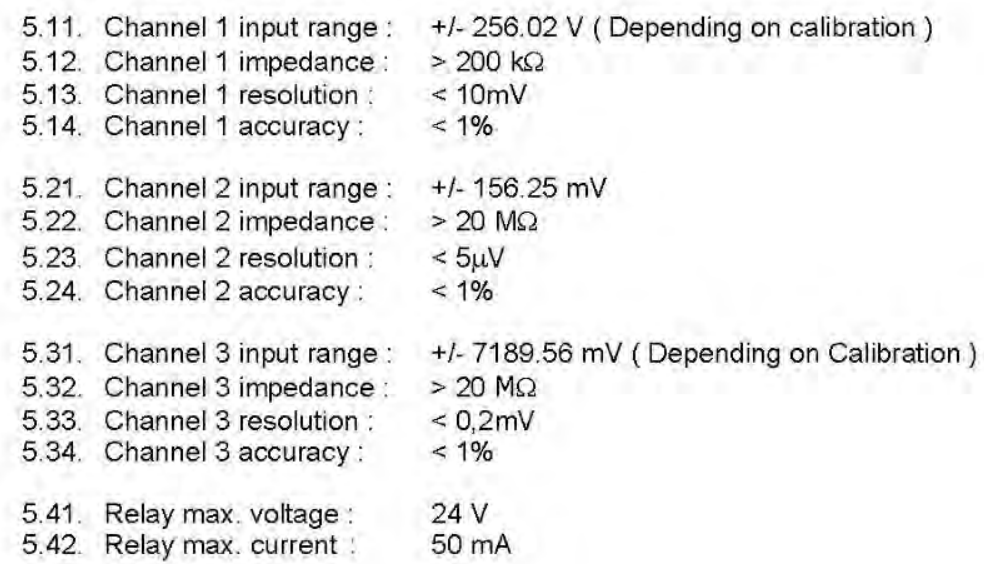

\section{LED's ( Determined by Software)}

\subsection{Data Logger Mode}
6.1.1. LED A :
Activated with full memory (End of measurements)
6.1.2. LED B : Deactivated with new settings ( Initialisation )
6.1.3. LEDC:
Activated with first sample (Start of cycle)
6.1.3. LED C : Deactivated with last sample (End of cylcle)
POWER LED ( $1 \mathrm{kHz}$ )

6.2. Interrupter Mode :
6.2.1. LED A :
State of relay 1
6.2.2. LED B :
State of relay 2
6.2.3. LED C :
POWER LED ( $1 \mathrm{kHz})$ 
Dart for Rectifier - Hardware Specification 2007-07-30 -

\section{Board Layout and Photo}

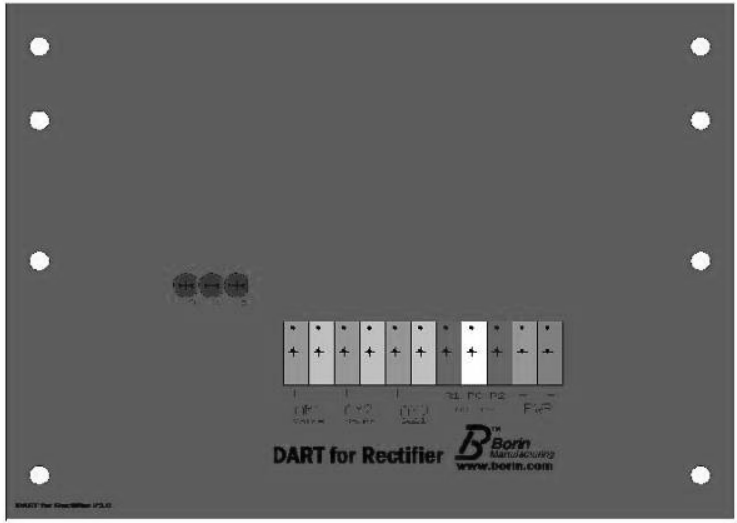

Fig. 1 : Dart for Rectifier, board layout

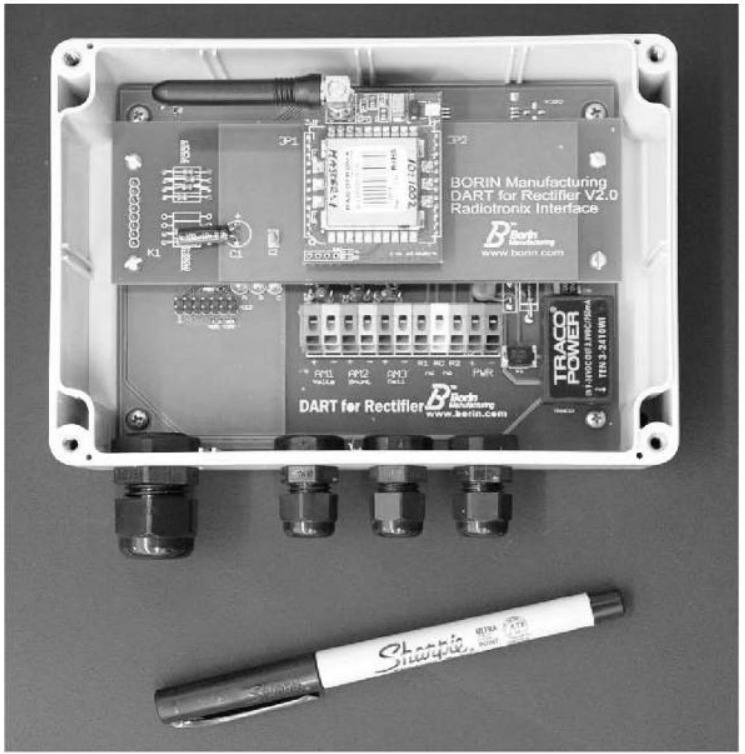

Fig 2 : Dart for Rectifier, photo

\begin{tabular}{|llll|}
\hline 13449 Beach Avenue, Marina del Rey, CA90292 & B O R I N M a n u f a o f u r i n g \\
\hline
\end{tabular} Page 3 of 5 
8. Outline ( inch ) for mounting holes - not to scale

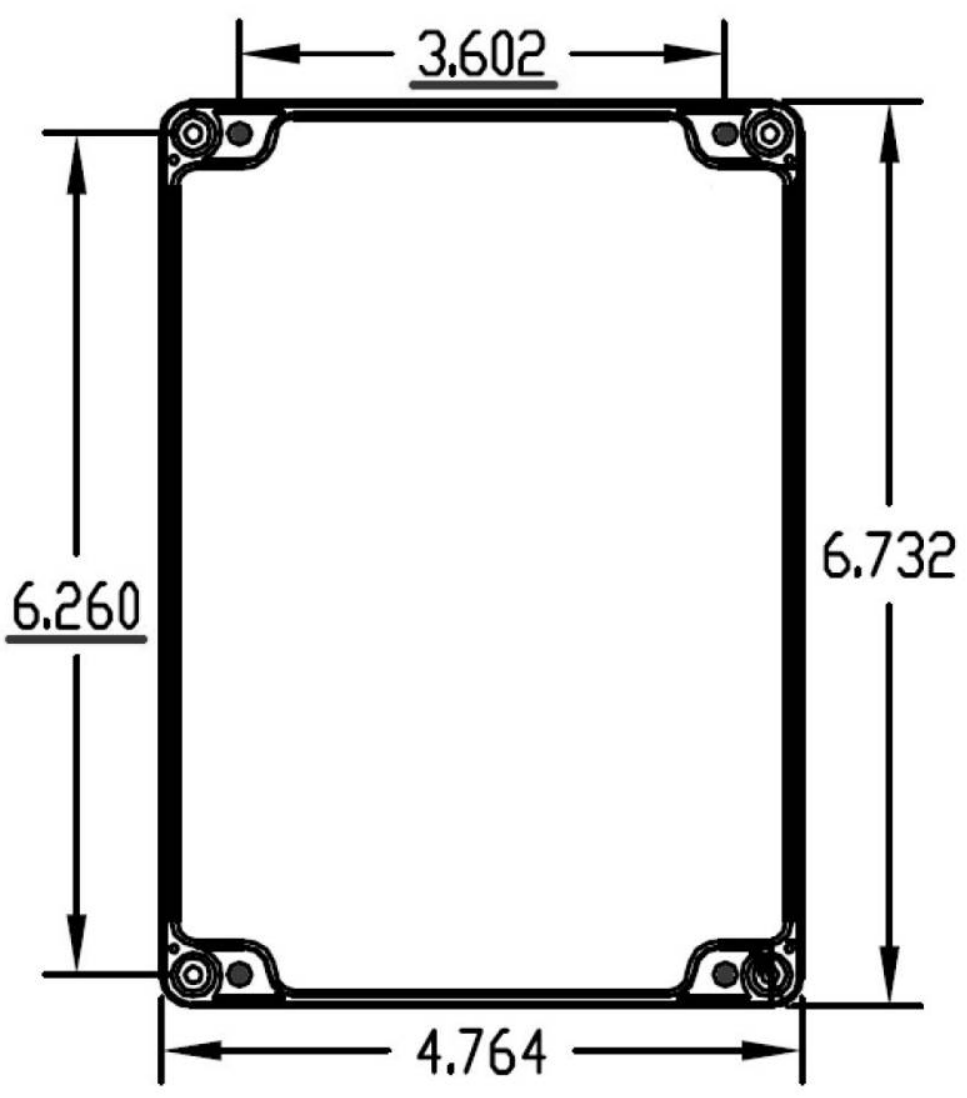

Fig 3 : Mounting holes 
Dart for Rectifier - Hardware Specification 2007-07-30 -

\section{Timing Parameters}
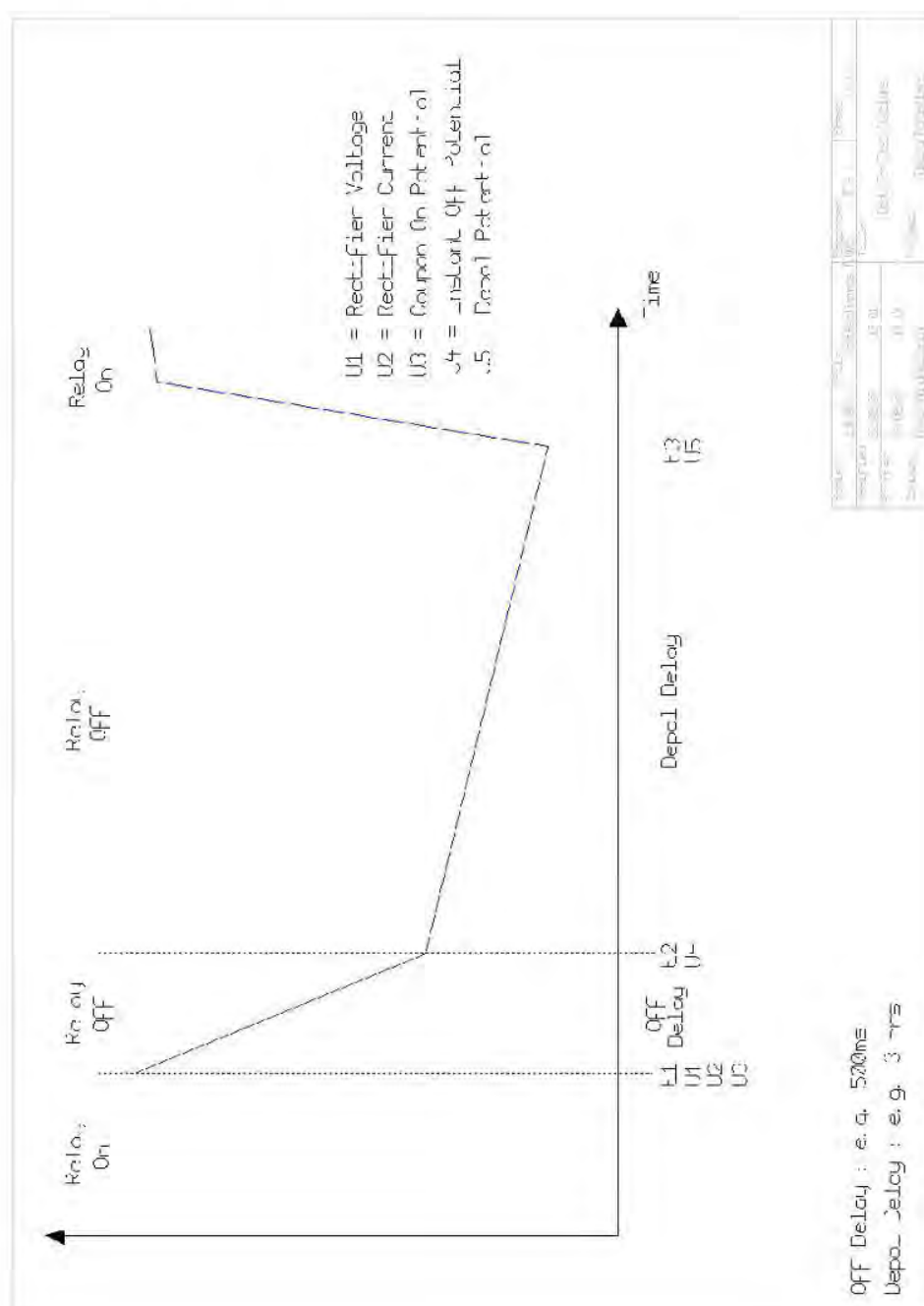

13449 Beach Avenue, Marina del Rey, CA90292

BORIN Manufacturing Tel (310) 8221000 , Fax (310) 8220789 Thomas A. Theissen, Director R\&D Page 5 of 5 



\section{Appendix D: Baseline Native Potential Surveys}

Native potentials of gas lines before RMU installation, 24 March 2007

\begin{tabular}{|c|c|}
\hline $\begin{array}{l}\text { Proposed DART } \\
\text { Site No. }\end{array}$ & $\begin{array}{l}\text { Native Potential } \\
\text { (-mV vs portable Cu-CuSO4) }\end{array}$ \\
\hline 1 & -169 \\
\hline 2 & -399 \\
\hline 3 & -801 \\
\hline 4 & -135 \\
\hline 5 & -378 \\
\hline 6 & -555 \\
\hline 7 & -422 \\
\hline 8 & -517 \\
\hline 9 & Locked area \\
\hline 10 & -361 \\
\hline 11 & -410 \\
\hline 12 & -381 \\
\hline 13 & -428 \\
\hline 14 & -643 \\
\hline 15 & Locked area \\
\hline 16 & -3441 \\
\hline 17 & -556 \\
\hline 18 & -310 \\
\hline 19 & -401 \\
\hline 20 & -388 \\
\hline 21 & -411 \\
\hline 22 & -625 \\
\hline 23 & -327 \\
\hline 24 & -185 \\
\hline 25 & -347 \\
\hline 26 & $\begin{array}{l}-98 \text { outside plastic } \\
\text { conduit; and }-77 \text { inside } \\
\text { conduit }\end{array}$ \\
\hline 27 & -435 \\
\hline 28 & -146 \\
\hline 29 & -288 \\
\hline 30 & -317 \\
\hline 31 & -331 \\
\hline
\end{tabular}




\begin{tabular}{|c|c|}
\hline $\begin{array}{l}\text { Proposed DART } \\
\text { Site No. }\end{array}$ & $\begin{array}{l}\text { Native Potential } \\
\text { (-mV vs portable Cu-CuSO4) }\end{array}$ \\
\hline 32 & $\begin{array}{l}-65 \text { in wetted concrete in } \\
\text { plastic conduit }\end{array}$ \\
\hline 33 & -491 \\
\hline 34 & -602 \\
\hline 35 & -581 \\
\hline 36 & -249 \\
\hline 37 & -381 \\
\hline 38 & -206 \\
\hline 39 & -417 \\
\hline 40 & -1587 \\
\hline 41 & -260 \\
\hline 42 & -336 \\
\hline 43 & -956 \\
\hline 44 & -435 \\
\hline 45 & -236 \\
\hline 46 & -455 \\
\hline 47 & -564 \\
\hline 48 & -335 \\
\hline 49 & -376 \\
\hline 50 & -22 \\
\hline 51 & -502 \\
\hline 52 & -151 \\
\hline 53 & -178 \\
\hline 54 & -384 \\
\hline 55 & -379 \\
\hline 56 & -3 \\
\hline 57 & -406 \\
\hline 58 & -467 \\
\hline 59 & -434 \\
\hline 60 & -437 \\
\hline 61 & -411 \\
\hline 62 & -490 \\
\hline 63 & -420 \\
\hline 64 & -429 \\
\hline 65 & -333 \\
\hline 66 & -286 \\
\hline 67 & -384 \\
\hline 68 & -349 \\
\hline 69 & -412 \\
\hline
\end{tabular}




\begin{tabular}{|c|c|}
\hline $\begin{array}{l}\text { Proposed DART } \\
\text { Site No. }\end{array}$ & $\begin{array}{l}\text { Native Potential } \\
\text { (-mV vs portable Cu-CuSO4) }\end{array}$ \\
\hline 70 & -344 \\
\hline 71 & -416 \\
\hline 72 & -401 \\
\hline 73 & -439 \\
\hline 74 & -9 \\
\hline 75 & -469 \\
\hline 76 & -411 \\
\hline 77 & -400 \\
\hline 78 & -479 \\
\hline 79 & -500 \\
\hline 80 & -441 \\
\hline 81 & -229 \\
\hline 82 & -404 \\
\hline 83 & -378 \\
\hline 84 & -1 \\
\hline 85 & -293 \\
\hline 86 & -275 \\
\hline 87 & -419 \\
\hline 88 & -395 \\
\hline 89 & -554 \\
\hline 90 & -429 \\
\hline 91 & -459 \\
\hline 92 & -381 \\
\hline 93 & -328 \\
\hline 94 & 0 \\
\hline 95 & -433 \\
\hline 96 & -209 \\
\hline 97 & -183 \\
\hline 98 & -317 \\
\hline 99 & -473 \\
\hline 100 & -465 \\
\hline 101 & -316 \\
\hline 102 & -329 \\
\hline 103 & -458 \\
\hline 104 & -316 \\
\hline 105 & -340 \\
\hline 106 & -377 \\
\hline 107 & -311 \\
\hline
\end{tabular}


Native potentials of gas lines, CP not energized, 19 October 2007

\begin{tabular}{|c|c|c|}
\hline $\begin{array}{l}\text { Test Station } \\
\text { No. }\end{array}$ & $\begin{array}{l}\text { Structure Potential (mV) vs } \\
\text { Portable Cu/CuSO4 Ref Cell }\end{array}$ & $\begin{array}{l}\text { Structure Potential (mV) vs DART } \\
\text { Ref Cell (PR1) }\end{array}$ \\
\hline 1 & -121 & -182 \\
\hline 2 & -499 & -485 \\
\hline 3 & -761 & -774 \\
\hline 4 & -173 & -162 \\
\hline \multicolumn{3}{|l|}{5} \\
\hline 6 & -343 & -373 \\
\hline 7 & -348 & -445 \\
\hline 8 & -457 & -403 \\
\hline \multicolumn{3}{|l|}{9} \\
\hline 10 & -341 & -330 \\
\hline 11 & -393 & -380 \\
\hline 12 & -311 & -292 \\
\hline 13 & -443 & $\begin{array}{l}\text { Structure and coupons all zero } \\
\text { vs Borin reference cell }\end{array}$ \\
\hline 14 & -205 & -182 \\
\hline \multicolumn{3}{|l|}{15} \\
\hline 16 & -4527 & -3933 \\
\hline 17 & -642 & -668 \\
\hline 18 & -310 & -277 \\
\hline 19 & -507 & -434 \\
\hline 20 & -298 & -354 \\
\hline 21 & -333 & -285 \\
\hline 22 & -235 & -252 \\
\hline 23 & -286 & -308 \\
\hline 24 & -185 & -161 \\
\hline 25 & -141 & -71 \\
\hline 26 & -483 & -456 \\
\hline 27 & -485 & -441 \\
\hline 28 & -151 & -148 \\
\hline 29 & -323 & -288 \\
\hline 30 & -331 & -284 \\
\hline 31 & -232 & -205 \\
\hline 32 & -362 & -379 \\
\hline 33 & -518 & -486 \\
\hline 34 & -380 & -279 \\
\hline 35 & -577 & -538 \\
\hline
\end{tabular}




\begin{tabular}{|c|c|c|}
\hline $\begin{array}{l}\text { Test Station } \\
\text { No. }\end{array}$ & $\begin{array}{l}\text { Structure Potential (mV) vs } \\
\text { Portable } \mathrm{Cu} / \text { CuSO4 Ref Cell }\end{array}$ & $\begin{array}{l}\text { Structure Potential (mV) vs DART } \\
\text { Ref Cell (PR1) }\end{array}$ \\
\hline 36 & -236 & -187 \\
\hline 37 & -409 & -424 \\
\hline 38 & -263 & -179 \\
\hline \multicolumn{3}{|l|}{39} \\
\hline 40 & -1349 & -1268 \\
\hline 4 & -238 & -237 \\
\hline \multicolumn{3}{|l|}{42} \\
\hline 43 & -765 & -757 \\
\hline 44 & -398 & -393 \\
\hline 45 & -254 & -237 \\
\hline 46 & -289 & -268 \\
\hline 47 & -393 & -411 \\
\hline 48 & -247 & -226 \\
\hline 49 & -190 & -162 \\
\hline 50 & -222 & -233 \\
\hline 51 & -289 & -327 \\
\hline \multicolumn{3}{|l|}{52} \\
\hline \multicolumn{3}{|l|}{53} \\
\hline \multicolumn{3}{|l|}{54} \\
\hline 55 & -386 & -352 \\
\hline 56 & -406 & -387 \\
\hline 57 & -391 & -367 \\
\hline 58 & -460 & -487 \\
\hline 59 & -446 & -431 \\
\hline 60 & -441 & -416 \\
\hline 61 & -437 & -412 \\
\hline 62 & -475 & -435 \\
\hline 63 & -375 & -375 \\
\hline 64 & -454 & -386 \\
\hline 65 & -377 & \\
\hline 66 & -313 & -310 \\
\hline 67 & -243 & -271 \\
\hline 68 & -351 & -377 \\
\hline 69 & -396 & -370 \\
\hline 70 & -136 & -132 \\
\hline 71 & -458 & -408 \\
\hline 72 & -426 & -418 \\
\hline 73 & -428 & -402 \\
\hline
\end{tabular}




\begin{tabular}{|l|l|l|}
\hline $\begin{array}{l}\text { Test Station } \\
\text { No. }\end{array}$ & $\begin{array}{l}\text { Structure Potential (mV) vs } \\
\text { Portable Cu/CuSO4 Ref Cell }\end{array}$ & $\begin{array}{l}\text { Structure Potential (mV) vs DART } \\
\text { Ref Cell (PR1) }\end{array}$ \\
\hline 74 & -327 & -312 \\
\hline 75 & & \\
\hline 76 & & \\
\hline 77 & & \\
\hline 78 & & \\
\hline 79 & & \\
\hline 80 & & \\
\hline 81 & & \\
\hline 82 & & \\
\hline 83 & & \\
\hline 84 & & \\
\hline 85 & & \\
\hline 86 & & \\
\hline 87 & & -328 \\
\hline 88 & & -506 \\
\hline 89 & -500 & -173 \\
\hline 90 & -439 & -203 \\
\hline 91 & -297 & \\
\hline 92 & -256 & -456 \\
\hline 93 & -390 & \\
\hline 94 & -513 & \\
\hline 95 & -299 & \\
\hline 96 & -231 & \\
\hline 97 & -263 & \\
\hline 98 & & \\
\hline 99 & & \\
\hline 100 & & \\
\hline 101 & & \\
\hline 102 & & \\
\hline 103 & & \\
\hline 104 & & \\
\hline 105 & & \\
\hline
\end{tabular}

\section{Notes}

All 4 DART terminals - 393 mV vs portable ref cell. On 10/ 19/ 07 retested by disconnecting all leads from DART unit and measuring them individually vs Borin ref cell; Structure lead - 388 mV; coupon 1 lead - 304 mV; 
coupon 2 lead - $303 \mathrm{mV}$. Borin ref cell lead $-54 \mathrm{mV}$ vs portable ref cell. Structure vs. portable ref cell, $-443 \mathrm{mV}$. Reconnected all leads and reread. This time readings OK per preceding. Apparently whatever "short" existed appears to have cleared as a result of disconnecting the DART leads and reconnecting them.

Retested on 10/19/ 07; similar data obtained as on 10/16/07; did troubleshooting and found DART wired backwards; i.e., \#12 and \#16 black leads reversed; yellow and orange leads reversed; rewired correctly and remeasured TS-65 (see below).

\section{DART RMU Terminals}

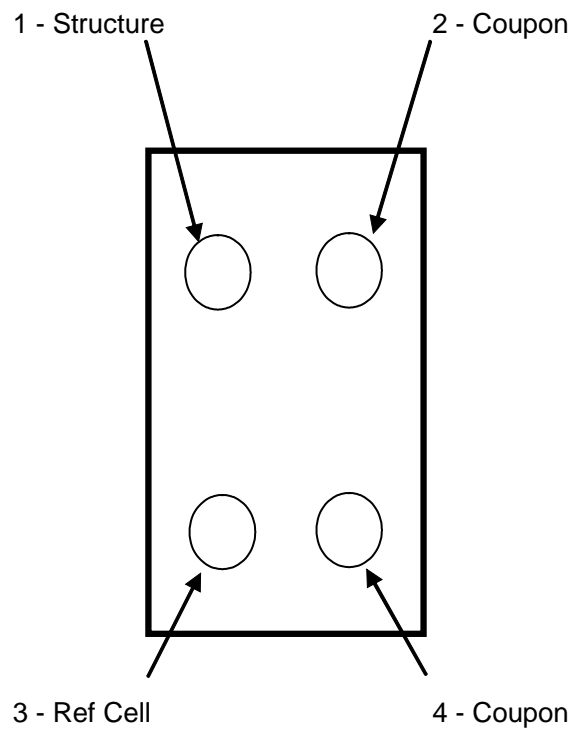

\begin{tabular}{|c|c|c|}
\hline \multicolumn{3}{|c|}{$\begin{array}{c}\text { TS-65 : Measured Potentials } \\
\text { on 10/16/07 }\end{array}$} \\
\hline Terminal & $\begin{array}{c}\text { vs. DART } \\
\text { Ref Cell } \\
\text { (mV) }\end{array}$ & $\begin{array}{c}\text { vs. } \\
\text { Portable } \\
\text { Ref Cell } \\
\text { (mV) }\end{array}$ \\
\hline & & \\
\hline 1 & 0 & -377 \\
\hline 2 & 1 & -375 \\
\hline 3 & N/A & -21 \\
\hline 4 & -355 & -375 \\
\hline
\end{tabular}





\title{
Appendix E: Transformer/Rectifier Data
}

\author{
Washington Transformer/Rectifier
}

Model No. CCASFS60-34MaQa

S/N 07R-0408

AC Voltage 115/230; AC Amperage 33/16.5

DC Voltage 60; DC Amperage 34

NEMA 3R Enclosure $60 \mathrm{~Hz} / 1-\mathrm{PH}$

\begin{tabular}{|c|c|c|c|c|}
\hline Date & $10 / 19 / 07$ & $10 / 19 / 07$ & $11 / 14 / 07$ & $12 / 12 / 07$ \\
\hline Time & 2:35 p.m. & 2:40 p.m. & 9:00 a.m. & 3:34 p.m. \\
\hline T/R clock reading, hrs & 1.7 & 1.7 & 621.7 & 1299.5 \\
\hline Tap setting, \% & 75 & 75 & 75 & 75 \\
\hline Current adjust setting, $\%$ & 0 & 40 & 40 & 40 \\
\hline $\mathrm{T} / \mathrm{R}$ mode & $\mathrm{N} / \mathrm{A}$ & voltage & voltage & voltage \\
\hline$T / R$ Meter reading $D C$ volts & 0 & 49 & 48.5 & 48 \\
\hline $\mathrm{T} / \mathrm{R}$ meter reading $\mathrm{DC}$ amps & 0 & 1.2 & 1.7 & 2 \\
\hline Reading across $+/$ - terminals, DC volts & 0 & 49.48 & 49.11 & 48.85 \\
\hline Reading across $50 \mathrm{mV} / 40 \mathrm{~A}$ shunt, $\mathrm{mV}$ & 0 & 1.94 & 2.72 & 2.83 \\
\hline $\begin{array}{l}\text { Computed current from shunt voltage } \\
\text { drop, amps }\end{array}$ & 0 & 1.552 & 2.176 & 2.264 \\
\hline $\begin{array}{l}\text { Reading across 0.01-ohm anode shunt } \\
\text { No. 1, mV }\end{array}$ & 0 & 2.16 & 2.88 & 2.92 \\
\hline $\begin{array}{l}\text { Reading across } 0.01 \text {-ohm anode shunt } \\
\text { No. } 2, \mathrm{mV}\end{array}$ & 0 & 3.35 & 4.28 & 4.26 \\
\hline $\begin{array}{l}\text { Reading across } 0.01 \text {-ohm anode shunt } \\
\text { No. } 3, \mathrm{mV}\end{array}$ & 0 & 3.99 & 6.79 & 7.00 \\
\hline $\begin{array}{l}\text { Reading across } 0.01 \text {-ohm anode shunt } \\
\text { No. } 4, \mathrm{mV}\end{array}$ & 0 & 5.98 & 7.76 & 8.24 \\
\hline $\begin{array}{l}\text { Computed current from sum of voltage } \\
\text { drops across anode shunts, amps }\end{array}$ & 0 & 1.548 & 2.171 & 2.242 \\
\hline $\begin{array}{l}\text { TS-7 Native potential, volts vs. Borin } \\
\mathrm{Cu} \text { /CuSO4 half cell }\end{array}$ & -0.454 & & & \\
\hline $\begin{array}{l}\text { TS-7 Native potential, volts vs. portable } \\
\text { Cu/CuSO4 half cell }\end{array}$ & -0.468 & & & \\
\hline $\begin{array}{l}\text { TS-7 Polarized potential, volts vs. Borin } \\
\mathrm{Cu} / \mathrm{CuSO} 4 \text { half cell }\end{array}$ & & -2.656 & -3.159 & -3.503 \\
\hline $\begin{array}{l}\text { TS-7 Polarized potential, volts vs. } \\
\text { portable } \mathrm{Cu} \text { /CuSO4 half cell }\end{array}$ & & -2.858 & -3.142 & \\
\hline
\end{tabular}




\section{CEP\#1 Transformer/Rectifier (outside Bldg 2288)}

Model No. CCASFS60-34MaQa

S/N 07R-0407

AC Voltage 115/230; AC Amperage 33/16.5

DC Voltage 60; DC Amperage 34

NEMA 3R Enclosure $60 \mathrm{~Hz} / 1-\mathrm{PH}$

\begin{tabular}{|c|c|c|c|c|c|}
\hline Date & $10 / 19 / 07$ & $10 / 19 / 07$ & $11 / 14 / 07$ & $12 / 12 / 07$ & $1 / 24 / 08$ \\
\hline Time & 3:15 p.m. & 3:20 p.m. & 9:35 a.m. & 4:00 p.m. & 1:25 p.m. \\
\hline T/R clock reading, hrs & 0.9 & 0.9 & 620.9 & 1298.3 & 2326.9 \\
\hline Tap setting, \% & 75 & 75 & 75 & 75 & 75 \\
\hline Current adjust setting, $\%$ & 0 & 65 & 65 & 65 & 70 \\
\hline$T / R$ mode & N/A & voltage & voltage & voltage & voltage \\
\hline$T / R$ Meter reading $D C$ volts & 0 & 56 & 56 & 57 & 56 \\
\hline $\mathrm{T} / \mathrm{R}$ meter reading $\mathrm{DC}$ amps & 0 & 17 & 16.5 & 16 & 16 \\
\hline Reading across $+/$ - terminals, DC volts & 0 & 56.5 & 56.1 & 56.5 & 56.1 \\
\hline Reading across $50 \mathrm{mV} / 40 \mathrm{~A}$ shunt, $\mathrm{mV}$ & 0 & 21.53 & 21.06 & 20.89 & 20.54 \\
\hline $\begin{array}{l}\text { Computed current from shunt voltage } \\
\text { drop, amps }\end{array}$ & 0 & 17.224 & 16.848 & 16.712 & 16.432 \\
\hline $\begin{array}{l}\text { Reading across } 0.01 \text {-ohm anode shunt } \\
\text { No. } 1, \mathrm{mV}\end{array}$ & 0 & 44.02 & 42.34 & 41.50 & 41.42 \\
\hline $\begin{array}{l}\text { Reading across } 0.01 \text {-ohm anode shunt } \\
\text { No. } 2, \mathrm{mV}\end{array}$ & 0 & 34.14 & 31.49 & 30.37 & 27.31 \\
\hline $\begin{array}{l}\text { Reading across } 0.01 \text {-ohm anode shunt } \\
\text { No. } 3, \mathrm{mV}\end{array}$ & 0 & 43.40 & 41.06 & 41.75 & 41.53 \\
\hline $\begin{array}{l}\text { Reading across } 0.01 \text {-ohm anode shunt } \\
\text { No. } 4, \mathrm{mV}\end{array}$ & 0 & 50.00 & 53.30 & 53.00 & 53.7 \\
\hline $\begin{array}{l}\text { Computed current from sum of voltage } \\
\text { drops across anode shunts, amps }\end{array}$ & 0 & 17.156 & 16.819 & 16.662 & 16.396 \\
\hline $\begin{array}{l}\text { TS-16 Native potential, volts vs. Borin } \\
\text { Cu/CuSO4 half cell }\end{array}$ & -3.941 & & & & \\
\hline $\begin{array}{l}\text { TS-16 Native potential, volts vs. portable } \\
\mathrm{Cu} / \text { CuSO4 half cell }\end{array}$ & -4.135 & & & & \\
\hline $\begin{array}{l}\text { TS-16 Polarized potential, volts vs. Borin } \\
\mathrm{Cu} / \text { CuSO4 half cell }\end{array}$ & & -6.11 & -5.47 & -5.37 & \\
\hline $\begin{array}{l}\text { TS-16 Polarized potential, volts vs. } \\
\text { portable Cu/CuSO4 half cell }\end{array}$ & & -6.67 & -5.64 & & \\
\hline
\end{tabular}




\section{Hill \& Hardee Transformer/Rectifier}

Model No. CCASFS60-34MaQa

S/N 07R-?

AC Voltage 115/230; AC Amperage 33/16.5

DC Voltage 60; DC Amperage 34

NEMA 3R Enclosure $60 \mathrm{~Hz} / 1-\mathrm{PH}$

\begin{tabular}{|c|c|c|c|c|c|}
\hline Date & $10 / 19 / 07$ & \begin{tabular}{l|l}
$10 / 19 / 07$ \\
\end{tabular} & $711 / 14 / 07$ & $12 / 12 / 07$ & $7 / 24 / 08$ \\
\hline Time & 3:45 p.m. & 3:20 p.m. & 10:25 a.m. & 4:15 p.m. & 1:35 p.m. \\
\hline$T / R$ clock reading, hrs & 1.2 & 1.2 & 621.4 & 1298.3 & 2326.8 \\
\hline Tap setting, \% & 75 & 75 & 75 & 75 & 75 \\
\hline Current adjust setting, $\%$ & 0 & 50 & 50 & 50 & 50 \\
\hline $\mathrm{T} / \mathrm{R}$ mode & $N / A$ & voltage & voltage & voltage & voltage \\
\hline$T / R$ Meter reading $D C$ volts & 0 & 59 & 59 & 58.5 & 57.5 \\
\hline $\mathrm{T} / \mathrm{R}$ meter reading $\mathrm{DC}$ amps & 0 & 9 & 9.5 & 9.5 & 9.5 \\
\hline Reading across $+/$ - terminals, DC volts & 0 & 58.5 & 58.2 & 57.4 & 56.8 \\
\hline Reading across $50 \mathrm{mV} / 40 \mathrm{~A}$ shunt, $\mathrm{mV}$ & 0 & 11.68 & 12.21 & 12.07 & 11.98 \\
\hline $\begin{array}{l}\text { Computed current from shunt voltage } \\
\text { drop, amps }\end{array}$ & 0 & 9.344 & 9.768 & 9.656 & 9.584 \\
\hline $\begin{array}{l}\text { Reading across 0.01-ohm anode shunt } \\
\text { No. } 1, \mathrm{mV}\end{array}$ & 0 & 28.59 & 26.79 & 25.36 & 24.05 \\
\hline $\begin{array}{l}\text { Reading across } 0.01 \text {-ohm anode shunt } \\
\text { No. } 2, \mathrm{mV}\end{array}$ & 0 & 17.81 & 18.95 & 19.63 & 20.91 \\
\hline $\begin{array}{l}\text { Reading across } 0.01 \text {-ohm anode shunt } \\
\text { No. } 3, \mathrm{mV}\end{array}$ & 0 & 28.53 & 33.22 & 33.17 & 31.74 \\
\hline $\begin{array}{l}\text { Reading across } 0.01 \text {-ohm anode shunt } \\
\text { No. } 4, \mathrm{mV}\end{array}$ & 0 & 17.79 & 18.44 & 18.08 & 18.85 \\
\hline $\begin{array}{l}\text { Computed current from sum of voltage } \\
\text { drops across anode shunts, amps }\end{array}$ & 0 & 9.272 & 9.74 & 9.624 & 9.555 \\
\hline \multicolumn{6}{|l|}{$\begin{array}{l}\text { Native potential, volts vs. Borin } \\
\mathrm{Cu} / \mathrm{CuSO} 4 \text { half cell }\end{array}$} \\
\hline $\begin{array}{l}\text { Native potential, volts vs. portable } \\
\mathrm{Cu} / \text { CuSO4 half cell }\end{array}$ & -0.454 & & & & \\
\hline \multicolumn{6}{|l|}{$\begin{array}{l}\text { Polarized potential, volts vs. Borin } \\
\mathrm{Cu} / \mathrm{CuSO} 4 \text { half cell }\end{array}$} \\
\hline $\begin{array}{l}\text { Polarized potential, volts vs. portable } \\
\text { Cu/CuSO4 half cell }\end{array}$ & & -9.36 & -6.15 & & \\
\hline
\end{tabular}





\section{Appendix F: DART RMU Data}




\begin{tabular}{|c|c|c|c|c|c|c|c|c|c|c|c|c|c|c|c|}
\hline Test Stations & Date & $\begin{array}{l}\text { Structure } \\
\text { Potential }\end{array}$ & $\begin{array}{l}\text { Coupon ON } \\
\text { Potential* }\end{array}$ & $\begin{array}{l}\text { Coupon } \\
\text { Instant OFF }\end{array}$ & $\begin{array}{l}\text { Coupon } 4 \mathrm{Hr} \\
\text { Depolanized } \\
\text { Potential }\end{array}$ & $\begin{array}{l}\text { Potential } \\
\text { More Neg. } \\
\text { the }-850 \mathrm{mV}\end{array}$ & $\begin{array}{l}\text { Polar- } \\
\text { ization }=\text { or }> \\
100 \mathrm{mV}\end{array}$ & $\begin{array}{l}\text { Polar- } \\
\text { ization }>50 \\
\mathrm{mV}\end{array}$ & $\begin{array}{l}\text { Polar- } \\
\text { ization }>\mathbf{2 0} \\
\mathrm{mV}\end{array}$ & $\begin{array}{l}\text { Polar- } \\
\text { ization }>10 \\
\mathrm{mV}\end{array}$ & $\begin{array}{l}\text { Polar- } \\
\text { ization }>0 \\
\mathrm{mV}\end{array}$ & $\begin{array}{l}\text { Coupon } \\
\text { Current } \\
\text { Pick Up }\end{array}$ & $\begin{array}{l}\text { Polar- } \\
\text { ization } \\
=\text { or }>0\end{array}$ & $\begin{array}{l}\text { Original } \\
\text { Natives }\end{array}$ & $\begin{array}{l}\text { Valid } \\
\text { Data }\end{array}$ \\
\hline TS1 -Commissary & 14-Jan-08 & 166.643 & 177.739 & 496.702 & 574.98 & No & No & No & No & No & No & No & No & & Yes \\
\hline TS1 -Commissary & 21-Jan-08 & 168.862 & 181.37 & 516.876 & 593.137 & No & No & No & No & No & No & No & No & & Yes \\
\hline TS2 -5715 North & 14-Jan-08 & 266.119 & 254.722 & 253.523 & 265.519 & No & No & No & No & No & No & Yes & Yes & & Yes \\
\hline TS2 -5715 North & 21-Jan-08 & 178.145 & 192.741 & 191.941 & 167.549 & No & No & No & Yes & Yes & Yes & No & Yes & & Yes \\
\hline TS5 & 14-Jan-08 & 344.746 & 375.667 & 575.246 & 622.43 & No & No & No & No & No & No & No & No & & Yes \\
\hline TS5 & 21-Jan-08 & 350.569 & 380.887 & 579.864 & 628.454 & No & No & No & No & No & No & No & No & & Yes \\
\hline TS6 -1699 & 14-Jan-08 & 388.671 & 392.688 & 483.881 & 515.215 & No & No & No & No & No & No & No & No & & Yes \\
\hline TS6 -1699 & 21-Jan-08 & 396.103 & 399.116 & 490.71 & 520.639 & No & No & No & No & No & No & No & No & & Yes \\
\hline TS7 -Wash. \& Essay. & 14-Jan-08 & 4098.851 & 4060.352 & 1331.748 & 939.702 & Yes & Yes & Yes & Yes & Yes & Yes & Yes & Yes & & Yes \\
\hline TS7 - Wash. \& Essay. & 21-Jan-08 & 3751.553 & 3526.604 & 1429.71 & 1102.366 & Yes & Yes & Yes & Yes & Yes & Yes & Yes & Yes & & Yes \\
\hline TS8- Wash. \& Marion & 14-Jan-08 & 561.341 & 546.891 & 500.531 & 490.095 & No & No & No & No & Yes & Yes & Yes & Yes & & Yes \\
\hline TS8- Wash. \& Marion & 21-Jan-08 & 569.971 & 557.328 & 482.268 & 471.631 & No & No & No & No & Yes & Yes & Yes & Yes & & Yes \\
\hline \multirow[t]{2}{*}{ TS10 - 2240} & 11-Jan-08 & 636.369 & 632.138 & 517.113 & 438.146 & No & No & Yes & Yes & Yes & Yes & Yes & Yes & & Yes \\
\hline & & & & & & No & No & No & No & No & No & Yes & Yes & & No \\
\hline TS11 - Across 2260 & 14-Jan-08 & 818.99 & 801.134 & 598.091 & 507.003 & No & No & Yes & Yes & Yes & Yes & Yes & Yes & & Yes \\
\hline TS11 - Across 2260 & 21-Jan-08 & 833.636 & 819.993 & 612.938 & 518.239 & No & No & Yes & Yes & Yes & Yes & Yes & Yes & & Yes \\
\hline TS12 -2260 & 14-Jan-08 & 624.678 & 594.768 & 592.342 & 580.015 & No & No & No & No & Yes & Yes & Yes & Yes & & Yes \\
\hline TS12 -2260 & 21-Jan-08 & 589.715 & 562.028 & 560.815 & 561.422 & No & No & No & No & No & No & Yes & Yes & & Yes \\
\hline TS13 -3260 & 14-Jan-08 & 672.565 & 674.741 & 635.981 & 628.07 & No & No & No & No & No & Yes & No & Yes & & Yes \\
\hline TS13 -3260 & 21-Jan-08 & 677.114 & 675.729 & 634.794 & 623.126 & No & No & No & No & Yes & Yes & Yes & Yes & & Yes \\
\hline TS14 -2410 & 14-Jan-08 & 366.169 & 391.922 & 608.606 & 645.223 & No & No & No & No & No & No & No & No & & Yes \\
\hline TS14 -2410 & 21-Jan-08 & 403.188 & 448.457 & 527.123 & 550.863 & No & No & No & No & No & No & No & No & & Yes \\
\hline TS16 -2288 & 14-Jan-08 & 5024.995 & 3696.737 & 1015.666 & 679.526 & Yes & Yes & Yes & Yes & Yes & Yes & Yes & Yes & & Yes \\
\hline TS16 -2288 & 21-Jan-08 & 5243.184 & 3955.183 & 1019.692 & 710.524 & Yes & Yes & Yes & Yes & Yes & Yes & Yes & Yes & & Yes \\
\hline TS17 -4333 & 14-Jan-08 & 1099.567 & 1079.282 & 769.438 & 594.629 & No & Yes & Yes & Yes & Yes & Yes & Yes & Yes & & Yes \\
\hline TS17 -4333 & 21-Jan-08 & 1086.839 & 1060.588 & 863.505 & 736.425 & Yes & Yes & Yes & Yes & Yes & Yes & Yes & Yes & & Yes \\
\hline TS18 -1895 & 14-Jan-08 & 293.871 & 293.871 & 281.618 & 281.819 & No & No & No & No & No & No & Yes & Yes & & Yes \\
\hline TS18-1895 & 21-Jan-08 & 306.526 & 306.124 & 294.273 & 295.277 & No & No & No & No & No & No & Yes & Yes & & Yes \\
\hline
\end{tabular}




\begin{tabular}{|c|c|c|c|c|c|c|c|c|c|c|c|c|c|c|c|}
\hline Test Stations & Date & $\begin{array}{l}\text { Structure } \\
\text { Potential }\end{array}$ & $\begin{array}{l}\text { Coupon ON } \\
\text { Potential* }\end{array}$ & $\begin{array}{l}\text { Coupon } \\
\text { Instant OFF }\end{array}$ & $\begin{array}{l}\text { Coupon } 4 \mathrm{Hr} \\
\text { Depolarized } \\
\text { Potential }\end{array}$ & $\begin{array}{l}\text { Potential } \\
\text { More Neg. } \\
\text { the }-850 \mathrm{mV}\end{array}$ & $\begin{array}{l}\text { Polar- } \\
\text { ization = or }> \\
100 \mathrm{mV}\end{array}$ & $\begin{array}{l}\text { Polar- } \\
\text { ization }>50 \\
\mathrm{mV}\end{array}$ & $\begin{array}{l}\text { Polar- } \\
\text { ization > } 20 \\
\mathrm{mV}\end{array}$ & $\begin{array}{l}\text { Polar- } \\
\text { ization }>10 \\
\mathrm{mV}\end{array}$ & $\begin{array}{l}\text { Polar- } \\
\text { ization }>0 \\
\mathrm{mV}\end{array}$ & $\begin{array}{l}\text { Coupon } \\
\text { Current } \\
\text { Pick Up }\end{array}$ & $\begin{array}{l}\text { Polar- } \\
\text { ization } \\
=\text { or }>0\end{array}$ & $\begin{array}{l}\text { Original } \\
\text { Natives }\end{array}$ & $\begin{array}{l}\text { Valid } \\
\text { Data }\end{array}$ \\
\hline TS19 -Wash. \& Hall & 14-Jan-08 & 1112.495 & 1108.663 & 527.003 & 406.395 & No & Yes & Yes & Yes & Yes & Yes & Yes & Yes & & Yes \\
\hline TS19 -Wash. \& Hallt & 21-Jan-08 & 1125.201 & 1106.242 & 535.877 & 398.731 & No & Yes & Yes & Yes & Yes & Yes & Yes & Yes & & Yes \\
\hline TS20 -4710 & 14-Jan-08 & 675.53 & 689.954 & 748.853 & 761.274 & No & No & No & No & No & No & No & No & & Yes \\
\hline TS20 -4710 & 21-Jan-08 & 651.69 & 667.116 & 747.851 & 764.078 & No & No & No & No & No & No & No & No & & Yes \\
\hline TS21 -2179 & 14-Jan-08 & 484.355 & 498.671 & 698.1 & 747.503 & No & No & No & No & No & No & No & No & & Yes \\
\hline TS21 -2179 & 21-Jan-08 & 503.309 & 515.811 & 696.89 & 749.923 & No & No & No & No & No & No & No & No & & Yes \\
\hline TS22 -2078 & 14-Jan-08 & 466.889 & 465.685 & 379.611 & 264.443 & No & Yes & Yes & Yes & Yes & Yes & Yes & Yes & & Yes \\
\hline \multirow[t]{2}{*}{ TS22-2078 } & 21-Jan-08 & 482.94 & 485.147 & 401.48 & 258.023 & No & Yes & Yes & Yes & Yes & Yes & No & Yes & & Yes \\
\hline & & & & & & No & No & No & No & No & No & Yes & Yes & & No \\
\hline TS24 -2139 South & 14-Jan-08 & 221.633 & 226.857 & 465.772 & 512.59 & No & No & No & No & No & No & No & No & & Yes \\
\hline TS24 -2139 South & 21-Jan-08 & 235.297 & 240.32 & 460.346 & 505.959 & No & No & No & No & No & No & No & No & & Yes \\
\hline TS25 -2139 Back & 14-Jan-08 & 299.356 & 554.452 & 580.405 & 586.44 & No & No & No & No & No & No & No & No & & Yes \\
\hline TS25 -2139 Back & 21-Jan-08 & 425.295 & 606.96 & 626.475 & 635.93 & No & No & No & No & No & No & No & No & 334 & Yes \\
\hline TS26 -2159 & 14-Jan-08 & 506.749 & 544.6 & 544.6 & 545.002 & No & No & No & No & No & No & No & Yes & & Yes \\
\hline TS26 -2159 & 21-Jan-08 & 529.097 & 549.834 & 549.834 & 549.23 & No & No & No & No & No & Yes & No & Yes & & Yes \\
\hline TS27 -2280 & 14-Jan-08 & 523.299 & 522.696 & 348.665 & 245.773 & No & Yes & Yes & Yes & Yes & Yes & Yes & Yes & & Yes \\
\hline TS27 -2280 & 21-Jan-08 & 525.912 & 526.313 & 429.049 & 387.651 & No & No & No & Yes & Yes & Yes & Yes & Yes & & Yes \\
\hline TS28 -3210 & 14-Jan-08 & 372.24 & 374.655 & 530.593 & 558.36 & No & No & No & No & No & No & No & No & & Yes \\
\hline TS28-3210 & 21-Jan-08 & 386.526 & 388.136 & 525.563 & 552.525 & No & No & No & No & No & No & No & No & & Yes \\
\hline TS29 -3255 & 14-Jan-08 & 370.766 & 376.979 & 536.709 & 560.358 & No & No & No & No & No & No & No & No & & Yes \\
\hline TS29-3255 & 21-Jan-08 & 377.38 & 382.991 & 534.705 & 560.558 & No & No & No & No & No & No & No & No & & Yes \\
\hline TS30 - 3250 & 14-Jan-08 & 311.537 & 320.977 & 439.486 & 476.646 & No & No & No & No & No & No & No & No & & Yes \\
\hline TS30 - 3250 & 21-Jan-08 & 316.96 & 327.003 & 449.127 & 488.095 & No & No & No & No & No & No & No & No & & Yes \\
\hline TS31 -3280 North & 14-Jan-08 & 227.371 & 259.881 & 523.978 & 551.07 & No & No & No & No & No & No & No & No & & Yes \\
\hline TS31 -3280 North & 21-Jan-08 & 209.31 & 212.922 & 275.133 & 410.192 & No & No & No & No & No & No & No & No & & Yes \\
\hline TS32 -4210 & 14-Jan-08 & 343.783 & 638.857 & 645.097 & 645.701 & No & No & No & No & No & No & No & No & 0.05 & Yes \\
\hline TS32-4210 & 21-Jan-08 & 390.681 & 638.455 & 641.474 & 642.279 & No & No & No & No & No & No & No & No & & Yes \\
\hline TS33 -2420 & 11-Jan-08 & 484.302 & 484.705 & 436.134 & 425.654 & No & No & No & No & Yes & Yes & Yes & Yes & & Yes \\
\hline
\end{tabular}




\begin{tabular}{|c|c|c|c|c|c|c|c|c|c|c|c|c|c|c|c|}
\hline Test Stations & Date & $\begin{array}{l}\text { Structure } \\
\text { Potential }\end{array}$ & $\begin{array}{l}\text { Coupon ON } \\
\text { Potential* }\end{array}$ & $\begin{array}{l}\text { Coupon } \\
\text { Instant OFF }\end{array}$ & $\begin{array}{l}\text { Coupon } 4 \mathrm{Hr} \\
\text { Depolarized } \\
\text { Potential }\end{array}$ & $\begin{array}{l}\text { Potential } \\
\text { More Neg. } \\
\text { the }-850 \mathrm{mV}\end{array}$ & $\begin{array}{l}\text { Polar- } \\
\text { ization = or }> \\
100 \mathrm{mV}\end{array}$ & $\begin{array}{l}\text { Polar- } \\
\text { ization }>50 \\
\mathrm{mV}\end{array}$ & $\begin{array}{l}\text { Polar- } \\
\text { ization > } 20 \\
\mathrm{mV}\end{array}$ & $\begin{array}{l}\text { Polar- } \\
\text { ization > } 10 \\
\mathrm{mV}\end{array}$ & $\begin{array}{l}\text { Polar- } \\
\text { ization >0 } \\
\mathrm{mV}\end{array}$ & $\begin{array}{l}\text { Coupon } \\
\text { Current } \\
\text { Pick Up }\end{array}$ & $\begin{array}{l}\text { Polar- } \\
\text { ization } \\
=\text { or }>0\end{array}$ & $\begin{array}{l}\text { Original } \\
\text { Natives }\end{array}$ & $\begin{array}{l}\text { Valid } \\
\text { Data }\end{array}$ \\
\hline & & & & & & No & No & No & No & No & No & Yes & Yes & & No \\
\hline TS34 -4250 & 14-Jan-08 & 739.773 & 723.909 & 724.11 & 723.106 & No & No & No & No & No & Yes & Yes & Yes & & Yes \\
\hline TS34 -4250 & 21-Jan-08 & 736.158 & 724.913 & 724.913 & 723.909 & No & No & No & No & No & Yes & Yes & Yes & & Yes \\
\hline TS35 -4169 & 14-Jan-08 & 552.899 & 553.502 & 523.768 & 512.517 & No & No & No & No & Yes & Yes & Yes & Yes & & Yes \\
\hline TS35 -4169 & 21-Jan-08 & 553.703 & 553.904 & 522.763 & 524.772 & No & No & No & No & No & No & Yes & Yes & & Yes \\
\hline \multirow[t]{2}{*}{ TS36 - 4270} & 11-Jan-08 & 366.846 & 674.845 & 696.389 & 703.969 & No & No & No & No & No & No & No & No & 38 & Yes \\
\hline & & & & & & No & No & No & No & No & No & Yes & Yes & & No \\
\hline TS37 -4310 & 14-Jan-08 & 7.988 & 64.303 & 328.708 & 384.624 & No & No & No & No & No & No & No & No & & Yes \\
\hline TS37 -4310 & 21-Jan-08 & -119.82 & -55.117 & 328.908 & 396.407 & No & No & No & No & No & No & No & No & & Yes \\
\hline TS38-4330 & 14-Jan-08 & 234.055 & 235.064 & 426.748 & 452.373 & No & No & No & No & No & No & No & No & & Yes \\
\hline TS38 -4330 & 21-Jan-08 & 271.181 & 270.979 & 411.615 & 435.222 & No & No & No & No & No & No & Yes & No & & Yes \\
\hline TS39-4323 & 14-Jan-08 & 1329.034 & 1272.458 & 604.742 & 358.847 & No & Yes & Yes & Yes & Yes & Yes & Yes & Yes & & Yes \\
\hline TS39 -4323 & 21-Jan-08 & 1345.427 & 1289.051 & 619.536 & 360.446 & No & Yes & Yes & Yes & Yes & Yes & Yes & Yes & & Yes \\
\hline TS40 -Shopette & 14-Jan-08 & 1384.291 & 1226.944 & 708.06 & 445.015 & No & Yes & Yes & Yes & Yes & Yes & Yes & Yes & & Yes \\
\hline TS40 -Shopette & 21-Jan-08 & 1467.769 & 1354.863 & 864.005 & 632.99 & Yes & Yes & Yes & Yes & Yes & Yes & Yes & Yes & & Yes \\
\hline TS41 -5330 & 14-Jan-08 & 246.465 & 255.074 & 401.632 & 465.501 & No & No & No & No & No & No & No & No & & Yes \\
\hline TS41 -5330 & 21-Jan-08 & 247.466 & 254.874 & 396.827 & 460.296 & No & No & No & No & No & No & No & No & & Yes \\
\hline \multirow[t]{2}{*}{ TS42 -2275 } & 11-Jan-08 & 360.709 & 367.595 & 368 & 369.013 & No & No & No & No & No & No & No & Yes & & Yes \\
\hline & & & & & & No & No & No & No & No & No & Yes & Yes & & No \\
\hline TS43 -Mosbey \& Forr. & 14-Jan-08 & 819.62 & 800.105 & 594.898 & 547.62 & No & No & No & Yes & Yes & Yes & Yes & Yes & & Yes \\
\hline TS43 -Mosbey \& Forr. & 21-Jan-08 & 820.224 & 808.354 & 608.378 & 555.668 & No & No & Yes & Yes & Yes & Yes & Yes & Yes & & Yes \\
\hline \multirow[t]{2}{*}{ TS44 -13200 } & 11-Jan-08 & 478.341 & 610.228 & 617.488 & 619.101 & No & No & No & No & No & No & No & No & 199 & Yes \\
\hline & & & & & & No & No & No & No & No & No & Yes & Yes & & No \\
\hline TS45 -13000 & 14-Jan-08 & 219.431 & 229.786 & 408.597 & 443.443 & No & No & No & No & No & No & No & No & & Yes \\
\hline TS45 -13000 & 21-Jan-08 & 214.254 & 222.219 & 346.471 & 371.958 & No & No & No & No & No & No & No & No & & Yes \\
\hline TS46 -TR12625 & 14-Jan-08 & 296.737 & 335.929 & 599.474 & 649.663 & No & No & No & No & No & No & No & No & & Yes \\
\hline TS46 -TR12625 & 21-Jan-08 & 312.534 & 351.126 & 601.873 & 655.462 & No & No & No & No & No & No & No & No & & Yes \\
\hline TS47 -TR12656 & 14-Jan-08 & 410.381 & 411.991 & 409.173 & 406.959 & No & No & No & No & No & Yes & No & Yes & & Yes \\
\hline
\end{tabular}




\begin{tabular}{|c|c|c|c|c|c|c|c|c|c|c|c|c|c|c|c|}
\hline Test Stations & Date & $\begin{array}{l}\text { Structure } \\
\text { Potential }\end{array}$ & $\begin{array}{l}\text { Coupon ON } \\
\text { Potential* }\end{array}$ & $\begin{array}{l}\text { Coupon } \\
\text { Instant OFF }\end{array}$ & $\begin{array}{l}\text { Coupon } 4 \mathrm{Hr} \\
\text { Depolarized } \\
\text { Potential }\end{array}$ & $\begin{array}{l}\text { Potential } \\
\text { More Neg. } \\
\text { the }-850 \mathrm{mV}\end{array}$ & $\begin{array}{l}\text { Polar- } \\
\text { ization = or }> \\
100 \mathrm{mV}\end{array}$ & $\begin{array}{l}\text { Polar- } \\
\text { ization }>50 \\
\mathrm{mV}\end{array}$ & $\begin{array}{l}\text { Polar- } \\
\text { ization }>\mathbf{2 0} \\
\mathrm{mV}\end{array}$ & $\begin{array}{l}\text { Polar- } \\
\text { ization }>10 \\
\mathrm{mV}\end{array}$ & $\begin{array}{l}\text { Polar- } \\
\text { ization }>0 \\
\mathrm{mV}\end{array}$ & $\begin{array}{l}\text { Coupon } \\
\text { Current } \\
\text { Pick Up }\end{array}$ & $\begin{array}{l}\text { Polar- } \\
\text { ization } \\
=\text { or }>0\end{array}$ & $\begin{array}{l}\text { Original } \\
\text { Natives }\end{array}$ & $\begin{array}{l}\text { Valid } \\
\text { Data }\end{array}$ \\
\hline \multirow[t]{2}{*}{ TS47 -TR12656 } & 21-Jan-08 & 386.028 & 390.455 & 458.886 & 474.786 & No & No & No & No & No & No & No & No & & Yes \\
\hline & & & & & & No & No & No & No & No & No & Yes & Yes & & No \\
\hline TS49 Old Church & 14-Jan-08 & 269.982 & 272.986 & 388.95 & 407.176 & No & No & No & No & No & No & No & No & & Yes \\
\hline TS49 Old Church & 21-Jan-08 & 288.007 & 288.408 & 315.646 & 321.254 & No & No & No & No & No & No & Yes & No & & Yes \\
\hline TS50 -Hill \& Marion & 14-Jan-08 & 214.618 & 260.607 & 440.33 & 476.032 & No & No & No & No & No & No & No & No & & Yes \\
\hline \multirow[t]{2}{*}{ TS50 -Hill \& Marion } & 21-Jan-08 & 183.958 & 224.501 & 416.124 & 448.196 & No & No & No & No & No & No & No & No & & Yes \\
\hline & & & & & & No & No & No & No & No & No & Yes & Yes & & No \\
\hline TS53 -5483 & 14-Jan-08 & 286.517 & 299.185 & 299.587 & 296.973 & No & No & No & No & No & Yes & No & Yes & & Yes \\
\hline TS53 -5483 & 21-Jan-08 & 307.83 & 329.143 & 329.545 & 322.91 & No & No & No & No & No & Yes & No & Yes & & Yes \\
\hline TS54 -11000 & 14-Jan-08 & 343.566 & 394.256 & 484.171 & 561.413 & No & No & No & No & No & No & No & No & & Yes \\
\hline TS54 -11000 & 21-Jan-08 & 344.169 & 385.808 & 485.378 & 561.815 & No & No & No & No & No & No & No & No & & Yes \\
\hline TS55 -3510 & 14-Jan-08 & 376.939 & 381.965 & 626.825 & 654.97 & No & No & No & No & No & No & No & No & & Yes \\
\hline TS55-3510 & 21-Jan-08 & 381.161 & 395.836 & 540.581 & 562.092 & No & No & No & No & No & No & No & No & & Yes \\
\hline TS56 -3500 back & 14-Jan-08 & 164.269 & 397.069 & 403.317 & 404.93 & No & No & No & No & No & No & No & No & & Yes \\
\hline TS56 -3500 back & 21-Jan-08 & 193.898 & 415.209 & 420.248 & 421.055 & No & No & No & No & No & No & No & No & 24 & Yes \\
\hline TS57 -2590 & 14-Jan-08 & 476.568 & 475.766 & 390.521 & 352.211 & No & No & No & Yes & Yes & Yes & Yes & Yes & & Yes \\
\hline TS57 -2590 & 21-Jan-08 & 485.594 & 485.193 & 429.834 & 408.372 & No & No & No & Yes & Yes & Yes & Yes & Yes & & Yes \\
\hline TS58 -2580 & 14-Jan-08 & 537.996 & 536.178 & 560.017 & 563.452 & No & No & No & No & No & No & Yes & No & & Yes \\
\hline TS58 -2580 & 21-Jan-08 & 542.239 & 543.451 & 573.351 & 575.169 & No & No & No & No & No & No & No & No & & Yes \\
\hline \multirow[t]{2}{*}{ TS59 -2570 } & 11-Jan-08 & 505.31 & 510.953 & 655.472 & 674.015 & No & No & No & No & No & No & No & No & & Yes \\
\hline & & & & & & No & No & No & No & No & No & Yes & Yes & & No \\
\hline TS60 -2570 & 14-Jan-08 & 430.068 & 436.523 & 529.718 & 540.812 & No & No & No & No & No & No & No & No & & Yes \\
\hline TS60 -2570 & 21-Jan-08 & 431.681 & 436.724 & 518.825 & 528.104 & No & No & No & No & No & No & No & No & & Yes \\
\hline TS61 -2570 South & 14-Jan-08 & 441.989 & 444.599 & 497.815 & 510.064 & No & No & No & No & No & No & No & No & & Yes \\
\hline TS61 -2570 South & 21-Jan-08 & 444.599 & 447.21 & 490.987 & 501.229 & No & No & No & No & No & No & No & No & & Yes \\
\hline TS62 -2572 & 14-Jan-08 & 473.304 & 472.903 & 454.46 & 447.644 & No & No & No & No & No & Yes & Yes & Yes & & Yes \\
\hline TS62 -2572 & 21-Jan-08 & 382.372 & 387.831 & 584.78 & 601.968 & No & No & No & No & No & No & No & No & & Yes \\
\hline TS63 -3501 & 14-Jan-08 & 382.372 & 387.831 & 584.78 & 601.968 & No & No & No & No & No & No & No & No & & Yes \\
\hline
\end{tabular}




\begin{tabular}{|c|c|c|c|c|c|c|c|c|c|c|c|c|c|c|c|}
\hline Test Stations & Date & $\begin{array}{l}\text { Structure } \\
\text { Potential }\end{array}$ & $\begin{array}{l}\text { Coupon ON } \\
\text { Potential* }\end{array}$ & $\begin{array}{l}\text { Coupon } \\
\text { Instant OFF }\end{array}$ & $\begin{array}{l}\text { Coupon } 4 \mathrm{Hr} \\
\text { Depolarized } \\
\text { Potential }\end{array}$ & $\begin{array}{l}\text { Potential } \\
\text { More Neg. } \\
\text { the }-850 \mathrm{mV}\end{array}$ & $\begin{array}{l}\text { Polar- } \\
\text { ization = or }> \\
100 \mathrm{mV}\end{array}$ & $\begin{array}{l}\text { Polar- } \\
\text { ization }>50 \\
\mathrm{mV}\end{array}$ & $\begin{array}{l}\text { Polar- } \\
\text { ization > } 20 \\
\text { mV }\end{array}$ & $\begin{array}{l}\text { Polar- } \\
\text { ization > } 10 \\
\mathrm{mV}\end{array}$ & $\begin{array}{l}\text { Polar- } \\
\text { ization >0 } \\
\mathrm{mV}\end{array}$ & $\begin{array}{l}\text { Coupon } \\
\text { Current } \\
\text { Pick Up }\end{array}$ & $\begin{array}{l}\text { Polar- } \\
\text { ization } \\
=\text { or }>0\end{array}$ & $\begin{array}{l}\text { Original } \\
\text { Natives }\end{array}$ & $\begin{array}{l}\text { Valid } \\
\text { Data }\end{array}$ \\
\hline TS63 -3501 & 21-Jan-08 & 374.081 & 380.35 & 563.953 & 580.332 & No & No & No & No & No & No & No & No & & Yes \\
\hline TS64 -3521 & 14-Jan-08 & 343.066 & 337.841 & 592.88 & 639.506 & No & No & No & No & No & No & Yes & No & & Yes \\
\hline TS64 -3521 & 21-Jan-08 & 333.419 & 374.016 & 596.899 & 634.482 & No & No & No & No & No & No & No & No & & Yes \\
\hline TS65 -2500 & 14-Jan-08 & 523.63 & 524.032 & 538.521 & 533.289 & No & No & No & No & No & Yes & Yes & No & & Yes \\
\hline TS65 -2500 & 21-Jan-08 & 544.156 & 543.955 & 545.565 & 551.401 & No & No & No & No & No & No & Yes & No & & Yes \\
\hline \multirow[t]{2}{*}{ TS66 -2510 } & 11-Jan-08 & 549.574 & 550.982 & 435.918 & 296.311 & No & Yes & Yes & Yes & Yes & Yes & No & Yes & & Yes \\
\hline & & & & & & No & No & No & No & No & No & Yes & Yes & & No \\
\hline TS67 -2520 & 14-Jan-08 & 546.727 & 547.533 & 555.585 & 557.598 & No & No & No & No & No & No & Yes & No & & Yes \\
\hline TS67 -2520 & 21-Jan-08 & 550.753 & 551.156 & 548.942 & 548.137 & No & No & No & No & No & Yes & Yes & Yes & & Yes \\
\hline TS68 -2530 & 14-Jan-08 & 555.803 & 556.609 & 633.591 & 641.451 & No & No & No & No & No & No & Yes & No & & Yes \\
\hline \multirow[t]{2}{*}{ TS68 -2530 } & 21-Jan-08 & 559.632 & 562.252 & 646.892 & 658.58 & No & No & No & No & No & No & No & No & & Yes \\
\hline & & & & & & No & No & No & No & No & No & Yes & Yes & & No \\
\hline TS70 - 2562 & 14-Jan-08 & 321.433 & 469.429 & 531.212 & 533.433 & No & No & No & No & No & No & No & No & & Yes \\
\hline TS70 - 2562 & 21-Jan-08 & 317.395 & 462.564 & 513.445 & 516.877 & No & No & No & No & No & No & No & No & & Yes \\
\hline TS71-2522 & 14-Jan-08 & 635.964 & 637.971 & 676.502 & 686.536 & No & No & No & No & No & No & No & No & & Yes \\
\hline TS71-2522 & 21-Jan-08 & 644.393 & 645.396 & 670.482 & 678.108 & No & No & No & No & No & No & No & No & & Yes \\
\hline \multirow[t]{2}{*}{ TS72 -2532 } & 11-Jan-08 & 627.096 & 630.121 & 663.402 & 682.766 & No & No & No & No & No & No & No & No & & Yes \\
\hline & & & & & & No & No & No & No & No & No & Yes & Yes & & No \\
\hline TS73 -2502 South & 14-Jan-08 & 997.382 & 1001.999 & 800.836 & 671.747 & No & Yes & Yes & Yes & Yes & Yes & No & Yes & & Yes \\
\hline TS73 -2502 South & 21-Jan-08 & 1004.007 & 1000.393 & 898.005 & 779.957 & Yes & Yes & Yes & Yes & Yes & Yes & Yes & Yes & & Yes \\
\hline TS74 -1558 & 14-Jan-08 & -89.097 & -73.986 & 430.768 & 508.679 & No & No & No & No & No & No & No & No & & No \\
\hline TS74 -1558 & 21-Jan-08 & -98.517 & -53.183 & 448.234 & 524.183 & No & No & No & No & No & No & No & No & & No \\
\hline TS75-5425 South & 14-Jan-08 & 476.913 & 659.547 & 665.008 & 678.761 & No & No & No & No & No & No & No & No & & Yes \\
\hline TS75 -5425 South & 21-Jan-08 & 459.114 & 663.795 & 668.851 & 676.334 & No & No & No & No & No & No & No & No & & Yes \\
\hline TS76 -5424 North & 14-Jan-08 & 414.168 & 415.369 & 407.762 & 397.753 & No & No & No & No & Yes & Yes & No & Yes & & Yes \\
\hline TS76 -5424 North & 21-Jan-08 & 400.956 & 400.756 & 394.15 & 391.348 & No & No & No & No & No & Yes & Yes & Yes & & Yes \\
\hline TS77 -5423 South & 14-Jan-08 & 419.433 & 450.71 & 657.218 & 683.483 & No & No & No & No & No & No & No & No & & Yes \\
\hline TS77 -5423 South & 21-Jan-08 & 409.207 & 442.088 & 650.001 & 684.085 & No & No & No & No & No & No & No & No & & Yes \\
\hline
\end{tabular}




\begin{tabular}{|c|c|c|c|c|c|c|c|c|c|c|c|c|c|c|c|}
\hline Test Stations & Date & $\begin{array}{l}\text { Structure } \\
\text { Potential }\end{array}$ & $\begin{array}{l}\text { Coupon ON } \\
\text { Potential* }\end{array}$ & $\begin{array}{l}\text { Coupon } \\
\text { Instant OFF }\end{array}$ & $\begin{array}{l}\text { Coupon } 4 \mathrm{Hr} \\
\text { Depolanized } \\
\text { Potential }\end{array}$ & $\begin{array}{l}\text { Potential } \\
\text { More Neg. } \\
\text { the }-850 \mathrm{mV}\end{array}$ & $\begin{array}{l}\text { Polar- } \\
\text { ization = or }> \\
100 \mathrm{mV}\end{array}$ & $\begin{array}{l}\text { Polar- } \\
\text { ization > } 50 \\
\mathrm{mV}\end{array}$ & $\begin{array}{l}\text { Polar- } \\
\text { ization }>\mathbf{2 0} \\
\mathrm{mV}\end{array}$ & $\begin{array}{l}\text { Polar- } \\
\text { ization }>10 \\
\mathrm{mV}\end{array}$ & $\begin{array}{l}\text { Polar- } \\
\text { ization }>0 \\
\mathrm{mV}\end{array}$ & $\begin{array}{l}\text { Coupon } \\
\text { Current } \\
\text { Pick Up }\end{array}$ & $\begin{array}{l}\text { Polar- } \\
\text { ization } \\
=\text { or }>0\end{array}$ & $\begin{array}{l}\text { Original } \\
\text { Natives }\end{array}$ & $\begin{array}{l}\text { Valid } \\
\text { Data }\end{array}$ \\
\hline TS78 -5421 North & 14-Jan-08 & 395.99 & 386.405 & 384.808 & 385.606 & No & No & No & No & No & No & Yes & Yes & & Yes \\
\hline TS78 -5421 North & 21-Jan-08 & 381.013 & 381.413 & 387.204 & 388.602 & No & No & No & No & No & No & Yes & No & & Yes \\
\hline TS79 -5502 & 14-Jan-08 & 704.003 & 430.578 & 661.523 & 706.795 & No & No & No & No & No & No & Yes & No & & Yes \\
\hline TS79-5502 & 21-Jan-08 & 706.396 & 432.373 & 661.922 & 708.789 & No & No & No & No & No & No & Yes & No & & Yes \\
\hline TS80 -5501 North & 14-Jan-08 & 408.528 & 428.894 & 581.739 & 607.953 & No & No & No & No & No & No & No & No & & Yes \\
\hline TS80 -5501 North & 21-Jan-08 & 402.68 & 418.207 & 575.488 & 605.936 & No & No & No & No & No & No & No & No & & Yes \\
\hline TS82 -5505 & 14-Jan-08 & 278.618 & 358.797 & 608.551 & 642.627 & No & No & No & No & No & No & No & No & & Yes \\
\hline TS82 -5505 & 21-Jan-08 & 298.062 & 359.398 & 628.997 & 667.081 & No & No & No & No & No & No & No & No & & Yes \\
\hline TS83 -5472 South & 14-Jan-08 & 354.47 & 438.639 & 372.063 & 353.87 & No & No & No & No & Yes & Yes & No & Yes & & Yes \\
\hline \multirow[t]{2}{*}{ TS83 -5472 South } & 21-Jan-08 & 369.664 & 437.839 & 383.859 & 368.065 & No & No & No & No & Yes & Yes & No & Yes & & Yes \\
\hline & & & & & & No & No & No & No & No & No & Yes & Yes & & No \\
\hline \multirow[t]{2}{*}{ TS86 -4394 } & 11-Jan-08 & 169.488 & 176.099 & 445.558 & 497.647 & No & No & No & No & No & No & No & No & & Yes \\
\hline & & & & & & No & No & No & No & No & No & Yes & Yes & & No \\
\hline TS89 -4710 & 14-Jan-08 & 368.769 & 365.755 & 365.755 & 365.956 & No & No & No & No & No & No & Yes & Yes & & Yes \\
\hline TS89 -4710 & 21-Jan-08 & 376.406 & 372.788 & 372.788 & 371.783 & No & No & No & No & No & Yes & Yes & Yes & & Yes \\
\hline TS90 -4442 & 14-Jan-08 & 468.928 & 466.128 & 410.312 & 390.307 & No & No & No & Yes & Yes & Yes & Yes & Yes & & Yes \\
\hline TS90 -4442 & 21-Jan-08 & 471.929 & 469.728 & 400.91 & 371.301 & No & No & No & Yes & Yes & Yes & Yes & Yes & & Yes \\
\hline TS91 -4405 South & 14-Jan-08 & 410.033 & 421.927 & 466.276 & 476.356 & No & No & No & No & No & No & No & No & & Yes \\
\hline TS91 -4405 South & 21-Jan-08 & 416.081 & 419.306 & 463.656 & 472.123 & No & No & No & No & No & No & No & No & & Yes \\
\hline TS92 -4406 & 14-Jan-08 & 221.49 & 209.864 & 209.864 & 214.274 & No & No & No & No & No & No & Yes & Yes & & Yes \\
\hline TS92 -4406 & 21-Jan-08 & 208.261 & 199.441 & 199.441 & 198.84 & No & No & No & No & No & Yes & Yes & Yes & & Yes \\
\hline TS93 -Post Office & 14-Jan-08 & 393.148 & -1.806 & -2.006 & -2.006 & No & No & No & No & No & No & Yes & Yes & & Yes \\
\hline TS93 -Post Office & 21-Jan-08 & 399.771 & -3.411 & -3.813 & -3.211 & No & No & No & No & No & No & Yes & Yes & & Yes \\
\hline TS94 -3499 & 14-Jan-08 & 415.678 & 420.285 & 420.285 & 419.484 & No & No & No & No & No & Yes & No & Yes & & Yes \\
\hline TS94 -3499 & 21-Jan-08 & 423.891 & 425.294 & 425.294 & 424.893 & No & No & No & No & No & Yes & No & Yes & & Yes \\
\hline TS95-2310 & 14-Jan-08 & 430.293 & 434.516 & 442.157 & 442.559 & No & No & No & No & No & No & No & No & & Yes \\
\hline TS95-2310 & 21-Jan-08 & 432.505 & 432.304 & 421.245 & 414.208 & No & No & No & No & No & Yes & Yes & Yes & & Yes \\
\hline TS96 -Palmento & 14-Jan-08 & 170.246 & 170.448 & 197.712 & 203.366 & No & No & No & No & No & No & Yes & No & & Yes \\
\hline
\end{tabular}




\begin{tabular}{|c|c|c|c|c|c|c|c|c|c|c|c|c|c|c|c|}
\hline Test Stations & Date & $\begin{array}{l}\text { Structure } \\
\text { Potential }\end{array}$ & $\begin{array}{l}\text { Coupon ON } \\
\text { Potential* }\end{array}$ & $\begin{array}{l}\text { Coupon } \\
\text { Instant OFF }\end{array}$ & $\begin{array}{l}\text { Coupon } 4 \mathrm{Hr} \\
\text { Depolarized } \\
\text { Potential }\end{array}$ & $\begin{array}{l}\text { Potential } \\
\text { More Neg. } \\
\text { the }-850 \mathrm{mV}\end{array}$ & $\begin{array}{l}\text { Polar- } \\
\text { ization = or }> \\
100 \mathrm{mV}\end{array}$ & $\begin{array}{l}\text { Polar- } \\
\text { ization }>50 \\
\mathrm{mV}\end{array}$ & $\begin{array}{l}\text { Polar- } \\
\text { ization }>\mathbf{2 0} \\
\mathrm{mV}\end{array}$ & $\begin{array}{l}\text { Polar- } \\
\text { ization > } 10 \\
\mathrm{mV}\end{array}$ & $\begin{array}{l}\text { Polar- } \\
\text { ization }>0 \\
\mathrm{mV}\end{array}$ & $\begin{array}{l}\text { Coupon } \\
\text { Current } \\
\text { Pick Up }\end{array}$ & $\begin{array}{l}\text { Polar- } \\
\text { ization } \\
=\text { or }>0\end{array}$ & $\begin{array}{l}\text { Original } \\
\text { Natives }\end{array}$ & $\begin{array}{l}\text { Valid } \\
\text { Data }\end{array}$ \\
\hline TS96 -Palmento & 21-Jan-08 & 177.516 & 177.516 & 195.086 & 187.008 & No & No & No & No & No & Yes & Yes & No & & Yes \\
\hline TS97-9810 Back. & 14-Jan-08 & 181.285 & 193.156 & 491.542 & 527.558 & No & No & No & No & No & No & No & No & & Yes \\
\hline TS97- 9810 Back. & 21-Jan-08 & 193.558 & 202.009 & 489.329 & 519.711 & No & No & No & No & No & No & No & No & & Yes \\
\hline TS98 -TR10773 & 14-Jan-08 & 289.349 & 290.356 & 214.997 & 175.503 & No & No & No & Yes & Yes & Yes & No & Yes & & Yes \\
\hline TS98 -TR10773 & 21-Jan-08 & 289.55 & 285.117 & 205.929 & 163.212 & No & No & No & Yes & Yes & Yes & Yes & Yes & & Yes \\
\hline TS99 -TR10775 & 14-Jan-08 & 399.889 & 407.101 & 479.426 & 495.053 & No & No & No & No & No & No & No & No & & Yes \\
\hline TS99 -TR10775 & 21-Jan-08 & 405.899 & 400.69 & 470.41 & 487.64 & No & No & No & No & No & No & Yes & No & & Yes \\
\hline TS100 -TR10774 & 14-Jan-08 & 402.275 & 396.413 & 304.637 & 237.524 & No & No & Yes & Yes & Yes & Yes & Yes & Yes & & Yes \\
\hline TS100 -TR10774 & 21-Jan-08 & 386.103 & 377.411 & 297.966 & 225.597 & No & No & Yes & Yes & Yes & Yes & Yes & Yes & & Yes \\
\hline TS101 -TR10788 & 14-Jan-08 & 288.559 & 285.337 & 220.296 & 176.8 & No & No & No & Yes & Yes & Yes & Yes & Yes & & Yes \\
\hline TS101 -TR10788 & 21-Jan-08 & 272.248 & 265.2 & 202.172 & 156.059 & No & No & No & Yes & Yes & Yes & Yes & Yes & & Yes \\
\hline TS102 -TR10777 & 14-Jan-08 & -0.201 & -0.201 & -0.201 & -0.201 & No & No & No & No & No & No & Yes & Yes & & No \\
\hline TS102 -TR10777 & 21-Jan-08 & -1.008 & -0.604 & -0.806 & -0.806 & No & No & No & No & No & No & Yes & Yes & & No \\
\hline TS104 -TR10778 & 14-Jan-08 & 285.193 & 303.644 & 499.79 & 528.47 & No & No & No & No & No & No & No & No & & Yes \\
\hline TS104 -TR10778 & 21-Jan-08 & 272.959 & 279.778 & 474.52 & 498.988 & No & No & No & No & No & No & No & No & & Yes \\
\hline TS105 -TR10779 & 14-Jan-08 & 333.413 & 336.64 & 344.91 & 351.97 & No & No & No & No & No & No & No & No & & Yes \\
\hline TS105 -TR10779 & 21-Jan-08 & 328.976 & 333.413 & 385.452 & 411.27 & No & No & No & No & No & No & No & No & & Yes \\
\hline TS106 -TR10782 & 14-Jan-08 & 350.983 & 363.982 & 502.775 & 519.175 & No & No & No & No & No & No & No & No & & Yes \\
\hline TS106 -TR10782 & 21-Jan-08 & 349.783 & 349.183 & 457.977 & 470.777 & No & No & No & No & No & No & Yes & No & & Yes \\
\hline TS107 -TR10783 & 14-Jan-08 & 291.11 & 7.76 & 8.357 & 10.944 & No & No & No & No & No & No & Yes & Yes & & Yes \\
\hline TS107 -TR10783 & 21-Jan-08 & 294.692 & 4.178 & 4.775 & 7.362 & No & No & No & No & No & No & Yes & Yes & & Yes \\
\hline
\end{tabular}




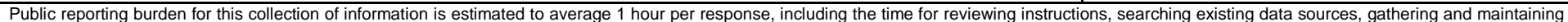

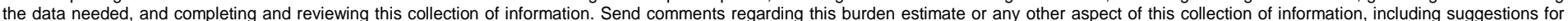

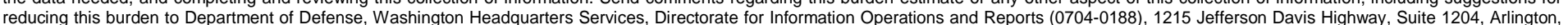

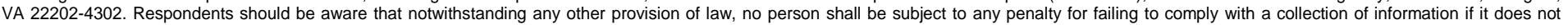
display a currently valid OMB control number. PLEASE DO NOT RETURN YOUR FORM TO THE ABOVE ADDRESS.

\begin{tabular}{l|l} 
1. REPORT DATE (DD-MM-YYYY) & 2. REPORT TYPE
\end{tabular} August 2009

$$
\text { Final }
$$

3. DATES COVERED (From - To)

4. TITLE AND SUBTITLE

Demonstration of Cathodic Protection Systems for Utilities in Severely Corrosive

Environments at Fort Jackson

5a. CONTRACT NUMBER

5b. GRANT NUMBER

5c. PROGRAM ELEMENT NUMBER

Corrosion Prevention and Control

6. AUTHOR(S)

L.D. Stephenson, Ashok Kumar, James B. Bushman, and Bopinder Phull

5d. PROJECT NUMBER

CPC FAR-20

5e. TASK NUMBER

MIPR6FCERB1020, MIPR6H6AG3CPC1

5f. WORK UNIT NUMBER

7. PERFORMING ORGANIZATION NAME(S) AND ADDRESS(ES)

U.S. Army Engineer Research and Development Center

8. PERFORMING ORGANIZATION REPORT NUMBER

ERDC/CERL TR-09-26

Construction Engineering Research Laboratory

P.O. Box 9005

Champaign, IL 61826-9005

9. SPONSORING I MONITORING AGENCY NAME(S) AND ADDRESS(ES)

10. SPONSOR/MONITOR'S ACRONYM(S)

U.S. Army Installation Management Command

Engineering Office, Directorate of Public Works (IMPW-E)

2511 Jefferson Davis Hwy.

Arlington, VA 22202

NUMBER(S)

\section{DISTRIBUTION / AVAILABILITY STATEMENT}

Approved for public release; distribution is unlimited.

\section{SUPPLEMENTARY NOTES}

Additional Task Number is MIPR6HMBHDE097

\section{ABSTRACT}

This project demonstrated and implemented emerging corrosion protection technologies for utilities at Fort Jackson, SC. These consisted of three deep anode impressed current cathodic protection (ICCP) systems, 100 drive-by- type remote monitoring units (RMU) for monitoring the cathodic protection on the buried gas lines, and a new cathodic protection system in the elevated water storage tank, providing complete and uniform protection in the tank interior below the water line. The CP system in the water storage tank is also equipped with remote monitoring capability. The remote monitoring units have reduced the amount of time that it takes a trained technician to collect the data from about a week to only about 3 hours. The CP data collected from the drive by RMUs are collected and stored on a laptop computer for use in different analysis, including transfer into an Excel spreadsheet where it is automatically analyzed on a pass/fail basis.

\section{SUBJECT TERMS}

Fort Jackson, SC; cathodic protection (CP); natural gas distribution systems; water storage tanks; remote monitoring systems; corrosion control

\section{SECURITY CLASSIFICATION OF:}

\section{a. REPORT}

Unclassified

\section{b. ABSTRACT}

Unclassified

\section{c. THIS PAGE}

Unclassified
17. LIMITATION OF ABSTRACT
18. NUMBER OF PAGES

139 19a. NAME OF RESPONSIBLE PERSON

19b. TELEPHONE NUMBER (include area code) 